\author{
UNIVERSIDADE DE SÃO PAULO \\ FFCLRP - DEPARTAMENTO DE BIOLOGIA \\ PROGRAMA DE PÓS-GRADUAÇÃO EM BIOLOGIA COMPARADA
}

\title{
Patterns of morphological evolution in the skull of turtles: contributions from digital paleontology, neuroanatomy and biomechanics
}

\begin{abstract}
Padrões de evolução morfológica no crânio das tartarugas: contribuições da paleontologia digital, neuroanatomia e biomecânica
\end{abstract}

Gabriel de Souza Ferreira

RIBEIRÃO PRETO - SP 


\author{
UNIVERSIDADE DE SÃO PAULO \\ FFCLRP - DEPARTAMENTO DE BIOLOGIA \\ PROGRAMA DE PÓS-GRADUAÇÃO EM BIOLOGIA COMPARADA
}

\begin{abstract}
Patterns of morphological evolution in the skull of turtles: contributions from digital paleontology, neuroanatomy and biomechanics
\end{abstract}

\begin{abstract}
Padrões de evolução morfológica no crânio das tartarugas: contribuições da paleontologia digital, neuroanatomia e biomecânica
\end{abstract}

\author{
Gabriel de Souza Ferreira \\ Supervisor: Prof. Dr. Max Cardoso Langer \\ Co-supervisor: Profa. Dra. Madelaine Böhme
}

Tese apresentada à Faculdade de Filosofia, Ciências e Letras de Ribeirão Preto da USP, como parte das exigências para a obtenção do título de Doutor em Ciências, Área: BIOLOGIA COMPARADA.

RIBEIRÃO PRETO - SP 
Autorizo a reprodução e divulgação total ou parcial deste trabalho, por qualquer meio convencional ou eletrônico, para fins de estudo e pesquisa, desde que citada a fonte

\section{FICHA CATALOGRÁFICA}

Ferreira, Gabriel de Souza

Patterns of morphological evolution in the skull of turtles: contributions from digital paleontology, neuroanatomy and biomechanics.

190 p. : il. ; $30 \mathrm{~cm}$

Tese de doutorado, apresentada ao Departamento de Biologia da Faculdade de Filosofia, Ciências e Letras de Ribeirão Preto/USP Área de concentração: Biologia Comparada.

Orientador: Langer, Max Cardoso.

Co-orientadora: Böhme, Madelaine

1. Computed tomography. 2. Digital endocast. 3. Finite-Element Analysis. 4. Testudinata. 5. Skull. 
Name: Ferreira, Gabriel de Souza

Title: Patterns of morphological evolution in the skull of turtles: contributions from digital paleontology, neuroanatomy and biomechanics.

Thesis presented to the Faculdade de Filosofia, Ciências e Letras de Ribeirão Preto da Universidade de São Paulo to obtain a doctorate in Sciences, Comparative Biology area, and to the MathematischNaturwissenschaftlichen Fakultät der Eberhard Karls Universität Tübingen to obtain a doctorate in Natural Sciences (Dr. rer. Nat.)

Approved in:

\section{Examination board}

Prof. Dr. Institution:

Verdict:

Prof. Dr. Institution:

Verdict:

Prof. Dr. Institution:

Verdict:

Prof. Dr. Institution:

Verdict:

Prof. Dr. Institution:

Verdict: 
In nature we never see anything isolated, but everything in connection with something else which is before it, beside it, under it and over it Johann Wolfgang von Goethe

Doubt is not a pleasant condition, but certainty is absurd

François Voltaire 


\section{Acknowledgements}

I am very grateful to my supervisor Max Langer, who offered me a space in his lab for the past ten years and immensily contributed to shape my career path until now. Max not only helped me think through paleo-problems, but also about career options and personal matters, always being present and giving support when I needed. I also thank my $\mathrm{PhD}$ cosupervisor in Tübingen, Prof. Dr. Madelaine Böhme, who accepted and welcomed me at the Senckenberg Institute and Universität Tübingen for a whole year, offering me not only a space to work, but also interesting discussions on various subjects. I am very grateful to my "unofficial" co-supervisor, Dr. Ingmar Werneburg, who has supported me from the beginning of my $\mathrm{PhD}$, helping already when I was writing my doctoral research project and now, during this agitated last year. He granted me an invaluable amount of time during my stay in Tübingen, and also after I returned to Brazil, through several Skype calls and email exchange. All the conversations and discussions with them were very productive and insightful and, no doubt, they shaped not only the way I think about paleontology, evolutionary biology and science, but also about my life. I would also like to thank Juliana Sterli, who was my co-supervisor during my Master dissertation and with whom I spent six months working in Trelew. I learned a lot with you and you also had an importat role in defining my career. To you, my sincere thanks!

I gratefully acknowledge the agreement FAPESP (São Paulo Research Foundation) and CAPES (Coordenação de Aperfeiçoamento de Pessoal de Nível Superior) for granting me the funding for my PhD project and my stay at the Universität Tübingen (grant numbers 2014/2539-5 and 2016/03934-2) and support by the Center for Biodiversity Documentation (Centro para Documentação da Biodiversidade), Department of Biology, FFCLRP, University of São Paulo, Brazil. This thesis constitutes part of the project 'Core-facility for the conservation of scientific documentation: biological collections and high technology research in comparative morphology' (CT-INFRA 01/2013), financed by the Funding Authority for Studies and Projects (FINEP), Ministry of Science, Technology, Innovations and Communication, Brazilian Federal Government. 
I acknowledge the contribution of the following colleagues for discussion, collaboration, reviewing, collection or facility access, etc.: A. C. Arruda-Campos (Monte Alto, Brazil), A. Tröscher (Tübingen, Germany), A. Kupfer (Stuttgart, Germany), A. Rincón (Caracas, Venezuela), A. Solórzano (Caracas, Venezuela), B. Simpson (Chicago, USA), C. A. Francisco (Monte Alto, Brazil), C. Mehling (New York, USA), C. Pfaff (Viena, Austria), D. J. Button (London, UK), D. Silva, (Monte Alto, Brazil), D. Brinkman (New Haven, USA), D. Schwarz (Berlin, Germany), D. Kizirian (New York, USA), E. Cadena (Bogotá, Colombia), E. Almeida (Ribeirão Preto, Brazil), F. A. Carbonaro (Bauru, Brazil), F. V. Iori (Monte Alto, Brazil), G. S. Bever (New York, USA), I. G. Danilov (St. Petersburg, Russia), I. Ruf (Frankfurt, Germany), J. Prochel (Tübingen, Germany), J. Ziermann (Washington DC, USA), J. Cundiff (Boston, USA), J. Carrillo (Zürich, Switzerland), J. Hinz (Tübingen, Germany), J. Kriwet (Viena, Austria), K. Tighe (Washington DC, USA), K. Mahlow (Berlin, Germany), L. E. Sabino (Araraquara, Brazil), L. Vonnahme (New York, USA), M. S. Magalhães (Manaus, Brazil), M. de la Fuente (San Rafael, Argentina), M. Sánchez-Villagra (Zürich, Switzerland), P. S. R. Romano (Viçosa, Brazil), R. Garbin (Fribourg, Switzerland), R. P. Ghilardi (Bauru, Brazil), R. Schoch (Stuttgart, Germany), R. Diaz Jr. (Riverside, USA), R. Hirayama (Tokyo, Japan), R. Butler (Birmingham, UK), R. Benson (Oxford, UK), R. Diogo (Washington DC, USA), S. Bandyopadhyay (Kolkata, India), S. Evers (Fribourg, Switzerland), S. Chapman (London, UK), S. Lautenschlager (Birmingham, UK), S. S. Nihei (São Paulo, Brazil), S. Walsh (Edinburgh, UK), T. Kohlsdorf (Ribeirão Preto, Brazil), T. Scheyer (Zürich, Switzerland), V. Volpato (Frankfurt, Germany), W. G. Joyce (Fribourg, Switzerland), W. Maier (Tübingen, Germany).

To all the PaleoLab past and present members for the uncountable hours of coffee breaks, Cantina do Seu Zé, bandejões, PaleoNatais and the endless and coolest (and sometimes also useless) discussions on an increadible diversity of topics. In particular, to my friends Tomate, Wafa, Julio, Simone, Mariela, Squirtle, Bruninho, Schumy, Fezão, Marquinho, Roque, Annie, who were part of my life during (very) different stages, and to the more recent coming, Bruna, Gustavo, Fellipe, Silvio, João, Chico, Gabriel, you became very rapidly an important part of my life. To all my Tübingen colleagues and friends, in particular Márton, Eme, Alex, Antonio, Anna, Priscila, Zeina, Melina, you helped me to have a great time during my German year. I am very thankful to all of you! 
To all my friends in Americana, Nacim, Diógenes, Giu, Danilo, Gui, and in Ribeirão Preto, from Tiana's lab, in particular Melissa, Gäelle, Nathalia, Aline, Gaga. To Gabriela, for your partnership and love during all these years, you have a special place in my heart, no matter what. To all 45ers, in particular Frango, Mestre, Ursa, Ket, Luigi, Zuado, Canjica, Garfo, MX, Paulinha, all of you. To Letícia, who notwithstanding I've found (or you found me?) in this troubled period, readly offered me happiness, companionship and love, pure love. Finally, to all my family, in particular my parents Ana and Gil, my grandparents, Vó Cida, Vó Peê and Vô Nésio, and my tia Cristina, who always supported and believe in me, since I was a little kid, with a lot of hair on my head. Thank you all, very much, for your companionship, friendship, and love, lots of love, through all those years!

O amor da gente é como um grão, morre e nasce trigo, vive e morre pão 


\section{English Abstract}

In the current framework of Evolutionary Biology, Paleontology has an important role to play. The fossil record represents a fundamental aspect in studies on the evolution of morphology, since from its study it is possible to retrieve reliable data on many pertinent aspects, e.g., rates of evolution, the role of mass extinctions on species diversity, the polarity of character changes, and a glimpse into morphotypes that don't exist nowadays. At the same time, new tools and methods, such as computed tomography, digital reconstructions, and Finite-Element Analysis, known collectively as digital or virtual paleontology, have brought novel possibilities on how to formulate and answer paleontological questions. In this Thesis, I employ digital paleontological techniques to analyze the patterns of morphological evolution of the skull of turtles and, based on these data, I provided novel interpretations of the neuroanatomical and functional relations of specific cranial traits to the whole skull architecture. Organized in four chapters, an overview of the osteological, muscular, developmental, and functional evolution of the craniocervical system of turtles is provided. By applying computed tomography and other 3-D digital methods, I performed reconstructions of the jaw adductor musculature and the neuroanatomical structures of one of the earliest turtles, Proganochelys quenstedti, to investigate the early evolution of the adductor chamber and the sensorial anatomy in this taxon. A new extinct side-necked turtle species, Yuraramirim montealtensis, is described, and its brain, inner ear, and neurovascular system were reconstructed in order to provide an account of the paleoneuroanatomy in one of the major turtle groups, the pleurodires. For the last chapter, I performed Finite-Element Analyses based on 3-D digital models of a series of extinct and extant taxa, together with hypothetical simulated morphotypes, to analyze the relation between muscle stress distribution patterns and skull architecture in the group. A scenario of progressive correlation between neck and skull morphological modifications is presented, which may be related to the great diversification of turtles during the Jurassic.

Keywords: computed tomography; digital endocast; Finite-Element Analysis; Testudinata; skull 


\section{Resumo em Português}

No estado atual da Biologia Evolutiva, a Paleontologia possui um importante papel. O registro fossilífero representa um aspecto fundamenteal em estudos da evolução da morfologia, uma vez que, por meio de seu estudo, é possível recuperar dados confiáveis acerca de muitos importantes aspectos, e.g., taxas de evolução, o papel das extinções em massa na diversidade de espécies, a polaridade de mudanças de caracteres e um vislumbre de morfótipos que não mais existem atualmente. Ao mesmo tempo, novas ferramentas e métodos, como tomografia computadorizada, reconstruções digitais e análises de elementos finitos, conhecidos coletivamente como paleontologia digital ou virtual, trouxeram novas possibilidades acerca de como formular e responder perguntas paleontológicas. Nesta Tese, eu utilizo técnicas da paleontologia digital para analizar os padrões de evolução morfológica do crânio das tartarugas e, com base nestes dados, forneço novas interpretações sobre as relações neuroanatômicas e funcionais de características cranianas específicas para com a arquitetura craniana como um todo. Organizada em quatro capítulos, uma visão geral sobre a evolução osteológica, muscular, ontogenética e funcional do sistema craniocervical das tartarugas é apresentada. Aplicando tomografia computadorizada e outros métodos digitais 3-D, realizei reconstruções da musculature adutora da mandíbula e de estruturas neuroanatômicas de uma das mais antigas tartarugas, Proganochelys quenstedti, para investigar a evolução inicial da câmara adutora e anatomia sensorial neste táxon. Uma nova espécie de tartaruga pleurodira, Yuraramirim montealtensis, é descrita, e seu cérebro, ouvido interno e sistema neurovascular foram reconstruídos fornecendo informações sobre a paleoneuroanatomia em um dos principais grupos de tartarugas, Pleurodira. No último capítulo, foram conduzidas análises de elementos finitos baseadas em modelos digitais 3-D de uma série de táxons extintos e viventes, além de morfótipos hipotéticos simulados, para analizar a relação entre padrões de distribuição de estresse gerados por contração muscular e arquitetura craniana no grupo. Um cenário de correlação progressiva entre modificações morfológicas no pescoço e no crânio é apresentado, que pode estar relacionado à grande diversificação das tartarugas durante o Jurássico.

Palavras-chave: tomografia computadorizada; moldes digitais; análise de elementos finitos; Testudinata; crânio 


\section{Deutsche Zusammenfassung}

Im gegenwärtigen Rahmen der Evolutionsbiologie, übernimmt die Paläontologie eine wichtige Rolle. Der Fossilbericht stellt ein unerläßliches Fundament für Untersuchungen zur Evolution morphologischer Strukturen dar, da man aus ihm zuverlässige Daten zu zahlreichen relevanten Fragestellungen erhalten kann: so zu Evolutionsraten, zur Rolle von Massenaussterbe-Ereignissen für die Vielfalt der Arten; zur Polarität von Merkmalsveränderungen; sowie zum Verständnis von Morphotypen, die heute nicht mehr existieren. Gleichzeitig haben neue Methoden, wie die Computertomographie, digitale Rekonstruktionen und Finite-Elemente Analysen - die in ihrer Vielfalt als digitale oder virtuelle Paläontologie bezeichnet werden - neue Möglichkeiten hervorgebracht, um paläontologische Fragen $\mathrm{zu}$ formulieren und $\mathrm{zu}$ beantworten. In der vorliegenden Arbeit verwende ich digitale paläontologische Techniken, um die Muster der morphologischen Evolution des Schildkrötenschädels zu analysieren. Darauf basierend entwickle ich neue Interpretationen neuroanatomischer und funktioneller Beziehungen von speziellen cranialen Merkmale zur gesamten Schädelarchitektur. In vier Kapiteln wird ein Überblick der osteologischen, entwicklungsbiologischen und funktionellen Evolution des craniocervicalen Systems bei Schildkröten vorgestellt. Unter Anwendung der Computertomographie und anderen digitalen 3-D Methoden erstellte ich Rekonstruktionen der Kieferadduktorenmuskulatur und neuroanatomischer Strukturen bei einer der ältesten Schildkröten, Proganochelys quenstedti, um die frühe Evolution der Adduktorenkammer und der Sinnesanatomie zu untersuchen. Eine neue, anzestrale Seitenwinder-Schildkröte, Yuraramirim montealtensis, wird beschrieben und die Anatomie ihres Gehirns, Innenohrs und des neurovaskulären Systems wird rekonstruiert, um einen Beitrag zur Paläoneuroanatomie einer der größten Schildkrötengruppen, der Pleurodiren, zu bieten. Für das letzte Kapitel führte ich, basierend auf 3-D Modellen von einer Reihe ausgestorbener und rezenter Taxa sowie hypothetischer und simulierter Morphotypen, Finite-Elemente Analysen durch, um das Verhältnis zwischen den Mustern der Muskelkraftverteilung und der Schädelarchitektur zu analysieren. Ein Szenario zunehmender Korrelationen zwischen der Hals- und Schädelmorphologie wird vorgestellt. Sie stehen womöglich im Zusammenhang mit der enormen Diversifizierung der Schildkröten im Jura. 
Schlüsselbegriffe: Computertomographie; digitale Schädelausgüsse; Finite-Elemente Analyse; Testudinata; Schädel 


\section{Summary}

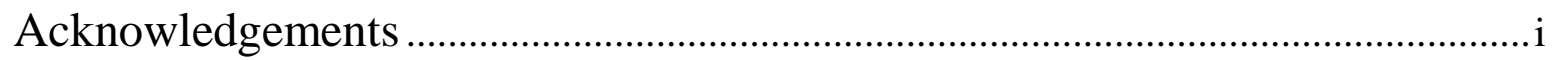

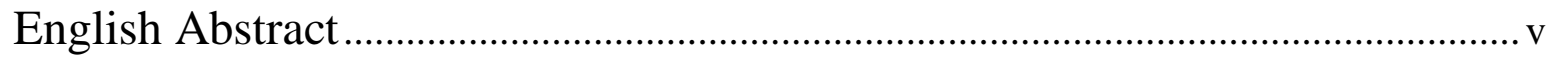

Resumo em Português ............................................................................................ vi

Deutsche Zusammenfassung ....................................................................................vii

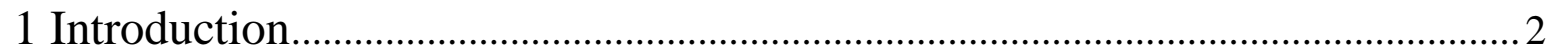

1.1. Historical background and Macroevolution ………........................................... 2

1.2. How Paleontology can contribute to Evolutionary Biology? ................................ 6

1.3. Digital paleontology: how modern approaches can tackle old problems ................ 9

1.4. Turtles as models of vertebrate evolution................................................................ 13

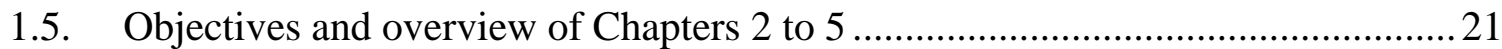

2 Evolution, diversity, and development of the craniocervical system in turtles, with 3D reconstruction of the jaw musculature of the oldest turtles

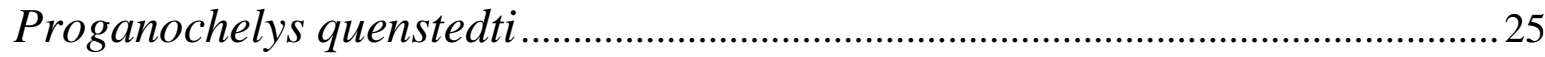

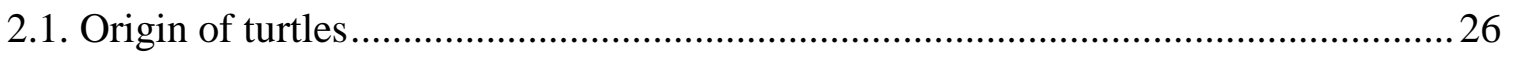

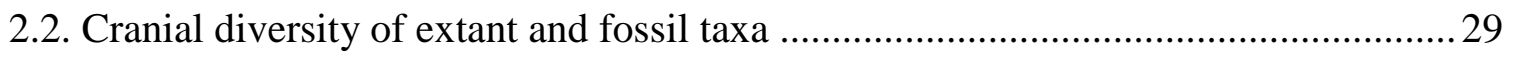

2.3. Importance of the turtle neck .............................................................................. 38

2.4. General morphology of the cranial musculature in turtles.......................................4 42

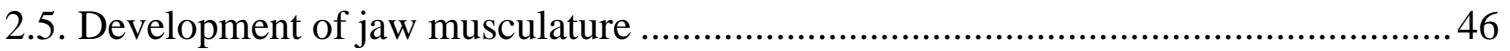

2.6. Functional anatomy of jaw muscles and feeding .................................................5 50

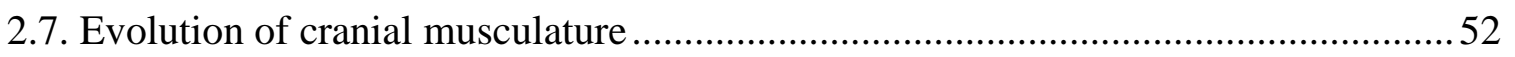

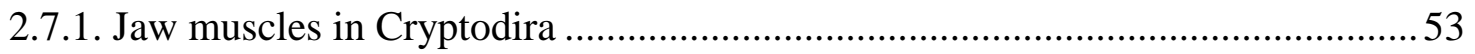

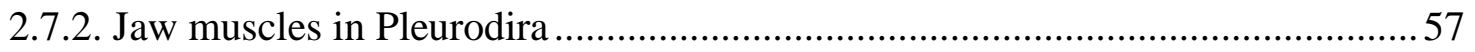

2.7.3. Jaw muscles in Proganochelys quenstedti .........................................................60

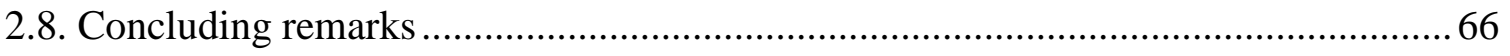

3 Sensory evolution and ecology of early turtles revealed by digital

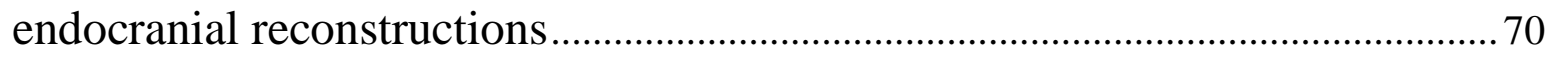

3.1. Introduction .................................................................................................. 71

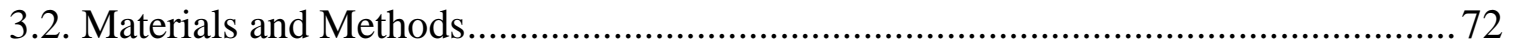

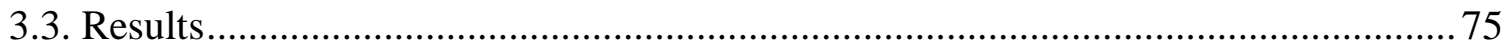

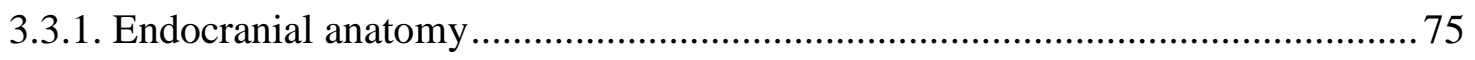




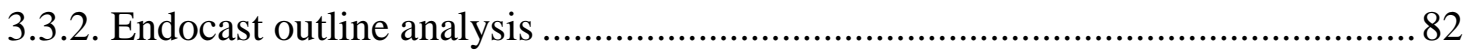

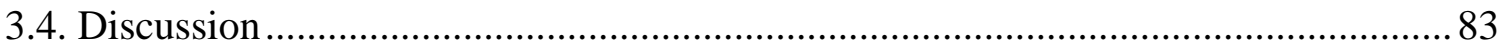

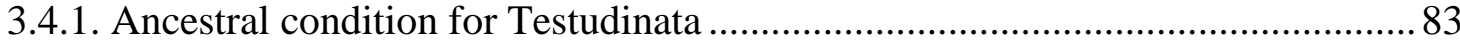

3.4.2. Sensory capabilities of Proganochelys quenstedti .......................................... 85

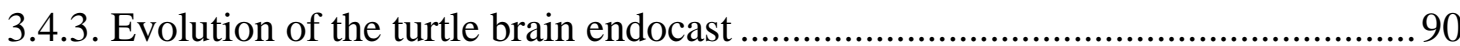

4 Cranial osteology, phylogenetic position and neuroanatomy of a new Cretaceous pleurodire turtle: Yuraramirim montealtensis ................................ 95

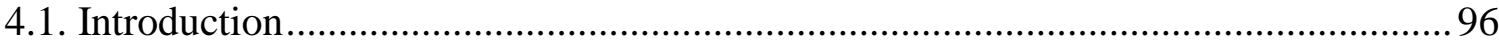

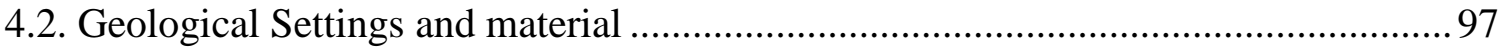

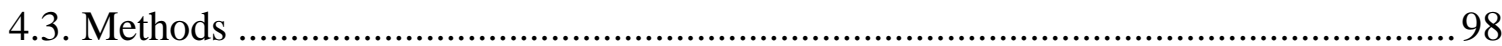

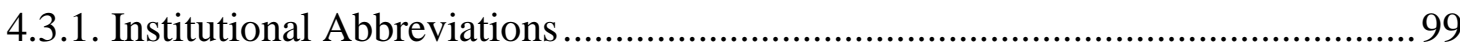

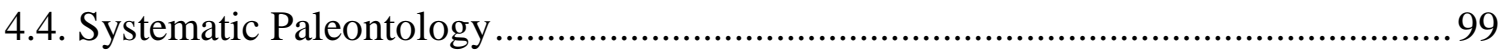

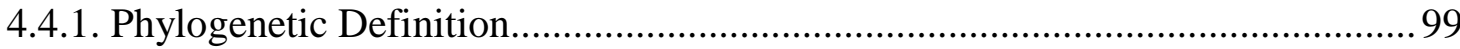

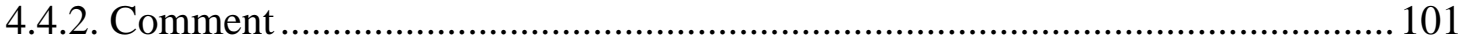

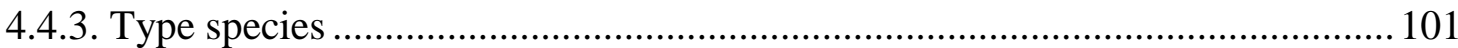

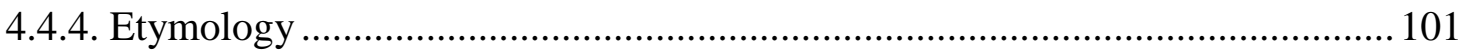

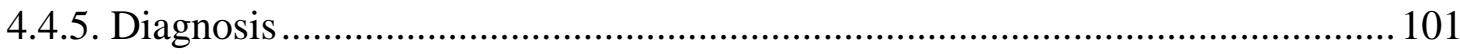

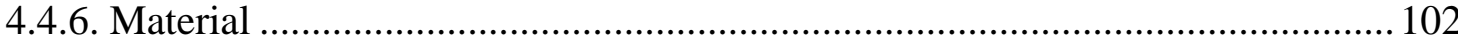

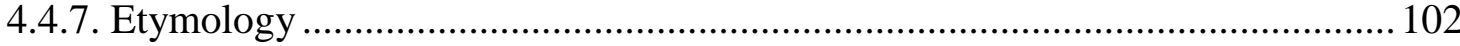

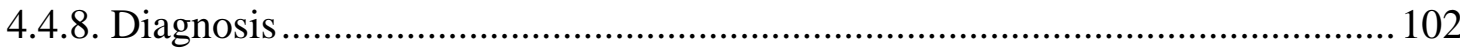

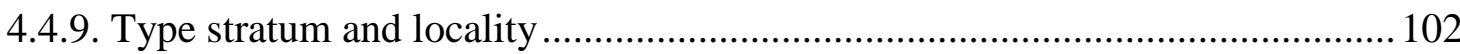

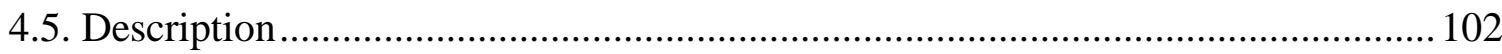

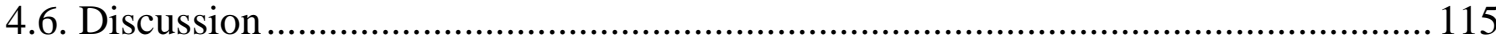

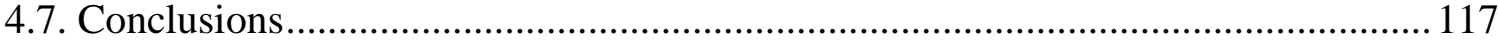

5 Feeding biomechanics suggests progressive correlation of skull architecture and neck evolution in turtles ................................................................................ 120

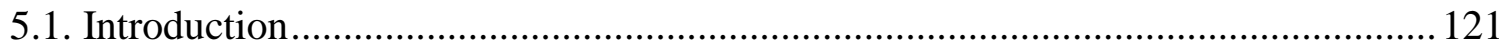

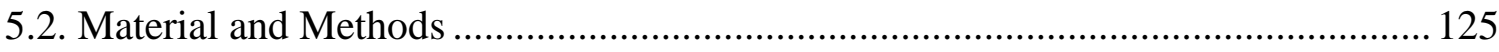

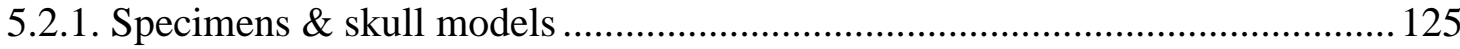

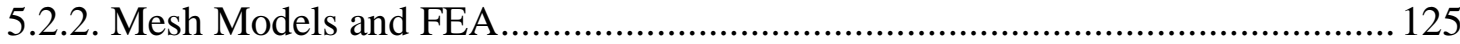

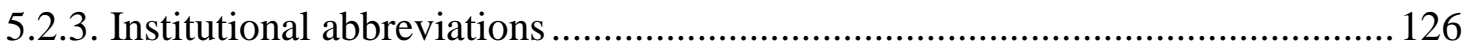

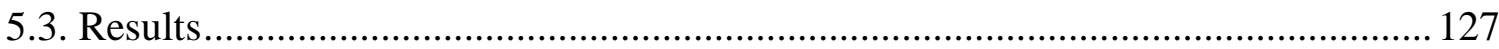




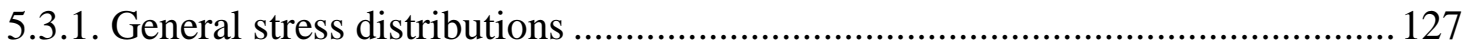

5.3.2. Simulations in Proganochelys and Eubaena ............................................... 128

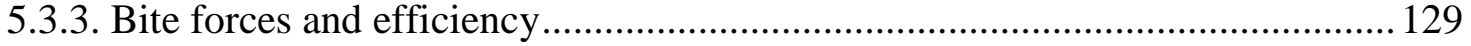

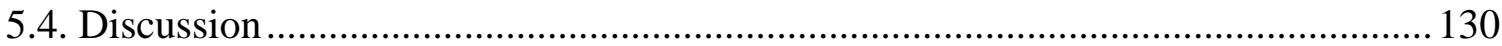

5.4.1. No increase of bite force in turtle evolution.............................................. 130

5.4.2. Neck retraction triggers a series of skull modifications ............................... 134

5.4.3. Reduction of the temporal skull coverage ................................................... 138

5.4.4. The pterygoid trochlear in pleurodires ....................................................... 139

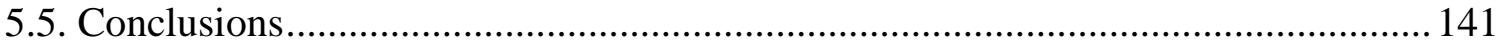

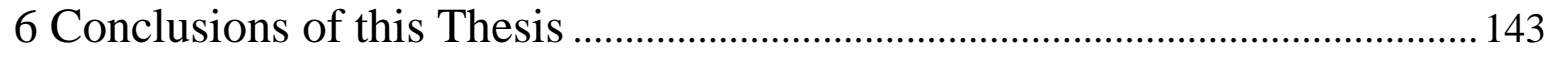

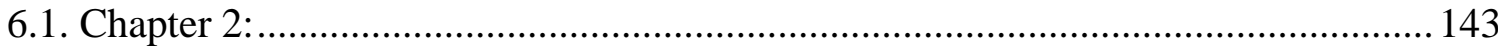

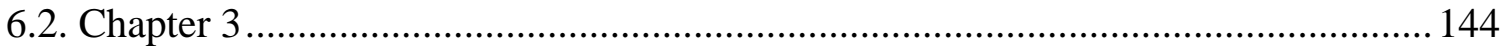

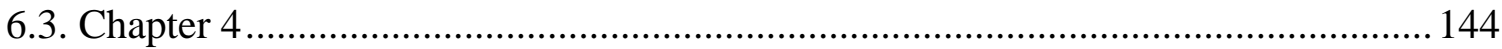

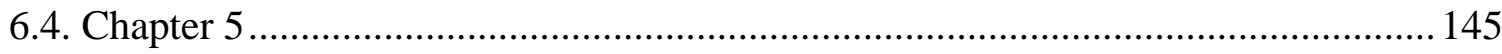

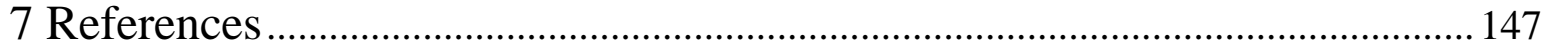




\title{
Chapter 1
}

\author{
Introduction
}




\subsection{Historical background and Macroevolution}

Macroevolution is a historical phenomenon, exciting not because it can be fitted into a particular mold, but because each major event is unique and worthy of detailed study in its own right. Every major transition is an intriguing problem to be solved, and each origin and radiation a mystery of its own

Robert L. Carroll (1997)

Since the 1858 paper "On the tendency of species to form varieties; and on the perpetuation of varieties and species by natural means of selection" by Charles Darwin and Alfred Russel Wallace, the theory of evolution has been the "greatest unifying theory in biology" (Mayr 1963). As in any research program (in the sense of Lakatos 1976) though, a series of methodological and conceptual advances has constantly revisited and modified the original framework (Müller 2017). Nevertheless, the central (or the "hard") core of the original theory remained untouched, i.e. the assumption that all organisms denscent from a common lineage. The second central tenet of the original Darwinism from the end of the $19^{\text {th }}$ century, natural selection as the major evolutionary driver and creative force (Pigliucci \& Müller 2010), has been controversial at beginning (Bowler 1983), and somewhat modified recently (Laland et al. 2015). Also, the mechanisms of heredity and the sources of variation which natural selection can act on were initially unknown and various speculative attempts (even by Darwin himself with the theory of pangenesis; Amundson 2005, p. 144) made to identify this important evolutionary factor failed until the "rediscovery" of Mendel's work in the beginning of the $20^{\text {th }}$ century. It was up to R. Fisher (1918), J. B. S. Haldane (1932) and S. Wright (1931) to work on the mathematical basis for the unification of Mendelian genetics and Darwinian natural selection into the theory of population genetics. This, in turn, became 
the basis in the 1930s and 1940s for the very successful movement that came to be known as the Modern Synthesis (Pigliucci \& Müller 2010).

The Modern Synthesis aimed to revise the conceptual framework of the theory of evolution, putting population genetics at its central core (Amundson 2005). This required a joint work of researchers on multiple areas of biology, including systematics, zoology, botany and paleontology (Pigliucci \& Müller 2010) to develop the concepts that became the core assumptions in the field (Laland et al. 2015). According to Futuyma (1986) those assumptions were: $(i)$ random genetic mutations and recombinations are the source of variation in natural populations; (ii) evolution occurs by populational changes in gene frequency, caused by genetic drift, gene flow, and natural selection, the last being the only explanation for adapation; (iii) small, gradual phenotypic changes result from genetic variance; (iv) the result of gradual phenotypic change and reproductive isolation of populations is diversification (speciation); and $(v)$ the accumulation of those microevolutionary processes results in evolution of higher taxonomic groups, i.e. macroevolution (Pigliucci \& Müller 2010; Laland et al. 2015).

The last one (i.e. the relation between micro- and macroevolution) was always a contentious issue for paleontologists. One of the "co-architects" of the Modern Synthesis, the paleontologist G. G. Simpson (Amundson 2005), proposed the concept of tachytelic evolution (Simpson 1944). This faster, large scale (i.e. taxonomic levels higher than species) evolutionary process, together with the developmental processes proposed by R. Goldschmidt (1940), would open the path to a distinction between micro- and macroevolution, that was promptly rejected in favor of the core assumptions of the Modern Synthesis (Pigliucci \& Müller 2010). Nervertheless, it became clear that Paleontology (and developmental biology; Goldschmidt 1940; Rieppel 2001, 2017) does not exclusively yield evidence for gradual, slow phenotypic changes; it actually shows plenty of examples (Eldredge \& Gould 1972; Carroll 1997; Rieppel 2017) on the contrary: morphological (phenotypic) change can, sometimes, occur at a fast pace. The clear mismatch between the fossil record and the exclusive gradual accumulation of small changes was only tackled again nearly 30 years later by N. Eldrege and S. J. Gould (Eldrege, 1971; Eldredge \& Gould 1972; 
Gould \& Eldredge 1977) that elaborated the theory of Punctuated Equilibria to explain the sudden (geologic) appearance of distinct, new species.

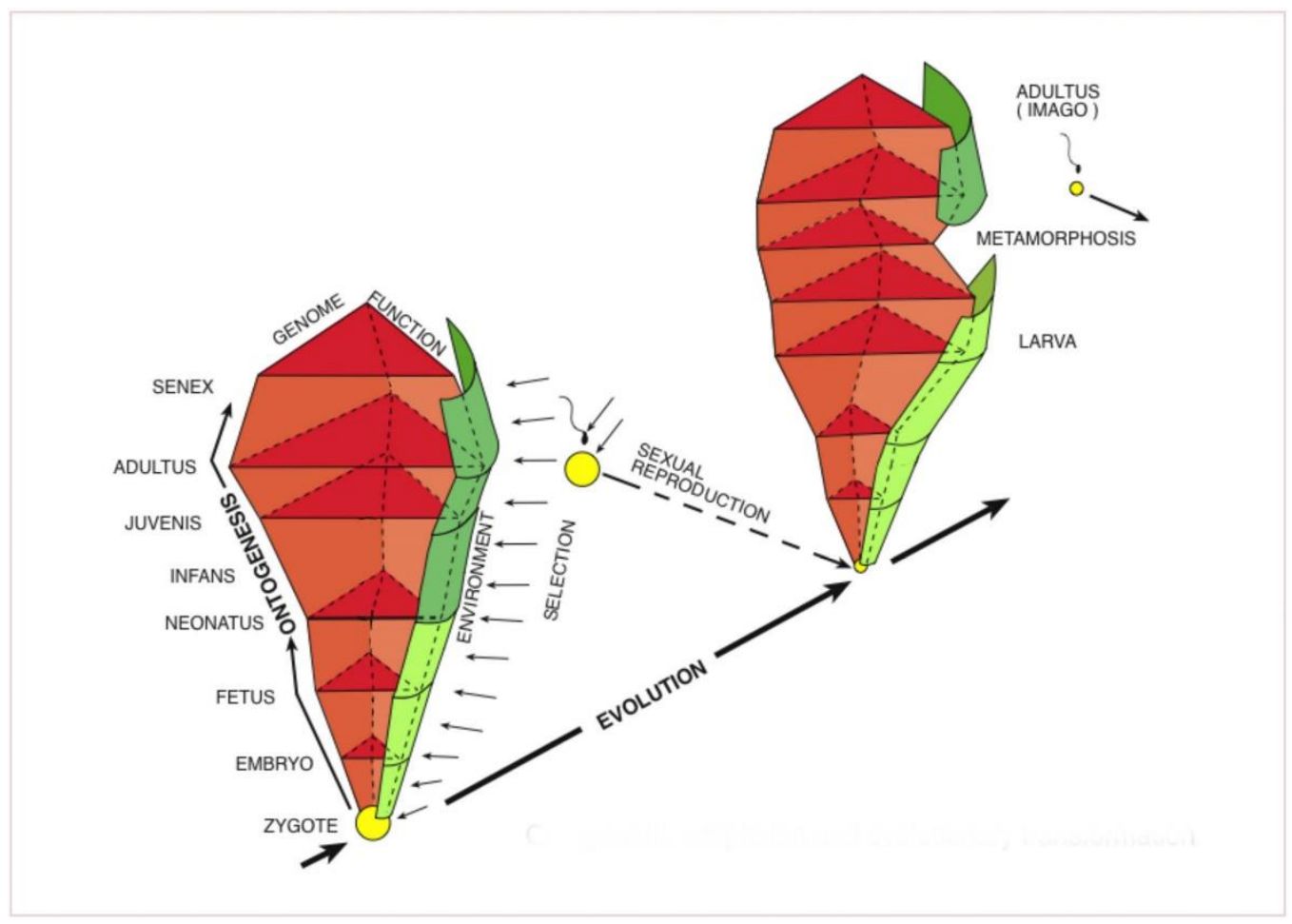

Figure 1.1. Representation of an example of the evolutionary "flow" that connects biological entities, including the relationship between ontogeny and phylogeny. Modified from Maier (1999), who formulated the holistic organism concept.

In addition to the theory of Punctuated Equilibria, the late 1970s and early 1980s witnessed other advances that seemed to contradict the central core of the Modern Synthesis. First, the publication of Ontogeny and Phylogeny by S. J. Gould (1977) brought back the concept of heterochrony as a mechanism of evolutionary change (Alberch et al. 1979; McNamara 1982; Klingenberg 1998), and, second, the discovery of the Homeobox (Hox) genes (Lewis 1978; Gehring 1985, 1998), which specify the identity of segments, revealed those genomic regions as fundamental sources of extensive reorganizations of body plans (Gehring \& Hiromi 1986). Those marked the beginning of profound theoretical and methodological changes in evolutionary biology, with the development of further conceptssuch as developmental plasticity (Via \& Lande 1985; Pigliucci 2001), developmental constraints (Maynard Smith et al. 1985; Beldade et al. 2002), and evolvability (Wagner \& Altenberg 1996; Wagner \& Draghi 2010) — and new research programs — such as Evo-Devo 
(Raff 2000; Müller 2007). Some authors have called for a new synthesis of evolutionary thought, the so-called Extended Evolutionary Synthesis (Pigliucci 2007; Carroll 2008; Laland et al. 2014, 2015; Müller 2017), which could incorporate all those new advancements and overcome the strict "gradualism, externalism and gene centrism" of the Modern Synthesis (Pigliucci \& Müller 2010).

It is becoming increasingly difficult to advocate that macroevolution is solely explained by the gradual accumulation of microevolutionary change. The possibility that morphology can be channeled by inherent properties of development, with considerable phenotypic variation resulting from small genetic mutations (e.g. facilitated variation; Gerhart \& Kirschner 2007), and that changes in environmental conditions can be incorporated into developmental features (part of niche construction theory; Badyaev \& Uller 2009; Odling-Smee 2010), constitute, in some cases, better explanations for the observed macroevolutionary patterns than the microevolutionary processes of selection, drift, mutation and gene flow (Laland et al. 2015). Also, historical, contingent events, such as mass extinctions, can drive evolution and diversification in directions that cannot be directly extrapolated from microevolutionary processes (Maynard Smith 1984; Gould 2002; Carroll 1997; Jablonski 2005, 2017). For example, the Cretaceous/Paleogene mass extinction, completely extinguishing the then dominant non-avian dinosaurs, opened the way for mammals to explore "niches" previously occupied by the former, leading to mammalian ecological dominance (among terrestrial vertebrates) during the Cenozoic (Smith et al. 2010; Archibald 2011; even though the mammalian lineage experienced an adaptive radiation already during the Jurassic; Close et al. 2015). Data gathered exclusively from neontological studies could hardly provide evidence for this large-scale faunal turnover, which led to the establishment of the mammalian diversity as we know it today. Borrowing the idea from Deleuze \& Guattari (1987), the evolutionary process should be viewed as a flow, in which all observed biological entities are contingent and, as such, can only be fully understood taking into account their past and the historical phenomena that led to their current status. Like the river mouth is the sum of all previous events, its spring, its tributaries, the environments they cross, etc., lineages and taxa are the result of their ontogenies, natural history, and phylogenetic evolutionary history (Fig. 1; Maier 1999; Sánchez-Villagra 2012). The identity of a trait, a population, or a lineage results (and emerges) from the network of historical and 
present connections it possesses with other traits, populations, or lineages (an equivalent point made for homologies by G. Wagner 2007, 2014). In this sense, paleontology has a key role not only in documenting the past diversity, but also in revealing macroevolutionary processes that shaped the evolutionary history of organisms.

\subsection{How Paleontology can contribute to Evolutionary Biology?}

The palaeontologists have too long been missing from the high table. Welcome back.

John Maynard Smith (1984)

A common thread to all those recent advancements is the focus on the evolution of form. At the dawn of the evolutionary thinking, in the late $19^{\text {th }}$ and early $20^{\text {th }}$ century, evolutionary morphology was a strong research program (Amundson 2007) aiming to understand organic form (Nyhart 1995), with well-known names such as E. Haeckel, C. Gegenbaur, and G. de Beer. However, the then absence of contemporary methods to answer the more integrated questions that were emerging and the increasing prevalence of the Modern Synthesis substantially obscured the evolutionary morphology approaches (Amundson 2005, 2007). For the late R. Raff, the recent advancements in the direction of revisiting an evolutionary morphology research program represent a clear change of focus in evolutionary biology (Amundson 2003; Wagner 2014): the research program of the Modern Synthesis was interested in species and the new, revived interest in evolutionary morphology is concerned with bodies (Raff 1996). In this context, Punctuated Equilibria, Evo-Devo, and the Extended Evolutionary Synthesis "brought morphology back to center stage in evolutionary biology" (Hall 2003).

The return of morphology to the focus of evolutionary biology marks an important ontological change in a long-lasting debate between functionalist and structuralist views of evolution (Hughes \& Lambert 1984; Amundson 2005; Wagner 2014). This is very important because it adds layers of complexity in the kinds of explanations that we employ to understand biological phenomena (Futuyma 2017). S. J. Gould and R. C. Lewontin, using a 
beautiful metaphor, explained that: some traits of living organisms are not the sole result of adaptation (the functionalist explanation), but, as the spandrels of the dome of St. Mark's Basilica in Venice, they might have an architectural, structural role, that preceeds its apparent function (Gould \& Lewontin 1979). The research program of the Extended Evolutionary Synthesis tries to incorporate this reasoning by considering both functional and structural processes when approaching evolutionary questions.

Most of the core assumptions of the Extended Evolutionary Synthesis are related to developmental mechanisms and how those produce the observed patterns of form in organisms (Hall 2003; Laland et al. 2015). In this framework, Müller (2007) recognized the following four major research programs: i) comparative embryology and morphology; ii) evolutionary developmental genetics; iii) experimental epigenetic; and $i v$ ) theoretical and computational programs. In the first of those, paleontology is supposed to contribute through the "characterization of large-scale patterns of morphological evolution" (Müller 2007, p. 943), providing "details of anatomical variation over hundreds of millions of years" that can be compared to data on extant taxa, whether that is derived from anatomy, development, or any other evolutionary biology field. Paleontology is our only window to long-gone body designs (Raff 2007), offering the record of evolutionary change patterns, through which we can understand how the evolutionary processes acted in deep time to produce those forms (Carroll 1997; Smith 1998; Sánchez-Villagra 2012). Questions about the origin of new structures and body plans, how organisms reached their current disparity levels, and how fast evolutionary change occurred-all pertinent matters in the current theoretical framework of evolutionary biology_can only be satisfactorily answered when one also takes the fossil record into account (Carroll 1997; Raff 2007).

Two examples might illustrate how paleontology, by informing us about evolutionary patterns, helps understanding the evolutionary processes. All post-Devonian tetrapods possess a maximum of five digits in their autopodia (except in cases of pathological polydactyly; e.g. Welscher et al. 2002). Embryological studies identified five-digit anlagen in taxa that lost their digits (Galis et al. 2001) and showed that re-evolution of digits is always limited to a count of five (Kohlsdorf \& Wagner 2006; Kohlsdorf et al. 2010; Siler \& Brown 2011), suggesting a possible relation between autopodium development and pentadactyly. 
However, the fossil record shows that the three earliest tetrapods, Acanthostega gunnari, Ichthyostega stensioei and Tulerpeton curtum, possessed more digits, respectively eight, seven, and six, respectively (Wagner 2014). That is, paleontology conclusively shows that pentadactyly estabilized after the autopodium evolved (Wagner \& Chiu 2001), suggesting that five digits, although highly conserved among later tetrapods, is not a condition strictly related to the mechanism that defines autopodium identity (Wagner 2014). The second example comes from the jaws and ears of mammals. It's been known for nearly two centuries that the mammalian middle ear ossicle named malleus develops from the posterior part of Meckel's cartilage, which ossifies into the articular bone in reptiles (Raff 2007). It might be tempting to consider this as a singular, unique event of morphological innovation given its complex gene expression during ontogeny (Tucker et al. 2004) and the observation that all mammals posses three middle ear ossicles and a single-bone lower jaw (Luo et al. 2011). However, the fossil record has shown us that, although the distinct lower jaw articulation to the skull appeared just once in the mammalian lineage, the incorporation of these ossicles into the middle ear happened at least three times (Raff 2007; Luo et al. 2011, 2017; Lautenschlager et al. 2018b), an insight that could hardly be gained from developmental evidence alone.

The dynamics of populations of extant species, the genetic network and developmental processes that give identity to morphological structures (Wagner 2014) all can, and should, be studied from experimental data on extant organisms, because developmental patterns are "genetically programmed and cyclical" (Raff 2000). Processes such as natural selection, genetic drift, and phenotypic plasticity likely occur at the level of population across all geographical limits and time scales, but many other aspects that are only visible on larger time scales (Carroll 1997) are not repeatable and, as such, cannot be studied by the experimental science methods (Cleland 2001, 2002). Evolution as a whole, however, is "non-programmed and contingent" (Raff 2000), that is, a handful of historical processes acted (and still act today) on the macroevolutionary level, e.g. extinctions and past climatic conditions. The patterns left by those processes are fundamental for the full comprehension of evolution and they can only be studied from the fossil record. Among those, R. L. Carroll identified five evolutionary phenomena that are particularly prone to be investigated from a paleontological perspective (Carroll 1997): (1) the origin of major evolutionary novelties; (2) 
the extremely irregular occupation of the adaptive landscape; (3) the apparent faster rates of evolution during the origin of groups in comparison to the rest of their evolutionary history; (4) the cause and nature of major radiations; and (5) the causes and significance of mass extinction on the evolution of biodiversity. Of course, all these issues would benefit from experimental studies on extant organisms, but their explicit historical components require taking into considerion the effect of large-scale changes as shown by the fossil record.

\subsection{Digital paleontology: how modern approaches can tackle old problems}

Virtual paleontology is no longer a niche undertaking; these techniques are now at the core of the discipline.

M. Sutton and colleagues (2017)

In the past 30 years, paleontology has been revolutionized by the fast increase in computational power and accessibility of new technologies. In the 1990s, the term Computational Paleontology started to be applied to a set of new tools, techniques, and methods, e.g. virtual modelling, computer simulations and, digital imaging (Elewa 2011), that soon became almost standard practice in the field (Sutton et al. 2017). This has given a boost to different types of macroevolution studies based on paleontological data, such as those testing evolutionary models of diversification (Crouch et al. 2019; Varela et al. 2019), biogeography (Poropat et al. 2016; Carbonaro et al. 2018; Ferreira et al. 2018a), and character evolution (Brusatte 2011; Lee et al. 2014; Brocklehurst 2017; Benson et al. 2018). Geometric morphometrics and disparity analyses are other types of approaches that were substantially stimulated by the development of computational paleontology (Reyment 2011; Close et al. 2015; Godoy et al. 2018). Additionally, studies of macroecological patterns, e.g. changes in diversity through time associated to morphological traits (Wagner et al. 2018) or climatic changes or extinctions (Lowery et al. 2018; Ezcurra \& Butler 2018), and functional analyses of locomotion using digital models (Pierce et al. 2012; Sellers et al. 2017; Nyakatura et al. 2019) have multiplied in recent years. 
One of the fastest evolving and widely used developments in computational paleontology is the set of tools gathered under the name of digital or virtual paleontology (Elewa 2011), defined as "the study of fossils through three-dimensional (3-D) digital visualizations" (Sutton et al. 2014, 2017). This includes several techniques and methods for obtaining digital images from body or trace fossils of plants, invertebrates, vertebrates, and microfossils (Rahman \& Smith 2014), and transforming them into 3-D models that can be posteriorly manipulated in various ways. Even though the first studies using radiographic images of fossils date back to the 1980s (e.g. Haubitz et al. 1988; and the use of X-ray images dates even further back, e.g. Kuhn-Schnyder 1974), a huge raise in the use of those tools happened in the last two decades related to the increasing availability of X-ray computed tomography (CT) (Sutton et al. 2017). Digital paleontology techniques have enormous basic benefits in paleontological research due to the very nature of fossils, which are commonly fragile, incomplete and/or disarticulated, hampering the extraction of information (Lautenschlager \& Rücklin 2014; Lautenschlager 2016; Sutton et al. 2017). Also, transforming the usually unique and frail fossils into digital models, that can be stored, replicated and printed at low costs, has additional important outcomes, facilitating outreach and scientific communication (Rahman et al. 2015), and the access and dissemination of fossil data that can be accessed by other researchers (Lautenschlager 2014; Sutton et al. 2017).

A number of imaging techniques are available for extracting information from fossils, e.g. magnetic resonance imaging (MRI; Clark et al. 2004), synchrotron X-ray tomographic microscopy (Donoghue et al. 2006), and surface-based techniques (e.g. laser scanning and photogrammetry; Falkingham 2012), but one of the most used are X-ray computed tomography and micro-tomography (CT and $\mu \mathrm{CT}$, respectively) (Sutton et al. 2017). Computed tomography is a type of non-destructive tomographic technology that creates a series of 2-D projections (cross-sections) of a fossil (or any other object) taken at different angles, creating a dataset of 'slices' that can be visualized and manipulated in specific softwares (Abel et al. 2012; Sutton et al. 2017). Aside from the previously mentioned practical advantages of using CT data, the possibility of isolating portions of interest of an object (e.g., a specific bone or structure) and of making use of methods for virtual restoration to infer "in-life" morphologies of deformed or incomplete specimens (Lautenschlager 2016) 
opened the way for countless applications in evolutionary (especially functional) studies, such as quantitative analyses of functional morphology (e.g., multibody dynamics analysis, MDA; Lautenschlager et al. 2018b), hydrodynamic flow modelling (Gutarra et al. 2019), and even paleohistological (Giles et al. 2013) and developmental analyses (Rücklin et al. 2012, 2014).

A

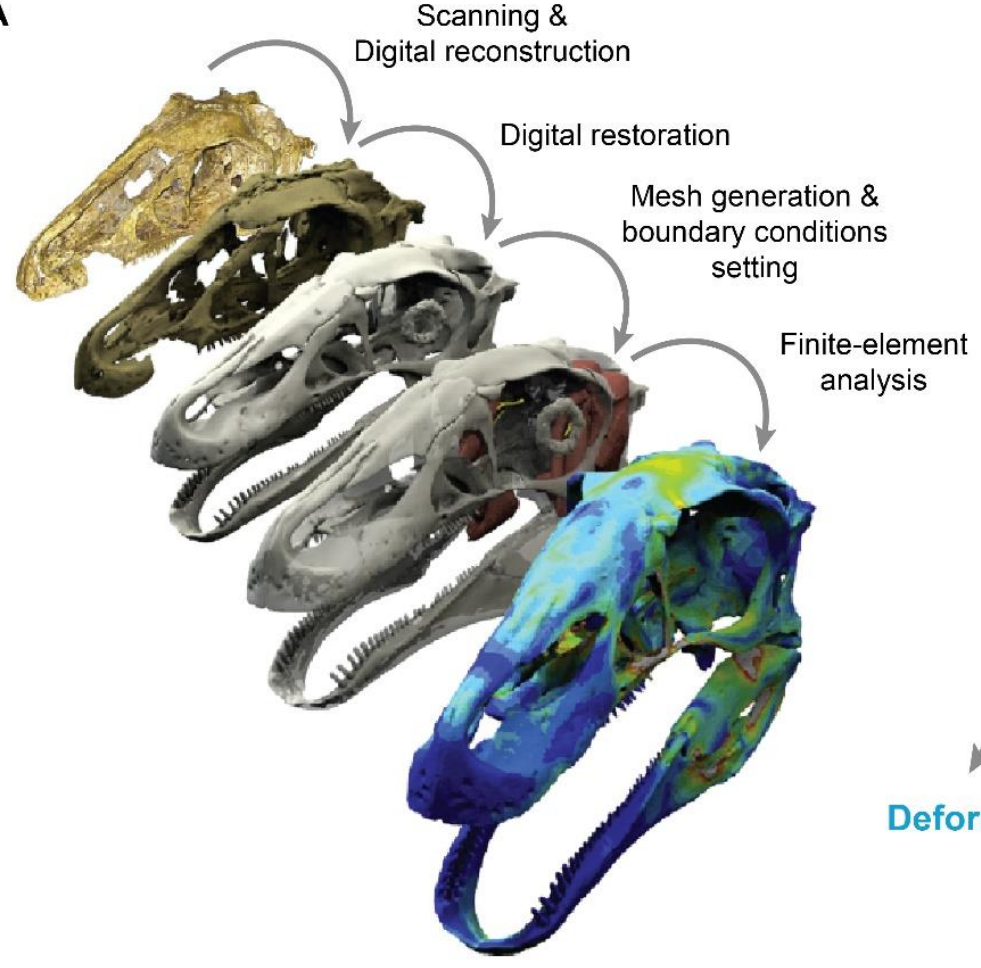

B

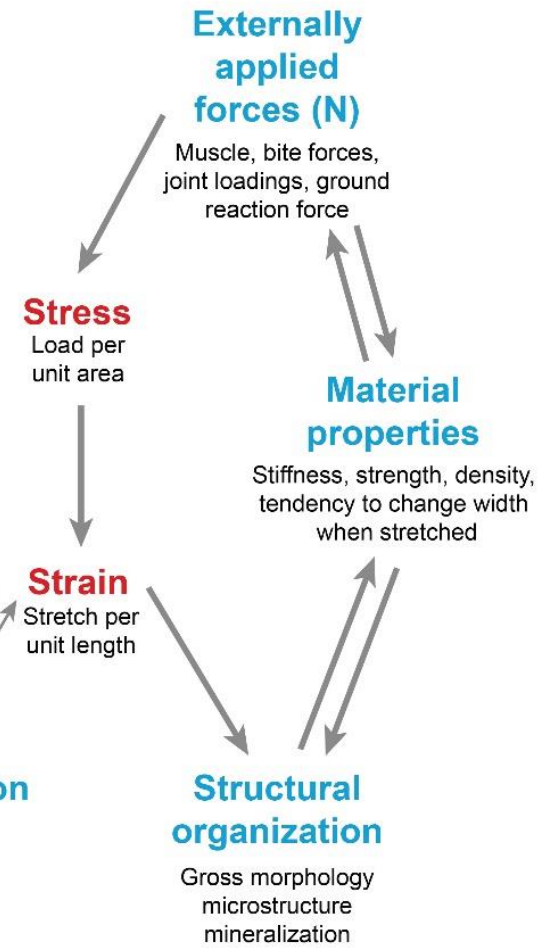

Figure 1.2. Summary of Finite-Element Analysis (FEA). (A) Main steps from obtaining a digital image of the original fossil specimen to the final results of a FEA exemplified by a model of the skull of Erlikosaurus andrewsi. (B) Relation between stress and strain and factors affecting (and being affected by) those. Modified from Rayfield (2007, Fig. 1) and Cunningham et al. (2014, Fig. 1).

Tomographic data also allow anatomical 3-D reconstruction of internal structures (Donoghue et al. 2006; Cunningham et al. 2014), such as endocasts of brain and inner ear cavities, as well as canals, sulci, and sinuses (Witmer et al. 2008; Porter \& Witmer 2015). This type of data, commonly inaccessible without digital paleontological techniques (Lautenschlager \& Rücklin 2014), provide invaluable empirical information on extinct organisms (Giles \& Friedman 2014; Balanoff et al. 2016) that can be used to better understand their sensorial evolution and paleobiology (e.g. Yi \& Norell 2015; Lautenschlager et al. 2018a), and other morphological features (e.g. Rollot et al. 2018). The workflow of acquiring, isolating, and generating 3-D models of endocasts is very straightforward 
(described in detail in Balanoff et al. 2016): 1) the specimen is scanned using any tomographic method, such as CT-scan; 2) the structure of interest (e.g., brain cavity or nerve canal) is identified in the 2-D slices; 3) segmentation (i.e., digitally "painting") of the structure proceeds, using appropriate softwares; and 4) a surface model is generated from the segmented object which is used for visualization, measurements, or other analyses. The nondestructive nature and relative fast methods for creating digital endocasts have fueled an increased interest in comparative paleoneuroanatomy, an fruitful way to study macroevolutionary patterns (e.g., Walsh et al. 2013; Lautenschlager et al. 2018a).

Functional analyses are noteworthy applications of 3-D digital models of biological structures obtained through CT-scan, because they present a vast potential to inform on the behavior and ecology of extinct organisms (Barrett \& Rayfield 2006). Among those, a technique applied in engineering and orthopedics, Finite Element Analyses (FEA), has recently become one of the most used methods for biomechanical analyses in Paleontology (Rayfield 2007; Bright 2014; Cunningham et al. 2014). The FE (Finite Element) method (described in detail by Rayfield 2007 and Bright 2014) consists in applying virtual loads and constraining anchors (called boundary conditions) to a digital three or two-dimensional representation of a structure of interest. This structure is divided into a finite number of discrete elements, which form a network (the finite element mesh) of interconnected (through nodes between the elements) pieces, and to which specific material properties (that represent the elasticity of the material) are assigned. The interplay between architectural geometry, material properties, and boundary conditions yield nodal displacements, which are used to calculate strain (stretch per unit length) and stress (load per unit area) on each node of the mesh object. The results of these calculations can then be summarized and represented by colored plots of a strain and stress index (tension/compression distortion or von Mises stress, a function that measures how stress distort a material), vector plots of the orientation of the resulting loads, or animations of structural deformations (Rayfield 2007).

The application of FEA in paleontology (and morphological studies in general) are far-reaching, being a very useful technique to infer performance in extinct organisms, i.e., when specific forces (such as locomotor or feeding related forces; e.g. Porro et al. 2013) may cause a musculoskeletal system to collapse or deform to a point that it can fail (Bright 2014). 
The array of issues that can be tackled by FEA is broad, ranging from the function of specific structures, to questions pertaining to the constraints and adaptations of the musculoskeletal system, and even to reverse engineering approaches to infer potential functions of particular structures (Rayfield 2007). Emily Rayfield recognized two general lines of applications of FE models in vertebrate morphological research, the inductive and the hypothetical-deductive approaches (Rayfield 2007). In the inductive approach boundary conditions are set and the pattern of stress distribution is assessed on focus models (Bright 2014). This approach is useful to test whether (and how) form and function are related in these specific cases, allowing to investigate the structure in individual taxa (such as the specific role of the masseter-like muscle in Psittacosaurus lujiatunensis; Taylor et al. 2017) and also to perform validation and sensitivity analyses (Rayfield 2007). The hypothetical-deductive approach, on the other hand, is a hypothesis-testing method in which FEAs are run on models that can, potentially, falsify a given hypothesis (Rayfield 2007). This method has a great potential to test evolutionary trend questions (Bright 2014), such as the role of the palate vacuities closure in temnospondyls (Lautenschlager et al. 2016), of the cranial sinuses in the mammalian face (Farke 2008; Tanner et al. 2008), the change in cranio/mandibular articulation in mammals (Lautenschlager et al. 2018b), or the protruding faces of Neanderthals (Wroe et al. 2018). In the hypothetical-deductive approach, digital manipulation techniques (Lautenschlager 2016) are very useful, as they give us the possibility to generate hypothetical morphologies and test particular functional predictions of a given hypothesis (Lautenschlager et al. 2016; Chapter 5 of this thesis). In summary, the combination of cutting-edge technology in imaging (e.g., CT scanning) and functional analyses (e.g., FEA) in Paleontology possess an invaluable potential to approach evolutionary questions.

\subsection{Turtles as models of vertebrate evolution}

In vertebrate paleontology, it might well be the origin of turtles, and the correlated evolution of the turtle shell, that constitute (one of) the mystery of mysteries

Olivier Rieppel (2013) 
The shell, the toothless jaws with beaks and the clumsy and slow locomotion, even from the outside, make turtles "one of nature's most immediately recognizable life forms" (Adler 2007). From "the inside", they may look even more different: their unfenestrated skulls (unique among extant reptiles; Ferreira \& Werneburg 2019; Chapter 2 of this thesis), their extremely mobile necks (Werneburg et al. 2015a), the anatomical composition of the carapace and plastron (Nagashima et al. 2009), their scapular and pelvic girdles inside the thoracic cage (Lyson \& Joyce 2012), and their highly conserved cervical and trunk vertebral count (Böhmer \& Werneburg 2017) are but a few of the morphological modifications of turtles that makes them one of the most intriguing vertebrate groups from a macroevolutionary perspective. At the same time that their very unique morphology leaves no room for doubts on their monophyly, it also makes it difficult to establish homologies with other reptiles (Carroll 2013), hampering the assessment of the group's origin and making the phylogenetic origin of turtles one of the oldest debates in vertebrate paleontology, lasting for more than 200 years (Rieppel 2013, 2017).

Pre-cladistic classifications strongly relied on skull traits, especially the temporal openings (fenestrae), to define the relationships of tetrapods (Werneburg 2019). In all those early classifications, the unfenestrated temporal region was considered as "primitive", the stock from which single- or double-fenestrated amniotes (Synapsida and Diapsida, respectively) have arisen (Gardiner 1982). Because the oldest known turtles, such as Proganochelys quenstedti, from the Late Triassic of Germany (Gaffney 1990), had an anapsid skull morphology (i.e., without temporal fenestrae) (Baur 1889; Hay 1905; Watson 1914; Williston 1917), and some extant turtles also possess a full coverage of the adductor chamber (e.g. Dermochelys coriacea; Schumacher 1972), all those early classifications placed turtles together with other anapsid reptiles (Osborn 1903; Williston 1917; Gregory 1946; Olson 1947; Romer 1956; see Ferreira \& Werneburg 2019; Chapter 2 of this thesis for a detailed summary of early classifications). Even though critiscisms to the heavy weight placed on the temporal fenestrae were already made several times (e.g., Goodrich 1916; Gardiner 1982), the first large-scale analyses of amniote relationships using computerassisted cladistic analysis (Gauthier et al. 1988) supported the pre-cladistic classifications, 
with turtles as ancestrally anapsid non-diapsid reptiles (in this particular analysis, together with Captorhinidae).

A

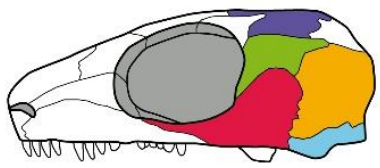

B

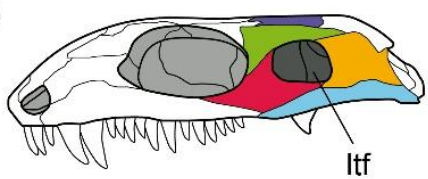

C

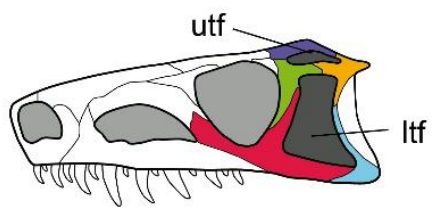

Morphology

Anapsid

Synapsid

Diapsid

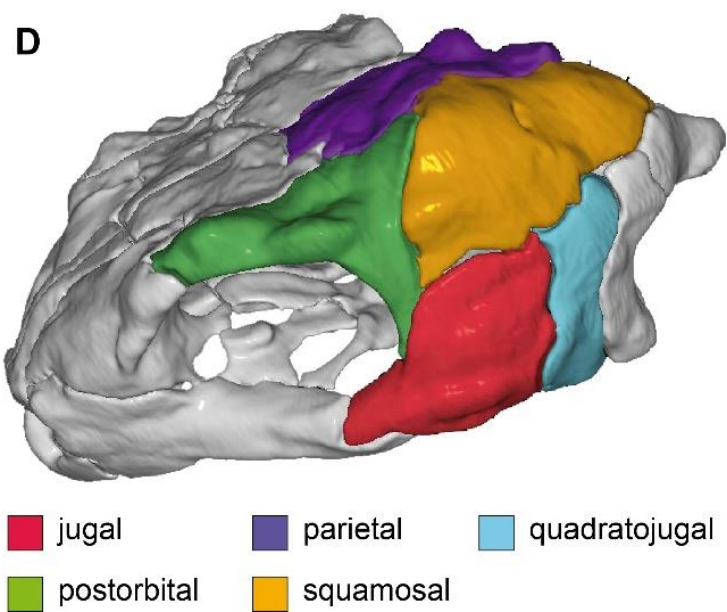

Figure 1.3. Diversity of temporal morphology among amniotes, highlighting the three main types of temporal fenestrae and the bone arrangement surrounding them. (A) the parareptile Milleretta rubidgei; (B) the synapsid Eothyris parkeyi; (C) the diapsid Euparkeria capensis; (D) one of the earliest turtles Proganochelys quenstedti.

While an apparent consensus existed from the late 1970s to the early 1990s that turtles were not diapsids (Løvtrup 1977; Gardiner 1982; Gauthier et al. 1988; Lee 1993, 1996, 1997; Laurin \& Reisz 1995), the closest taxon to turtles varied from captorhinids (Gauthier et al. 1988), to procolophonids (Laurin \& Reisz 1995) and pareiasaurs (Lee 1993). The first cladistic study to retrieve turtles as diapsids was that of Rieppel \& deBraga (1996), in which they appeared closest to sauropterygians, a group of marine diapsids. Subsequent analyses using the same data matrix (deBraga \& Rieppel 1997; Rieppel \& Reisz 1999) seemed to confirm those results, which agreed with earlier classifications that did not strongly relied on temporal fenestrae anatomy (e.g. Goodrich 1916, 1930; Boulenger 1918; Broom 1924; Lakjer 1926; DeBeer 1937; Hofsten 1941). Molecular-based phylogenetic analyses also revealed a signal of turtles as diapsids, but almost always closer to archosaurs than to lepidosaurs (Zardoya \& Meyer 1998, 2001; Hedges \& Poling 1999; Mannen \& Li 1999; Crawford et al. 2012; Hedges 2012; Wang et al. 2013; the only exception being a turtle + squamate clade found by Lyson et al. 2012). A common trait of these morphological analyses from the 1990s (Lee 1993, 1996, 1997; Laurin \& Reisz 1995; Rieppel \& deBraga 1996; deBraga \& Rieppel 1997; Rieppel \& Reisz 1999) was that they extended their databases to include a higher number of postcranial characters, i.e., they tried to get away from the 
temporal fenestrae-based classifications. Yet, the results didn't converge to any point; on the contrary, the array of possible sister-taxa to turtles increased.

These conflicting results are probably a consequence of the extremely modified body plan of the group, specially the turtle shell, which - as mentioned above-hinders the establishment of homologies among amniotes. This complex structure is formed by a dorsal and a ventral portion, the carapace and the plastron, respectively (Fig. 1.3) and has attracted much attention and generated intensive debate for more than 200 years (e.g., Cuvier 1799; Saint-Hilaire 1809; Meckel 1824; Rathke 1848; Goette 1899; Vallén 1924; Gilbert et al. 2001; Scheyer et al. 2008, 2013; Hirasawa et al. 2013). Even though other tetrapods may possess carapace-like structures (e.g., some extinct crocodiles, dinosaurs and armadillos), the turtle carapace is fundamentally different from any other known structure, because it is directly linked to the dorsal vertebrae and ribs, preventing any movement of the rib cage or intercostal muscles (Hirasawa et al. 2013; Wagner 2014; Lyson et al. 2014). Even more odd is the encapsulation of scapular girdle inside the thoracic cage; a unique feature among tetrapods which possess the scapular blade either anterior to or outside the thoracic ribs (Lyson \& Joyce 2012; Nagashima et al. 2012).

The turtle carapace is formed by a midline row of small bones, the neural plates, and laterally to that two parallel rows of flat and wide bones, the costal plates. Surrounding this inner structure, a series of small elements, the peripheral plates, link the anterior nuchal plate to the posterior pygal and suprapygal plates (Zangerl 1969). The exoskeletal origin of these external elements is broadly accepted (Hirasawa et al. 2013; but see Lyson et al. 2013 for a reinterpretation of the nuchal bone), but regarding the inner (neural and costal) plates, there is a lot of controversy. Since G. Cuvier interpreted them as derived from the expansion of the vertebral neural arches and ribs (i.e., exclusively endoskeletal derivatives; Cuvier 1799), and K. G. Carus opposed this idea, suggesting a composite structure derived from the fusion of endoskeletal elements to overlying exoskeletal ossifications, the osteoderms (Carus 1834), no consensus has been reached on the morphological and developmental origin of the carapace (until recently, see below). Those two ideas came to be known as the de novo and the composite hypotheses, respectively (Joyce 2015). Historically, researchers with a 
developmental background (e.g., Vállen 1942) favored the de novo hypothesis, whereas those paleontology-inclined preferred the composite hypothesis (e.g., Joyce et al. 2009).

Although not very informative to this issue (until recently, see below), the fossil record seemed to support the composite hypothesis. Proganochelys quenstedti was for a long time the earliest known turtle, and even though it already had a complete turtle shell (in the sense of Joyce et al. 2004), its neck and tail were covered by osteoderms. The description of Chinlechelys tenertesta, from the Late Triassic of USA, seemed to confirm this view, due to the poor association between its ribs and the overlying costal bones (Joyce et al. 2009). Also, some results of morphology-based phylogenetic analyses suggested turtles evolved from reptiles in which a dorsal coverage of osteoderms was frequent (e.g. pareiasaurs or sauropterygians: discussed by Lee 1993 and Rieppel \& deBraga 1996).

On the other hand, developmental biology was obtaining opposite conclusions. Early observations (e.g. Rathke 1848; Vállen 1942) could not evidence any dermal ossifications contributing to the neural and costal plates during the ontogeny of the carapace. More recent histological and developmental analyses also confirmed the absence of dorsal osteoderm formation, but suggested a third hypothesis, in which the entrance of the ribs into the dermis induced osteogenesis of the surrounding dermal tissue (Gilbert et al. 2001; Cebra-Thomas et al. 2005). A subsequent comparative developmental analysis contradicted those observations though, and concluded that the neural and costal plates are solely derived from vertebral neural arches and ribs, respectively, by extensive outgrowths of bone tissue around the rib cartilage (Hirasawa et al. 2013). Regardless of the specific process that leads to bone apposition surrounding the rib cartilaginous primordia, developmental data do not support the fusion of the endoskeletal elements to overlying dermal ossifications.

The most important contribution from developmental biology, though, was the identification of the carapacial ridge (Burke 1989, 1991; Nagashima et al. 2007). In general, the precursor cells of the trunk ribs of amniotes migrate during development from the somites on the axial domain to the lateral body wall, resulting in ventrally curved ribs. The turtle ribs, on the other hand, are flat and laterally directed, which is the result of the turtle-specific carapacial ridge, directing the development of those precursor cells into the axial domain (Fig. 1.4; Nagashima et al. 2012) and preventing them from entering the lateral body wall, a 
process called axial arrest (Burke 1989). The morphological structure and the development between the axial and abaxial domains of the embryonic body, as well as the (partially) similar gene expression during the development of the carapacial ridge highlight a resemblance to the apical ectodermal ridge (AER), the signaling center of the developing limb bud (Burke 1989, 1991; Gilbert et al. 2001; Cebra-Thomas et al. 2005; Nagashima et al. 2007), and suggest that its signaling pathway might have been co-opted from limb development and expressed in a novel manner in the ancestral turtle (Kuraku et al. 2005). The carapacial ridge is the developmental event that completely modifies the ancestral reptilian body plan into the turtle body plan. By encircling the dorsal portion of the embryonic body, forming a disc, it also induces the fan-shaped arrangement of the turtle ribs, folding the lateral body wall inward, resulting in extremely modified muscles that develop prior and after to the rib expansion (Nagashima et al. 2009). This novel rib arrangement also spreads the anteriormost ribs anteriorly, and the posteriormost posteriorly, secondarily covering the anteriorly placed scapular blade dorsally (Nagashima et al. 2009, 2012).

Even though a less detailed scenario is currently known for the morphological and developmental origins of the plastron, recent research presented important advancements (Cherepanov 1997; Cebra-Thomas et al. 2007, 2013; Rice et al. 2016). Most extant turtles possess nine bones in the plastron (Zangerl 1969), but stem-turtles, e.g. Proganochelys quenstedti (Gaffney 1990), and pleurodires (Vieira et al. 2009) usually possess eleven. From those, the three anterior plates, the epiplastra and entoplastron, are thought to be derived from the clavicles and interclavicles, respectively (Cherepanov 1997; Lyson et al. 2013) and the posterior plates have been associated with modified paired abdominal ribs, the gastralia (Romer 1956; Gaffney 1990; Kuratani et al. 2011), even though a distinct type of ossification (forming bone spicules) is characteristic of plastral bones (Rice et al. 2016). It has been shown that those plates have an important contribution from neural crest cells (CebraThomas et al. 2007, 2013; Gilbert et al. 2007) and that their appearance suppresses the development of a sternum in the ventral part of the embryonic turtle body and is concomitant with that of the carapacial ridge (Rice et al. 2016). Thus, albeit more work needs to be done to better understand the nature of the plastron, its appearance also seems to be related to the evolutionary novelty of turtles, the carapacial ridge (Kuratani et al. 2011). 

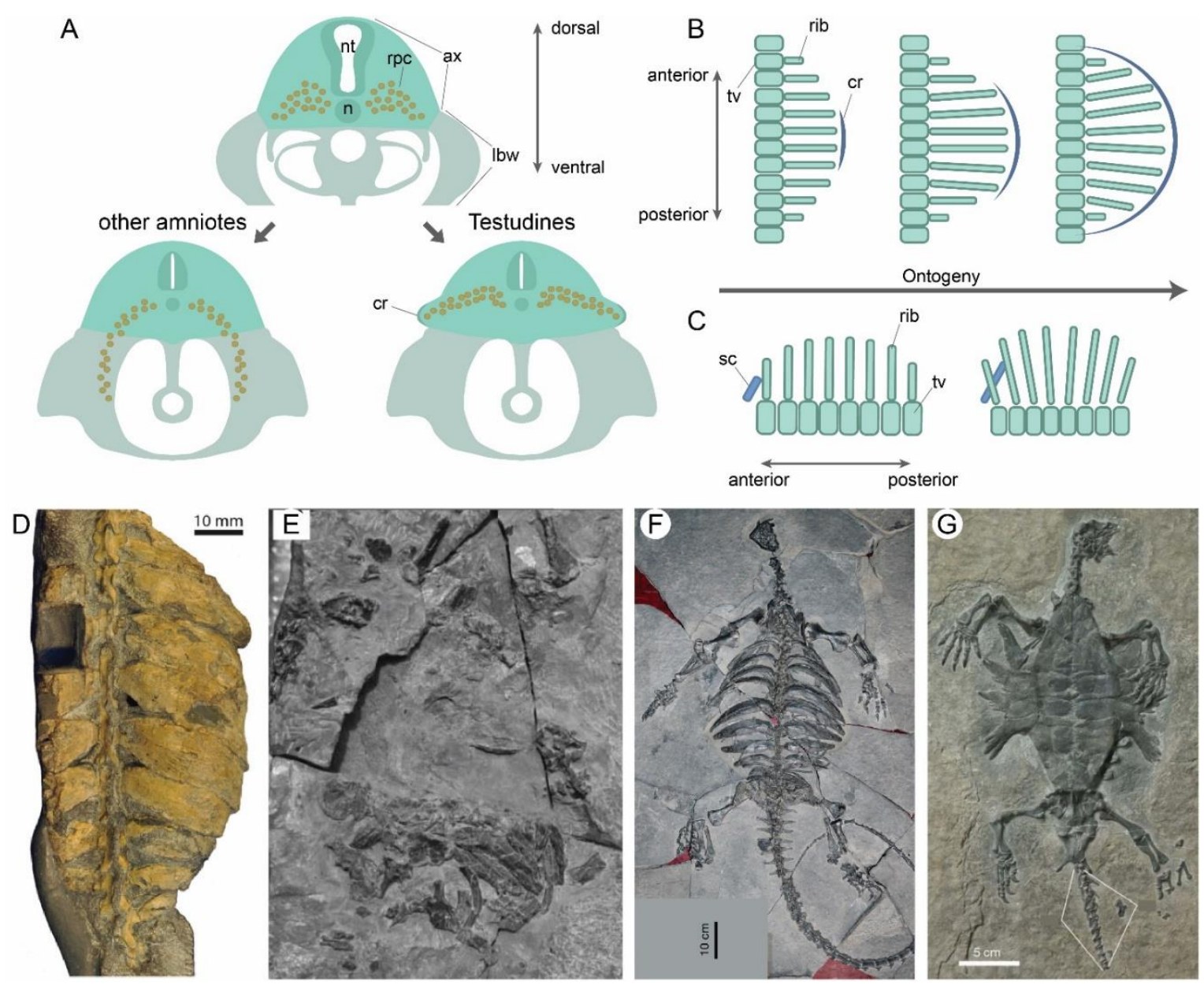

Figure 1.4. Recent advancements from (A-C) developmental biology and (D-G) paleontology that provided a more detailed account on the origin of the turtle carapace. (A-C) Embryonic development of the turtle carapace: (A) cross-sections on amniote embryos; (B) schematic drawing of the carapacial ridge development and its relation to the arrangement of the ribs. Note the fan-shaped arrangement being acquired during ontogeny; (C) schematic drawing of the scapular blade position in relation to the developing ribs. Note the ribs covering dorsally overlaying the scapula during ontogeny. (D-G) Fossil findings of reptiles recently associated to the turtle lineage: (D) Eunotosaurus africanus (Late Permian of South Africa); (E) Pappochelys rosinae (Middle Triassic of Germany); (F) Eorhynchochelys sinensis (Late Triassic of China); and (G) Odontochelys semitestacea (Late Triassic of China. Abbreviations: ax, axial domain; cr, carapacial ridge; lbw, lateral body wall; n, notochord; nt, neural tube; rpc, rib precursor cells; sc, scapular; tv, thoracic ribs. Composite figure based on modifications of Nagashima et al. (2007, 2012), Li et al. (2008, 2018); Lyson et al. (2016), and Schoch \& Sues (2017).

Interestingly, in that same period, paleontological findings also contributed to the issue of the origin of the shell (Fig. 1.4D-G). The finding of Odontochelys semitestacea from the Late Triassic of China, a proto-turtle (term used here to mean a non-Testudinata panTestudines; sensu Joyce et al. 2004) with marginal teeth, a complete plastron, and broad and flattened free ribs (Li et al. 2008), brought important insights on the timing of appearance of turtle traits. First, the broadening of the ribs preceeded their incorporation into the carapace. 
Second, the plastron of $O$. semitestacea is completely formed, but the carapace is incipient, suggesting that even if their developmental timing coincides in extant taxa (Rice et al. 2016) their phylogenetic (and hence historical) origin did not. Finally, the ribs are flat ( $\mathrm{Li}$ et al. 2008) i.e., they are axially arrested and do not enter the lateral body wall, but they do not grow in a fan shape to overlay the scapular girdle. This suggests that during the embryonic development of $O$. semitestacea the carapacial ridge might have been ephemerous and/or incomplete, not forming a carapacial disc that would attract the ribs' growth anteriorly and posteriorly (Nagashima et al. 2009, 2012; Kuratani et al. 2011). The additional findings of Pappochelys rosinae (Schoch \& Sues 2015, 2017) and Eorhynchochelys sinensis (Li et al. 2018) as well as the reinterpretation of Eunotosaurus africanus as a potential proto-turtle (Lyson et al. 2010, 2013; Bever et al. 2015), all of which show broad and free ribs that enter the lateral body wall and do not possess a plastron, seemed to confirm the decoupling of plastron and carapace formation, as well as that of the broadening of the ribs and their axial arrest.

The sequence of events (paleontological contribution) and the ontogenetic mechanisms (evo-devo contribution) that led to the origin of the turtle shell illustrates the acquisition of a true evolutionary novelty (Müller \& Wagner 1991; Nagashima et al. 2009; Kuratani et al. 2011; Wagner 2014). Its appearance completely reorganized the ancestral reptilian body plan in this lineage, not only modifying the ribs and dorsal vertebrae, but also completely reorganizing the whole turtle body. The musculoskeletal alterations related to the encapsulation of the scapular girdle and extensive reorganization of musculature related to the limb muscles (explained by the hypothesis of folding of the lateral body wall; Nagashima et al. 2009, 2012; Kuratani et al. 2011), the division of function between the hypaxial muscles and the dorsal ribs that led to the development of their unique ventilatory system (Lyson et al. 2014), the constraint on the number of cervical and thoracic vertebrae (Böhmer \& Werneburg 2017), and even modifications on the skull, such as the emarginations (Werneburg 2015), mode of palatoquadrate fixation (Werneburg \& Maier 2019), and the skull architecture (Chapter 5 of this Thesis) are thought to be related to the emergence of the turtle shell. A detailed review of the skull morphology, development and its modifications from a reptilian body plan are discussed in Chapter 2 of this thesis. 
It has been suggested that dinosaurs are good model organisms for investigating macroevolutionary questions, because of their extensive fossil record, variety of morphological adaptations, and (relative) phylogenetic stability and diversity (Weishampel et al. 2004). Turtles possess all those characteristics as well. The earliest true turtle (=Testudinata, sensu Joyce et al. 2004) dates back to the Late Triassic ( 220 Myrs; Gaffney 1990; Szczygielski \& Sulej 2016), and a not so numerous, but informative stem-lineage is currently known, illustrating the acquisition of several of their novel characters ( $\mathrm{Li}$ et al. 2008, 2018; Lyson et al. 2014; Schoch \& Sues 2015, 2017). The fossil record is welldocumented, with several extinct lineages known (Joyce et al. 2016; Evers \& Benson 2019) before the (potential) adaptive radiation that originated the crown-group Testudines (Sterli \& de la Fuente 2010). Testudines, in its turn, is a relatively diverse clade, also with a long and well-known fossil record (aprox. 170 Myrs, from the Middle Jurassic; Sterli et al. 2019) that includes noteworthy morphological and ecological disparity of both extinct and extant taxa (Foth \& Joyce 2016; Foth et al. 2017; Rhodin et al. 2017). A consensus on the general phylogenetic framework has also been achieved more recently (Joyce 2007; Rabi et al. 2013; Cadena \& Parham 2015; Joyce et al. 2016; Evers \& Benson 201), including the relationship between the extant lineages (Crawford et al. 2015; Pereira et al. 2017) Also, the existence of extant taxa that can be manipulated in experimental studies, e.g. developmental analyses (e.g. Cebra-Thomas et al. 2007, 2013; Hirasawa et al. 2013; Werneburg \& Maier 2019), can reveal evolutionary patterns and mechanisms that may then be reassessed by historical studies, e.g. paleontology (e.g. Nagashima et al. 2009; Böhmer \& Werneburg 2017; Szczygielski 2017; Chapter 5 of this thesis). All the above-mentioned reasons highlight the potential of turtles as an excellent model for macroevolutionary analyses, a value that has been shown by recent large-scale analyses of macroevolutive patterns in the group (e.g. Jaffe et al. 2011; Uyeda \& Harmon 2014; Nicholson et al. 2015, 2016; Rodrigues \& Diniz-Filho 2016; Rodrigues et al. 2019).

\subsection{Objectives and overview of Chapters 2 to 5}

Through the use of digital paleontology techniques of computed tomography, virtual 3-D reconstruction, and Finite-Element Analyses, the research project presented in this thesis 
had two main objectives: (1) to analyze the patterns of morphological evolution of the turtle skull; and, based on those, (2) to provide novel interpretations of the neuroanatomical and functional relations of specific cranial traits (e.g., jaw adductor musculature, brain size and shape, and skull rigidity) to the whole skull architecture.

In Chapter 2 an overview of the osteological, muscular, developmental, and functional evolution of the craniocervical system of turtles is presented. During the evolution of this taxon, both the skull and the neck were extremely modified in relation to those of the earliest turtles, such as the earliest Testudinata Proganochelys quenstedti. The neck increased in length and mobility, and developed two systems of retraction in the crown-lineages (Werneburg et al. 2015a, b). This, in turn, was correlated to modifications on the skull, such as the various patterns of dermatocranial bone reduction in Testudines (Werneburg 2015) and their mode of palatoquadrate fixation (Werneburg \& Maier 2019; Chapter 5 of this Thesis). Aside from that, several other important modifications were identified along the evolution of the stem-lineage, e.g. changes in carotid circulation, enlargement of the otic chamber, posterior expansion of the adductor chamber, and the development of a trochlear system (Gaffney 1975, 1979; Joyce 2007; Sterli \& de la Fuente 2010; Rabi et al. 2013). Some of those traits, such as the trochlear system and the adductor chamber, are directly related to the jaw adductor musculature (Schumacher 1973). Therefore, a 3-D digital reconstruction of the external and internal adductor musculature of Proganochelys quenstedti is presented and the modifications seen in cryptodires and pleurodires (represented by models of the cryptodire Pelodiscus sinensis and the pleurodire Pelomedusa subrufa) are discussed. This Chapter also summarizes the main issues pertaining the morphological evolution of the craniocervical system of turtles and sets the questions that will be tackled for the following contributions in this thesis (among others).

Chapter 3 is a study on the sensorial evolution at the dawn of turtle evolution, using micro-computed tomography $(\mu \mathrm{CT})$ and digital reconstructions of endocasts of the brain, nasal cavity, endosseous labyrinth, and cranial arteries and nerves of Proganochelys quenstedti. These data were used to infer the ecology in this taxon and to compare it with other turtles (also reconstructed or based on the literature) and other reptiles as well, using a morphospace approach with geometric morphometrics. This was the first attempt to explore 
large-scale comparisons of neuroanatomy among different reptilian groups, and with the available data we concluded that $P$. quenstedti strongly relied on the olfactory sense in life, a characteristic of terrestrial turtles (Paulina-Carabajal et al. 2017). The evidence presented in this Chapter further supports those from other sources, e.g., limb and shell anatomy and paleoenvironments in which early turtles were found, confirming that the earliest true turtle was a terrestrial taxon, but also show that, from a paleoneuroanatomical perspective, there are no evidences that it could have been a fossorial animal (Lyson et al. 2016).

In Chapter 4, I present the description of a new fossil pleurodire turtle, Yuraramirim montealtensis, from the Late Cretaceous of Monte Alto, Brazil. A comparative description of its skull is presented and a phylogenetic analysis conducted, which retrieved it as a member of Peiropemydidae, the sister taxon to the crown-lineage Podocnemididae (Ferreira et al. 2018a). I also present the first paleoneuroanatomical study of an extinct pleurodire based on $\mu \mathrm{CT}$ data, with the reconstruction of the endocasts of the brain, endosseous labyrinth and cranial canals (for arteries and nerves), which are described and compared to other turtles (including some pleurodires; Hopson 1979). This represents an important step towards a better comprehension of neuroanatomical evolution in pleurodires and turtles in general, and presents important data that can be used in broader studies (see also Chapter 3).

Finally, in Chapter 5, functional analyses using Finite-Element Analyses (FEA) are presented to evaluate the consequences of evolutionary changes in the turtle skull architecture to the patterns of stress distribution. Computed tomographic data of stem and crown turtles were used to reconstruct digital models of the skull and jaw adductor musculature of eleven taxa. Four additional models were generated using digital manipulation techniques, to model hypothetical morphotypes and test the functional consequences of specific traits, such as the change from a kinetic to an akinetic skull morphology, the origin of the temporal crests and posterior expansion of the adductor chamber, and the trochlear systems of cryptodires and pleurodires. Using inductive and hypothetico-deductive approaches for the FEAs (Rayfield 2007), previous functional hypotheses were evaluated and a scenario of progressive correlation between skull and neck traits is presented, which could be related to the great diversification of turtles during the Jurassic. 


\section{Chapter 2}

Evolution, diversity, and development of the craniocervical system in turtles, with 3D reconstruction of the jaw musculature of the oldest turtle Proganochelys quenstedti

A modified version of this chapter is published as:

Ferreira, G., \& Werneburg, I. (2019). Evolution, diversity, and development of the craniocervical system in turtles with special reference to jaw musculature. In J. Ziermann, R. R. Diaz Jr, \& R. Diogo (Eds.) Heads, Jaws and Muscles: Evolution, Development, Anatomical Diversity and Function (pp. 171-206). Heidelberg: Springer. doi: 10.1007/9873-319-93560-7_8. 


\title{
2 \\ Evolution, diversity, and development of the craniocervical system in turtles, with 3D reconstruction of the jaw musculature of the oldest turtles Proganochelys quenstedti
}

\begin{abstract}
Turtles are one of the most enigmatic groups of vertebrates with their highly modified body plan and, as such, attracted the attention of researchers for a long time. Aside from the obvious and odd turtle shell, the head in this group shows also great changes in comparison to that of other amniote groups. Since the skull has been considered one of most important body regions when analyzing the phylogenetic relationships of amniotes, the distinct turtle head morphology is one of the key features in defining their position among reptiles. Here, we review the current knowledge of the turtle head, summarizing the general morphology of the skull and neck as well as the different anatomical modifications characteristic of the main lineages of extant and extinct turtles. We explore the main questions that have been raised while studying those issues, for instance the origin and diversity of the temporal emarginations (dermal bone reductions), the different neck-retraction mechanisms and their influence on the shape of the head, and the anatomy and development of the jaw adductor musculature and its relations to some characteristics features of the turtle skull, such as its akinesis and the origin of the trochlear mechanisms in cryptodires and pleurodires. Additionally, using 3-D models and ancestral state reconstructions, the arrangement and gross morphology of the jaw adductor musculature in Proganochelys quenstendti, the earliest turtle with a complete shell, is inferred, an important step towards the understanding of the evolution of those muscles in turtles. Finally, I suggest that more integrative approaches, considering anatomical, developmental and paleontological data, and employing modern techniques in morphological and functional anatomic analyses (such as $\mu \mathrm{CT}$ scanning and finite element analysis) have a great potential to answer the still numerous open questions about the evolution of the turtle head.
\end{abstract}

Keywords: Testudinata, Proganochelys quenstedti, neck retraction, temporal openings, trochlear mechanism 


\subsection{Origin of turtles}

The phylogenetic position of turtles among amniotes has been a highly debated issue for the last 150 years (Rieppel 2008; Joyce 2015) and much of this controversy is related to the greatly modified body plan of these reptiles, especially in their postcranium (Scheyer et al. 2013). The body of turtles is encapsulated inside a bony shell and, consequently, most anatomical parts, such as their limbs, girdles, and their respiratory system, were severely modified with the emergence of this structure (Nagashima et al. 2012). Several lines of investigation, including paleontological ( $\mathrm{Li}$ et al. 2008; Lyson et al. 2010; Lyson and Joyce 2012; Lyson et al. 2013; Lyson et al. 2014; Lyson et al. 2015; Schoch \& Sues 2015) and developmental studies (Burke 1989; Clark et al. 2001; Cebra-Thomas et al. 2005; Gilbert et al. 2001; Gilbert et al. 2007; Gilbert et al. 2008; Loredo et al. 2001; Kuratani et al. 2011; Nagashima et al. 2007; Nagashima et al. 2009; Nagashima et al. 2013; Nagashima et al. 2015; Rieppel 2013), contributed to this debate, and now we have a comprehensive scenario for the origin of the shell, from a phylogenetic and ontogenetic perspectives (Nagashima et al. 2012; Joyce 2015; Rice et al. 2016; Ferreira 2016).

Nevertheless, the phylogenetic origin of turtles remains somewhat controversial (Fig. 2.1). Traditional classifications of amniotes (fully land-adapted tetrapods with a cleidoic eggs) have considered the temporal region of the skull as the most important character for defining large group interrelationships (e.g., Osborn 1903; Williston 1917; Gregory 1946; Olson 1947). Of special importance was the number of openings, the so-called fenestrae, in the temporal skull region. Using this feature, Osborn (1903) divided amniotes (and some non-amniotes) in two main lineages: the 'Synapsida', with one or no fenestra, and the 'Diapsida', with two fenestrae in the temporal region (Rieppel 2000). Later, Williston (1917) modified Olson's (1947) definition of 'Synapsida' by classifying the amniotes without temporal openings as another group that he called 'Anapsida', a group from which fenestrated reptiles presumably arose. In all those early classifications, the turtle skull was considered "primitively" anapsid (Baur 1889; Cope 1896; Hay 1905; Watson 1914), and the group was classified as synapsid (Osborn 1903) or anapsid (Williston 1917). Later and more comprehensive classifications considering both extant and extinct taxa (Gregory 1946; Olson 1947; Romer 1956) included not only turtles, but also diadectomorphs (stem amniotes), 
capthorhinids (stem diapsids), and placodonts (stem lepidosaurs, although they have large upper temporal fenestra), into 'Anapsida'; together with pareaisaurs and procolophonids, these groups were united as 'Cotylosauria'. Today, the cotylosaurs are considered a paraphyletic assemblage of early amniotes and non-amniotes (e.g., seymouriamorphs; Laurin 2002), but those traditional classifications were highly influential on later phylogenetic studies, that grouped turtles along with different anapsid reptiles such as capthorhinids (Gaffney 1980), pareiasaurs (Lee 1995, 1997), and procolophonids (Laurin and Reisz 1995).

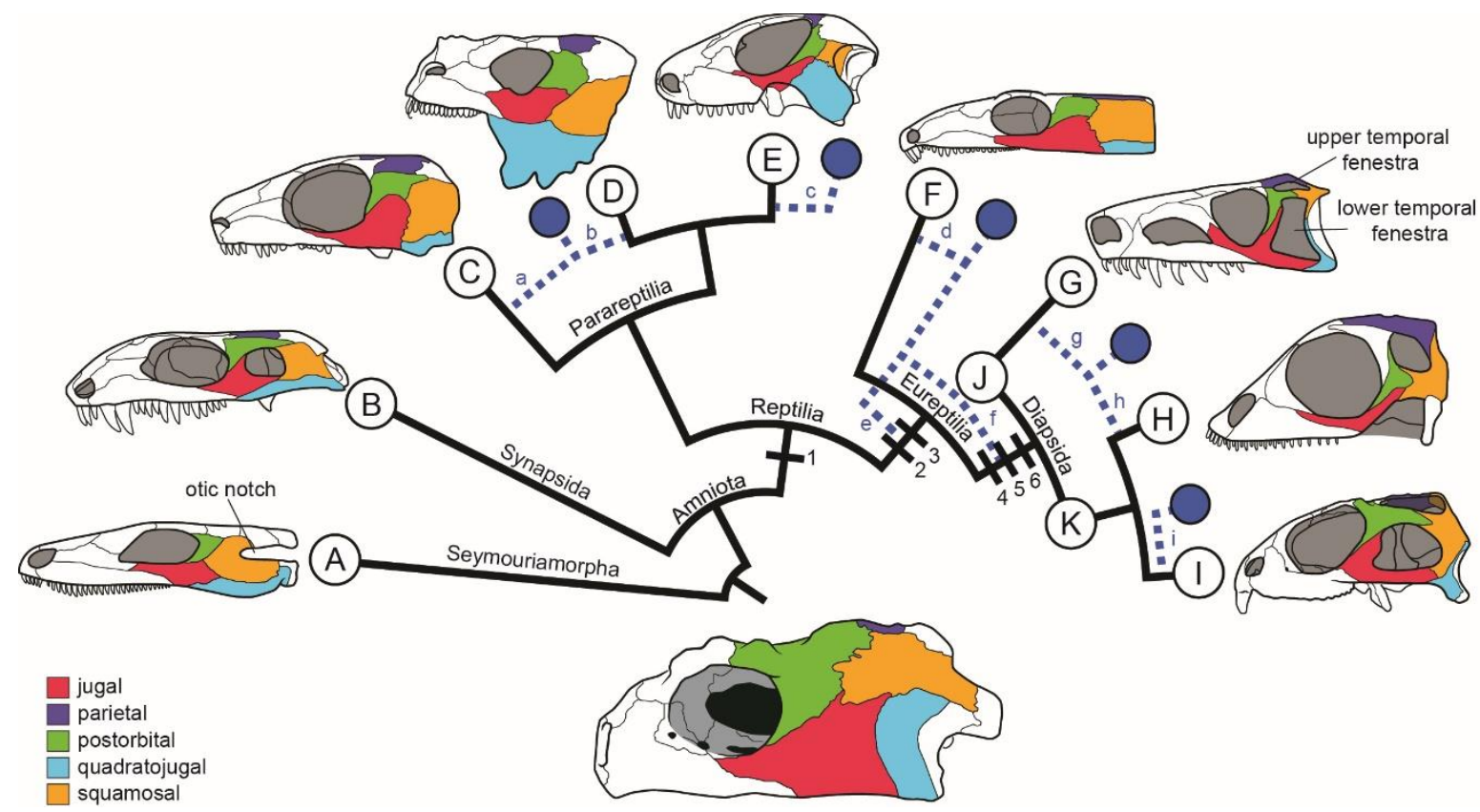

Figure 2.1. Phylogenetic tree of Reptiliomorpha based on Laurin and Reisz (1995), with the skulls of representative taxa of each lineage plotted in lateral view with highlighted temporal region bones. A, Seymouria sanjuanensis; B, Eothyris parkeyi; C, Milleretta rubidgei; D, Scutosaurus karpinskii; E, Procolophon trigoniceps; F, Captorhinus aguti; G, Euparkeria capensis; H, Palatodonta bleekeri; I, Sphenodon punctatus; $\mathbf{J}$, Archosauromorpha; K, Lepidosauromorpha. The skull on the bottom depicts the stem turtle Proganochelys quenstedti and the blue circles and dotted lines point to previously proposed relationships of turtles: a, Millerettidae (e.g., Lyson et al. 2010); b, Pareisauria (e.g., Lee 1993); c, Procolophonidae (e.g., Laurin \& Reisz 1995); d, Captorhinidae (e.g., Gaffney and Meylan 1988); e, stem Diapsida (e.g., Werneburg \& SánchezVillagra 2009); f, Diapsida (e.g., Neenan et al. 2013); g, Archosauria (e.g., Wang et al. 2013); h, Sauropterygia (e.g., Rieppel \& Reisz 1993); i, Lepidosauria (e.g. Müller 2003). The numbers represent selected possible synapomorphies for the respective clades (based on Laurin \& Reisz 1995 and Müller 2003): 1, large posttemporal fenestra; $\mathbf{2}$, supratemporal bone small or absent; $\mathbf{3}$, long interpterygoid vacuity; $\mathbf{4}$, upper temporal fenestra; $\mathbf{5}$, lower temporal fenestra; $\mathbf{6}$, loss of lower temporal bar.

Despite this influential view that considered turtles as "primitive" amniotes, survivors of an extinct lineage of reptiles (the 'Parareptilia' of Gauthier et al. 1988 or 'Anapsida' of Laurin \& Reisz 1995), several alternative early studies raised doubts about those affinities. Based on postcranial characters, Goodrich (1916) suggested close affinities btween turtles 
and other living reptiles within Sauropsida (= crown Reptilia, including birds). Goodrich (1930), Boulenger (1918), and Broom (1924), also emphasized that the arrangement of the bones in the temporal region of turtles is not comparable to that of other anapsid reptiles. They concluded that this morphology in turtles has been secondarily acquired (see also Müller 2003). Ontogenetic (de Beer 1937; Hofsten 1941) and of jaw adductor muscle anatomy studies (Lakjer 1926) revealed several features shared by turtles and other extant diapsids (Rieppel 2000). Some phylogenetic studies based on morphological characters also retrieved turtles closely related to diapsids, either to Lepidosauromorpha-a lineage that comprises tuataras, lizards, snakes, and the extinct marine reptiles, the sauropterygians (deBraga \& Rieppel 1997; Rieppel \& Reisz 1999) —or to Archosauromorpha—a lineage that includes crocodiles and birds, among others (Løvtrup 1977, 1985; Gardiner 1993). Molecular based phylogenetic reconstructions usually result in a closer relationship to one of the diapsid clades as well, more commonly archosaurs (Zardoya \& Meyer 1998, 2001; Hedges \& Poling 1999; Mannen \& Li 1999; Hedges 2012; Wang et al. 2013).

Most recent studies that examine fossils of extinct amniotes also support the view of turtles as diapsids. In one of the oldest turtles, Proganochelys quenstedti (Gaffney 1990), marginal teeth were absent, the preorbital region was short, and the temporal region was completely closed. The proto-turtle Odontochelys semitestacea (Li et al. 2008), although not defined as a member of Testudinata (sensu Joyce et al. 2004) due to the lack of a complete turtle carapace, is closer to this lineage than to other reptiles and greatly contributed to the debate of the origin of the turtle shell (Nagashima et al. 2009). Although retrieved together with turtles deeply nested within Diapsida (Li et al. 2008), the anapsid skull of $O$. semitestacea did not help to clarify how the transition from a diapsid to an anapsid skull could have happened. However, reinterpretations of the skull of Eunotosaurus africanus (Bever et al. 2015), a reptile known since the 19th century (Seeley 1892) and recently considered part of the turtle stem-lineage due to morphological similarities of their postcranial skeleton (Lyson et al. 2010), as well as the recent descriptions of Pappochelys rosinae (Schoch \& Sues 2015) and Eorhynchochelys sinensis (Li et al., 2018), provided some scenarios for this transition. However, the positioning of those taxa along the stem lineage of turtles and the morphological interpretation of their temporal skull region remains open to debate and some phylogenetic analyses, including $E$. africanus and turtles have retrieved a 
parareptilian affinity for this clade as well (e.g., Lyson et al. 2010; Lee 2013). As such, the turtle skull continues to be a controversial and very important morphological structure to understand not only the relationship of the different turtle lineages, but also their origin among amniotes.

In a recent study, the original dataset of Laurin \& Reisz (1995) was expanded by adding new information on the parareptilian clade Mesosauria and updating other information. The analysis resulted in a paraphyletic assemblage of parareptiles with mesosaurs being the sister taxon to eureptilians with the remainder of parareptiles, including turtles (as sister to pareiasaurs), nested inside diapsids (Laurin \& Piñeiro 2017; but see MacDougall et al. 2018). This result could resolve the obstacle why turtles have shown both parareptilian as well as diapsid affinities in previous studies; however, further fossils need to be included to this analysis in the future to strengthen this hypothesis.

\subsection{Cranial diversity of extant and fossil taxa}

Compared to those of early reptilian lineages, the skulls of turtles are highly modified, which makes it difficult to trace their morphological origin. Most of the features directly affects the morphology of the adductor chamber, but are not limited to this region of the skull. For example, one of the most unusual characters is the absence of teeth and the presence of keratinous ramphotecae (horny beaks) over the upper and lower jaws, similar to that of birds (Romer 1956). The Late Triassic (ca. 215 Myr) stem-turtle Proganochelys quenstedti presumably already had rhamphotecae and, although palatal teeth were still present (as in some other turtles such as Kayentachelys aprix and Sichuanchelys palatodentata, Gaffney et al. 1987; Joyce et al. 2016), marginal teeth were lost. The also Late Triassic (ca. 220 Myr) proto-turtle Odontochelys semistetacea had marginal and palatal teeth (Li et al. 2008), so the rhamphotecae should have been present in the common ancestor between $P$. quenstendti and all other turtles. The recent discovery of Eorhynchochelys sinensis finally proofed that ramphothecae were developed at the dawn of turtle evolution (Li et al. 2018).

From a superficial perspective, the skull of extant turtles is greatly expanded posterior to the orbits (temporal region) and greatly shortened anterior to them (preorbital region) (Romer 1956). A shortened preorbital region of the skull is also seen in Pr. quenstedti, but, 
as in other stem turtles such as Australochelys africanus (Gaffney \& Kitching 1994) and Palaeochersis talampayensis (Rougier et al. 1995), the temporal region is not elongated as in crown turtles (Gaffney 1990). O. semitestacea, on the other hand, possessed a more elongated skull, both in the temporal and in the preorbital regions ( $\mathrm{Li}$ et al. 2008). In all these proto- and stem-turtles the dermal roof is completely closed above the adductor chamber, without fenestrae or any deep marginal reduction, resulting in an anapsid morphotype (Werneburg 2012). The bones forming this dermatocranial covering are the jugal, quadratojugal, postorbital, squamosal, and parietal. A largely reduced supratemporal is putatively identifiable in $O$. semitestacea, Pr. quenstedti, and Pa. talampayensis (Rougier et al. 1995; Gaffney 1990; Li et al. 2008). In fact, reduction of dermal bones in the skull of turtles is recurrent: the supratemporal is lost in all other turtles, there is no sign of lacrimal, tabular, or postparietal bones, the postfrontal is fused with the postorbital, and the nasals are reduced or lost in many groups (Romer 1956). Several of those bones are commonly found in the skull of parareptiles which, in addition to the different shape of the jugal and quadratojugal of Pr. quenstedti (i.e., an elongated jugal and a short but high quadratojugal), led some authors to propose that the anapsid condition of the turtle skull is, actually, a secondary derivation (e.g., Goodrich 1930; Müller 2003). That means that in the ancestral lineage of turtles, the plesiomorphic temporal fenestrae were closed and their absence is not evidence of a closer relationship to other anapsid reptiles. The potential closure of the temporal fenestrae in turtle evolution would not be very surprising since increasing evidence suggests that changes in this region, the appearance and disappearance of fenestrae, frequently occurred among Reptilia, including parareptiles (Müller 2003; Tsuji and Müller 2009). Additionally, the three fossil taxa putatively assigned to the turtles' stem lineage prior to the divergence of $O$. semitestacea and Testudinata, Eorhynchochelys sinensis (ca. 230 Myr), Pappochelys rosinae (ca. $240 \mathrm{Myr}$ ) and Eunotosaurus africanus (ca. $260 \mathrm{Myr}$ ) (Li et al. 2018; Bever et al. 2015; Schoch \& Sues 2015), suggest that those still had one or two temporal fenestrae (with the lower one opened ventrally), resembling the condition in crowndiapsid reptiles (Bever et al. 2015; Bever et al. 2016; Schoch \& Sues 2015; Schoch \&Sues 2016). If the relationship of those taxa is further confirmed, then the closure of the fenestrae in the turtle lineage would have occurred simultaneously with the first steps of acquisition of the shell, in the common ancestor of Eo. sinensis, O. semitestacea and Testudinata. 


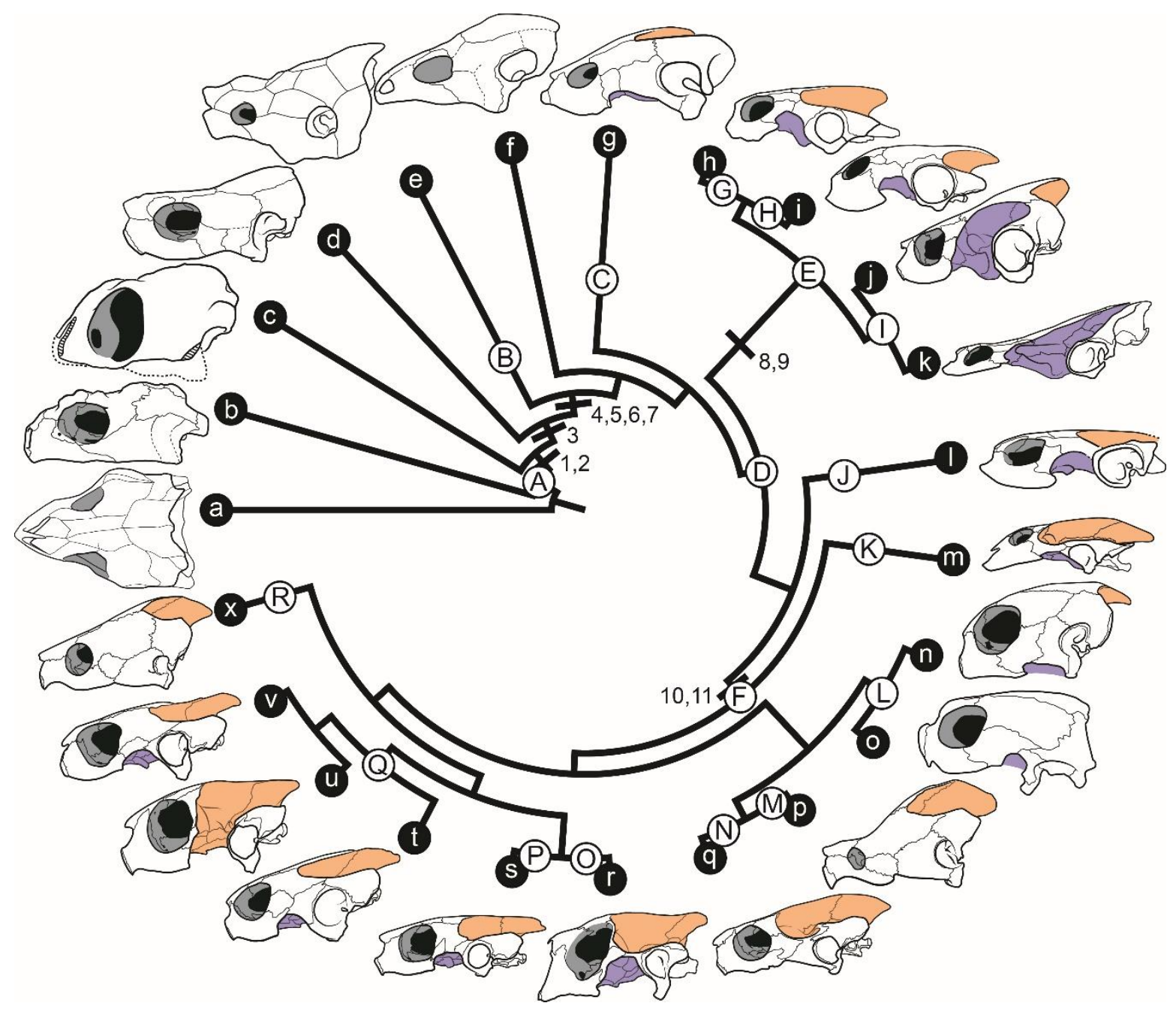

Figure 2.2. Diversity of turtle skull (phylogenetic hypothesis based on Joyce et al. 2016) with posterodorsal (orange) and anteroventral (blue) emarginations highlighted. Upper case letters indicate the large groups $\mathbf{A}$, Meiolaniformes; B, Baenidae; C, Pelomedusidae; D, Podocnemididae; E, Chelidae; F, Sinemydidae; G, Trionychia; H, Chelonioidea; I, Chelydridae; J, Kinosternidae; K, Testudinidae; L, Geoemydidae; M, Emydidae; N, Platysternidae. Lower case letters indicate the following taxa: a, Odontochelys semitestacea (in dorsal view); b, Proganochelys quenstedti; c, Australochelys africanus; d, Kayentachelys aprix; e, Meiolania platyceps; $\mathbf{f}$, Kallokibotion bajazidi; $\mathbf{g}$, Plesiobaena antiqua $; \mathbf{h}$, Pelusios sinuatus; $\mathbf{i}$, Podocnemis expansa; $\mathbf{j}$, Emydura macquarii $\mathbf{k}$, Chelodina expansa $; \mathbf{l}$, Sinemys gamera $; \mathbf{m}$, Lissemys punctata $; \mathbf{n}$, Chelonia mydas; $\mathbf{o}$, Dermochelys coriacea; $\mathbf{p}$, Macrochelys temmincki; $\mathbf{q}$, Kinosternon subrubrum; $\mathbf{r}$, Testudo graeca; $\mathbf{s}$, Cuora trifasciata; $\mathbf{t}$, Pseudemys concinna; $\mathbf{u}$, Terrapene ornata $; \mathbf{v}$, Emys orbicularis; $\mathbf{x}$, Platysternon megacephalum. The numbers represent selected synapomorphies for the respective clades (based on Sterli \& de la Fuente 2010, Rabi et al. 2013, and Werneburg et al. 2015a): 1, opisthotic tightly sutured to squamosal; 2, basipterygoid process sutured; $\mathbf{3}$, interpterygoid vacuity partially or completely closed; $\mathbf{4}$, processus inferior parietalis closing foramen nervi trigemini; $\mathbf{5}$, crista supraoccipitalis posteriorly developed; $\mathbf{6}$, posterodorsal emargination developed; 7, processus trochlearis oticum; 8, processus trochlearis pterygoidei and pleurodiran trochlear mechanism; 9, pleurodiran neck retraction; 10, cryptodiran trochlear mechanism; 11, cryptodiran neck retraction mode. Pictures from different sources (see Werneburg 2012 for details).

Although the condition among proto-turtles older than Eo. sinensis remains unknown, it is certain that in the stem lineage to the crown clade Testudines, the plesiomorphic state is 
an anapsid skull. Most taxa diverging prior to the origin of Testudines had a closed temporal region, surrounding the adductor chamber by bone (Werneburg 2012). This condition, however, was modified several times in different turtle lineages, and most extant taxa show a largely reduction in bones that arch above the adductor chamber (Zdansky 1923; Romer 1956; Rieppel 1993; Werneburg 2012). The type of dermatocranial reduction of turtles is, nevertheless, different from that found in other living reptiles that exhibit fenestrae. The temporal skull reduction in turtles is named emargination (Fig. 2.2), which presents marginal excavations either at the ventrolateral border of the skull or at the dorsal margin of the posttemporal fenestra (Romer 1956; Kilias 1957; Rieppel 1993; Werneburg 2012). The former is known as ventrolateral (sensu Werneburg 2013b) or cheek emargination and proceeds by usually reducing the jugal and quadratojugal bones. The latter is known as posterodorsal (sensu Werneburg 2013b), occiput, or temporal emargination, shown as reductions primarily of the parietal and squamosal. The extent of these emarginations varies greatly among different turtles (Fig. 2.2) but, in their general constitution, they can be used to characterize the main turtle clades (Werneburg 2012).

Most cryptodires possess a well-developed posterodorsal emargination (Fig. 2.2), with the exception of the big-headed turtle Platysternon megacephalum and of sea turtles (Chelonioidea), in which it is only shallow or almost not present (Romer 1956; Werneburg 2012). Likewise, the anteroventral emargination is absent or very shallow in several taxa, such as Pl. megacephalum, sea turtles, and snapping turtles (Chelydridae), but can be moderately to well-developed in other cryptodires, such as in Terrapene ornata, in which it is confluent with the posterodorsal emargination (Zdansky 1923; Werneburg 2012). In pleurodires, the degree of emargination is also variable (Fig. 2.2). In chelids, there is a large anteroventral emargination, sometimes merged with the shallow posterodorsal excavation, as seen in Chelodina (Romer 1956; Kilias 1957; Gaffney 1979). In pelomedusids and podocnemidids, there is only a shallow anteroventral emargination, but the former shows also a well-developed posterodorsal excavation, similar to that found in several cryptodires, while in podocnemidids there is a larger dermatocranial coverage with shallow posterodorsal emarginations (Romer 1956; Werneburg 2012). Among extinct turtle lineages (Fig. 2.2), xinjianchelyids and sinemydids usually possess deep posterodorsal and moderate anteroventral emarginations (Rabi et al. 2014; Zhou \& Rabi 2015), and pleurosternids and 
baenids have moderate posterodorsal and moderate to well-developed anteroventral emarginations (Gaffney 1975; Joyce \& Lyson 2015). However, these general descriptions may apply only to the most common members in each of these clades, and the development of the emarginations in individual taxa can be highly variable (Zangerl 1948; Gaffney 1979; Werneburg 2012).
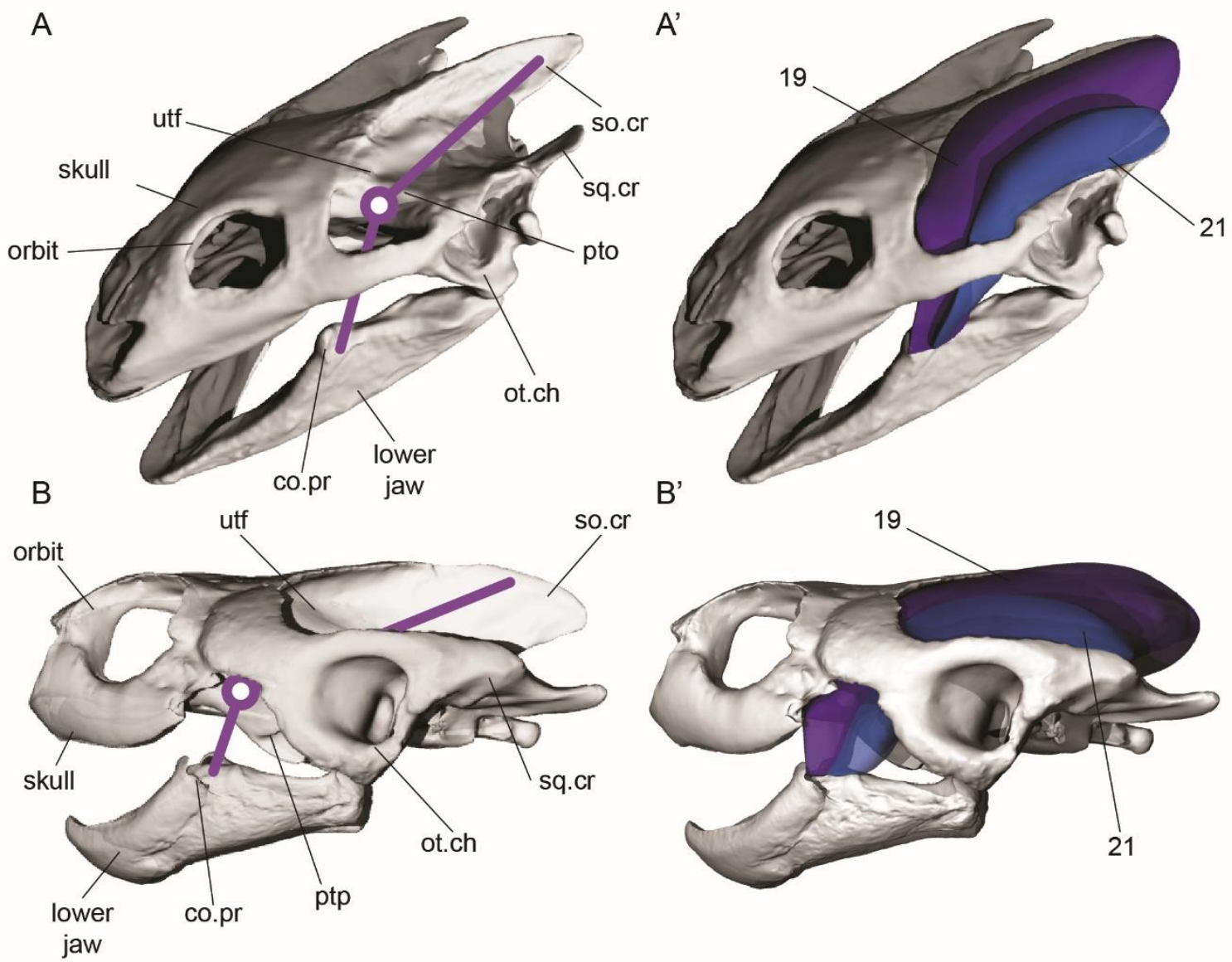

Figure 2.3. The trochlear mechanism in $\left(\mathbf{A}, \mathbf{A}^{\prime}\right)$ the cryptodire Pelodiscus sinensis, and in $\left(\mathbf{B}, \mathbf{B}^{\prime}\right)$ the pleurodire Pelomedusa subrufa. The external jaw muscle portions partes profundus (19) and superficialis (21) originate, respectively, on the supraoccipital (so.cr) and squamosal (sq.cr) crests in the upper temporal fossa (utf) and insert to the coronoid process (co.pr) of the lower jaw. On this course (simplified in $\mathbf{A}$ and $\mathbf{B}$ by the purple line), they bend (circle) around the expanded otic chamber (ot.ch), turning their fibers almost vertically in the lower temporal fossa. This bending is realized by the processus trochlearis oticum (pto) in Cryptodira, and by the processus trochlearis pterygoidei (ptp) on Pleurodira. The simplified view $(\mathbf{A}, \mathbf{B})$ with just one line neglects the complexity indicated by the more realistic $3 \mathrm{D}$ reconstruction of the whole muscle mass $\left(\mathbf{A}^{\prime}, \mathbf{B}^{\prime}\right)$.

Numerous factors have been raised to explain the repeated evolution of dermatocranial bone reductions (see Werneburg 2012), either forming fenestrae or emarginations, including phylogenetic constraints (particularly in cases when a whole clade 
possess the same pattern, such as synapsids or trionychids; Kilias 1957), reducing skull weight (Frolich 1997), skull dimensions (Tarsitano et al. 2001), diet (Versluys 1919), ear anatomy, and jaw muscle bending mechanism (in the case of turtles; Karl 1997), plasticity of bones influenced by internal forces on the skull (Kilias 1957; Frazzetta 1968; Tarsitano et al. 2001), and environmental pressures (Gaupp 1895; Nick 1912; Zdansky 1923). The most common of those, however, are the anatomy and function of the jaw adductor musculature (Gregory \& Adams 1915; Zdansky 1923; Rieppel 1993; Werneburg 2012). In this case, the contraction of the jaw musculature would pressure the bones and bony bars in the temporal region resulting in the modification of this area (discussed by Werneburg 2012). More recently, Werneburg (2015) showed that the neck-bending mechanisms are strongly correlated to type and degree of temporal skull reduction in turtles. It is more likely, however, that no single factor alone causes the reduction of the dermatocranial bones, but actually that several of those in conjunction influence the shaping of the temporal region in turtles and other amniotes (Werneburg 2012).

Reductions of the dermatocranial coverage of the adductor chamber may have become possible after the reinforcement of the attachment of the braincase to the palate and the ear capsule (i.e., palatoquadrate-related structures) in the stem lineage of turtles (Gaffney 1990; Eßwein 1992; Sterli \& de la Fuente 2010; Werneburg 2012; Werneburg \& Maier 2019). Pr. quenstedti, O. semitestacea and Eo. sinensis possess robust basipterygoid processes that articulate with the pterygoid ventrolaterally (Rabi et al. 2013), which results in a less rigid, possibly kinetic, basicranial articulation as found in stem amniotes and stem tetrapods (Gaffney 1979; Rabi et al. 2013). In addition, the parietal of Pr. quenstedti does not develop a descending process anterior to the trigeminal nerve foramen, that would connect the pterygoid ventrally (as it does in crown turtles), and the opisthotic is not strongly sutured to the quadrate (Gaffney 1990). As such, the dermatocranial temporal bone coverage may have been the only structure giving mechanical support to the quadrate while developing stronger bite forces in stem turtles (Werneburg 2012). A suture between the parabasisphenoid and the pterygoid is already seen in A. africanus and Pa. talampayensis (Rabi et al. 2013), providing evidence for the trend to increasingly strengthening the contact between the braincase and palate by the basipterygoid articulation (Fig. 2.2). These changes preceded the closure of the interpterygoid vacuities realized by an extension of the contact between the 
pterygoids and an anterior extension of the parabasisphenoid (Sterli \& de la Fuente 2010), the development of the descending process of the parietal, and the sutural contact between the opisthotic and the quadrate (Eßwein 1992; Werneburg \& Maier 2019). All those features made the skull more rigid in crown turtles, releasing the temporal region from supporting the jaw articulation (quadrate-articular) during biting movements, and allowing the development of posterodorsal and anteroventral emarginations (Romer 1956; Werneburg 2012).

Closure of the interpterygoid vacuity and the reinforcement of the basipterygoid articulation had consequences on the carotid circulation in turtles, as well (Sterli et al. 2010; Müller et al. 2011; Rabi et al. 2013). The internal carotid artery in most amniotes bifurcates into cerebral and palatal branches before the former pierces the parabasisphenoid and enters the pituitary fossa, and the latter continues anteriorly and ventral to the braincase. In squamates and parareptiles (similar to birds and some sauropterygians, also), however, the internal carotid enters the braincase and only afterward the do the cerebral and palatal branches separate from each other (Müller et al. 2011). Among turtles, two general patterns can be identified: (1) in stem-turtles such as Pr. quenstedti (Gaffney 1990), the cerebral branch separates from the palatal branch before entering the skull, and (2) in all crown turtles, it is ventrally floored by bone and bifurcates inside the skull (Sterli \& de la Fuente 2010; Sterli et al. 2010). Several variations of those two basic morphotypes exist in turtles (Sterli \& de la Fuente 2010; Sterli et al. 2010; Müller et al. 2011; Rabi et al. 2013; Rollot et al. 2018), but the increasing ossification of the parabasisphenoid-pterygoid articulation and the posterior projection of the pterygoid, closing the interpterygoid vacuities, enclose the carotid arteries inside the skull (Sterli et al. 2010; Rabi et al. 2013); this is also seen in therapsids, sauropterygians, and crocodyliformes, which also evolved more rigid skulls (Romer 1956; Rabi et al. 2013; Werneburg \& Maier 2019).

The stronger attachment of the quadrate to the braincase and to the palate is also thought to be related to the trochlear mechanism, a structure specific to turtles (Schumacher 1954b, a, 1954/55, 1956; Gaffney 1975; Werneburg \& Maier 2019) (Fig. 2.3). All crown turtles possess an enlarged otic chamber, with the quadrate forming a wall that separates the middle ear into two distinct portions: the cavum tympani (laterally) and the cavum acusticojugulare (medially) (Gaffney 1979). This separation is not seen in the stem turtles $\operatorname{Pr}$. 
quenstedti or A. africanus (Gaffney 1990; Gaffney \& Kitching 1995), but in Kayentachelys aprix it is already formed (Sterli \& Joyce 2007). Enlargement of the quadrate, which becomes cup-shaped and forms the otic chamber, fills a large portion of the adductor chamber and separates it into upper and lower temporal fossae. This condition imposes an obstacle to the course of the jaw musculature from its origin on the skull roof to its insertion on the coronoid process of the lower jaw (Fig. 2.3), which, as a consequence, is redirected around the otic chamber by a pulley system, named trochlear mechanism (Schumacher 1956, 1973; Gaffney 1975, 1979; Joyce 2007). The pressure thought to be exerted by the trochlea during jaw movements can only be accommodated because of the more rigid skull of crown turtles.

Although all crown turtles developed the same solution to this problem of limited space, two different mechanisms are found in Cryptodira and Pleurodira (Fig. 2.3), each enabling a similar pulley system. The former developed its trochlea on the anterodorsal aspect of the otic chamber itself — called processus trochlearis otici-and the quadrate and prootic may form a protuberant or roughened surface (Schumacher 1954b; Gaffney 1975; Joyce 2007). Where the coronar aponeurosis of the external jaw adductors (see below) contacts this bony process, a sesamoidal cartilago transiliens (Schumacher 1954a, 1956) or a bony os transiliens in Gopherus polyphemus (Ray 1959; Bramble 1974) is developed. In this true articulation, cryptodires develop a gliding joint, surrounded by a capsule that involves the cartilage and the bone process (Schumacher 1973; Gaffney 1979). On the other hand, pleurodires develop their trochlea anterior to the otic chamber, around an enlarged flange of the pterygoid, called processus trochlearis pterygoidei (Schumacher 1973; Gaffney 1975; Joyce 2007). The coronar aponeurosis also develops a transiliens cartilage in the contact to this process of the pterygoid in pleurodires, but there is no joint capsule around them. Alternatively, a fold of the oral mucosa (the ductus angularis oris) is enlarged in pleurodires (Fuchs 1931) and forms a pocket that extends between the processus trochlearis pterygoidei and the transiliens cartilage and provides a lubricated surface over which the structure glides (Schumacher 1973; Gaffney 1979). These differences led Gaffney (1975) to conclude that these trochlear mechanisms are nonhomologous structures that arose independently in cryptodires and pleurodires. However, the analysis of new fossils as well as the growing support for a long stem lineage to Testudines, including several taxa previously considered cryptodires (e.g., Joyce 2007; Sterli et al. 2010; Joyce \& Sterli 2012; Rabi et al. 2013) suggest 
that a cryptodiran-like trochlear mechanism is the plesiomorphic condition for the crown turtles (Joyce \& Sterli 2012). Considering this, Joyce (2007) proposed a scenario for the evolution of the pleurodiran trochlear mechanism through a transfer of function from the processus trochlearis otici to the processus trochlearis pterygoidei with a hypothetical ancestor possessing both types of trochleae (Joyce 2007; Joyce \& Sterli 2012). However, this has been criticized elsewhere (e.g., Gaffney \& Jenkins 2010; Werneburg \& Maier 2019) for its lack of functional (see Chapter 6 of this Thesis) and paleontological support, since there is no known extinct taxon that could represent this intermediate condition. Furthermore, preliminary observations suggest that the trochlear mechanism, at least in pleurodires, may be related to other features of the skull, such as larger origin sites for the pterygoid muscles, aside from redirecting the external muscles around the otic chamber.

Regardless of the origin of the trochlear mechanism in turtles, its appearance represented a new possibility for enabling more powerful muscle function in limited space caused by the expanded otic chamber. With the pulley system, the external adductor muscles became delimited into two parts, one behind the trochlea with horizontally oriented fibers closer to the muscle's origin on the skull, and another in front of the trochlea with vertically oriented fibers closer to the muscle's insertion to the lower jaw (Schumacher 1973; Gaffney 1975; Joyce 2007; Werneburg 2013a). In several taxa, the supraoccipital and the squamosal develop elongated projections posteriorly in the latter part of the adductor chamber (Sterli \& de la Fuente 2010; Werneburg 2012). These posterior crests increase the area for fiber attachment and by the subsequent elongation of muscle fibers, increase the generation of muscle power of the external adductors. It is important to note that all these modifications in the turtle skull (stronger attachment of the braincase to the palate and the skull roof, the development of temporal emarginations, the extension of supraoccipital and squamosal crests, as well as the origin of trochlear mechanisms) occur after the Jurassic (ca. $200 \mathrm{Myr}$ ). Additionally, these changes occurred in the clade containing the last common ancestor of Meiolaniformes and Testudines (Sterli \& de la Fuente 2010; Rabi et al. 2013), highlighting the correlation between a more rigid skull and stronger and more robust jaw muscles in turtles (Werneburg \& Maier 2019). 


\subsection{Importance of the turtle neck}

To understand the diversity of the turtle skull, it is particularly important to consider postcranial characteristics as well. Obviously, a highly integrated functional chain exists among the carapace, neck, and skull (Werneburg 2015). The functional origin of the turtle shell has been controversially. If turtles evolved from marine ancestors, heavy abdominal ribs (gastralia) could have permitted controlling buoyancy (Schoch \& Sues 2015) resulting in the primary emergence of a plastron as seen in Odontochelys semitestacea (Li et al. 2008: but see Reisz \& Head 2008; Scheyer et al. 2013). The carapace might have evolved as a defensive structure (Romer 1956), but recently, Lyson et al. (2016) hypothesized that turtles might have had fossorial ancestors in which a strong ossification of the whole body would have developed to withstand external pressure of the soil when digging; curiously, however, other fossorial vertebrates reduce ossifications and form a slender body (Gauthier et al. 2012). Whatsoever the origin of the shell was, the emergence of a stiffened bony armor influenced a great set of anatomical features, including the ventilatory system (Lambertz et al. 2010; Lyson et al. 2014) and the whole locomotory apparatus (Walker 1973; Joyce et al. 2013b).

In addition to the limbs and girdles, the cervical region also had to correspond with such a comprehensive stiffening of the turtle body. Crown turtles evolved a great flexibility of their neck, which, as compensation, enables fast and elaborated nutrition strategies (Herrel et al. 2008). As such, neck mobility and feeding behavior seem to be strongly connected (Natchev et al. 2015). In some forms, particularly in chelids, the neck may be longer than the shell, and many taxa, including trionychids and kinosternids, are able to stretch their heads completely over the carapace for defense or hunting purposes. Related to such great mobility of the neck, the cervical vertebrae of extant turtles are highly modified compared to that of other reptiles, including stem turtles (Williams 1950; Werneburg et al. 2015b).

A unique feature among all vertebrates is the ability of turtles to retract their neck and head inside the shell. Each of the two major extant turtle groups evolved a highly specialized mode of retraction, but both fold their neck in a S-shape manner (Werneburg et al. 2015b). In a horizontal plane, pleurodires lay their head and their neck below the anterior edge of the carapace. Cryptodires, in contrast, retract their necks in a vertical plane and withdraw them even between the shoulder girdles (Herrel et al. 2008). Cervical ribs, which were still present 
in stem turtles, are reduced in extant taxa throughout ontogeny, enhancing mobility and facilitating neck retraction into the shell and between the shoulder girdles (Werneburg et al. 2013). Pr. quenstedti and Meiolania platyceps, like most other stem turtles, have relatively compact cervical vertebrae and short necks, and, as such, they were hypothesized to have performed only limited mobility (Gaffney 1985; Gaffney 1990; Jannel 2015). However, Werneburg et al. (2015a) have shown, using radiographs, CT scan images, and morphometrics, that also those stem turtles might have even been able to laterally tuck their neck below the anterior edge of the carapace similarly to pleurodires, but in a simpler manner. Protective osteoderms on dorsal surface of the neck of this stem turtle support the hypothesis that defense might have been the major reason for the emergence of neck retraction. It must be noted, however, that stem turtles were mostly terrestrial herbivores as the reduction of marginal teeth and presence of keratinized ramphothecae clearly indicate. The movements that later allowed neck retraction might have evolved initially in relation to this feeding behavior, enabling those turtles to pull down plants while maintaining the cumbersome body steady (compare to extant land tortoises, in which, however, the limbs also "still" support; Natchev et al. 2015). Recently, Anquetin et al. (2017) hypothesized that in the early evolution of crown turtles a specialized foraging strategy under water (suction feeding) might have been related to increased neck mobility in general and might have enforced the origin of the cryptodiran neck retraction. In both of these scenarios, the protective function of retracting the neck and head inside the shell would be an exaptation of the high mobility already present (Anquetin et al. 2017).

Specialized neck muscles, linked to neck retraction, have evolved in turtles, and, as for some skull features (see above), a more rigid skull may be related to their appearance. The major neck retractor, m. retrahens collique (Werneburg 2011), broadly attaches to the basicranium, in which an immobile basicranial articulation support stronger forces. Dorsal neck muscles attach to the temporal skull region and are in close topographic relation to the external jaw musculature. One of the major challenges in future turtle research is establish to homology of turtle neck musculature with that of other amniotes (Gasc 1981; Werneburg 2011) as several reorganizations must have occurred in relation to the novel movement abilities of turtles (Werneburg et al. 2013). 

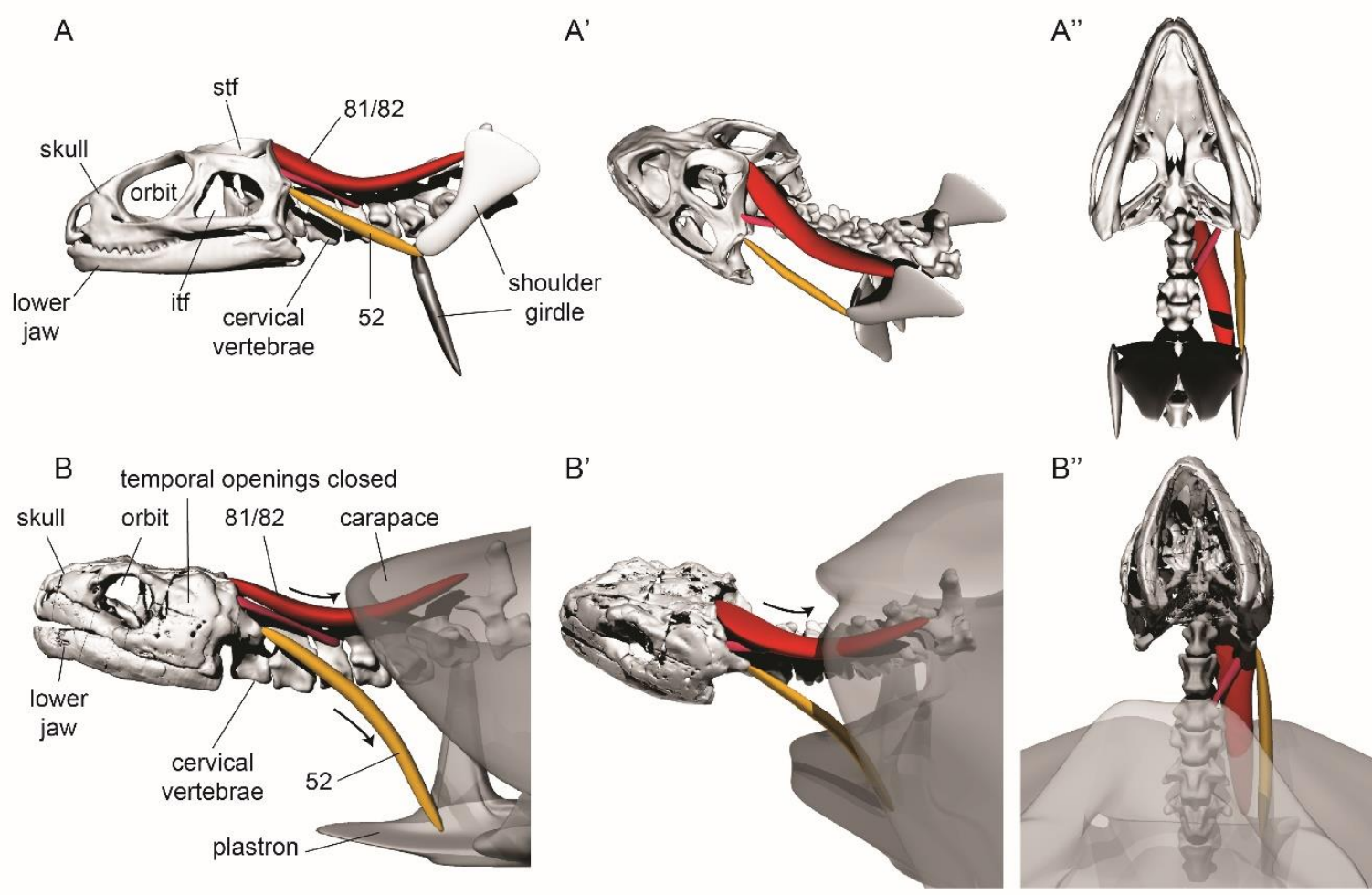

C

$C^{\prime}$
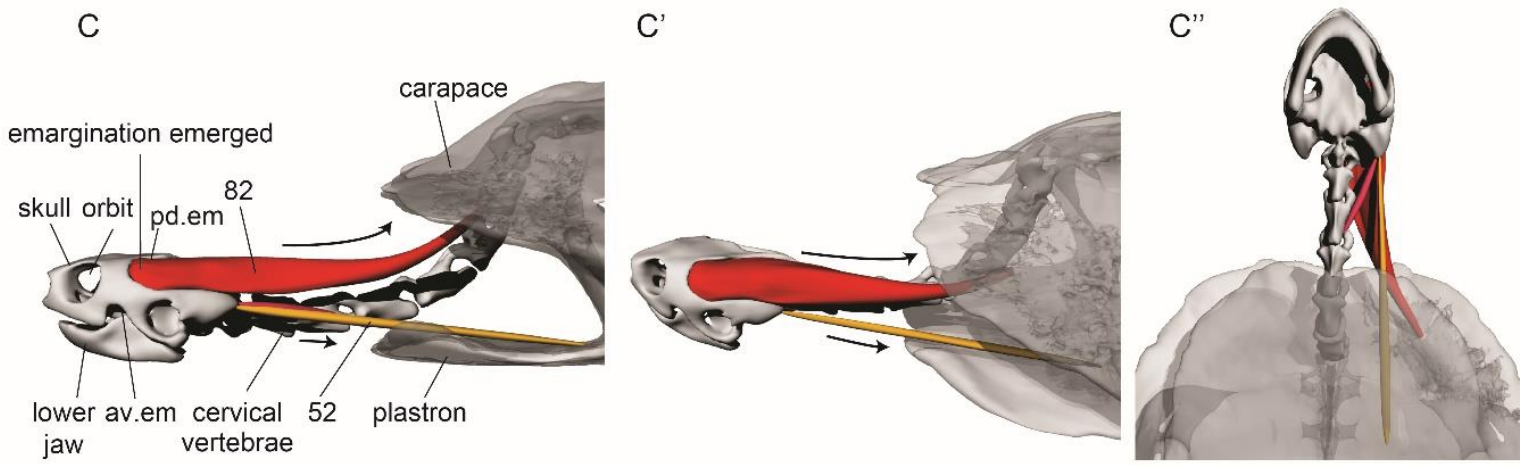

jaw

vertebrae

D'
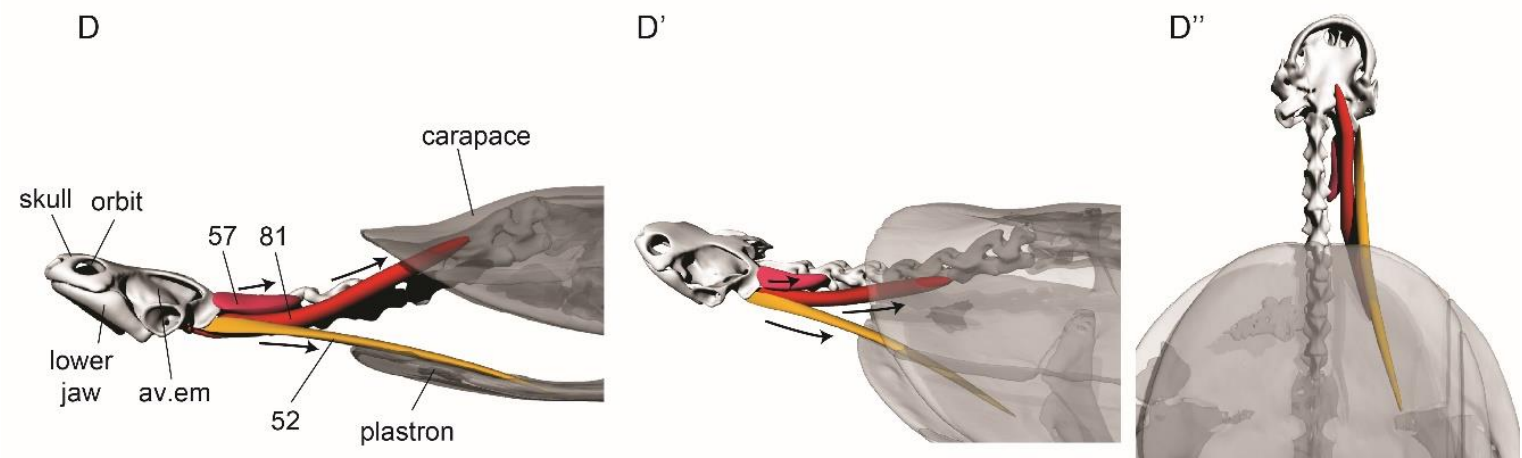

Figure 2.4. Scenario for the origin of the anapsid skull and temporal emargination in turtles as proposed by Werneburg (2015). The 3d models were built using CAD software Rhinoceros 3D (McNeel \& Associates, 2003). Further information on the models can be found in Werneburg et al. (2015). All models are shown in 
left lateral (left column), oblique dorsolateral (middle column), and ventral (right column) view. (A) In the ancestral diapsid condition (visualized by Sphenodon punctatus), the selected neck muscles contact the shoulder girdle posteriorly and stabilize the head anteriorly. (B) In stem turtles (exemplified by Proganochelys quenstedti), the trapezius $(\mathbf{8 1 / 8 2}$ of Werneburg 2011) and sternocleidomastoideus $(\mathbf{5 2},=\mathrm{m}$. plastrosquamosus in turtles) muscles lost contact to the shoulder girdle (see Lyson et al. 2013) and posteriorly attach to the carapace and plastron respectively. Stem turtles were already able to simple retract their head and neck inside the shell (Werneburg et al. 2015a, b). For that, large tension forces of the trapezius and sternocleidomastoideus muscles acted on the temporal skull region. As a response to withstand those forces and to maintain skull integrity, the infratemporal (ift) and supratemporal fenestrae (stf) were closed in the potential diapsid ancestor of Testudinata. (C) Cryptodirans (exemplified by Graptemys pseudogeographica) retract their neck in a vertical plane inside the shell. For that, strong dorsal neck musculature $(\mathbf{8 2}$, a cryptodiran derivative of m. trapezius, $=$ $\mathrm{m}$. carapacocervicocapitis medialis pars capitis) acts on the temporal skull region. To withstand those neck forces, which largely increased compared to those of stem turtles, marginal posterodorsal emarginations (pd.em) evolved providing broader insertion sites and better distributing neck tension forces. (D) In pleurodirans (exemplified by the chelid Phrynops hilarii), the pleurodiran derivative of $\mathrm{m}$. trapezius $(\mathbf{8 1},=\mathrm{m}$. carapacocervicocapitis medialis pars capitis) inserts to the base of the skull. As such, neck muscles do not have a comparable influence on the temporal region as in cryptodires. In pleurodires, several neck muscles enable large lateral neck movement (exemplified by $\mathbf{5 7}, \mathrm{m}$. collosquamosus) and might influence the shaping of the skull. The origin of the anteroventral emargination (av.em)-in pleurodires and cryptodires alike-is not fully understood (see Werneburg 2015). However, the extent of both anterovental and posterodorsal emarginations appear to influence each other enabling-associated to particular skull dimensions-a stable, bridge-like construction. The reduction of the dermal armor in the temporal region is certainly associated with a number of intrinsic and extrinsic factors (Werneburg 2012), which need to be identified and quantified in the future. Homology, function, and diversity of turtle neck musculature is hardly understood and require comprehensive research programs in the future. As such, the hypothesis on neck muscle influence for shaping the turtle skull (Werneburg 2015) has to be understood only as a first attempt to incorporate this type of data. Models modified after Werneburg et al. (2015a, b).

Werneburg et al. (2015a) tested the influence of neck mobility for shaping the temporal skull region in turtles and suggested that ventral flexing of the neck and the cryptodiran mode of retraction significantly influence the size of the posterodorsal emargination. As Werneburg (2013a) highlighted, jaw muscle attachments are highly dependent on bone arrangement, the indirect influence of neck mobility also for jaw muscle anatomy may have been underestimated. Werneburg (2015) has also shown that the expansion of posterodorsal and anteroventral emarginations are significantly and highly correlated to each other. When one emargination expands (e.g., influenced by neck mobility), the other shows a correlated change in size. The broad tendinous insertion of dorsal neck muscles to the posterodorsal region of the skull enables a better force distribution when moving the neck. Expanded supraoccipital and squamosal crests also provide broader attachment sites for the neck musculature. These observations led Werneburg (2015) to formulate a hypothesis for the origin of the anapsid skull in turtles (Fig. 2.4).

Following this hypothesis, the stepwise emergence of the turtle shell (Li et al. 2008; Schoch and Sues 2015) was highly correlated with the increased mobility of the turtle neck. 
The forces related to neck movement — via strong dorsal and ventral neck muscles - greatly influenced the shaping of the turtle skull. If the turtle ancestor actually had a diapsid morphology of the skull (Fig. 2.4), temporal fenestrae could have closed in response to the increased pulling force of the neck muscles, resulting in an anapsid condition. The skulls of Pappochelys rosinae (Schoch and Sues 2015), with its small dorsal fenestra, and the skull of Eunotosaurus africanus (Bever et al. 2015), in which only the ventral fenestra (which is ventrally open) and perhaps the dorsal fenestrae are present, could illustrate this stepwise closure of the skull opening. Later, among crown turtles (Testudines), necks became increasingly elongated (Williams 1950; Werneburg et al. 2015b) thereby enabling complex neck retractions. These further stressed the turtle skull resulting in the formation of the posterodorsal emargination, which distributed neck forces evenly in the skull. The anteroventral excavation developed as a counterpart to the posterodorsal one, enabling the integrity of the temporal skull region in a bridge-like construction. It is worth mentioning that the dorsal neck muscles in many pleurodires (related to horizontal neck retraction) insert near to the ear capsule, more laterally to the back of the skull than in cryptodires and other sauropsids. This means a less powerful force distribution to the dermal coverage of the adductor chamber and a less excavated posterodorsal emargination in many forms. In most pleurodires the anteroventral emargination is more prominent than in cryptodires. This might be related to the more flattened skull of many pleurodires, such as some Chelidae.

\subsection{General morphology of the cranial musculature in turtles}

Several authors in the last two centuries dissected and described cranial musculature in turtles. Some of them focused on specific taxa (Bojanus 1819; Ogushi 1913a), whereas others applied a comparative approach to understand the general structure and diversity of this part of the turtle body (Hoffmann 1890; Lakjer 1926; Poglayen-Neuwall 1953; Schumacher 1954b, a, 1954/55, 1956, 1973; Kilias 1957). However, those who took a comparative approach concluded that although turtles show a variety of diets and behaviors related to their diverse habitats (Ernst \& Barbour 1992), the cranial muscles, and especially the jaw muscles, are highly conserved (e.g., Iordansky 1996). Although this is accurate in a general view and the observed variation is usually related to relative sizes of muscles and 
tendinous structures, some portions or entire muscles may be present or absent in different taxa (Werneburg 2011), resulting in more profound differences.

Muscles associated with the skull of turtles follow the general pattern of innervation by cranial nerves in gnathostomes (Edgeworth 1935; Diogo et al. 2008). Cranial nerves IIIXII are responsible for the movements of the muscles in the testudine head (Werneburg 2011). Nn. oculomotorius (III), trochlearis (IV), and abducens (VI) innervate the muscles related to eye and eyelid movement, while the jaw depressor, superficial neck musculature, and some muscles related to the ear capsule are innervated by n. facialis (VII). The muscles related to the branchiovisceral region and to the larynx-related musculature are innervated by the glossopharyngeus (IX), vagus (X), and accessorius (XI) nerves, whereas n. hypoglossus (XII) innervates the musculature related to the hyoid apparatus, including the tongue. Some of those posterior nerves also innervate the neck musculature, although this region is mainly innervated by spinal nerves (Werneburg 2011). Finally, the most prominent muscle group in the turtle head, the jaw adductor musculature, is innervated by the trigeminal nerve (V) and represents the most-studied muscular complex in turtles (and in reptiles in general; Lakjer 1926; Edgeworth 1935; Schumacher 1973; Diogo \& Abdala 2010; Werneburg 2013a). This is mainly due to its direct relation to dietary preferences and feeding mechanisms (Schumacher 1973) and, putatively, to their relation to dermatocranial bone reductions (fenestrae and emarginations; see Werneburg 2012, 2013b).

In addition to the seven external eye muscles found in all tetrapods (two mm. obliqui, four $\mathrm{mm}$. recti, and perhaps $\mathrm{m}$. retractor bulbi), several others were described in reptiles and birds (Sauropsida) (Underwood 1970; Løvtrup 1985; Werneburg 2011). Their presence and variation among different sauropsid groups is in most cases related to the presence, extent, and mobility of the greatly developed "third eyelid", the membrana nictitans (Werneburg 2011). One of those, the m. pyramidalis (which is innervated by the $\mathrm{n}$. abducens [VI]) (Edgeworth 1935; Werneburg 2011), has its origin on the medial surface of the eye bulbus and inserts via one tendon to the membrana nictitans and via a second tendon to the lower eyelid (Løvtrup 1985; Werneburg 2011). This muscle is of special interest because it is only found in crocodiles and turtles and, as such, represents a potential synapomorphy of a possible clade containing those taxa (Thomson 1932; Underwood 1970; Schumacher 1972; 
Løvtrup 1985; Rieppel 2000, 2004; Eger 2006). However, extrinsic musculature of the eye is not well documented in most reptilian taxa, and greater taxon sampling and ontogenetic studies will be useful to clarify the homologies of these muscular units (Werneburg 2011; see also there for basic muscle terminology). A m. levator bulbi, innervated by the trigeminal nerve (V), is only found in rare cases and is reduced during ontogeny (see Werneburg 2011 for discussion). In trionychian turtles, which have a moveable nose, particular nose muscles, also innervated by n. trigeminus (V), are present.

Three main units are generally recognized in the jaw adductor musculature (the external, internal, and posterior muscles) and are established according to their relation to the n. trigeminus (V) branches (Luther 1914; Lakjer 1926; Schumacher 1973; Werneburg 2011). Among those, the external adductors are the strongest and most prominent in turtles, as in squamates (Rieppel 1980, 1984) and contrary to crocodiles (Schumacher 1973), and may be subdivided at least in three portions (Lakjer 1926): pars profundus, originating on the lateral wall of the braincase and on the supraoccipital crest; pars superficialis, lateral to the previous and originating on the lateral wall of the skull and squamosal crest; and pars medialis, more anteriorly located than the other portions, originating mainly on the quadrate surface anteriorly on the otic chamber (Werneburg 2011). These portions may not be clearly distinguishable in some turtles, and some variation of the relative size and shape of parts may occur (e.g., the pars profundus is slightly reduced in Dermochelys coriacea; Lakjer 1926; Schumacher 1972; Poglayen-Neuwall 1966). The general pattern is that the three portions fuse together anteriorly and insert to a large and strong tendon that attaches to the coronar process of the lower jaw, the so-called coronar aponeurosis (also called bodenaponeurose or central tendon; Schumacher 1973; Rieppel 1990; Werneburg 2011). This tendon is very important, not only because of its main function in transferring the main contraction forces of these muscles to execute the adductor movements in the lower jaw (Iordansky 1996), but also because in its ventral face the cartilage/os transiliens of the trochlear mechanism develops (Schumacher 1973). The position of this structure varies with the different trochlear processes, being on the dorsal and anterior surfaces of the prootic and quadrate in cryptodires and on the lateral pterygoid process (the processus trochlearis pterygoidei; Gaffney 1979) in pleurodires (Schumacher 1973; Werneburg 2011). It develops as a sesamoid cartilage (or 
bone in Gopherus polyphemus; Ray 1959), meaning it likely arises as a result of mechanical stress (Ray 1959; Bramble 1974; Iordansky 1994) across this structure.

An additional jaw adductor muscle, the m. zygomaticomandibularis, may be found in the clade Trionychia which includes soft-shelled turtles (Trionychidae) and the pig-nosed turtle (Carettochelys insculpta) (Ogushi 1913a; George \& Shah 1955; Dalrymple 1975; Werneburg 2011). Analogously to the masseter muscle of mammals, this muscle originates ventrally and laterally on the jugal and the quadratojugal on the "zygomatic bar" and inserts laterally to the lower jaw, near the insertion of the external adductors (Werneburg 2011, 2013a, b). Based on its position relative to the other external adductors, some authors have described this unit as part of the pars superficialis of the external musculature (Lakjer 1926; Poglayen-Neuwall 1953). Indeed, this muscle in trionychids is comparable to the postorbital head of the pars superficialis found in some turtles with a stronger postorbital/temporal region, such as snapping (Chelydridae) and sea turtles (Chelonioidea) (Rieppel 1990; Werneburg 2011; Jones et al. 2012). In the chelonioid Caretta caretta, this head can be almost completely separated from the rest of the pars superficialis (Jones et al. 2012), becoming very similar to the topology of $\mathrm{m}$. zygomaticomandibularis in trionychids. However, whether these results of convergent evolution or actually represent homologous structures remains unresolved, and comparative anatomical and developmental studies should be conducted in order to test this hypothesis (Werneburg 2011).

The internal and posterior adductors form a fan-shaped arrangement of muscles spanning in the lower temporal fossa of turtles, below the external adductor layer (Schumacher 1973). The internal adductors, located anteriorly to the posterior adductor in this fan, may be subdivided into two main portions, the partes pseudotemporalis and pterygoideus. The latter is the anterior-most portion and originates on the dorsal, lateral, and ventral surfaces of the pterygoid bone, reaching the palatine near the orbit cavity and the parietal on the medial wall of the temporal fossa (Werneburg 2011). The fibers of pars pterygoideus insert on the posteromedial surface of the lower jaw near the jaw joint (Iordansky 2010) either directly or by the subarticular (internal) tendon (Schumacher 1973) and/or the pterygoidal aponeuroses (Schumacher 1973; Werneburg 2011). 
The pars pseudotemporalis is the central portion of the muscle series (Lakjer 1926; Schumacher 1973; Rieppel 1990) and originates mainly on the descending process of the parietal bone. It inserts directly or via the subarticular aponeurosis on the medial surface of the lower jaw anteriorly to the insertion of pars pterygoideus (Werneburg 2011). A third and smaller part of the internal adductors, the pars intramandibularis, can be found in several turtles. It originates from a tendon that connects it to the pars pseudotemporalis, the so-called Zwischensehne (Poglayen-Neuwall 1953; Schumacher 1973; Iordansky 1994, 1996) and in this case the latter does not attach to the lower jaw, but to the zwischensehne. The pars intramandibularis inserts laterally to Meckel's cartilage, inside fossa primordialis of the lower jaw (Werneburg 2011).

The pars pseudotemporalis may be closely associated to the posterior adductor in some turtles (Werneburg 2011), which led some authors to consider it as a portion of m. adductor mandibulae posterior (Schumacher 1954a, 1954/55; Hacker 1954). However, the innervation patterns of both structures and their development are completely different (Poglayen-Neuwall 1953; Poglayen-Neuwall 1954; Poglayen-Neuwall 1966; Werneburg 2011) which suggest they are of different identity. Finally, the posterior adductor originates mainly on the anterior surface of the quadrate medially to m. adductor mandibulae externus pars medialis and inserts directly, with its own tendon, or via the subarticular aponeurosis, on the posteromedial surface of the lower jaw, near the insertion sites of the internal adductors (Werneburg 2011).

\subsection{Development of jaw musculature}

The adductor musculature in turtles starts to develop as a single homogeneous cell aggregation (Fig. 2.5) that surrounds the mandibular (V3) branch of the trigeminal nerve. Although there is no sign of compartmentalization in this aggregate, the portion lateral to the nerve branch will develop into the external adductor and the one medial to it into the internal and posterior adductors (Rieppel 1990; Tvarožková 2006). At early stages this cluster of cells is restricted anteroposteriorly, the medial portion of which extends anteriorly to the pterygoid process of the palatoquadrate (i.e., known only for the cryptodire Chelydra serpentina), posteriorly to the quadrate cartilage, dorsally to a level below the Gasserian ganglion (where 
the trigeminal foramen will be formed), and posteroventrally to Meckel's cartilage (Rieppel 1990; Tvarožková 2006). Contrary to the development in squamates (e.g., Podarcis; Rieppel 1987b), the portion that will differentiate into the external adductors begins to extend posterodorsally before the posterodorsal extension of the prospective internal adductors (Rieppel 1990).

Subsequently (at stage 15; Rieppel 1990), both rudiments (internal and external) begin to differentiate and become compartmentalized (Fig. 2.5). For the external adductors the differentiation of the coronar aponeurosis (Lakjer 1926; Schumacher 1973) subdivides their anlage into medial (pars profundus) and lateral (partes superficialis and medialis) portions. These rudiments continue to extend posterodorsally across the paroccipital process of the chondrocranium until they finally reach their origin sites, when the parietal, postorbital, and jugal ossifications are already expanded (Rieppel 1990; Tvarožková 2006). The medial portion, the prospective pars profundus, follows the posterior elongation of the supraoccipital crest, attaching to it. The lateral portion also extends posteriorly and, although some fibers become attached to the quadrate and others continue their posterior elongation; the superficial and medial parts will become compartmentalized only later during ontogeny (Rieppel 1990).

The internal adductors, distributed between the mandibular branch of the trigeminal nerve (laterally) and the ascending process of the palatoquadrate (medially) (as typical for all reptiles; Lakjer 1926; Edgeworth 1935), start to become compartmentalized by the development of an anterior ventromedial projection, which will become the anlage of the partes pterygoidei (Rieppel 1990). This portion grows first posteroventrally to the lower jaw and then anteriorly to the dorsal and ventral surfaces of the developing pterygoid (Tvarožková 2006). Another projection extends dorsally along the lateral flange of the parietal and represents the prospective pars pseudotemporalis. In contrast to squamates (Rieppel 1987b), both parts do not become fully separated and share during all development a horizontal tendinous structure (the anlage of the subarticular aponeurosis; Werneburg 2011), that divides the partes pterygoidei ventrally and the pars pseudotemporalis dorsally (Rieppel 1990). However, distally they become well separated, with the pterygoid portions elongating anteromedially and the pseudotemporalis dorsally (Fig. 2.5). The former also extend posteroventrally to attach to the lower jaw, near the jaw joint, and the 
pseudotemporalis elongates ventrally to reach the Meckel's cartilage (by the intramandibularis muscle in taxa that possess it; Rieppel 1990).
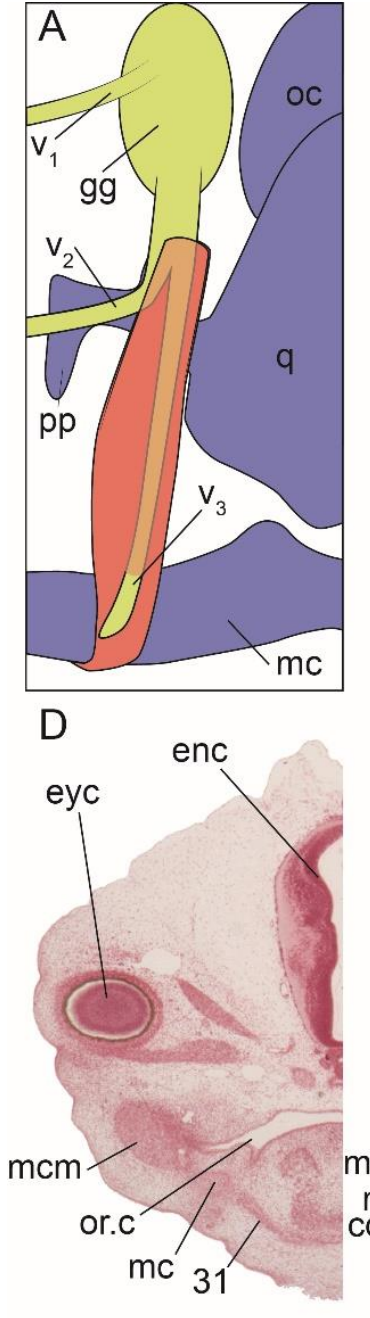

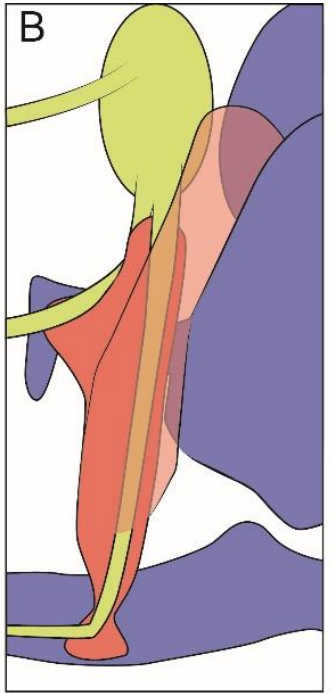

$\mathrm{E}$

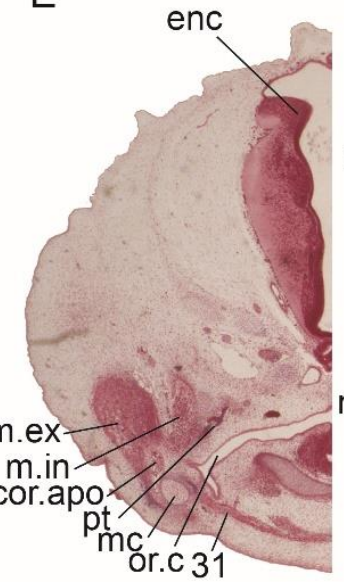

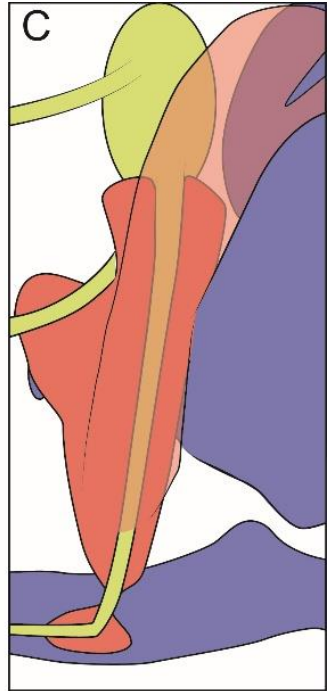

$\mathrm{F}$

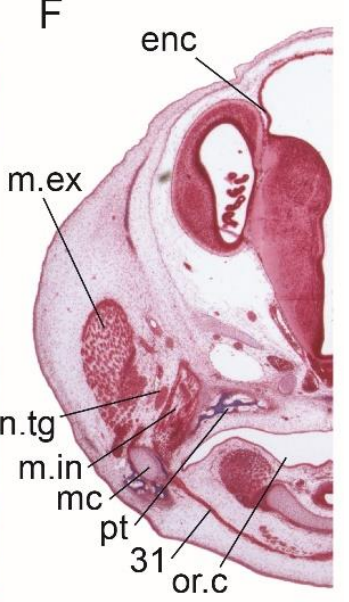

Figure 2.5. Schematic drawings $(\mathbf{A}-\mathbf{C})$ representing three stages of development of the muscles in Chelydra serpentina, based on Rieppel (1990), and histological slices with Azan-staining after Haidenhain (Mulisch \& Welsch 2015) of Emydura subglobosa embryos (D-F) in different stages (D, Y15; E, Y17; F, Y18; Wolfgang Maier collection Tübingen; $Y=$ Yntema staging system, Yntema 1968). Development starts from an indistinguishable muscle cell mass $(\mathbf{m c m})$ around the mandibular branch $\left(\mathbf{V}_{\mathbf{3}}\right)$ of the trigeminal nerve anlage (n.tg). It extends from near the Gasserian ganglion (gg) dorsally and to the Meckel's cartilage (me) ventrally $(A, D)$. The cell aggregate progressively differentiates $(\mathbf{B}, \mathbf{E}, \mathbf{F})$ into two portions lateral and medial to the $\mathbf{V}_{\mathbf{3}}$, which will become the external (m.ex) and internal (m.in) muscles, respectively. The latter also becomes progressively projected anteriorly and dorsally, which will differentiate into the pterygoid portions and the pseudotemporalis/posterior muscle anlage $(\mathbf{C})$. Note how the initial cell mass is connected to the ventrally located intermandibularis muscle (31) in C. serpentina (A) and how they become distinct latter during development (B-C). Additional abbreviations: cor.apo, coronar aponeurosis; enc, encephalon; eyc, eye capsule; oc, otic capsule; or.c, oral cavity; pp, palatal process; pt, pterygoid; $\mathbf{q}$, quadrate cartilage; $\mathbf{V}_{\mathbf{1}}, \mathbf{V}_{\mathbf{2}}$, ophthalmic and maxillary branches of trigeminal nerve, respectively. 
Two muscles, the posterior adductor and the intramandibularis, feature noteworthy ontogenies in turtles relative to to other reptiles. The former develops not from its own rudiment, but rather from the $\mathrm{m}$. internus anlage in Testudines, after the compartmentalization of the pterygoideus rudiment (Rieppel 1990; Tvarožková 2006). The anlage of the internal muscles, posterior to the pterygoideus rudiment, in its dorsal expansion, begins to surround the exit of the maxillary and mandibular branches from the Gasserian ganglion until it is finally pierced by those branches. The portion of this rudiment anterior to the trigeminal mandibular branch corresponds to the pseudotemporalis anlage, while the posterior adductor develops from the posterodorsal portion behind the mandibular branch (Rieppel 1990). This corresponds to the topological criteria proposed by Lakjer (1926) to identify the adductor muscle portions. In contrast, in lepidosaurs (Rieppel 1987b) the posterior adductor differentiates from the external anlage and becomes topologically equivalent to the posterior muscle of turtles. While most authors consider those as posterior adductors based on its adult topology, origin, and insertion sites (Lakjer 1926; PoglayenNeuwall 1953; Schumacher 1973; Werneburg 2011), from a developmental perspective, it seems that they are analogous, not homologous (Rieppel 1990).

The intramandibularis, in contrast, starts its development in Chelydra serpentina (Rieppel 1990; Tvarožková 2006) in the ventral part of the same homogeneous cell aggregation (Fig. 2.5), deep to the mandibular branch of the trigeminal nerve, in continuity to another bunch of cells ventromedially to the Meckel's cartilage. The latter corresponds to the intermandibularis rudiment that will expand between the two rami of the lower jaws (Rieppel 1990). It becomes gradually separated from the intramandibularis anlage, which attaches dorsally to the Meckel's cartilage and remains continuous to the dorsal pseudotemporalis rudiment. This close association to the pseudotemporalis and, earlier, to the intermandibularis, is also found in crocodiles (Schumacher 1973; Rieppel 1990), but differs from the development of the intramandibularis in lizards. In the latter group, this muscle develops closer to the Meckel's cartilage as an anterior extension of the posterior adductor, rather than the internal adductor anlage (Rieppel 1987). As for the posterior adductors, the intramandibularis of turtles and squamates seem to be nonhomologous structures from a developmental point of view, but evidence suggests that this portion is also 
not related to the crocodilian intramandibularis, since only few taxa nested deep within Cryptodira develop it (Werneburg 2011, 2013a).

\subsection{Functional anatomy of jaw muscles and feeding}

The movements related to feeding in turtles are generally executed by a set of motions by the jaws, neck, and forelimbs (Bramble 1974; Dalrymple 1977; Iordansky 1987, 1996). Some variation can be observed among turtles feeding in terrestrial environments or under water, but the generalized behavior includes the jaws closing to hold the prey and the forelimbs and neck moving to tear it in smaller pieces that can be swallowed (Iordansky 1996). The feeding behavior of extant aquatic turtles involves movements of the head towards the prey and a suction feeding mechanism (Schumacher 1973; Lemell et al. 2002), followed by the closure of the jaw holding the prey (Natchev et al. 2015). Some aquatic turtles have the suction mechanism extremely well developed, swallowing the food item without grabbing it with their jaws (e.g., Chelus fimbriatus and Apalone spinifera; Lemell et al. 2002; Anderson 2009), but most turtles use only a weak suction flow and, hence, holding the prey with the closure of jaws is an important part of the feeding behavior (Natchev et al. 2015).

Although stem turtles most probably occupied terrestrial habitats, the ancestral testudine was certainly aquatic (Joyce 2015), and the mode of feeding seen in extant terrestrial turtles (Testudinoidea) evolved independently several times from aquatic ancestors (Summers et al. 1998; Natchev et al. 2009). Most testudinoids (i.e., Emydidae and Geoemydidae) use their jaws to grab food items (known as "jaw prehension") on land or in water (Bels et al. 1997; Bels et al. 2008; Summers et al. 1998; Heiss et al. 2008; Natchev et al. 2009; Stayton 2011). However, the exclusive terrestrial tortoises (Testudinidae) developed a different way to grab food items in which they first touch the food with their tongue ("tongue prehension"), and then they bring them to the mouth (Wochesländer et al. 1999; Bels et al. 2008). Natchev et al. (2015) proposed a four-stage scenario in which this terrestrial feeding behavior might have originated from an aquatic ancestor. First, amphibious but predominantly aquatic turtles might have explored terrestrial environments and taken food items with their jaws, but would have to drag the food into the water to swallow it (as 
seen in some emydids; Weisgram 1985; Stayton 2011). In the second step, these turtles might have still been able to use hydrodynamic mechanisms to swallow food underwater but might also use their tongue to swallow food items, allowing complete intake of food on land (a behavior that has been documented for the geoemydid Cuora; Heiss et al. 2008; Natchev et al. 2009; Natchev et al. 2010). The ability to swallow underwater would have been lost during the third stage (seen in Manouria emys; Natchev et al. 2015). Finally, tortoises started to use their tongues to grasp food items on land (Weisgram 1985; Wochesländer et al. 1999; Bels et al. 2008). How stem turtles fed is still a controversial issue, but the apparent completely terrestrial behavior (Joyce et al. 2004; Scheyer and Sander 2007; Joyce 2015; Lautenschlager et al. 2018) and the presence of palatal teeth (Gaffney et al. 1987; Gaffney 1990; Joyce et al. 2016) suggest they held and processed food items with their jaws (Matsumoto \& Evans 2017).

Thus, the mechanisms of closure of the lower jaw are extremely important for feeding behavior in turtles, and bite force or speed of closure may vary, depending on diet. The main force component of adduction of the lower jaw is generated by the large external adductors (Schumacher 1973; Iordansky 1996). Although originating posteriorly (mainly on the walls of the temporal fossa, supraoccipital and squamosal crests) and running anteriorly in a horizontal plane, this large muscle mass is redirected by the trochlear mechanism and inserts almost vertically on the coronoid process, providing an adduction as well as a retraction component to the lower jaw (Iordansky 1996). This force vector is compensated by the internal pterygoid muscles which, originating anteriorly mostly on the pterygoid and inserting near to the jaw joint produce a protraction component (Schumacher 1973; Iordansky 1996, 2010). Finally, the internal pseudotemporalis and the posterior adductor run almost entirely vertically relative to their insertion point and generate more adductive forces. This results in a strong adductor vector during lower jaw closure (Schumacher 1973; Iordansky 1996). It is important to highlight that these force vectors were hypothesized simply based on the topological position of the different muscular units in some turtle taxa (e.g., Iordansky 1996). A comparative approach using biomechanical models to infer direction and strength of muscle vectors, considering more taxa with different muscle arrangements, would provide a more detailed view of the functions developed by the adductor musculature in turtles (Chapter 5 of this thesis). 
The size and shape of the adductor muscles are greatly affected by the shape of the skull, which can expand or limit the relative areas of origin and insertion of those muscles. Bite force (Herrel et al. 2002) and skull shape morphometric analyses of durophagous (i.e., eaters of hard food items) turtles (Claude et al. 2004) found that higher skulls tend to produce more powerful bites. At the same time, aquatic turtles feeding on fast and elusive preys usually rely on powerful suction mechanisms, produced mostly by an increase in buccal volume associated with movements of the hyoid apparatus (Lemell et al. 2002; Lemell et al. 2010) and a rapid lowering of the floor of the buccal cavity. Increasing any dimension of the skull can generate larger buccal volumes, but increasing height can compromise the ability to withdraw the head inside the shell. Considering this, Herrel et al. (2002) proposed that specialized suction feeding turtles, such as Chelus fimbriatus (Lemell et al. 2002) and Apalone spinifera (Pritchard 1984), have relatively flattened skulls with expanded posterior and lateral regions, permitting those turtles to still maintain their neck retraction mechanism but compromising their bite performance (Herrel et al. 2002). Nevertheless, some taxa, such as Phrynops geoffroanus and Pelusios castaneus, seem to combine suction feeding with a strong bite force (Lemell \& Weisgram 1997; Herrel et al. 2002) even with relatively flat skulls. Thus, it seems likely that, aside from general skull proportions, different factors (e.g., different fiber types, differences between relative size of the internal and external muscles) also affect the force and speed of contraction of the jaw adductors in turtles.

\subsection{Evolution of cranial musculature}

Approximately 40 of the 356 known species of extant turtles (Rhodin et al. 2017) have been dissected and had their jaw musculature described, including at least one representative of each main lineage (Fig. 2.2) of Testudines (Werneburg 2011). These data allowed for a comprehensive study that considers the evolution of this region of the turtle head, such as that of Werneburg (2013a). In that study, the variation of the jaw muscles observed in several taxa was included into a taxon-character matrix to investigate the general trends during the evolution of turtles and ancestral state reconstructions for jaw muscle anatomy in the last common ancestor of Pleurodira, Cryptodira, and Testudines were provided. For the present chapter, 3-D models were created (see details on Figures captions) 
for the skulls and jaw muscles of a cryptodiran and a pleurodiran turtle, Pelodiscus sinensis (Fig. 2.6) and Pelomedusa subrufa (Fig. 2.7), respectively, to compare topology, origin, and insertion of their jaw muscles to the reconstructed ancestral conditions of Cryptodira and Pleurodira. Using the predicted states for the Testudines crown-node, I also inferred and plotted the jaw musculature on a 3D model of the skull of Proganochelys quenstedti (Fig. 2.8) (scan data from Werneburg et al. 2015a).

As suggested by Werneburg (2013a), modelling reconstructed states for Testudines onto a stem turtle, such as $\operatorname{Pr}$. quenstedti, should be interpreted tentatively because those states are inferred for a different node on the turtle tree and we usually cannot directly access soft tissue data in extinct taxa. However, this represents a first step towards a better understanding of the adductor chamber in stem and ancestral turtles (Pr. quenstedti, Cryptodira and Pleurodira ancestors) and may be useful to infer general trends that occurred during the evolution of these lineages. Careful analyses of bone surfaces in the adductor chamber and on the lower jaw (e.g., Araújo \& Polcyn 2013, Witzmann \& Werneburg 2017) and internal bone structures, such as Sharpey's fibers (e.g., Scheyer \& Sander 2007), to identify attachment sites could provide direct evidence about the arrangement of the jaw musculature in stem turtles. That being said, I describe below first the jaw musculature in cryptodires and pleurodires, considering the changes between the ancestral condition and that of the chosen extant taxa, and then in Pr. quenstedti, commenting on the general transformations of the jaw musculature from stem to crown turtles.

\subsubsection{Jaw muscles in Cryptodira}

The extant cryptodire chosen for jaw muscle visualization, Pelod. sinensis (Fig. 2.6), belongs to Trionychia, a clade that forms the sister taxon to all other cryptodires based on molecular data (Shaffer 2009; Guillon et al. 2012; Crawford et al. 2015). In many regards, Trionychia show plesiomorphic skull conditions, however, a list of unique characters also exists (Vitek \& Joyce 2015). Their skulls possess long supraoccipital and squamosal crests and a broad adductor chamber that affect not only the condition of the external adductors, but also that of the internal and posterior adductors. In Pelod. sinensis, one of the best described trionychid species regarding its jaw muscles (Ogushi 1911, 1913a, b, 1914), the partes profundus and superficialis of the external adductor have extended their origins far 
posteriorly due to its elongated crests, but also to other bones when compared to the reconstructed ancestral cryptodiran condition. The pars profundus extends its origin to the postorbital, opisthotic, and prootic beyond the ancestral cryptodiran origins on the parietal and supraoccipital, and the pars superficialis in Pelod. sinensis originates on the quadratojugal, jugal, and opisthotic (Ogushi 1913a; Lakjer 1926; George \& Shah 1955), in addition to the squamosal and quadrate as in the ancestral cryptodire (Werneburg 2013a). Furthermore, the origin of both portions is strengthened by several tendinous sheets, extending from the coronar aponeurosis to the supraoccipital and squamosal crests of trionychids (Schumacher 1956; Werneburg 2011). The pars medialis (Fig. 2.6A'), which lies ventral to those parts and originates more anteriorly than the other portions of the external adductors (Werneburg 2013a), remained attached to the anterior surfaces of the quadrate and squamosal in the ancestral cryptodire, but in Pelod. sinensis it extends its origin posteroventrally near to the jaw joint on the quadrate, below the tympanic cavity (Ogushi 1913a; Werneburg 2011). All three portions fuse distally during their course to the insertion sites on the dorsal and lateral aspects of the lower jaw in all cryptodires (Werneburg 2011).

The three portions overlay a strong tendinous bundle, the coronar aponeurosis, which inserts to the coronoid process on the lower jaw of all turtles (Werneburg 2011). Although all cryptodires possess a trochlear articulation on the external surface of the otic chamber (Schumacher 1973; Gaffney 1975), there is variation among the different groups on the components of this mechanism (i.e., the surface of the bones, the size and shape of the tendon structure, and the type of gliding joint or surface developed between them). In Pelod. sinensis, the quadrate and prootic form an anterodorsal projection onto the lower temporal fossa, pushing the trochlear articulation to a position right above the high coronoid process of the lower jaw where the coronar aponeurosis inserts. As in the ancestral cryptodiran condition, several fibers surrounding the coronar aponeurosis also insert directly to the dorsal and lateral surfaces of the lower jaw. In the ancestral cryptodire, the direct fibers were restricted to the coronoid bone, but in Pelod. sinensis they expand anteriorly and posteriorly to the surangular and dentary (Ogushi 1913a; Werneburg 2013a). The m. zygomaticomandibularis, found only in Trionychia and not in the ancestral cryptodire (Werneburg 2011), originates with two heads lateral to the external adductors in Pelod. sinensis (Ogushi 1913a). The anterior head originates anteriorly on the medial and ventral 
surfaces of the jugal and quadratojugal in the postorbital bridge (Werneburg 2013a), and the posterior head covers it, attaching to the ventral and lateral aspects of this bone bridge but also on the temporal fascia and the anterolateral surface of the quadrate. The heads run ventrad and fuse on their way to insert broadly, partly via a tendon but mostly directly into a lateral depression of the dentary and surangular (Ogushi 1913a; Werneburg 2011, 2013a).
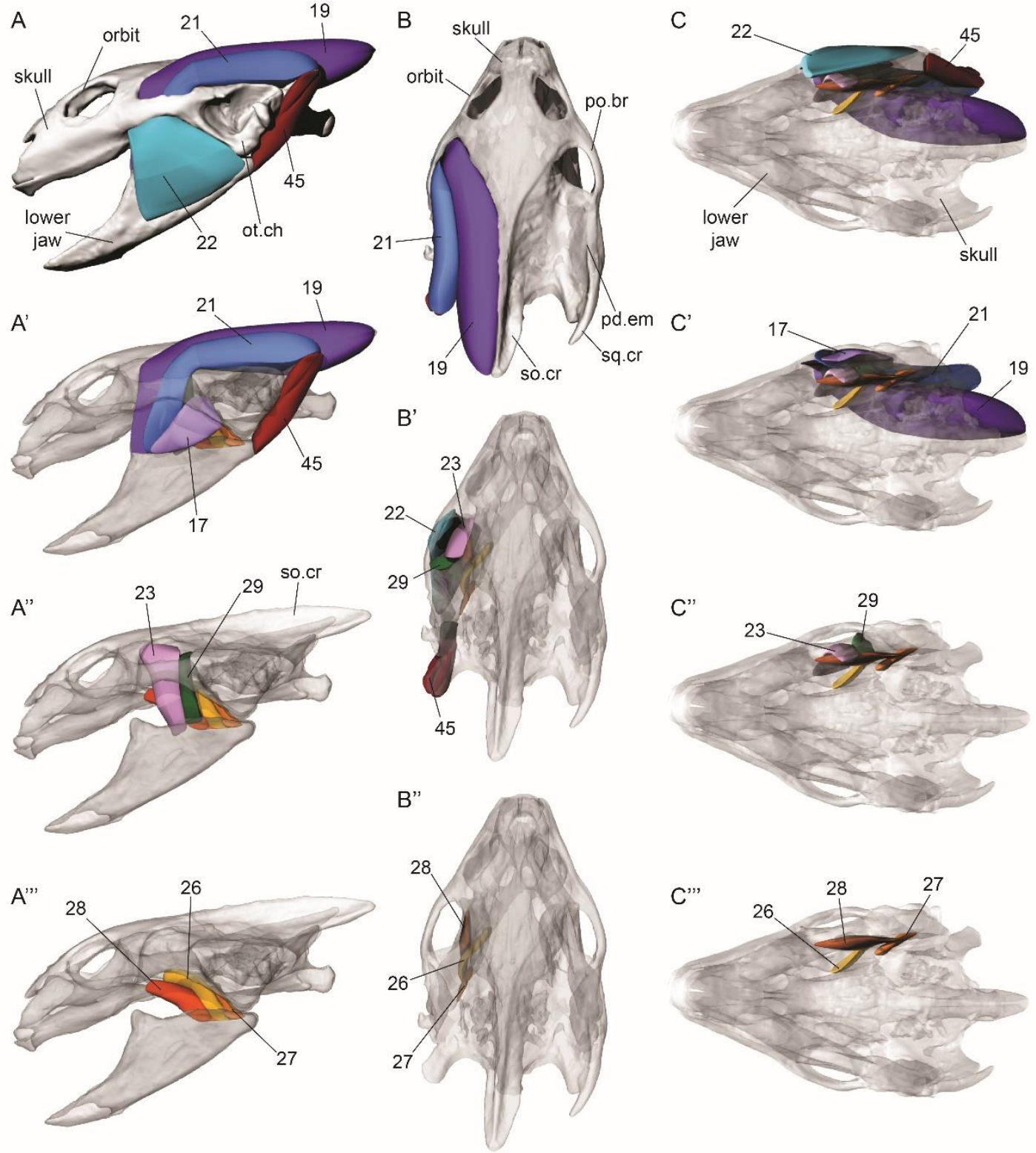

Figure 2.6. Digital three-dimensional reconstruction of the jaw adductor and depressor musculature of the cryptodire Pelodiscus sinensis based on Ogushi (1913), Schumacher (1954), and Werneburg (2011, 2013a) made with CAD software Rhinoceros 3D (Robert McNeel \& Associates, 2003). Skull with solid (A, B) and transparent ( $\left.\mathbf{A}^{\prime}-\mathbf{A}^{\prime \prime \prime}, \mathbf{B}^{\prime}-\mathbf{B}^{\prime \prime}, \mathbf{C}-\mathbf{C}^{\prime \prime \prime}\right)$ textures in left lateral view (left column), dorsal (middle column), and ventral (right column) view. (A) All jaw adductor and depressor muscles plotted. (A') M. zygomaticomandibularis (22; numbers following the proposal of Werneburg 2011) removed. (A") 22, all 
external adductor (m. add. mandibulae ext.) portions, and m. depressor mandibulae (man.) (45) removed. (A'"') 22, all ext. add. portions, $\mathbf{4 5}$, m. add. man. internus (int.) pars pseudotemporalis (23), and m. add. man. posterior (29) removed. (B) Dorsal view with all adductor and depressor muscles plotted. (B') m. add. man. ext. pars profundus (19) and superficialis (21) removed. (B") All external adductor portions, 22, 23, 29, and 45 removed. (C) Ventral view with all adductor and depressor muscles plotted. ( $\left.C^{\prime}\right) 22$ and 45 removed. (C' $)$ 22, 45, and all external adductor portions removed. (C'") 22, 23, 29, 45, and all external adductor portions removed. Additional abbreviations: 17, m. add. man. ext. pars medialis; 26, m. add. man. int. pars pterygoideus dorsalis; 27, m. add. man. int. pars pterygoideus posterior; 28, m. add. man. int. pars pterygoideus ventralis; ot.ch, otic chamber; pd.em, posterodorsal emargination; po.br, postorbital bridge; so.cr, supraoccipital crest; sq.cr, squamosal crest.

The arrangement of the internal adductors (Fig. 2.6A", $\mathrm{A}^{\prime \prime \prime}$ ) of Pelod. sinensis is influenced by the broad horizontal plate of the pterygoid that extends posteriorly to the quadrate and by the anterodorsal projection of the prootic and quadrate described above. The fibers of the pterygoid muscle, as in the ancestral cryptodire, run posteriorly from their origin on the pterygoid and palatine, mostly above the horizontal plate of the pterygoid (Werneburg 2011). The enlarged plate of trionychids supports broader pterygoid muscles as well, in contrast to that found in other cryptodires, such as the marine turtle Lepidochelys kempii (Jones et al. 2012) and the snapping turtle Chelydra serpentina (Rieppel 1990). In Pelod. sinensis these are more robust, and the dorsalis portion reaches also the descending process of the parietal (Fig. 2.6B"). The pars pseudotemporalis also expands its origin anteriorly to reach the posteroventral face of the frontal (Ogushi 1913a; Werneburg 2013a), differing from the ancestral cryptodiran condition, in which this muscle portion originated only on the descending process of the parietal. As in all turtles, the pars pseudotemporalis is very closely related to the posterior adductor (Rieppel 1990), which originates posteriorly to the former (Fig. 2.6A") on the quadrate and prootic in the reconstructed ancestral cryptodire and in Pelod. sinensis.

All the internal adductors insert to the medial aspect of the posterior half of the lower jaw (Fig. 2.6C'), in the region between the coronoid process and the retroarticular process near the jaw joint, mainly via tendinous structures (Schumacher 1973; Werneburg 2011). The insertions in Pelod. sinensis and in the ancestral cryptodire do not differ much. The pars pseudotemporalis runs ventrad and inserts entirely to the subarticular aponeurosis, which inserts to the prearticular, surangular, and articular, and to which some fibers of the pterygoid portions and of the posterior adductor also insert. Most fibers of the posterior muscle, however, insert directly to the medial surfaces of the articular and prearticular. The pterygoid muscles insert on a broader area (Fig. 2.6A") ranging from the coronoid to the articular on 
the retroarticular process (pars pterygoideus posterior) via the subarticular aponeurosis and direct fibers. Although seemingly absent in trionychids (Werneburg 2013a), in several other cryptodires and in the ancestral cryptodiran condition, the pterygoid muscles develop their own tendon (pterygoid aponeurosis = lamina anterior of the subarticular aponeurosis of Schumacher 1973), to which several fibers insert (Werneburg 2011, 2013a). Lastly, the m. depressor mandibulae has almost the same condition in Pelod. sinensis and in the ancestral cryptodire, originating on the ventral and lateral surfaces of the squamosal, running ventrad, and inserting to the posterior and ventral faces of the articular on the retroarticular process via the retroarticular tendon (Werneburg 2013a). In Pelod. sinensis, however, it originates with two heads that fuse distally, and may insert to the surangular also (Ogushi 1913a).

\subsubsection{Jaw muscles in Pleurodira}

Among the three major side-necked turtle lineages, Chelidae, Podocnemididae, and Pelomedusidae (Gaffney \& Meylan 1988), the skull of the latter is relatively similar (in many general aspects) to that of some cryptodire turtles (Fig. 2.7). It is dorsoventrally flattened, but not as much as in some chelids (e.g., Chelodina oblonga, Gaffney 1977). It has large posterodorsal and shallow-to-moderate anteroventral emarginations, and its supraoccipital and squamosal crests are posteriorly elongated (but not as extremely as in trionychids). As such, the skull of pelomedusids may be morphologically closer to that of the pleurodiran ancestors than the skulls of Chelidae and Podocnemididae. Indeed, by comparing the condition of Pelomedusa subrufa (Schumacher 1954b) to that of the reconstructed ancestral states for the jaw musculature of the Pleurodira node we find only some minor variations (Werneburg 2013a).

The external adductors in the ancestral pleurodires originated (Werneburg 2013a) on the parietal and supraoccipital, extending posteriorly to cover the crista supraoccipitalis (pars profundus), on the medial faces of the quadrate and squamosal, spanning to the lateral wall of the upper temporal fossa (pars superficialis), and to the anterior face of the quadrate (pars medialis). Their fibers fuse together soon after their origin and inserts to the coronar aponeurosis, which runs anteroventrad underneath the muscle layers and bends over the processus trochlearis pterygoidei where it develops a transiliens cartilage and forms a gliding surface on the dorsal aspect of that bone. Most fibers insert via the coronar aponeurosis on 
the dorsal and lateral aspects of the coronoid process, but some fibers of the partes profundus and superficialis insert directly to the coronoid, whereas some fibers of the pars medialis pass directly to the dorsal and lateral surfaces of the surangular, posteriorly to the other portions. In Pelom. subrufa, the only modifications from this morphology are the anterior expansion of the superficialis origin also to the quadratojugal, postorbital, and parietal and its insertion more posteriorly, with some fibers also reaching the surangular (Schumacher 1954b; Iordansky 1996).
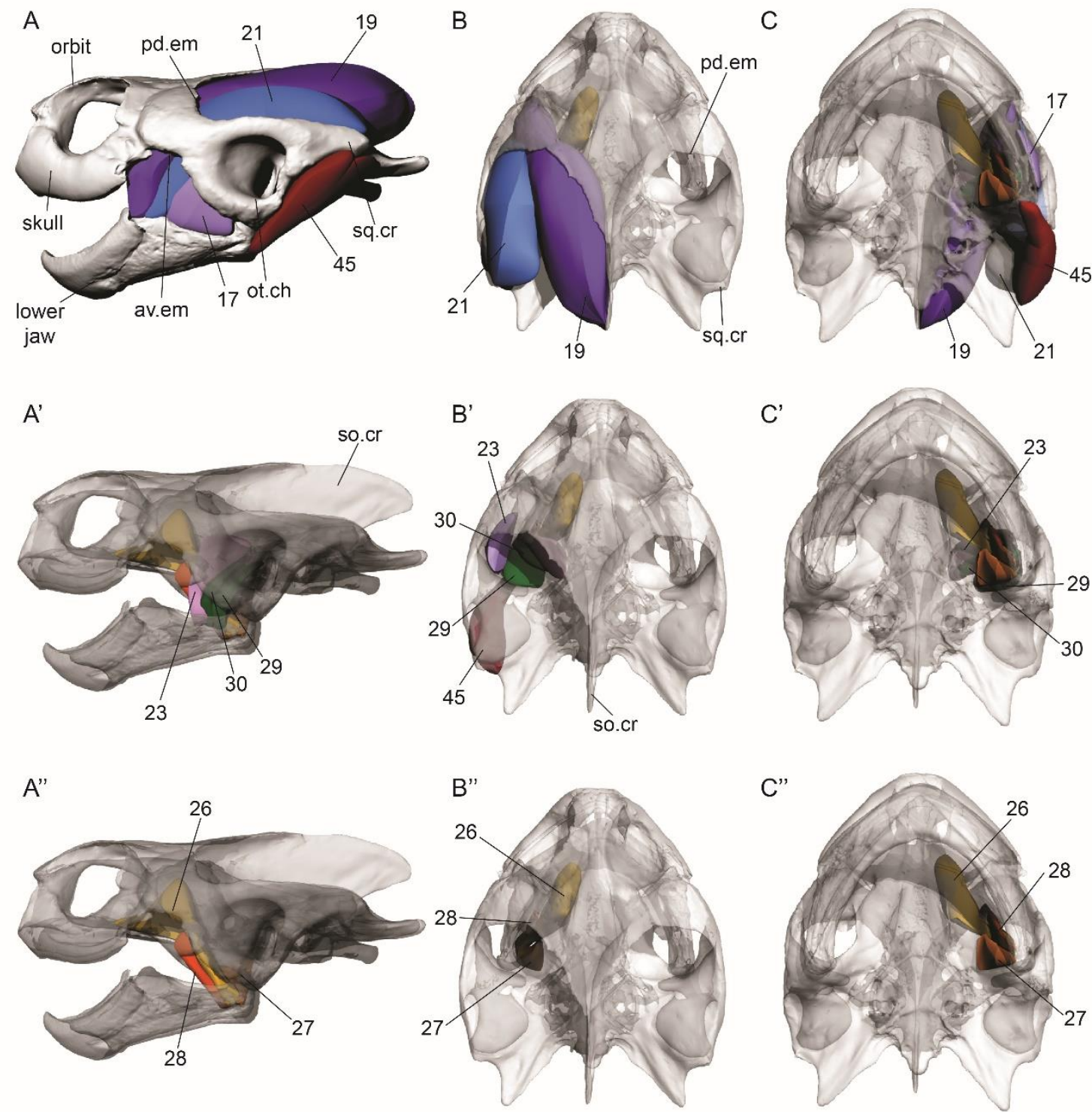

Figure 2.7. Digital three-dimensional reconstruction of the jaw adductor and depressor musculature of Pelomedusa subrufa based on Schumacher (1954b; 1954/55) and Werneburg (2011, 2013a) made with CAD software Rhinoceros 3D (Robert McNeel \& Associates, 2003). Skull with solid (A) and transparent ( $\mathbf{A}^{\prime}-\mathbf{A}^{\prime \prime}$, 
B-B"', C-C'"') textures in left lateral (left column), dorsal (middle column), and ventral (right column) views. (A, B, C) Skulls with all jaw adductor and depressor muscles plotted. (A', B', $\mathbf{C}^{\prime}$ ) All external adductor (m. add. mandibulae ext.) portions and $\mathrm{m}$. depressor mandibulae (man.) (45; numbers following the proposal of Werneburg 2011) removed (45 plotted in $\mathbf{B}^{\prime}$ ). (A', B', $\mathbf{C}^{\prime \prime}$ ) All external adductor muscles, $\mathbf{4 5}$, m. add. man. internus (int.) pars pseudotemporalis (23) and m. add. man. posterior (29) removed. Additional abbreviations: 17, m. add. man. ext. pars medialis; 19, m. add. man. ext. pars profundus; 21, m. add. man. ext. pars superficialis; 26, m. add. man. int. pars pterygoideus dorsalis; 27, m. add. man. int. pars pterygoideus posterior; 28, m. add. man. int. pars pterygoideus ventralis; 30, m. add. man. posterior pars rostralis; av.em, anteroventral emargination; ot.ch, otic chamber; pd.em, posterodorsal emargination; so.cr, supraoccipital crest; sq.cr, squamosal crest.

Similarly, the internal and posterior adductors maintain, with some small changes, the inferred ancestral condition for pleurodires in Pelom. subrufa. The pars pterygoideus dorsalis originated anteriorly on the dorsal faces of the pterygoid and palatine, entering the tunnellike structure formed by the pterygoid ventrally and the postorbital and parietal dorsally (= sulcus palatino-pterygoideus of Gaffney et al. 2006) and inserting also on its medial wall (Fig. 2.7A") on the descending process of the palatine (Schumacher 1954b, 1954/55). The pars pterygoideus ventralis originated on the dorsal and lateral aspects of the pterygoid, bordered laterally by the processus trochlearis pterygoidei. The pars pterygoideus posterior originated on the dorsal and ventral surfaces of the pterygoid, posteriorly to the origins of the partes pterygoideus ventralis and dorsalis (Fig. 2.7B"). In Pelom. subrufa, the pars pterygoideus posterior expands its origins to the ventral aspect of the skull (Fig. 2.7C"), a trend that is observed to a greater extent in podocnemidids. In Podocnemis expansa, for example, the pars pterygoideus posterior inserts inside a cavity (cavum pterygoidei sensu Gaffney et al. 2006) formed by the pterygoid ventrally and the basisphenoid, quadrate, and prootic dorsally (Schumacher 1954a, 1973; Gaffney 1979).

As mentioned above, the pars pseudotemporalis and the posterior adductor are much integrated in pleurodires, as in cryptodires (Werneburg 2011), and are positioned anteriorly and posteriorly, respectively, to the mandibular branch $\left(\mathrm{V}_{3}\right)$ of the trigeminal nerve (Lakjer 1926; Schumacher 1973; Werneburg 2011). The former originates, in the reconstructed pleurodire ancestor, on the descending process of the parietal, ran ventrad and inserted on the subarticular aponeurosis (together with some fibers of the partes pterygoidei), which inserted on the medial aspect of the prearticular (Werneburg 2013a). In Pelom. subrufa (Fig. 2.7A') the origin of the pars pseudotemporalis extends to the prootic also, above the foramen nervi trigemini (Schumacher 1954b, 1954/55; Iordansky 1996). The posterior adductor originates broadly on the anterior surfaces of the quadrate and prootic in the ancestral pleurodire. It is 
more restricted laterally in Pelom. subrufa (Fig. 2.7B'), reaching only the anterolateral surface of the prootic (Werneburg 2013a). In both Pelom. subrufa and the ancestral pleurodire, the posterior adductor fibers run ventrad and insert to the medial face of the surangular on the lower jaw. Similarly, to the ancestral condition of cryptodires, the m. depressor mandibulae of the ancestral pleurodire originated only with one head but develops a second head (Fig. 2.7A) in Pelom. subrufa (Schumacher 1954b, 1954/55; Iordansky 1996). On the other hand, the depressor mandibulae origin site is broader in all pleurodires, spanning from the ventral and lateral surfaces of the squamosal to the opisthotic in the ancestral condition and in Pelom. subrufa also on the medial face of the quadrate. In the latter, it runs ventrad and inserts to the posterior surface of the articular, but in the inferred pleurodire ancestor it inserted more broadly, via a retroarticular tendon to the retroarticular process of the lower jaw.

\subsubsection{Jaw muscles in Proganochelys quenstedti}

Although the skull of Proganochelys quenstedti may seem similar to that of some crown turtles, especially to those with a full dermal bone covering such as sea turtles, there are several important differences that most likely made its jaw musculature distinct from the crown turtle general pattern (Fig. 2.8). Pr. quenstedti lacked supraoccipital and squamosal crests (Gaffney 1990), which, together with the smaller otic chamber than that of crown turtles, suggest a more vertical orientation of the external adductors inside the closed adductor chamber. As inferred from the reconstructed pattern of Testudines ancestor, the pars profundus originated on the dorsal plate of the parietal and on the lateral aspect of the supraoccipital occupying around half of the upper temporal fossa (Fig. 2.8B). The pars superficialis was likely attached, based on our reconstruction, to the medial faces of the quadrate and the squamosal (certainly, it also expanded to the medial face of the quadratojugal, jugal, and postorbital as in extant sea turtles, but this we could not reconstruct with the available data), mostly on the lateral braincase wall, and possibly some fibers to the roof of the adductor chamber. This arrangement is very similar to that of diapsids, such as Sphenodon punctatus (Jones et al. 2009) and Alligator mississippiensis (Holliday \& Witmer 2007), except for the pars medialis. The inferred position for this muscle in the ancestral Testudines resembles that of other turtles, and in Pr. quenstedti it should also be similar, 
based on the arrangement of the surrounding structures. The site of origin for the pars medialis likely was much more restricted than that of the other portions of the external adductors, only on the anterior surface of the quadrate (Fig. 2.8A) and extending slightly onto the lateral wall of the adductor chamber. This is more similar to the condition of $A$. mississippiensis (Holliday \& Witmer 2007), in which it is also restricted to the anterior face of the quadrate, than to that of S. punctatus, in which it has a broad origin on the posttemporal bar, near to the insertion of pars profundus (Jones et al. 2009).

The external adductor fibers in Pr. quenstedti ran ventrad to insert to the dorsal and lateral aspects of the lower jaw (Fig. 2.8A), on the low coronoid process, the dentary, and the surangular. Although all extant turtles possess a coronar aponeurosis to which most fibers of the external adductors attach, we cannot assure if it was present in Pr. quenstedti, because the conditions in the outgroup representatives are diverse. The coronar aponeurosis of lepidosaurs (Lakjer 1926; synonyms = basal aponeurosis, Jones et al. 2009, bodenaponeurosis see Werneburg 2013b) develops in a different way than that of turtles, namely between the internal and external adductor anlagen (Rieppel 1987b, 1990) and is shared only by the profundus and medialis portions of the external adductors (Jones et al. 2009). Among archosaurs, a similar structure could not be identified in birds and, although crocodiles possess a tendon shared by all external adductors, as in turtles (potential synapomorphy), it is significantly folded (due to the suturing of the quadrate to the braincase; Holliday \& Witmer 2007) and shared also by the posterior adductor (Iordansky 1994; Holliday \& Witmer 2007; Werneburg 2013b). It is important to note that the coronar aponeurosis would not form a transiliens cartilage in Pr. quenstendti. The almost vertical arrangement of the external adductors in the adductor chamber of Pr. quenstedti, confirmed by our reconstructions (Fig. 2.8A), suggests that it was not affected by the otic chamber in its course to the lower jaw, so there was no mechanical stress on the coronar aponeurosis to develop a transiliens cartilage (also present on the internal muscles of crocodiles and possibly temnospondyls; Tsai \& Holliday 2011; Witzmann \& Werneburg 2017) as found in crown turtles.

The internal and posterior adductors of Pr. quenstedti were certainly more restricted than in crown turtles (Fig. 2.8A'), especially by two features of its skull. First, this stem turtle 
lacked a descending process of the parietal, which contributes to the secondary lateral braincase wall anteriorly in extant turtles (Gaffney 1990; Eßwein 1992), and from which most of the pars pseudotemporalis and some fibers of the pars pterygoideus dorsalis originates (Werneburg 2011). Secondly, Pr. quenstedti possessed very large eyes relative to the size of the rest of the skull (Gaffney 1990, fig. 41, p. 51; Fig. 2.8), which most likely limited the space available for the anterior expansion of the pterygoid muscle portions. This also results in a much more restricted adductor chamber in comparison to crown turtles and, hence, the internal adductor should have been smaller as well. The pterygoid muscle portions should have been more integrated than in other turtles, given their topology: they all originated more or less in a gradient on the dorsal surface of the pterygoid (Fig. 2.8B"). The dorsalis portion is more anteriorly located extending on a dorsal depression, just posterior to the border of the foramen palatinum posterius (Gaffney 1990). It was followed by the ventralis, which would have originated on the lateral border of the pterygoid as well, and by the posterior portion, originating also on a small dorsal projection near the suture with the quadrate. The ancestral state reconstruction does not support a ventral origin of any portion of the pterygoid muscle for the ancestral Testudines (Werneburg 2013a). Given the presence of teeth on the ventral surface of the pterygoid bone in Pr. quenstendti (Gaffney 1990), this was likely the same state in this taxon and other stem turtles (compare to Witzmann \& Werneburg 2017). Thus, the extension of the pterygoid origin to the ventral aspect of this bone should have happened at least two times in Testudines, one within Cryptodira, in Americhelyidia (sensu Joyce et al. 2013a), and one within Pleurodira, among Pelomedusoides (Werneburg 2013a).

In $\operatorname{Pr}$. quenstedti, the pars pseudotemporalis likely originated anteriorly to the prootic foramen (Fig. 2.8A'), on the small and thin process of the parietal that closed it anteriorly and contacted the basisphenoid ventrally, near the processus clinoideus (Gaffney 1990). It may have been continuous to the origin of the posterior adductor, which attached to the anterior faces of the prootic and quadrate, medial to the origin of the pars medialis of the external adductor (Fig. 2.8B'). If so, this would not differ much from the condition seen in several extant turtles in which the pseudotemporalis and posterior are highly integrated (Werneburg 2011) and can only be distinguished as separate unities by the passage of the mandibular branch $\left(V_{3}\right)$ of the trigeminal nerve that pierces this muscle mass (Lakjer 1926; Rieppel 
1990). The main difference would be that pars pseudotemporalis in Testudines extends more anteriorly than that of Pr.quenstedti, following the anteroventral expansion of the descending process of the parietal, which approaches the palate in the former. In the ancestral Testudines the posterior adductor originated on the prootic and quadrate, probably reaching the pars pseudotemporalis. However, in Pr. quenstedti it is unclear if this condition was present, given the open foramen nervi trigemini forming a groove that extends to the prootic foramen (Gaffney 1990). It is plausible that in this stem turtle the origin of the posterior adductor and that of the pars pseudotemporalis were separated by that space between the prootic and trigeminal nerve foramina. A well separated pars pseudotemporalis and a posterior adductor can be seen in archosaurs (Holliday \& Witmer 2007) and lepidosaurs (Jones et al. 2009) and, if this was the case in $\operatorname{Pr}$. quenstedti also, a greater integration between those muscles would be a feature acquired during the evolution of turtles. This had the possible advantage of them acting as one united powerful muscle vector during jaw closure.

The insertions of the internal and posterior adductors in the ancestral Testudines and Pr. quenstedti roughly corresponded to that of crown turtles. The pars pseudotemporalis inserted via the subarticular aponeurosis on the medial and dorsal surfaces of the prearticular, inside the Meckel's fossa. A pars intramandibularis, as found in some extant turtles (Werneburg 2011), was most likely absent. Some fibers of the partes pterygoidei shared the subarticular aponeurosis, but a pterygoidal aponeurosis was most likely present in the ancestral Testudines (Werneburg 2013a) and some fibers would also insert directly on the medial surfaces of the prearticular and articular. The posterior adductor inserted above the insertion sites of the pterygoid portions and posterior to the pseudotemporalis insertion (Fig. $2.8 \mathrm{~A}^{\prime}$ ), also on the prearticular and articular, closer to the jaw joint. Finally, the m. depressor mandibulae originated with only one head on the ventral and lateral aspects of the squamosal in the ancestor of Testudines and likely also on lateral portions of the opisthotic in $\operatorname{Pr}$. quenstedti. The depressor mandibulae ran ventrad (as in all turtles) to insert posteriorly on the retroarticular process of the articular bone (Fig. 2.8A), possibly via the retroarticular aponeurosis and direct fibers. 

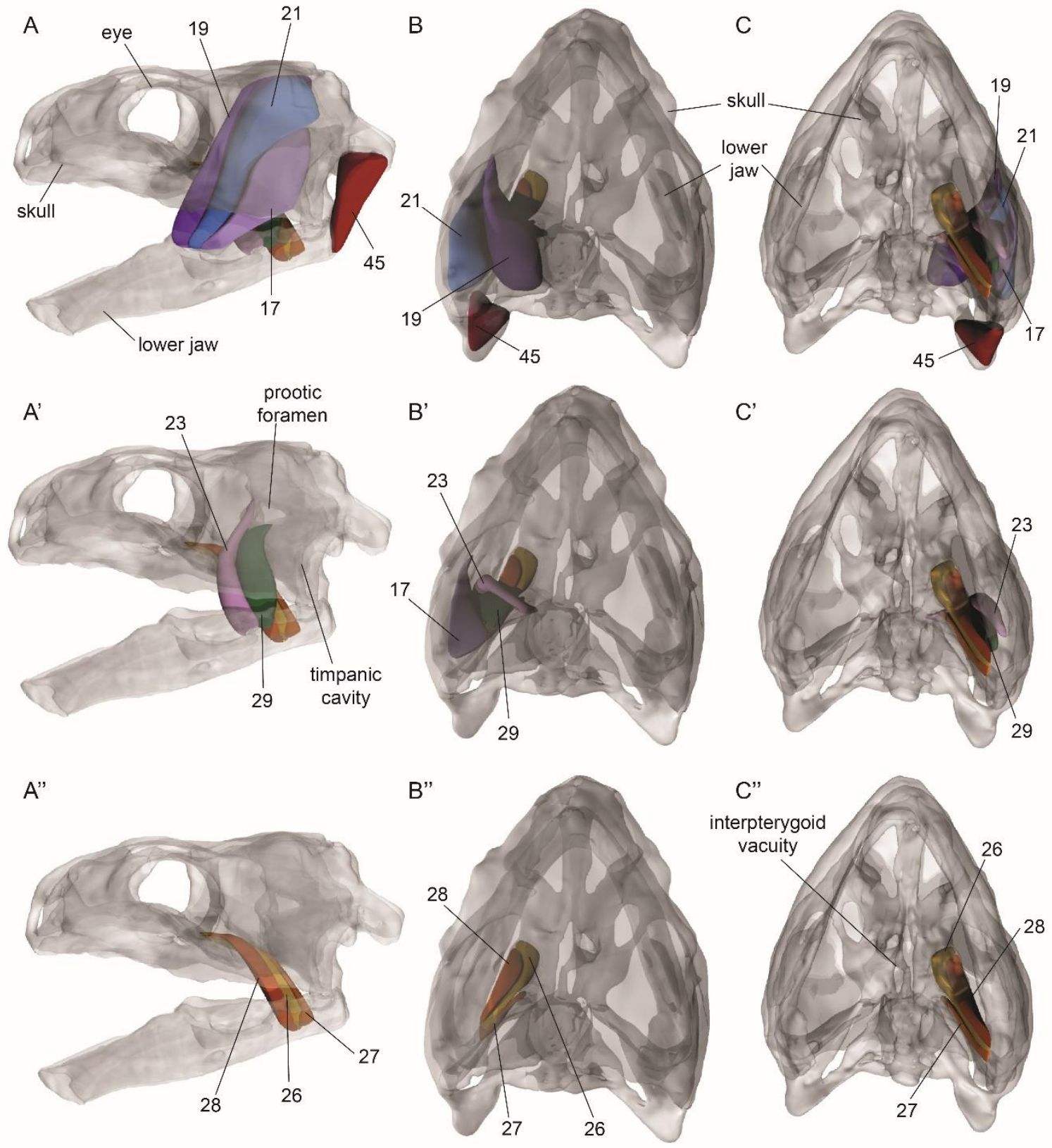

Figure 2.8. Digital three-dimensional reconstruction of the jaw adductor and depressor musculature of Proganochelys quenstedti made with CAD software Rhinoceros 3D (Robert McNeel \& Associates, 2003). Skull with transparent textures in left lateral (left column), dorsal (middle column), and ventral (right column) views. $(\mathbf{A}, \mathbf{B}, \mathbf{C})$ Skulls with all jaw adductor and depressor muscles plotted. $\left(\mathbf{A}^{\prime}, \mathbf{B}^{\prime}, \mathbf{C}^{\prime}\right)$ All external adductor (m. add. mandibulae ext.) portions and $\mathrm{m}$. depressor mandibulae (man.) (45; numbers following the proposal of Werneburg 2011) removed (note: m. add. man. externus pars medialis in $\left.\mathbf{B}^{\prime}\right)$. (A", B", $\mathbf{C}^{\prime \prime}$ ) All external adductor muscles, $\mathbf{4 5}, \mathbf{m}$. add. man. internus (int.) pars pseudotemporalis (23), and m. add. man. posterior (29) removed. Additional abbreviations: 17, m. add. man. externus (ext.) pars medialis; 19, m. add. man. ext. pars profundus; 21, m. add. man. ext. pars superficialis; 26, m. add. man. int. pars pterygoideus dorsalis; 27, m. add. man. int. pars pterygoideus posterior; $\mathbf{2 8}, \mathrm{m}$. add. man. int. pars pterygoideus ventralis. 
Extant turtles do not show a m. levator pterygoidei, a muscle, which connects the primary braincase wall with the pterygoid and enables movement of the palate in reptiles with kinetic skulls. A rudimentary anlage of this muscle, however, was found in the emydid cryptodire Emys orbicularis (Fuchs 1915). A kinetic basicranial articulation was likely present in Pr. quenstedti (Gaffney 1990) and other stem turtles (Rabi et al. 2013), which is further supported by the recapitulation of this embryonic structure in an extant species.

The ancestor of Testudines possessed more robust external adductors relative to the internal and posterior adductors, as in all other turtles (Iordansky 1996; Schumacher 1973; Werneburg 2011), and likely the same condition was found in Pr. quenstedti. Lepidosaurs show the same relation (Jones et al. 2009), while in archosaurs the opposite is observed (Holliday \& Witmer 2007). Regarding the portions of the external adductors, all turtles (including $P r$. quenstedti) show a greater integration between the partes medialis and superficialis (Rieppel 1990; Werneburg 2011), contrasting to the condition in lepidosaurs, in which the partes medialis and profundus are more closely related (Jones et al. 2009; Daza et al. 2011; Diogo \& Abdala 2010). The strong coronar aponeurosis of turtles is developed between the external adductor layers, as in crocodiles, contrasting to the condition in lepidosaurs, in which it develops between the internal and external rudiments (Rieppel 1987a, 1990; Holliday \& Witmer 2007; Jones et al. 2009). More integrated pseudotemporalis and posterior adductor, on the other hand, are features exclusive to turtles, whereas in archosaurs and lepidosaurs these parts are more extensively separated (Holliday \& Witmer 2007; Jones et al. 2009). In addition to other features reported by previous studies supporting relationships of turtles either with archosaurs [i.e., external eye pyramidalis muscle (Werneburg 2011) and closely related internal and posterior adductors and inter-/intramandibularis (Rieppel 1990; Werneburg 2011)] or with lepidosaurs [i.e., the compartmentalization of $\mathrm{m}$. intramandibularis from the internus anlage (Rieppel 1990; Werneburg 2011)], available data seem to present a mosaic of archosaurian and lepidosaurian features in the turtle head musculature. This may suggest that these are actually simplesiomorphies retained alternatively in those groups and in turtles and, as such, do not support closer relationships with either archosaurs or lepidosaurs. 
The homology of specific parts of the jaw musculature (i.e., the different portions of the external, internal, and posterior adductors) between different extant sauropsid groups (archosaurs, lepidosaurs, and turtles) is still poorly understood (Holliday \& Witmer 2007; Werneburg 2011). This is largely due to the fact that we can only directly assess the morphology of the muscles of extant reptilian taxa, which diverged from each other and started to diversify as early as in the Permian (approximatelly 300-250 million years ago; Mulcahy et al. 2012). Hence, using ancestral state estimates in conjunction with detailed anatomical analyses of fossils that aim to reconstruct the jaw musculature in extinct taxa will provide real potential to help resolving these issues. The known skull material of $\operatorname{Pr}$. quenstedti does not have well-preserved surfaces in this region, so it is difficult to infer sites of muscle attachment with sufficient detail to musculature reconstruction (see Witzmann \& Werneburg 2017). Nevertheless, further analysis of additional stem turtles can generate more data on those potential attachment sites expanding our knowledge of the early evolution of the jaw musculature in turtles.

\subsection{Concluding remarks}

Although turtles have attracted the attention of researchers for a long time, important aspects of their evolution are still debated. New anatomical, paleontological, and developmental data have the potential to increase our understanding of the nature of certain derived morphological structures, such as the turtle shell (Nagashima et al. 2012; Li et al. 2008). Additionally, considerable controversy still surrounds the phylogenetic origin and the interrelationship of turtles among reptiles. In this context, the turtle skull presents one of the most promising structures among to resolve those open questions.

One of the open questions is the multiple origins of turtle temporal emarginations and dermatocranial bone reductions in amniotes, in general. For many years (Zdansky 1923; Romer 1956; Kilias 1957), the bulging of the jaw adductor muscles was thought to be the primary responsible for those reductions, but current interpretations suggest that other factors might also be related to them. In the case of turtles, the modifications induced by the origin of the shell and alternate mechanisms of neck retraction seem to play prominent roles in the emergence of emarginations (Werneburg et al. 2015a; Werneburg et al. 2015b; Werneburg 
2015). However, variation among taxa with similar neck retraction mechanisms (such as chelids and pelomedusids) suggests other factors may also contribute to shape their morphology. Additionally, one can ask if the factors shaping the temporal emarginations in turtles also affect the repeated origin of temporal openings in other amniotes. New studies of functional morphology (e.g., finite element analyses), allied to comparative developmental analysis focusing on those structures, may help to clarify their role and evolution in the amniote head.

Developmental studies with larger samples can also be useful to assess some putative synapomorphies of turtles with other amniotes. For example, the $\mathrm{m}$. pyramidalis of the eye is found only in turtles, crocodiles, and birds and is used as morphological evidence supporting the prevailing results of molecular phylogenetics that place turtles closer to archosaurs (Rieppel 1990; Eger 2006). Although morphologically they seem to be homologous structures, their ontogenetic origin has never been studied in a more comprehensive reptile framework. At the same time, the pattern of differentiation of the posterior adductor and intermandibularis muscles in turtles are more similar to those of crocodiles than to that of squamates (Rieppel 1987b, 1990). Further support or rejection of these primary statements of homology may be obtained via studies of the ontogeny of these structures in turtles. To date, muscle development has been studied in detail only in Chelydra serpentina (Rieppel 1990). However, though Tvarozkova (2006) studied other taxa, she had access to only a few embryos at later stages of development, and although Edgeworth (1935) studied three other turtle species, this was done only superficially.

Several other evolutionary questions remain open. For example, the relation of the $\mathrm{m}$. zygomaticomandibularis in Trionychia to the other adductors and to structures in other turtles, such as the postorbital head of the pars superficialis in chelydrids and chelonioids (Werneburg 2011; Jones et al. 2012), can be an important issue, revealing new synapomorphies that can contribute to the debated interrelationships of cryptodiran clades (Sterli 2010). Also, functional anatomical analyses of this muscle may also contribute to broader questions, since the repeated evolution of comparable structures in other non-related taxa, such as parrots, mammals and in the dinosaur Psittacosaurus (Schulman 1906; Tokita 2004; Taylor et al. 2016), suggests specific functional roles for this muscle unit, perhaps 
related to particular feeding preferences. The trochlear mechanism found in the adductor chamber of turtles is another debated evolutionary question. The employment of functional models (e.g., finite element analyses) to further explore its role during the contraction of the external adductors would be a worth contribution (Chapter 6 of this Thesis), especially considering the different morphotypes found in cryptodires and pleurodires. Their origin is relevant to understand whether or not stem turtles had a trochlear mechanism and, if so, how its anatomy presented. Was it similar to that of cryptodiran taxa only in its position (on the outer surface of the otic chamber) or in other aspects (e.g., bone projections and synovial capsule like the cryptodiran trochlea)? Or, how did the pleurodiran mechanism evolve? Was it independently acquired or derived from a cryptodiran-like mechanism of stem turtles? And if the latter is more likely, did the pleurodiran ancestors possessed an intermediate stage with two trochleas (as hypothesized by Joyce 2007)? Those questions can be approached comparatively from the perspective of developmental data (comparing the ontogeny of those structures in pleurodires and cryptodires), functional and structural anatomy of extant species (comparing the mechanisms in different taxa to see how much variation exists), and paleontology (to evaluate the condition in extinct turtles), i.e., in sum, a 'holistic organism approach' (Maier \& Werneburg 2014).

Finally, the presented approach to reconstruct the jaw musculature in Proganochelys quenstedti, combining 3-D models with ancestral state reconstructions (Werneburg 2013) is an important step toward the understanding of the evolution of jaw muscles in turtles and amniotes in general. This approach has been already used elsewhere with other groups, such as temnospondyls (Lautenschlager et al. 2016; Witzmann \& Werneburg 2017) and sauropterygians (Araújo \& Polcyn 2013; Foffa et al. 2014) to understand the evolution of some morphological structures and the biomechanics of their skulls and should be more applied when considering the questions highlighted above. 


\section{Chapter 3}

\section{Sensory evolution and ecology of early turtles revealed by digital endocranial reconstructions}

A modified version of this chapter is published as:

Lautenschlager, S.*, Ferreira, G.*, \& Werneburg, I. (2018). Sensory evolution and ecology of early turtles revealed by digital endocranial reconstructions. Frontiers in Ecology and Evolution, 6, 7. doi: 10.3389/fevo.2018.00007.

*These authors have contributed equally to this work.

Link to article and online supplementary material (open access):

https://www.frontiersin.org/articles/10.3389/fevo.2018.00007/full 


\title{
3 Sensory evolution and ecology of early turtles revealed by digital endocranial reconstructions
}

\begin{abstract}
In the past few years, new fossil finds and novel methodological approaches have prompted intensive discussions about the phylogenetic affinities of turtles and rekindled the debate on their ecological origin, with very distinct scenarios, such as fossoriality and aquatic habitat occupation, proposed for the earliest stem-turtles. While research has focused largely on the origin of the anapsid skull and unique postcranial anatomy, little is known about the endocranial anatomy of turtles. Here, I provide 3-D digital reconstructions and comparative descriptions of the brain, nasal cavity, neurovascular structures and endosseous labyrinth of Proganochelys quenstedti, one of the earliest stem-turtles, as well as other turtle taxa. The results demonstrate that $P$. quenstedti retained a simple tube-like brain morphology with poorly differentiated regions and mediocre hearing and vision, but a well-developed olfactory sense. Endocast shape analysis indicates that an increase in size and regionalization of the brain took place in the course of turtle evolution, achieving an endocast diversity comparable to other amniote groups. Based on the new evidence presented herein, I further conclude that $P$. quenstedti was a highly terrestrial, but most likely not fossorial, taxon.
\end{abstract}

Keywords: neuroanatomy; sensory adaptation; digital endocast; stem turtles; turtle origin 


\subsection{Introduction}

Turtles (Testudinata sensu Joyce et al. 2004) are a diverse group of reptiles with an unusual 'bauplan' fundamentally different from that of other amniotes. Unique morphological characters, including the anapsid cranial configuration, which lacks temporal fenestrations, and the presence of a bony shell formed by a dorsal carapace and a ventral plastron have long obfuscated the phylogenetic affinities of turtles (Rieppel 2007; Lyson et al. 2010). While most molecular studies have recovered turtles nested within diapsid reptiles and often as a sister-group to Archosauria (birds and crocodiles) (Hedges \& Poling 1999; Wang et al. 2013; Field et al. 2014), most studies based on comparative anatomy have placed turtles outside of Diapsida (Gauthier et al. 1988; Lee 1997; Werneburg \& Sánchez-Villagra 2009; Neenan et al. 2013; Scheyer et al. 2017) or alternatively inside Lepidosauromorpha (deBraga \& Rieppel 1997; Rieppel \& Reisz 1999; Li et al. 2008; Liu et al. 2011). The scant fossil record of stem-turtles (i.e. non-Testudines Testudinata) has further obscured the evolutionary origin of this group. Recent discoveries of new species and reanalysis of existing specimens with novel methodological approaches (e.g. computed tomography and digital visualization) have provided new data to the debate of turtle ancestry (Li et al. 2008; Bever et al. 2015; Schoch \& Sues 2015). These studies found support for the diapsid origin of turtles and produced potential evidence for closure of the temporal fenestrae early in their evolutionary history (Schoch \& Sues 2015; Lyson et al. 2016; Werneburg 2015).

Regarding the environmental origin of the group, although all Triassic turtles were clearly terrestrial (Joyce 2015), data provided by recently described taxa have painted an ambiguous picture regarding the paleoecological setting in which the Testudinata ancestors evolved. While the earliest known potential proto-turtle (i.e. non-Testudinata Pantestudines) Eunotosaurus africanus (ca. $260 \mathrm{Ma}$ ) has been found in terrestrial environments (Lyson et al. 2016), the somewhat younger Pappochelys rosinae (ca. $240 \mathrm{Ma}$ ) and Odontochelys semitestacea (ca. $220 \mathrm{Ma}$ ) were retrieved from lacustrine and deltaic deposits and were considered to have been semi-aquatic (Li et al. 2008; Rieppel 2013; Schoch \& Sues 2015). In the last two taxa, the dorsoventrally flattened, expanded ribs and thickened gastralia have been interpreted as adaptations for buoyancy control in an aquatic environment (Schoch \& Sues 2015). In contrast, the morphology of the ribs, as well as the more rigid body wall, 
powerful forelimbs and triangular skull, have been considered to represent adaptations to fossoriality in E. africanus (Lyson et al. 2016). On the other hand, the type localities of both $P$. rosinae and $O$. semitestacea have also yielded terrestrial taxa (Joyce 2015; Schoch \& Sues 2017) and, in fact, terrestrial diapsid remains are dominant at the type locality of the former (Schoch \& Sues 2015). Additionally, Joyce (2015) argued in favor of Odontochelys semitestacea as a terrestrial proto-turtle, based on its phalangeal formula. Hence, terrestrial, fossorial and semi-aquatic habits have all been suggested for the early stages of turtle evolution, before the origin of the protective shell characteristic of the definitely terrestrial stem-turtles (Joyce \& Gauthier 2004; Scheyer \& Sander 2007; Joyce 2015).

While research on early turtles has focused largely on the acquisition of the anapsid condition and the evolution of the postcranial anatomy employing comparative morphology, histology and genetics, little is known about the endocranial anatomy of stem-turtles (or indeed turtles in general). Using micro-computed tomography ( $\mu \mathrm{CT})$ scanning and digital visualization, I provide here a reconstruction of the endocranial anatomy of Proganochelys quenstedti, one of the earliest testudinates from the Late Triassic of Germany. I further compare the reconstructed brain anatomy with different stem- and crown-turtles (Testudines) and other vertebrate taxa using endocast outline analysis to elucidate related anatomical and ecological aspects of turtle origins.

\subsection{Materials and Methods}

For digital reconstruction of endocranial anatomy (brain, inner ear, neurovascular structures, nasal cavity) two specimens of Proganochelys quenstedti from the Late Triassic of Germany were studied: MB 1910.45.2 (Museum für Naturkunde Berlin) from the Baerecke and Limpricht Quarry, Halberstadt (Jaekel 1918), and SMNS 16980 (Staatliches Museum für Naturkunde Stuttgart) from the Plateosaurus-quarry in Trossingen (Gaffney 1990). Both specimens consist of nearly complete and articulated cranial skeletons. MB 1910.45.2 shows substantial taphonomic artifacts in the form of anteroposterior shearing and some moderate mediolateral crushing and deformation. However, these artifacts only marginally affect the braincase and the digital reconstruction of the various endocranial structures (see Results for more details). 
MB 1910.45.2 was CT scanned at the Leibniz-Institut für Zoo- und Wildtierforschung Berlin/Germany (IZW) using a Toshiba Aquilon ONE medical CT scanner. Scanning parameters were set at $225 \mathrm{kV}$ and $300 \mu \mathrm{A}$ resulting in an image stack of $512 \times 512$ x 213 pixels and a voxel size of $2.0 \mathrm{~mm}$ per slice. The dataset was subsequently 'upsampled' (1024 x 1024 x 426 pixels, $0.5 \mathrm{~mm}$ effective voxel size) by averaging the existing slice data. This process does not increase the actual resolution of the data, but provides more slices available for segmentation permitting clearer identification of features and resulting in smoother surface models.

SMNS 16980 was scanned at the Riedberg Campus of Goethe-Universität Frankfurt/Germany using a Phoenix Nanotom m scanner. Due to its relatively large size, the specimen was scanned in three stages. The resulting image stacks were combined into a single stack with 3583 x 4011 x 5658 pixels and a voxel size of $0.025 \mathrm{~mm}$ per slice. The dataset was subsequently downsampled $(870 \times 954 \times 1161$ pixels, $0.1 \mathrm{~mm}$ voxel size $)$ to permit further processing and segmentation.

Datasets for both specimens were imported into Avizo 8 (Visualisation Science Group) for the segmentation of endocranial structures. Due to poor grayscale attenuation (in particular for SMNS 16980), segmentation was performed manually using the paintbrush and interpolation tools in the Avizo segmentation editor (both reconstructions performed by the first author for consistency following Balanoff et al. 2016). 3-D surface models and volumes were created to visualize the endocranial components. In addition, surface models of the individual structures were downsampled to a degree that allowed for small file sizes but preserved all details, and were exported as separate OBJ-files for the creation of the interactive 3-D figures provided in the supplementary material (see link on the first page of this chapter) as outlined in Lautenschlager (2014b) using Adobe 3D reviewer (Adobe Systems Inc.).

To provide a basis for comparisons, the endocranial anatomy of nine extant turtles and of one additional stem-turtle, Naomichelys speciosa (FMNH PR273), was reconstructed in the manner described above. FMNH PR273 was scanned at the Institut für Naturwissenschaftliche Archäologie at the Universität Tübingen at a resolution of $0.1 \mathrm{~mm}$ resulting in an image stack of 1068 x 1382 x 622 pixels. The following extant species were 
scanned at the Steinmann-Institut für Geologie, Mineralogie \& Paläontologie/Rheinische Friedrich-Wilhelms-Universität Bonn/Germany and at the Museum für Naturkunde Berlin/Germany: Podocnemis unifilis (SMF 55470), Chelodina reimanni (ZMB Herpetologie 49659), Emydura subglobosa (PIMUZ lab\# 2009.37), Pelodiscus sinensis (IW576-2), Chelonia mydas (ZMB 37416 MS), Macrochelys temminckii (TCGT, Teaching collection Geowissenschaften Towisse), Emys orbicularis (WGJ 1987a), Platysternon megacephalum (SMF 69684), Malacochersus tornieri (SMF 58702). Data derived from the reconstructions was further used for a shape analysis of brain morphology.

Due to the absence of unambiguous and consistently identifiable landmarks on the endocast across different amniote taxa, outline shape analysis was performed to quantify morphological differences. Although this approach uses only two-dimensional outlines (in contrast to three-dimensional landmarks), it allows quantification of shape data for geometries lacking homologous landmarks (Haines \& Crampton 2000). For shape analysis, a sagittal cross-section through the surface model of each brain (i.e., digital cast of the endocranial cavity) was produced in Avizo for each reconstruction. Contours of the twodimensional cross-sections were imported into tpsDig2.16 (Rohlf 2010), digitized and saved as $1000 \mathrm{x} / \mathrm{y}$-coordinate pairs. All outline data were subsequently analyzed in PAST 3.17 (Hammer et al. 2001) using fast Fourier transformation (FFT) and principal components analysis (PCA) with the hangle module as outlined in Crampton \& Haines (1996) and Lautenschlager (2014a). Outlines were smoothed ten times to eliminate pixel noise, and 23 Fourier harmonics were found to describe the outlines of all sampled taxa sufficiently (average Fourier power $>99 \%$ ) (see also online supplementary material). In addition to the reconstructed endocasts, further outlines of 52 taxa were collected from the literature (Hopson 1979; Franzosa 2004; Neenan \& Scheyer, 2012; Bona \& Paulina-Carabajal 2013; Carabajal et al. 2013; George \& Holliday 2013; Herrera et al. 2013; Holloway et al. 2013; Laaß et al. 2017; Paulina-Carabajal et al. 2017; von Baczko \& Desojo 2016; Lautenschlager \& Butler 2016; Jirak \& Janacek 2017; Pierce et al. 2017; and Digimorph) for different turtle, archosauromorph, lepidosauromorph and other amniote taxa (for list of taxa see Table S2 on supple). These outlines were redrawn in Adobe Illustrator to ensure sufficient resolution for the digitization process. For PCA, each taxon was assigned to a phylogenetic and an ecological (marine, freshwater, terrestrial, fossorial) group. To test for significant differences 
between those groups, I also conducted a non-parametric MANOVA test (Anderson 2001) using PC scores representing 95\% of total variance transformed into an Euclidean distance matrix, replicated with 10000 permutations and compared using Bonferroni correction for the post-hoc analyses.

\subsection{Results}

\subsubsection{Endocranial anatomy}

The reconstruction of MB 1910.45.2 (Figs. 3.1A-3.1D) provided most details of the endocranial anatomy, but exhibited some moderate medio-lateral deformation. In comparison, the reconstruction of SMNS 16980 (Fig. 3.1E-3.1H) showed no obvious artifacts, but the poor grayscale contrast permitted only a few structures (i.e. brain, pituitary fossa and some cranial nerves) to be visualized. In combination, both specimens allowed for a detailed reconstruction of most endocranial components.

The brain endocast is anteroposteriorly elongate and straight in both specimens, with only moderate cephalic and pontine flexures (Fig. 3.1B, 3.1F). The endocasts are tubular and mediolaterally narrow without prominent expansion or constriction of the fore-, mid- or hindbrain regions. The close similarity of these features in both specimens confirms that this morphology is natural and unlikely to be a result of taphonomic deformation. The olfactory nerve (CN I) contributes approximately a third to half of the full endocast's length, but a clear distinction between the base of the olfactory nerve and the cerebral hemispheres is not visible. The olfactory bulbs are only weakly reproduced by the ventral surfaces of the nasals. Cerebral hemispheres or distinct optic lobes are not visible in either specimen, suggesting that both structures were very small and/or that the venous sinus and the dura mater obscured the underlying morphology. 


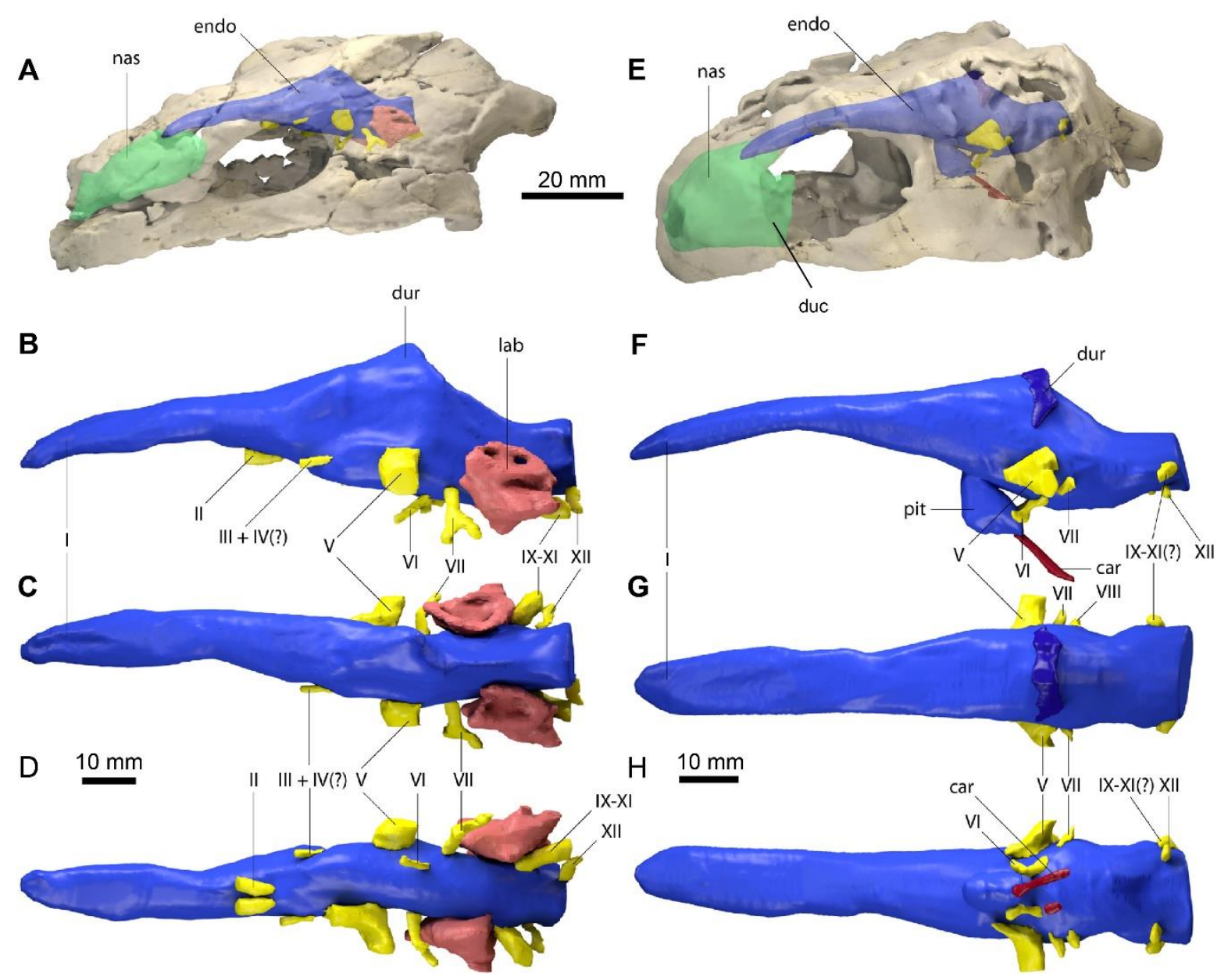

Figure 3.1. Endocranial anatomy of Proganochelys quenstedti specimens (A-D) MB 1910.45.2 and (E-H) SMNS 16980. Endocast and nasal cavity (A, B) in situ in left lateral oblique view with bone rendered semitransparent and isolated endocast in $(\mathbf{B}, \mathbf{F})$ left lateral, $(\mathbf{C}, \mathbf{G})$ dorsal and $(\mathbf{D}, \mathbf{H})$ ventral views. Abbreviations: car, carotid artery; dur, dural peak; endo, brain endocast; lab, endosseous labyrinth; nas, endocast of nasal cavity; pit, pituitary fossa; I, olfactory nerve; II, optic nerve canal; III, oculomotor nerve canal; IV, trochlear nerve canal; V, trigeminal nerve canal; VI, abducens nerve canal; VII, facial nerve canal; IX-XI shared canal for the glossopharyngeal, vagus and spinal accessory nerve; XII, hypoglossal nerve canal.

The midbrain region is confluent with the forebrain and only weakly demarcated. The only distinguishing feature is a dorsal expansion extending above the level of the olfactory nerve. This dural peak or cartilaginous rider (Zangerl 1960; Gaffney \& Zangerl 1968; Paulina-Carabajal et al. 2017) is more prominently developed in MB 1910.45.2 (Fig. 3.1B). In SMNS 16980, the dorsal expansion is shallower and somewhat separated from the main body of the midbrain by a bony margin, suggesting that this structure corresponds to the cartilaginous portion of the supraoccipital, which ends abruptly anteriorly in Proganochelys quenstedti (Gaffney 1990). The pituitary fossa is visible in SMNS 16980 and forms a pendant pocket, projecting ventrally from the main body of the midbrain endocast. 


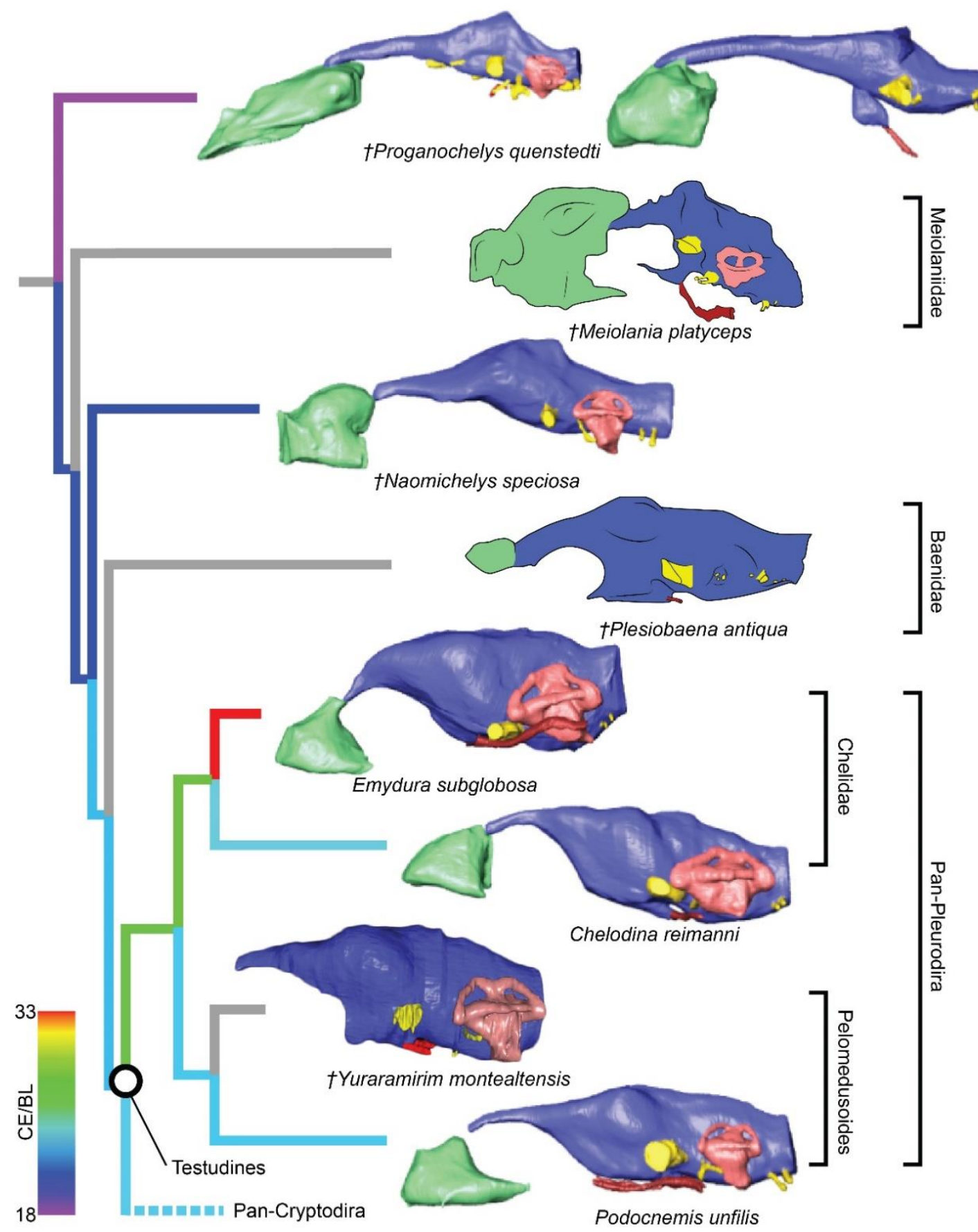

Figure 3.2. Comparative endocranial anatomy of different stem-Testudines and pleurodiran taxa. Original reconstructions and redrawn endocasts (Plesiobaena antiqua from Gaffney 1982; Meiolania platyceps from Paulina-Carabajal et al. 2017; Yuraramirim montealtensis from Ferreira et al. 2018b) in left lateral view. Topology based on Joyce et al. (2016), Guillon et al. (2012) and Ferreira et al. (2018a). Heat mapping on branches based on the ratio (CE/BL) between cubic root of endocast volume and basicranial length (Table 3.1). 


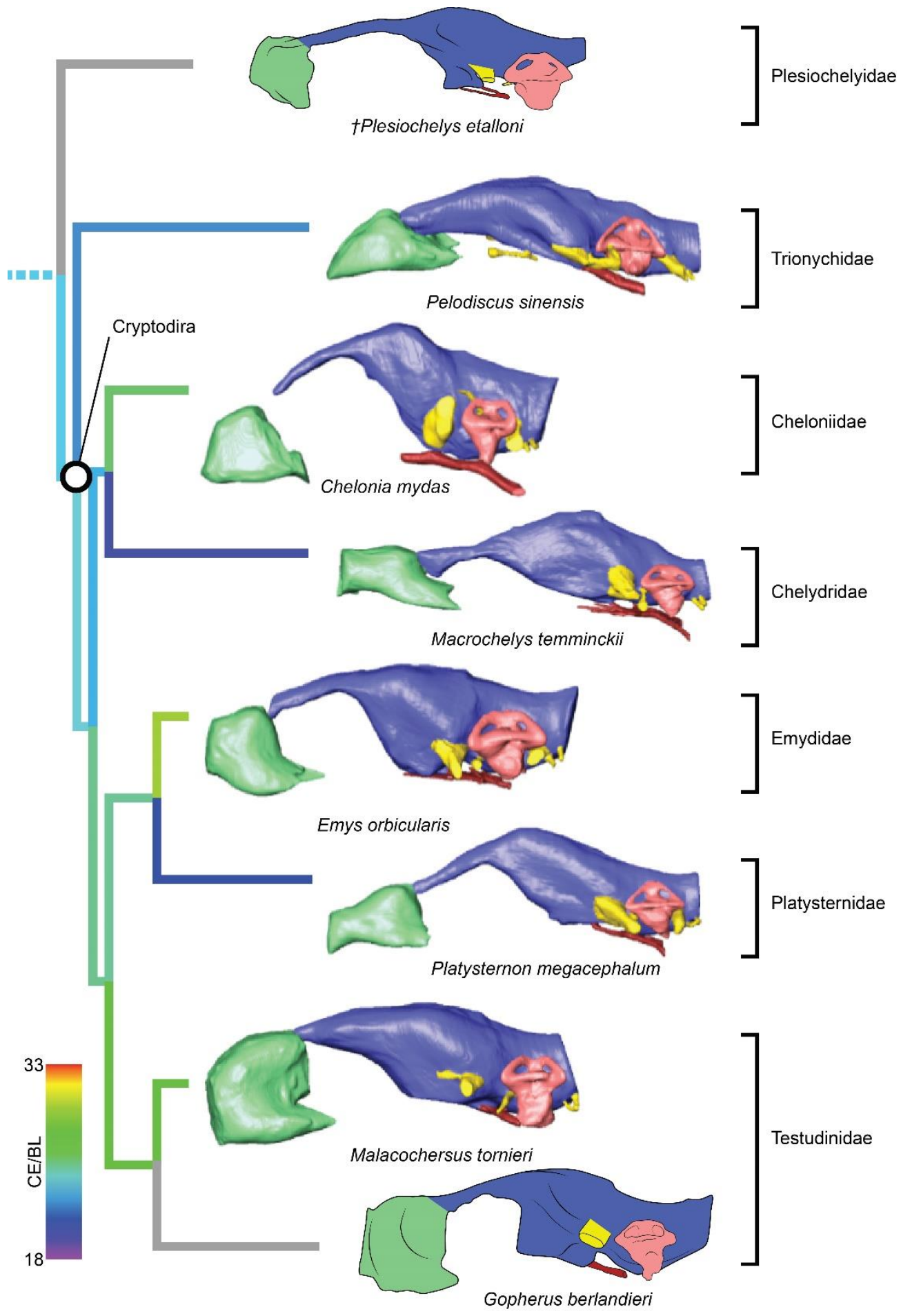

Figure 3.3. Comparative endocranial anatomy of different pan-cryptodiran taxa. Original reconstructions and redrawn endocasts (Plesiochelys etalloni from Carabajal et al. 2013; Gopherus berlandieri from PaulinaCarabajal et al. 2017) in left lateral view. Topology based on Joyce et al. (2016), Guillon et al. (2012). Heat mapping on branches based on the ratio $(\mathbf{C E} / \mathbf{B L})$ between cubic root of endocast volume and basicranial length (Table 3.1). 
The hindbrain region is anteroposteriorly short and not constricted mediolaterally between the endosseous labyrinths. Floccular lobes are not visible. Posteriorly, the hindbrain exits the braincase through the foramen magnum, which is oval and wider than high in SMNS 16980 and slightly higher than wide in MB 1910.45.2. The latter may be the result of the mediolateral compression of this specimen.

The nasal cavity is very enlarged when compared to the other sampled taxa (Figs. 3.2-3.3; Table 3.1). The strong lateral compression of MB 1910.45.2 may be responsible for the seemingly increased volume, and, hence, the reconstruction of the nasal cavity in SMNS 16980 is considered here as more reliable. Usually, three portions of the nasal cavity can be identified in turtles and other reptilians (Parsons 1959, 1970; Halpern 1992; PaulinaCarabajal et al. 2017): the vestibulum nasi, which connects the nasal chamber to the external nares; the ductus nasopharyngeus, connecting the nasal chamber to the choanae; and the cavum nasi proprium, the chamber itself, bounded anteriorly by the vestibulum, posteroventrally by the ductus, and posterodorsally by the olfactory nerve (CN I). The ductus nasopharyngeus can be distinguished from the rest of the nasal cavity in $P$. quenstedti as two ventrolateral projections (Fig. 3.1). A proper duct (at least not bounded by bone) was not expected, since the choanae in $P$. quenstedti are very extensive, and occupy almost the whole ventral surface of the nasal cavity. The vestibulum on the other hand is short, as in most other turtles (Paulina-Carabajal et al. 2017), connected to the large cavum nasi proprium, which constitutes most of the nasal cavity. The cavity as a whole is considerably broad and also high in comparison (Figs. 3.2-3.3) to several other taxa (Carabajal et al. 2013; PaulinaCarabajal et al. 2017).

The endosseous labyrinth is reconstructed only for MB 1910.45.2, as the grayscale attenuation did not allow differentiation of the bony housing in SMNS 16980. It is dorsoventrally compressed and compact. The anterior and posterior semicircular canals are smalland anteroposteriorly longer than high and have low internal radii. The crus communis is also very low in comparison to other taxa (Carabajal et al. 2013; Mautner et al. 2017; Paulina-Carabajal et al. 2017; Ferreira et al. 2018b, Chapter 4 of this thesis) which results in an almost horizontal orientation of the anterior and posterior semicircular canals (Fig. 3.4). The lateral semicircular canal barely extends laterally from the vestibulum. The cochlear duct 
is expanded ventrally, but short. The canal of the fenestra ovalis is clearly visible projecting anterolaterally from the vestibulum.

Table 3.1. Measurements and ratios for sampled taxa. ASC-PSC, angle between anterior and posterior semicircular canals; BL, basicranial length; CE/BL, cubic root of endocast volume/basicranial length; CE/SL, cubic root of endocast volume/skull length; EV, endocast volume; NV, nasal cavity volume; N/E, nasal cavity/endocast volume ratio; OR, olfactory ratio; SL, skull length.

\begin{tabular}{llllllllll} 
Taxon & $\begin{array}{l}\text { SL } \\
{[\mathbf{m m}]}\end{array}$ & $\begin{array}{l}\text { BL } \\
{[\mathbf{m m}]}\end{array}$ & $\begin{array}{l}\mathbf{E V} \\
{\left[\mathbf{m m}^{3}\right]}\end{array}$ & $\begin{array}{l}\mathbf{N V} \\
{\left[\mathbf{m m}^{3}\right]}\end{array}$ & $\begin{array}{l}\text { N/E } \\
\text { CE/SL }\end{array}$ & $\mathbf{C E / B L}$ & $\begin{array}{l}\text { OR } \\
{[\%]}\end{array}$ & $\begin{array}{l}\text { ASC- } \\
\text { PSC }\end{array}$ \\
\hline Proganochelys & 175 & 148.75 & 8170.84 & 12209.34 & 1.49 & 11.51 & 13.54 & 62.5 & $107^{\circ}$ \\
Proganochelys & 97 & 85.36 & 3790.56 & 3709.39 & 0.98 & 16.07 & 18.27 & 57.14 & - \\
Naomichelys & 117 & 103.50 & 9805.97 & 4077.77 & 0.42 & 18.29 & 20.68 & $15-19$ & $79^{\circ}$ \\
Podocnemis & 67 & 51.32 & 1732.45 & 531.57 & 0.31 & 17.93 & 23.40 & 13.39 & $81^{\circ}$ \\
Chelodina & 36 & 36.00 & 760.10 & 140.84 & 0.18 & 25.35 & 25.35 & 11.34 & $98^{\circ}$ \\
Chelonia & 112 & 80.64 & 7077.93 & 2667.23 & 0.38 & 17.14 & 23.81 & 31.65 & $94^{\circ}$ \\
Macrochelys & 120 & 105.88 & 9583.53 & 3568.33 & 0.37 & 17.70 & 20.06 & 38.18 & $88^{\circ}$ \\
Platysternon & 60 & 46.43 & 898.13 & 314.33 & 0.35 & 16.08 & 20.78 & 28.23 & $82^{\circ}$ \\
Malacochersus & 35 & 40.92 & 1364.13 & 669.45 & 0.49 & 31.69 & 27.11 & 16.06 & $86^{\circ}$ \\
Emys & 31 & 30.42 & 668.07 & 118.54 & 0.18 & 28.20 & 28.74 & 17.31 & $102^{\circ}$ \\
Emydura & 35 & 35.00 & 1556.29 & 160.65 & 0.10 & 33.11 & 33.11 & 9.80 & $90^{\circ}$ \\
Pelodiscus & 59 & 39.48 & 707.23 & 444.09 & 0.63 & 15.10 & 22.57 & 20.25 & $79^{\circ}$ \\
\hline
\end{tabular}

The proximal portion of the majority of cranial nerves could be reconstructed for MB 1910.45.2 (Fig. 3.1), whereas only some of the larger nerve canals are visible in SMNS 16980. The optic nerves (CN II) exit the braincase through two large ( $3 \mathrm{~mm}$ in diameter each) foramina anteriorly and ventrally from the cerebral region of the endocast in MB 1910.45.2. Posterior and lateral to $\mathrm{CN}$ II, the oculomotor (CN III) and possibly the trochlear nerve $(\mathrm{CN}$ IV) (Gaffney 1990) originate ventrolaterally. In SMNS 16980, CN II-IV could not be reconstructed. The foramina through which those three cranial nerves (II-IV) exit the braincase are formed by the laterosphenoid (= "pleurosphenoid") (Gaffney 1990; Bhullar \& Bever 2009). This is the second $P$. quenstedti specimen with a preserved laterosphenoid, however the fact that this ossification is severely crushed hampers any further comment on the morphology of this ossification. The trigeminal nerve $(\mathrm{CN} \mathrm{V})$ is large (ca. $6 \mathrm{~mm}$ in diameter) and exits the braincase laterally in both specimens through the prootic foramen. Based on both specimens (as well as other specimens described by Gaffney 1990) we confirm that this foramen is surrounded exclusively by the prootic bone, contrary to Bhullar \& Bever's (2009) interpretation that the laterosphenoid would form its anterior margin. A 
separation of the ophthalmic branch $\left(\mathrm{CN} \mathrm{V}_{1}\right)$ is apparent on the right side in $\mathrm{MB}$ 1910.45.2, but this could be a result of the high degree of distortion of this specimen.

Table 3.2. Summary of the results of the principal component analyses of the brain outlines of different turtle specimens and other groups.

\begin{tabular}{cccc}
\hline PC & Eigenvalue & $\begin{array}{c}\% \\
\text { variance }\end{array}$ & $\begin{array}{c}\% \\
\text { cumulative } \\
\text { variance }\end{array}$ \\
\hline 1 & 0.01042 & 41.4 & 41.4 \\
2 & 0.00464 & 18.5 & 59.9 \\
3 & 0.00298 & 11.8 & 71.7 \\
4 & 0.00174 & 6.9 & 78.7 \\
5 & 0.00137 & 5.5 & 84.1 \\
6 & 0.00093 & 3.7 & 87.8 \\
7 & 0.00067 & 2.6 & 90.5 \\
8 & 0.00042 & 1.7 & 92.1 \\
9 & 0.00032 & 1.3 & 93.4 \\
10 & 0.00028 & 1.1 & 94.5 \\
11 & 0.00021 & 0.8 & 95.4 \\
\hline
\end{tabular}

The abducens nerve (CN VI), clearly visible in both specimens, originates from the ventral surface of the endocast. It pierces the basisphenoid through the foramen nervi abducens and enters laterally the pituitary fossa, which is bottomed by the sella turcica (Gaffney 1990). Posterior to CN V, the facial nerve (CN VII) exits the braincase laterally through the prootic. In MB 1910.45.2, a distal branching of CN VII outside the braincase wall is visible, also on the prootic bone. The vestibulocochlear nerves (CN VIII) could not be reconstructed in either specimen. The foramina for the CN VIII branches are usually very small and may lie on cartilaginous structures (Gaffney 1979), so they are not expected to leave unambiguous traces on fossilized skulls. The glossopharyngeal (CN IX), vagus (CN X) and accessory nerves (CN XI) originate immediately posterior to the endosseous labyrinth and exit the braincase though the anterior jugular foramen in MB 1910.45.2. Although the sutures are not very clear, this foramen is thought to be formed by the exoccipital, basioccipital and opisthotic in P. quenstedti (Gaffney 1990). In SMNS 16980, a large nerve canal originates in a more dorsolateral position (Fig. 3.1). Due to the low resolution, it is unclear whether this canal represents the anterior jugular foramen or parts of the longitudinal sinus, though the latter is more likely. The hypoglossal nerve (CN XII) is transmitted through 
a single foramen on each side of the basioccipital (posterior to the jugular foramen) in both specimens.

Table 3. Results of one-way PERMANOVA test (10000 permutations) with $95 \%$ of variance (PC1-PC11), excluding Proganochelys and Diadectes (for phylogenetic groups only).

\begin{tabular}{|c|c|c|c|}
\hline \multicolumn{4}{|l|}{ Phylogenetic groups } \\
\hline Permutation $\mathrm{N}$ & 10000 & & \\
\hline Total sum of squares (SQ) & 1,901 & & \\
\hline Within-group SQ & 1,599 & & \\
\hline $\mathrm{F}$ & 3,653 & & \\
\hline \multirow[t]{2}{*}{$\mathrm{p}$} & $1.00 \mathrm{E}-01$ & & \\
\hline & Testudinata & Archosauromorpha & Lepidosauromorpha \\
\hline \multicolumn{4}{|l|}{ Testudinata } \\
\hline Archosauromorpha & 0.8423 & & \\
\hline Lepidosauromorpha & 0.003 & 0.0005999 & \\
\hline Synapsida & 0.327 & 0.1056 & 0.4488 \\
\hline \multicolumn{4}{|l|}{ Ecological groups } \\
\hline Permutation $\mathrm{N}$ & 10000 & & \\
\hline Total SQ & 77 & & \\
\hline Within-group SQ & 72 & & \\
\hline $\mathrm{F}$ & 1 & & \\
\hline \multirow[t]{2}{*}{$\mathrm{p}$} & 0.1656 & & \\
\hline & Terrestrial & Aquatic & Marine \\
\hline \multicolumn{4}{|l|}{ Terrestrial } \\
\hline Aquatic & 1 & & \\
\hline Marine & 0.252 & 1 & \\
\hline Fossorial & 0.6485 & 1 & 0.8387 \\
\hline
\end{tabular}

\subsubsection{Endocast outline analysis}

The morphology of the endocast of Proganochelys quenstedti was compared to different turtles and other amniote taxa using shape analysis. The PCA results show that the first three PCs account for $71.7 \%$ (Table 3.2) of the brain endocast outline shape variation (Figs. 3.5-3.6). In no PC plot is there clear separation between either the phylogenetic or the ecological groups considered. However, the PERMANOVA tests supports that Lepidosauromorpha differs significantly from Archosauromorpha $(\mathrm{p}=0.0006)$ and from Testudinata $(\mathrm{p}=0.003)$ although these tests find no significant differences between the ecological groups (Table 3.3). The outgroup Diadectes is recovered consistently in a position 
inside the morphospace occupied by other groups, whereas $P$. quenstedti is displaced from the occupied area in all plots; however, on the PC1 axis, Kawingasaurus is even more displaced in the positive direction (Fig. 3.5-3.6). P. quenstedti is distant from other turtles and the minimum spanning-tree (see Supplementary Material) places it closer to the lepidosauromorphs Placodus and Chalarodon, and to the archosauromorph Pseudopalatus, on the PC1/PC2, PC1/PC3 and PC2/PC3 plots, respectively. With regard to the ecological morphospaces, $P$. quenstedti is similarly found in a position outside all the groups, except on the PC1/PC3 plot, on which it is inside the fossorial morphospace and very close to the terrestrial one (Fig. 3.5).

\subsection{Discussion}

\subsubsection{Ancestral condition for Testudinata}

Even though more taxa have been assigned to the turtle stem-lineage recently ( $\mathrm{Li}$ et al. 2008; Lyson et al. 2010; Schoch \& Sues 2015), Proganochelys quenstedti remains one of the most important stem-turtles, given its phylogenetic position as the earliest shelled turtle with a completely preserved skull (Parsons 1959, 1970; Halpern 1992; Joyce et al. 2016). Its endocast is a relatively simple structure when compared to that of crown-turtles (Carabajal et al. 2013; Mautner et al. 2017; Paulina-Carabajal et al. 2017; Ferreira et al. 2018b, Chapter 4 of this thesis). It has a tube-like shape, with only small pontine and cephalic flexures and poorly differentiated brain regions. As in other amniotes, the portion between the fore- and midbrain is the most voluminous, but this is achieved exclusively by an increase in height, since the endocast is nearly constant in width over its entire length (Fig. 3.1). Another striking feature is the pendant pituitary fossa, which is very common in archosaurs (Witmer et al. 2008; Lautenschlager \& Butler 2016; Araújo et al. 2017; Pierce et al. 2017), but does not occur in extant turtles, in which the dorsum sellae and the sella turcica are aligned, positioning the pituitary fossa approximately at the same level as the posterior portions of the endocast (Figs. 3.2-3.3). Although the pituitary fossa of turtles can also house other smaller structures (e.g. internal carotid and abducens nerve) the size of the pituitary gland should be at least partially responsible for the larger size of the fossa in $P$. quenstedti. A similar condition was found for sauropod and theropod dinosaurs (Witmer et al. 2008), in which 
enlarged pituitary glands have been linked to larger body sizes (Edinger 1942). While $P$. quenstedti reached a carapace length of at least $67 \mathrm{~cm}$ (based on MB 1910.45.2) (Gaffney 1990), it was not one of the largest turtles, being much smaller than some extant turtles (e.g. up to 150-200 cm in Chelonia mydas and Pelochelys cantorii) (Angielczyk et al. 2015) and meiolanids (Gaffney 1996). Turtles included in our sample that are comparable in size to $P$. quenstedti, such as Podocnemis unifilis and Macrochelys temminckii (up to 68 and $66 \mathrm{~cm}$ of carapace length) (Angielczyk et al. 2015), and also Chelonia mydas, do not show a pendant pituitary fossa (Figs. 3.2-3.3). An alternative explanation is that it is not the pituitary fossa that is larger in $P$. quenstedti, but rather the brain that was comparatively smaller. Indeed, in our sample, this taxon has the lowest value for the ratio endocast volume/basicranial length (Table 3.1), supporting the hypothesis that the brain increased in size during turtle evolution.

The brain endocast in turtles does not seem to be consistent with general skull anatomy. Taxa with higher/lower and wider/thinner endocasts do not possess similar skull proportions, which seem more related to the size and shape of the adductor chamber and the associated supraoccipital and squamosal crests (Fig. 3.7). Proportional changes observed in the adductor chamber throughout the turtle lineage rather reflect the distinct volume and size of the external jaw adductor musculature in different taxa (Claude et al. 2004; Foth \& Joyce 2016; Foth et al. 2017; Ferreira \& Werneburg 2019, Chapter 2 of this thesis). Also, the position of the exits of the cranial nerves change only slightly, even with profound changes in the arrangement of related structures such as the eyes and muscles. For example, in $P$. quenstedti the external jaw adductor musculature innervated by the trigeminal nerve $\left(\mathrm{CN} \mathrm{V}_{3}\right)$ is vertically oriented and entirely positioned anteriorly to the quadrate (Ferreira \& Werneburg 2019, Chapter 2 of this Thesis), while in crown-turtles it extends far posteriorly, following the enlargement of the supraoccipital and squamosal crests (Poglayen-Neuwall 1953; Werneburg 2011, 2013). However, the relative position of the exit of CN V remains roughly the same through turtle evolution when compared to the remainder of the endocast and the surrounding bones (Fig. 3.7). Hence, the actual change that occurs when the muscles expand posteriorly involves only growth and reorientation of distal $\mathrm{V}_{3}$-branches and not a repositioning of the trigeminal nerve foramen (Poglayen-Neuwall 1953; Schumacher 1973). 
A

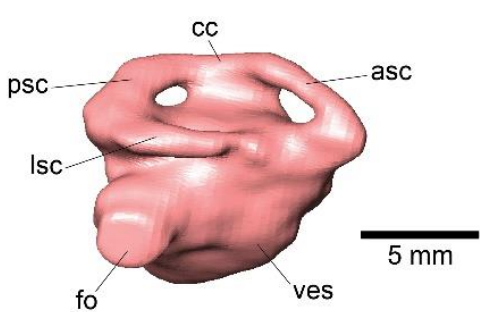

B
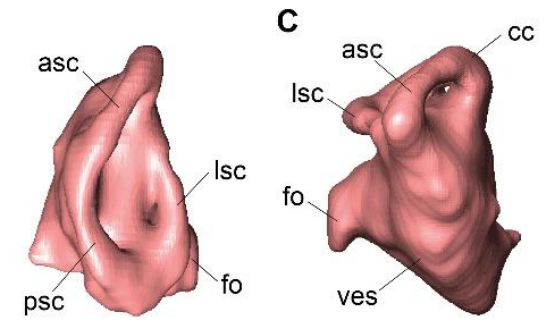

D

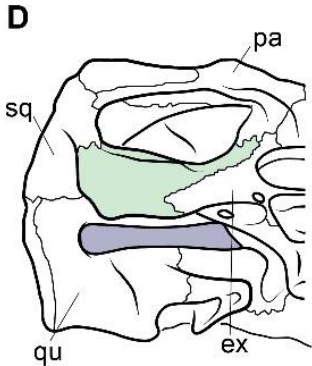

E
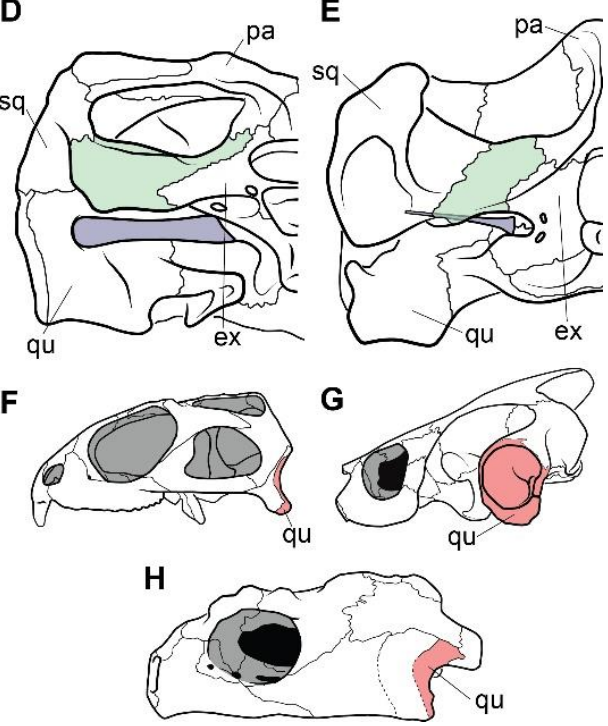

Figure 3.4. Inner ear and otic region anatomy of Proganochelys quenstedti. Digital reconstruction of the right endosseus labyrinth of $P$. quenstedti in (A) right lateral, (B) dorsal, and (C) anterior views. Skulls of (D) $P$. quenstedti and (E) Eubaena cephalica in posterior view, redrawn from Gaffney (1990) with opisthotic and stapes coloured in green and blue, respectively. Skulls of (F) Sphenodon punctatus, (G) Emydura macquarii, and (H) P. quenstedti in lateral view, redrawn from Ferreira \& Werneburg (2019), with quadrate coloured in red. Note the larger proportion of the stapes and its contact with the quadrate bone in $P$. quenstedti, and its slender and tall quadrate, similar to that of $S$. punctatus, and distinct from the round one of other turtles, that completely encloses the tympanic membrane. Abbreviations: asc, anterior semicircular canal; cc, crus communis; ex, exoccipital; fo, fenestra ovalis; lsc, lateral semicircular canal; pa, parietal; psc, posterior semicircular canal; qu, quadrate; sq, squamosal; ves, vestibulum.

\subsubsection{Sensory capabilities of Proganochelys quenstedti}

The endosseous labyrinth of Proganochelys quenstedti is slightly distinct from that of crown-turtles in being more compact and robust, with short and thick semicircular canals and a low crus communis resulting in almost horizontally oriented canals (Fig. 3.4). The 
anterior and posterior semicircular canals (ASC and PSC, respectively) are nearly at the same level as the lateral semicircular canal (LSC), whereas in other turtles the first two run dorsally in relation to the last (Carabajal et al. 2013; Mautner et al. 2017; Paulina-Carabajal et al. 2017; Ferreira et al. 2018b, Chapter 4 of this thesis). The angle between the ASC and LSC is also very wide (Table 3.1), with similar values to meiolaniids and tortoises (PaulinaCarabajal et al. 2017). This combination of features suggests that the semicircular canals of $P$. quenstedti were not very sensitive during movements within the sagittal (head moving up and down) and coronal planes (head tilt) (Brichta et al. 1988; Spoor et al. 2007; David et al. 2010). Instead, the LSC was likely more effective in stabilizing gaze during yaw movements (head moving left and right). Thus, the labyrinth anatomy of $P$. quenstedti indicates this species was slow and non-agile (Spoor et al. 2007; David et al. 2010), compatible with a highly terrestrial and possibly fossorial lifestyle. This is also tentatively indicated by its position in morphospace outside of, but close to, terrestrial and fossorial groupings in the shape analysis (Fig. 3.6).

Although $P$. quenstedti cervical vertebrae were capable of a certain level of mobility (Werneburg et al. 2015a), its short neck coupled with the relatively low carapace, strong osteoderms on the dorsal neck surface and cervical ribs (Gaffney 1990) imply restricted mobility along the same planes (sagittal and coronal) (Werneburg et al. 2015a, 2015b) indicated by its labyrinth morphology. Crown turtles, however, evolved longer necks and several taxa are capable of complex and, sometimes, very fast neck and head movements (Poglayen-Neuwall 1953; Herrel et al. 2008; Werneburg et al. 2015a, 2015b). This could be related to the apparent increase in size of the semicircular canals in crown turtles (Spoor 2003; Spoor et al. 2007) when compared to those of P. quenstedti (although when compared to more agile reptiles, all turtles possess short canals; Witmer et al. 2008). 
Patterns of morphological evolution in the skull of turtles - Chapter 3
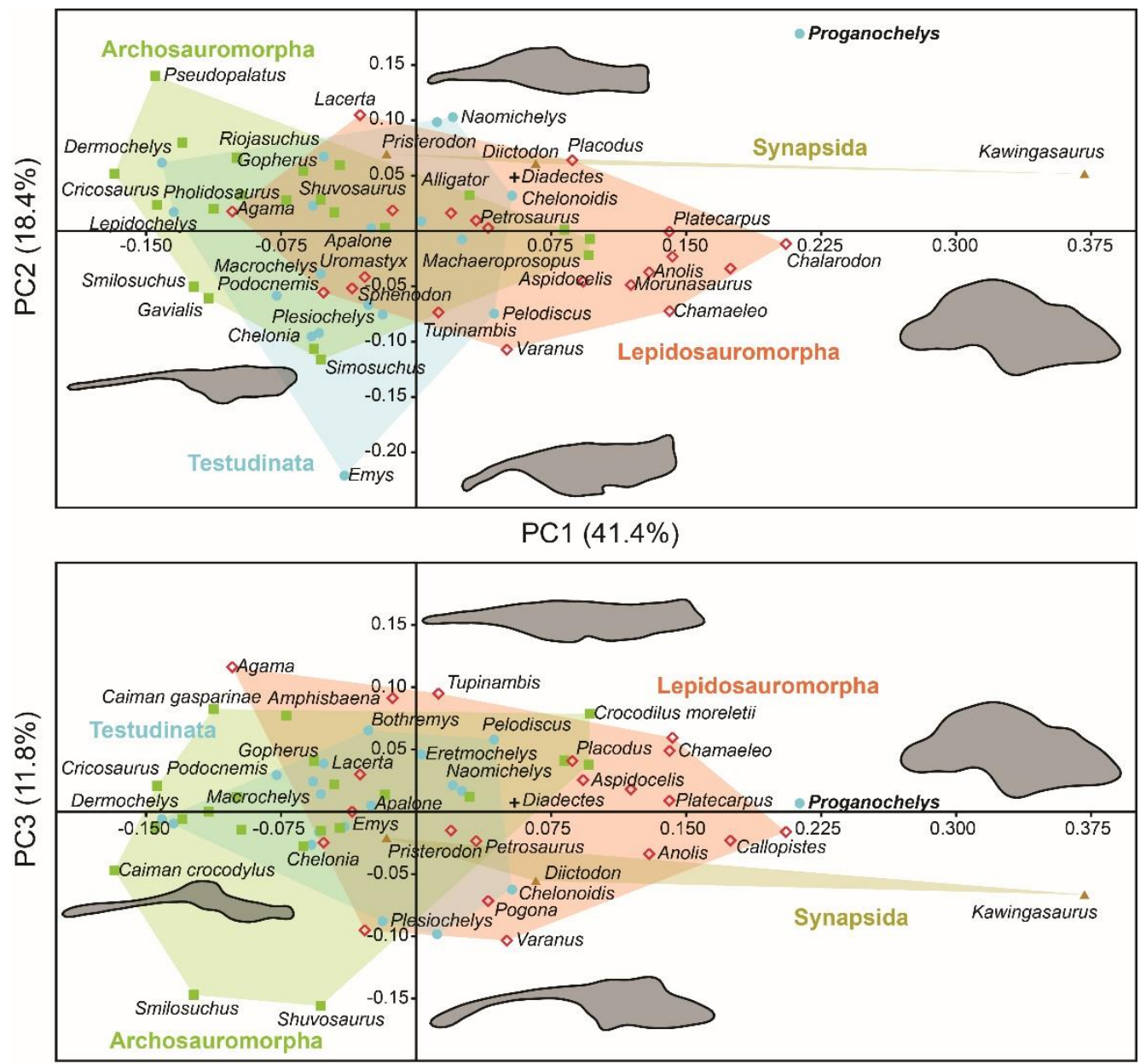

PC1 $(41.4 \%)$

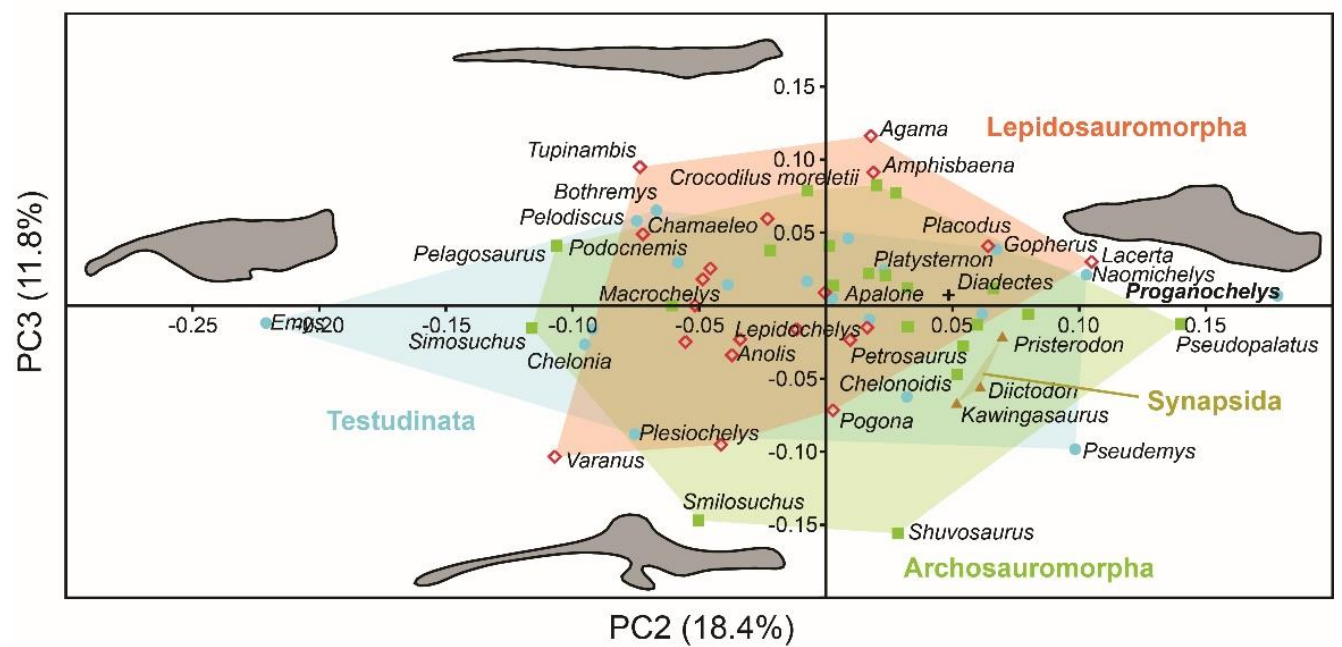

Figure 3.5. Two dimensional morphospace plots of brain endocast outlines based on the first three PC axes using a priori defined phylogenetic groups. Diadectes is shown as a black cross, Proganochelys quenstedti (SMNS 16980) in bold. The symbols are used to identify the clade to which a point was assigned. Different vertebrate groups are indicated by convex hulls. 

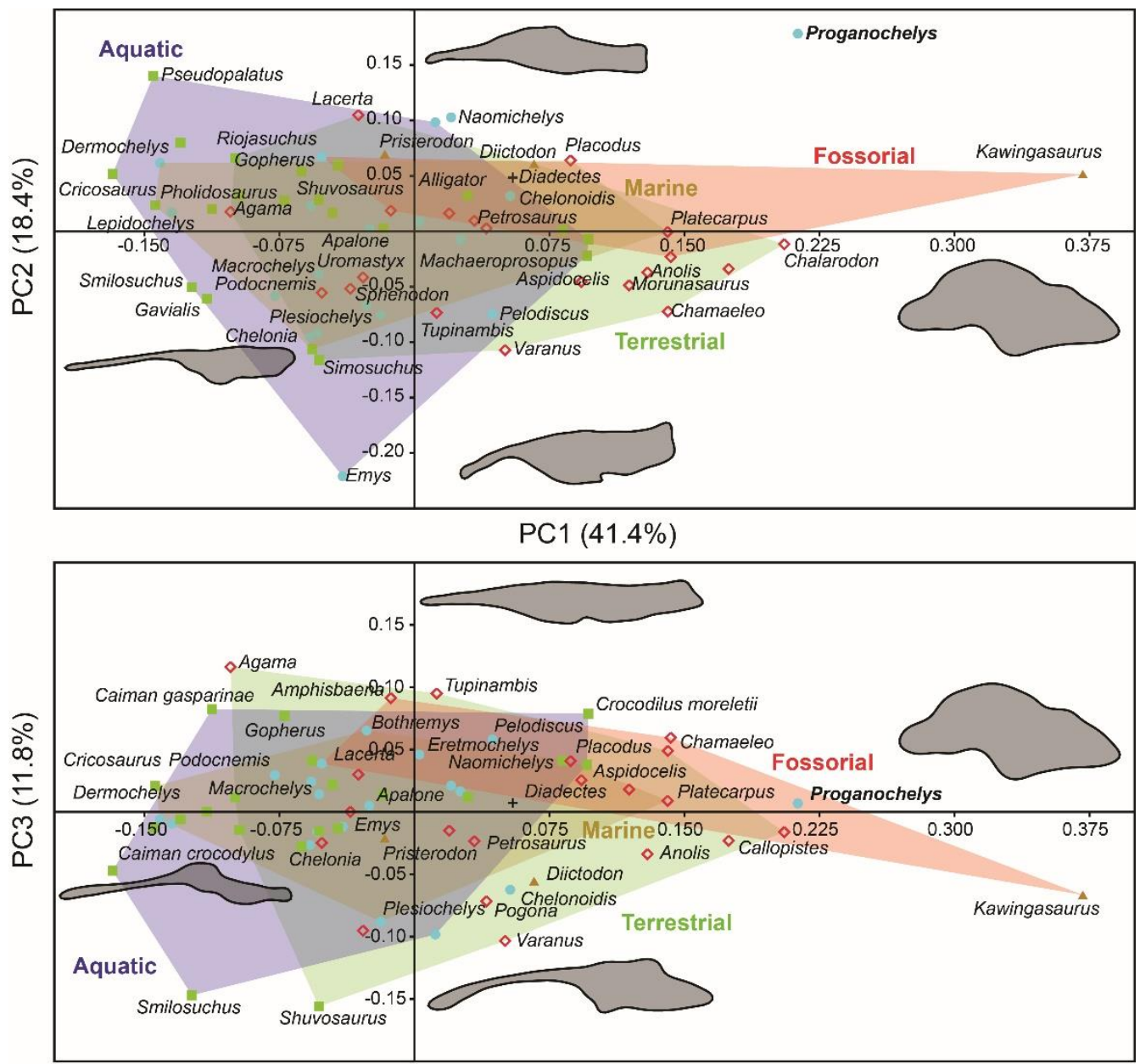

PC1 (41.4\%)

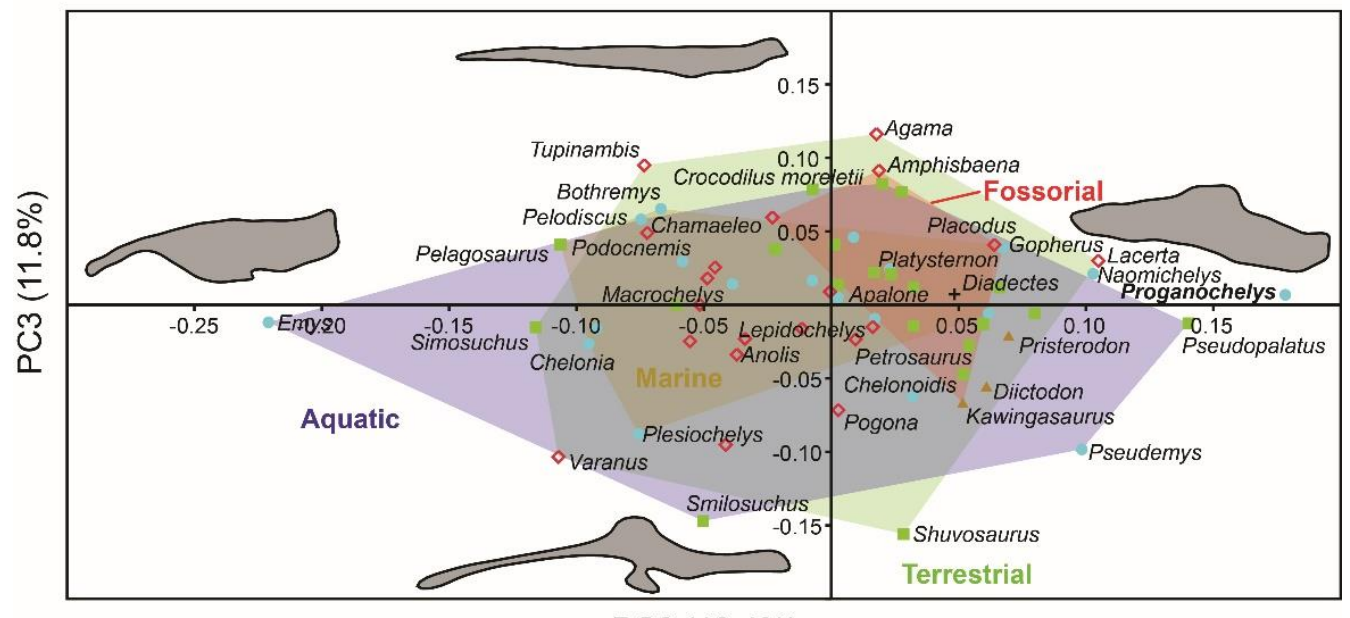

PC2 (18.4\%)

Figure 3.6. Two dimensional morphospace plots of brain endocast outlines based on the first three PC axes using a priori defined ecological groups. Diadectes is shown as a black cross, Proganochelys quenstedti (SMNS 16980 ) in bold. The symbols are used to identify the clade to which a point was assigned. Different vertebrate groups are indicated by convex hulls. 
Hearing was likely not well-developed in P. quenstedti, given the small overall size of the endosseous cochlear duct (Walsh et al. 2009) in comparison to other turtles. Even though its quadrate does not form the characteristic lateral round structure that encloses the cavum tympani in crown-turtles (Figs. $3.4 \mathrm{~F}-\mathrm{H}$ ), it possibly had a tympanic ear similar to those of extant squamates and cheloniids, in which the tympanum is supported by both bone and connective tissue (Henson 1974; Gaffney 1990). However, the stapes of P. quenstedti was much stouter than that of crown-turtles (Figures 3.4D-E), and possibly articulated with the quadrate (Gaffney 1990), suggesting that it was not as effective as the thin vibratory element characteristic of extant amniotes with tympanic hearing, including modern turtles (Baird 1970; Clack 1997). As proposed by Clack (1997) for diapsids, elongation of the paraoccipital process of the opisthotic and its tight suturing to the squamosal, which occurred in the group including all testudinates but Proganochelys quenstedti (Sterli et al. 2010), may have completely released the stapes from its ancestral structural function (connecting the quadrate to other elements of the braincase) during turtle evolution.

The nasal cavity of $P$. quenstedti represents at least $42.2 \%$ of the total endocast volume (Table 3.1), fitting in the volume spectrum of terrestrial turtle taxa, which ranges from 29-43\% in tortoises and 58.5-64\% in meiolaniids (Carabajal et al. 2013). Larger nasal cavities have been related to occupation of arid environments, thermoregulation, soundproduction or higher olfactory capabilities (Parsons 1959, 1970; Paulina-Carabajal et al. 2017). In P. quenstedti, the cavum nasi proprium represents most of the volume of the nasal cavity and extends far dorsally and posteriorly. Within the nasal cavity, sensory epithelium occurs only on the cavum walls (Parsons 1970), and, as such, the cavum's relative size could be used as a proxy for inferences about olfactory capability in extinct reptiles. This connection, however, should be interpreted cautiously, due to the possible relation between cavum size and other functions, such as thermoregulation or vocalization (Bourke et al. 2014; Paulina-Carabajal et al. 2017).

The size and volume of the olfactory bulbs have been shown to be related to a greater reliance on the olfactory sense in mammals and birds (Bang 1971; Bang \& Wenzel 1985; Healy \& Guilford 1990; Gittleman 1991). In a series of studies, the olfactory ratio (ratio between olfactory bulb and cerebral hemisphere maximum diameters; OR values) were used 
as a proxy to study olfactory acuity and capacity in theropod dinosaurs (including birds) and crocodilians (Zelenitsky et al. 2009, 2011). More recently this has also been applied to turtles (Paulina-Carabajal et al. 2017), showing that tortoises and meiolaniids (both terrestrial taxa) have the highest OR values (36-62\% and 20-45\%, respectively). Even though OR may not be an exact measure of olfactory acuity it is currently the best available proxy and its use for a variety of reptilian taxa (Zelenitsky et al. 2009, 2011; Paulina-Carabajal et al. 2017) makes it a useful comparative metric. Here, the OR is shown to be even higher in P. quenstedti, between $57-62 \%$ (Table 3.1), but in this case, these values may be also related to the lessdeveloped cerebral hemispheres rather than to larger olfactory bulbs. Nevertheless, the large nasal cavity in association with the high OR values supports the presented hypothesis that olfaction was possibly the most developed sense in $P$. quenstedti.

\subsubsection{Evolution of the turtle brain endocast}

In the shape analysis, Proganochelys quenstedti is not contained in the morphospace occupied by any of the considered phylogenetic groups (Fig. 3.5). There is extensive overlap in the PCA plots, but, at the same time, the PERMANOVA test shows a separation between Lepidosauromorpha, Testudinata and Archosauromorpha (Table 3.3). These results suggest that all amniotes (excluding dinosaurs and mammals) share a similar plesiomorphic brain endocast morphology, but that those lineages evolved in different directions in the morphospace.

Comparing general ecological groups (freshwater, marine, terrestrial and fossorial) provided similar results, with extensive overlap among the occupied morphospaces (Fig. 3.6). P. quenstedti is contained in the morphospace occupied by the fossorial group on the PC1/PC3 plot, but it falls outside every group on the other plots. Additionally, the statistical tests do not support significant differences between any of the considered groups (Table 3.3). On the other hand, the minimum spanning trees (see Supplementary Material) show that even when inside the fossorial morphospace P. quenstedti is closest to Placodus, a marine lepidosauromorph, and Pseudopalatus, an aquatic archosauromorph. A phylogenetic proximity to Sauropterygia (the lepidosauromorph lineage that includes Placodus) has been proposed previously (deBraga \& Rieppel 1997) and is associated with the hypothesis that turtles originated in marine environments (Joyce \& Gauthier 2004; Joyce 2015). The 
proximity of P. quenstedti and Placodus in our PC1/PC2 plot (Fig. 3.6) may recall this hypothesis, but the poor sampling of sauropterygians together with the extensive overlap between all groups (phylogenetic and ecological) suggests this might not be a robust interpretation.
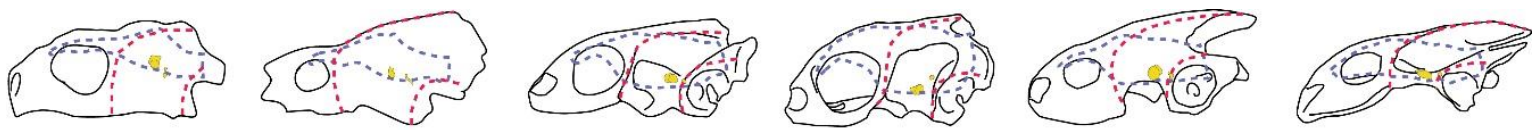

tProganochelys
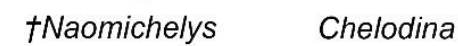

Emydura

Podocnemis

Pelodiscus
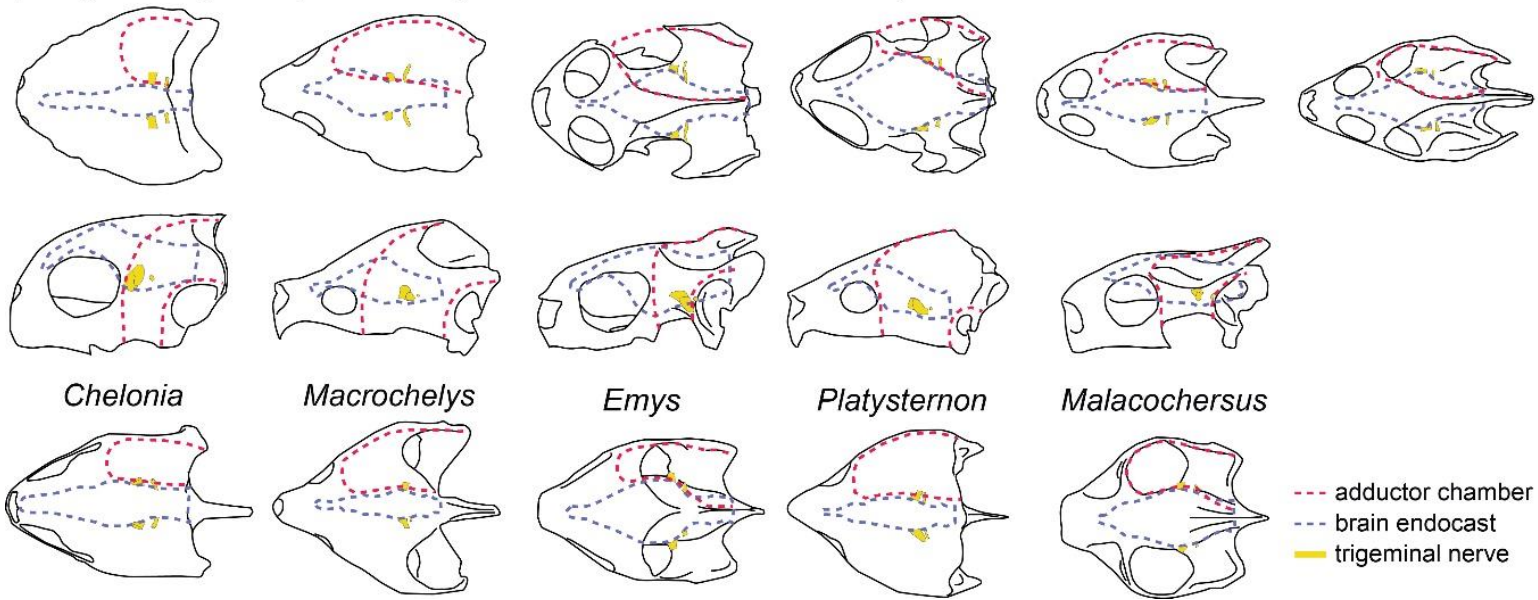

Figure 3.7. Overall skull shape and proportional relation to cranial structures in different turtle taxa. Brain endocast and adductor chamber plotted in left lateral (first and third rows) and dorsal (second and fourth rows) views. Note the similar position of the trigeminal nerve exit regardless of the changes in surrounding structures.

The shape analysis presented here is the first attempt to explore the evolution of neuroanatomy in amniotes with a quantitative approach. Even though the results do not support inferences about lifestyles from neuroanatomical data, the significant separation between some of the considered phylogenetic groups (Fig. 3.5, Table 3.3) seems promising. There are some caveats in the sample used in this study (e.g. few marine reptiles, synapsids and early amniotes) that can be easily overcome with the increasing use of computer tomography in paleontological and anatomical studies. The approach using sagittal crosssection outlines could have also influenced the results, since there is a loss of information when the 3-D endocast is simplified to a 2-D outline.

More recently, Lyson et al. (2016) thoroughly analyzed the morphology of Eunotosaurus africanus, identifying some osteological correlates that led them to conclude that it was likely well-adapted for fossoriality. The authors also identified some of those correlates (e.g. large claws) in other proto- (e.g. Odontochelys semitestacea) and stem-turtles 
(Proganochelys quenstendti and Palaeochersis talampayensis), concluding that "fossoriality played an important role in the early evolution of turtles" (Lyson et al. 2016). Although in the PC1/PC3 plot (Fig. 3.6) P. quenstedti is contained in the fossorial morphospace, the minimum spanning tree (see online supplementary material) shows it to be closest to the terrestrial non-fossorial taxon Chalarodon and the statistical analyses do not support any significant differences between the considered groups (Table 3.3). While the shape analyses do not shed light on this problem conclusively, other sources of data are more convincing. Proganochelys quenstedti fossils were found in continental deposits (Gaffney 1990) and analyses of forelimb proportions (Joyce \& Gauthier 2004) and paleohistology (Scheyer \& Sander 2007) support it as a terrestrial turtle. The morphology of its endosseous labyrinth with short semicircular canals oriented at high angles to each other and the large cavum nasi proprium (Parsons 1970; David et al. 2010; Paulina-Carabajal et al. 2017) agree with these previous studies, strongly supporting the interpretation that $P$. quenstedti was a well-adapted terrestrial turtle. However, since its vestibule is not particularly large, in contrast to the condition of truly fossorial taxa (Yi \& Norell 2015) or of the semi-fossorial tortoise Gopherus (Paulina-Carabajal et al. 2017), the present data suggest it was likely not a fossorial taxon. In $P$. quenstedti, the relatively enlarged vestibule in comparison to the other turtles in this study results from the relatively small semicircular canals. Thus, even if fossoriality had an important role during the early evolution of shell components (Lyson et al. 2016), the present data suggests the complete turtle shell first appeared in a terrestrial taxon, with no evident link to fossoriality (at the Testudinata node).

If we assume that the relatively simple morphology of $P$. quenstedti closely resembles that of the testudinate ancestors, some trends can be inferred for the evolution of endocranial structures in turtles. An increase in overall encephalization, for example, with longer and more voluminous endocasts in relation to skull length is found already in the stem-turtle Naomichelys speciosa and continues in crown-turtles (Figs 3.2-3.3). Some regions became more pronounced as well. In N. speciosa, meiolaniids (Paulina-Carabajal et al. 2017), Plesiochelys etalloni (Carabajal et al. 2013) and all other crown-turtles (Mautner et al. 2017; Ferreira et al. 2018b, Chapter 4 of this thesis) the cerebral hemispheres are clearly distinguishable from the remainder of the endocast and are wider in relation to skull and endocast length than in P. quenstedti (Figs. 3.2-3.3). The olfactory bulb can also be seen in 
the endocasts of some taxa, e.g., Testudo graeca and Plesiochelys etalloni (Carabajal et al. 2013; Paulina-Carabajal et al. 2017). However, this does not seem to be a general trend but rather one of the features that show noteworthy variations among crown-turtles, as are the degree of development of the cephalic and pontine inflexions and the sizes of the nasal cavity and the orbits. Considering that the brain of $P$. quenstedti was a simple tube-like structure with poorly differentiated regions, an increase in size and in regionalization of the brain took place later during the course of turtle evolution, similarly (although in a much lesser degree) to the trend observed during bird evolution (Balanoff et al. 2013), and achieved an endocast diversity comparable to other groups of amniotes, such as lepidosaurs and archosaurs (excluding dinosaurs; Figs. 3.5-3.6). Indeed, extant turtles possess high brain weights in relation to body weight, comparable to that of crocodiles (Gürtürkün et al. 2016), but that was not the ancestral condition of the group based on our analyses. Given the recurrent results of phylogenetic analyses suggesting that turtles have parareptilian affinity (e.g. Laurin \& Piñeiro 2017), it is important to sample the endocast diversity in that clade and explore the similarities between turtles and all other reptilian lineages. The simpler brain structure together with the large nasal cavity and nearly horizontal and short semicircular canals of the inner ear supports a picture of $P$. quenstedti as a terrestrial but most likely not fossorial turtle, with likely mediocre hearing and vision, but a well-developed olfactory sense. 


\section{Chapter 4}

Cranial osteology, phylogenetic position and neuroanatomy of a new Cretaceous pleurodire turtle: Yuraramirim montealtensis

A modified version of this chapter is published as:

Ferreira, G., Iori, F. V., Hermanson, G., \& Langer, M. C. (2018). New turtle remains from the Late Cretaceous of Monte Alto-SP, Brazil, including cranial osteology, neuroanatomy and phylogenetic position of a new taxon. Paläontologische Zeitschrift, 92(3), 481-498. doi: 10.1007/s12542-017-0397-x.

Link to article and online supplementary files: https://doi.org/10.1007/s12542-017-0397-x 


\title{
4 Cranial osteology, phylogenetic position and neuroanatomy of a new Cretaceous pleurodire turtle: Yuraramirim montealtensis
}

\begin{abstract}
A high diversity of land vertebrates is known from the Late Cretaceous deposits of the Bauru Basin, Brazil, including at least five turtle taxa, all belonging to the clade Podocnemidoidae. Some of the richest fossil sites of this basin are in the area of Monte Alto-SP, which yielded several squamate, dinosaur, and crocodyliform taxa. Yet, the single turtle reported so far from this area was only briefly described. Here, I describe another specimen, a partial skull, found in outcrops of the Adamantina Formation. The comparative description of the skull and its inclusion in a phylogenetic study, supports the proposal of a new taxon, Yuraramirim montealtensis, representing a lineage (Peiropemydidae) so far known only from the Marília Formation of the Bauru Basin and the early Paleocene of Bolivia. The digitally reconstructed endocast and inner ear of the new taxon were also described, as not previously done for a fossil pleurodire, and provides data that can be used for larger scale sutides of neuroanatomical evolution of turtles.
\end{abstract}

Keywords: Podocnemidoidae; inner ear; neuroanatomy; carotid circulation; digital reconstruction 


\subsection{Introduction}

The Late Cretaceous deposits of the Bauru Basin have yielded a high diversity of land vertebrates, including anurans, lizards, crocodylomorphs, non-avian and avian dinosaurs, and mammals (e.g. Bertini et al. 1993; Alvarenga \& Nava 2005; Brito et al. 2006; Bittencourt \& Langer 2011; Martinelli \& Nava 2011; Báez et al. 2012). The record of freshwater turtles is also rich, including five valid taxa, namely Bauruemys elegans (Suárez 1969), Cambaremys langertoni França \& Langer 2005, Peiropemys mezzalirai Gaffney et al. 2011, Pricemys caiera Gaffney et al. 2011, and Roxochelys wanderleyi Price 1953, two dubious taxa, "Podocnemis" harrisi Pacheco 1913, and "Podocnemis" brasiliensis Staesche 1937, and more fragmentary records that may represent additional taxa (e.g. Gaffney et al. 2011; Kischlat 2015; Menegazzo et al. 2015; Hermanson et al. 2016; but see Romano et al. 2013 for other taxonomic interpretations). All Bauru group turtles belong to the stem-based clade Podocnemidoidae (França \& Langer 2006; Podocnemididae of Gaffney et al. 2011), a sidenecked turtle lineage that includes the crown-group Podocnemididae and its sister-clade Peiropemydidae (see Phylogenetic Definition and Comments below).

Deposits of the Adamantina and Marília formations crop out extensively in the area of Monte Alto, São Paulo, Brazil, and their study has been chief to improve the knowledge of the vertebrate fauna of the Bauru Basin. The fossil record in the region includes notosuchian (Pinheiro et al. 2008; Andrade \& Bertini 2008; Iori \& Carvalho 2009, 2011), peirosaurid (Carvalho et al. 2007), and trematochampsid crododyliforms (Iori \& Garcia 2012), titanosaur (Bertini et al. 2001; Santucci \& Arruda-Campos 2011) and theropod dinosaurs (Mendez et al. 2014; Tavares et al. 2014), as well as squamates (Fachini \& Iori 2009; Fachini \& Hsiou 2011). A single turtle specimen from the area, assigned to Pleurodira, has been briefly reported in a conference abstract (Iori \& Carvalho 2010) and was recently fully described (Ferreira et al. 2018b).

Here, I present an additional turtle specimen from the Late Cretaceous deposits of Monte Alto, an almost complete skull, that represents a new podocnemidoid taxon, Yuraramirim montealtensis (Ferreira et al. 2018b). Its osteology and neuroanatomy are described here and the taxon is included in a phylogenetic analysis. 


\subsection{Geological Settings and material}

The Bauru Basin (Fig. 4.1) is a large depression developed during the Cretaceous in the southeastern portion of the South American Plate (Fernandes \& Coimbra 1996). The filling-up of this basin occurred under semi-arid to arid climatic conditions, between the Aptian and the Maastrichtian (Batezelli 2015). Two of its lithostratigraphic units crop out in the area of Monte Alto-SP, the Adamantina and Marília formations. Although the stratigraphy and age of the Bauru Basin units are controversial, there is a broad consensus that the Adamantina Fm. is older than the Marília Fm. (for a recent review on the issue, see Menegazzo et al. 2016).

The specimen described here was collected from a sites in the area of Monte Alto that yield the sandy fluvial/lacustrine deposits of the Adamantina Formation (Fernandes \& Coimbra 1994, 1996; Dias-Brito et al. 2001; Batezelli et al. 2003, 2005). MPMA 04-0008/89 comes from the "Barreiro" site, along road SP-333, at the entrance to "Sítio da Serra", typelocality of the crocodyliform Barreirosuchus franciscoi (Iori \& Garcia 2012). This site exposes an approximately $50 \mathrm{~m}$ thick sequence, composed mostly of the Adamantina Formation topped by the Marilia Formation. The specimen described herein, along with bivalve, fish, crocodyliform, and sauropod dinosaur remains were recovered from the basal bed (Iori \& Garcia 2012), mostly composed of lightly cemented fine reddish sandstones, with sparse carbonate nodules. In the same bed, disarticulated post-cranial remains of at least three other turtles were also found (MPMA 04-0009/89, MPMA 04-0014/89 and MPMA 040017/89). The turtle skeletons disarticulated during the biostratinomic phase, but remained concentrated in the same area. 


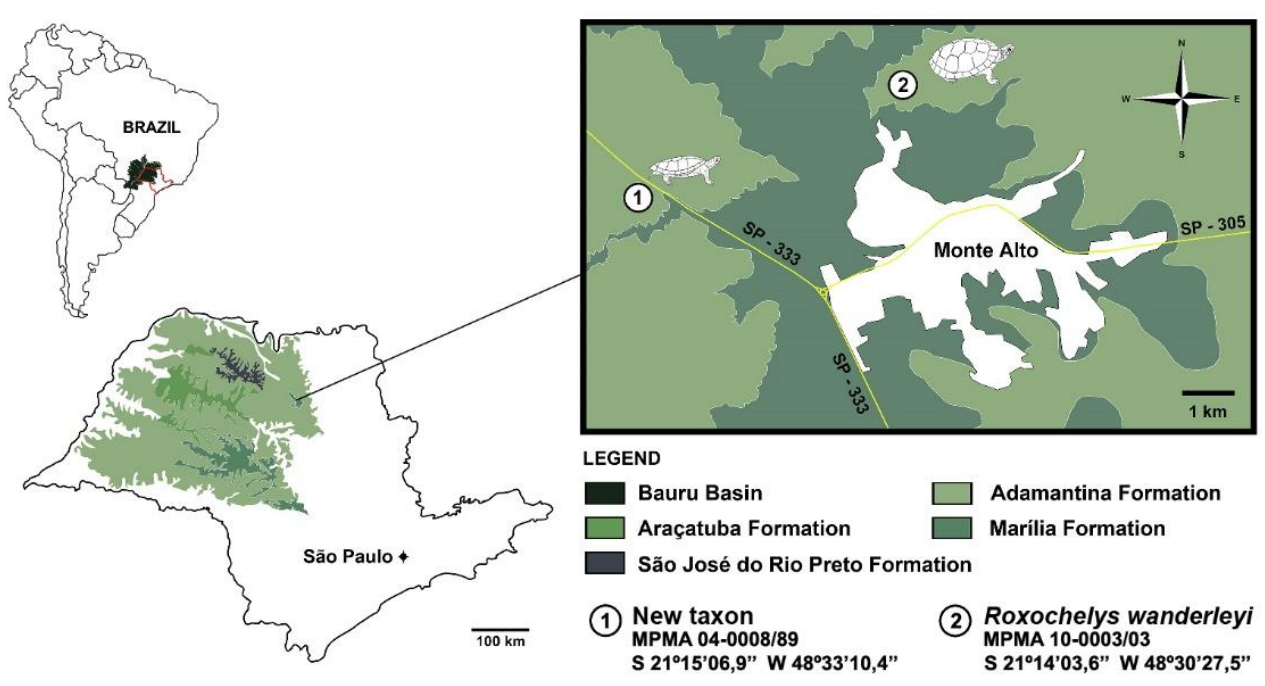

Figure 4.1. Location of the Bauru Basin on a South American map (top left), São Paulo state map showing the surface distribution of the stratigraphic units of the basin (bottom left), and map of the Monte Alto region highlighting the localities where the described fossil was found together with the other specimen described in Ferreira et al. (2018b).

\subsection{Methods}

A phylogenetic data-matrix with 39 taxa and 95 characters (see Nexus file on the online supplementary material link on the first page of this chapter) was compiled using the original matrix of Gaffney et al. (2011), with the addition of MPMA 04-0008/89, Bairdemys thalassica (Ferreira et al. 2015), and 21 characters from other sources (see online supplementary material; Gaffney et al. 2006; Meylan et al. 2009; Cadena et al. 2012; Dumont Junior 2013; Cadena 2015; Ferreira et al. 2015). As MPMA 04-0008/89 is clearly a representative of the Podocnemidoidae, based on the presence of the processus trochlearis pterygoidei and cavum pterygoidei, I used this data-matrix that focuses on this lineage, instead of more inclusive ones (e.g. Gaffney et al. 2006; Cadena 2015). The matrix was analyzed in TNT v. 1.5 (Goloboff et al. 2008), with Chelidae set as the primary outgroup and parsimony as the search criterion ("traditional search" with 1.000 replicates, hold 20, random seed $=0$, collapse of zero length branches). Functions implemented in TNT were employed to summarize the most parsimonious trees (MPTs) in strict consensus, as well as to calculate Bremer support and Bootstrap (GC, 1000 replicates; Goloboff et al. 2003) values. 
Micro CT-scan images were obtained using a SkyScan 1176 at Faculdade de Odontologia de Araraquara (FOAr-UNESP), with 721 projections over $360^{\circ}$, exposure time of $540 \mathrm{~ms}$, voltage of $90 \mathrm{kV}$, current of $275 \mu \mathrm{A}$, and a resolution of $17 \mu \mathrm{m}$ per pixel. NRecon v. 1.6.9.8 and DataViewer v. 1.5.0 were used to process the cross-sectional images. Materialise Mimics Research edition version 18.0 was used for digital reconstructions and measurements of the skull bones and endocasts of the brain and inner ear.

\subsubsection{Institutional Abbreviations}

AMNH, American Museum of Natural History, New York, USA; CPPLIP, Centro de Pesquisas Paleontológicas "Llewellyn Ivor Price", Peirópolis, Uberaba, Brazil; MCT (DGM), Museu de Ciências da Terra, Divisão de Geologia e Mineralogia, Departamento Nacional de Produção Mineral, Rio de Janeiro, Brazil; MCZ, Museum of Comparative Zoology, Harvard University, Cambridge, Massachusetts, USA; MN, Museu Nacional, Universidade Federal do Rio de Janeiro, Brazil; MPMA, Museu de Paleontologia "Prof. Antonio Celso de Arruda Campos”, Monte Alto, Brazil; LPRP/USP, Laboratório de Paleontologia de Ribeirão Preto, University of São Paulo, Ribeirão Preto, Brazil.

\subsection{Systematic Paleontology}

Pleurodira Cope 1864

Pelomedusoides Broin 1988

Peiropemydidae nomen translatum ex Peiropemydodda Gaffney, Meylan, Wood, Simons \& Campos 2011

\subsubsection{Phylogenetic Definition}

Peiropemydidae refers to the branch-based clade that includes all taxa more closely related to Peiropemys mezzalirai Gaffney et al. 2011, and Lapparentemys vilavilensis (Broin 1971) than to Podocnemis expansa (Schweigger 1812). 

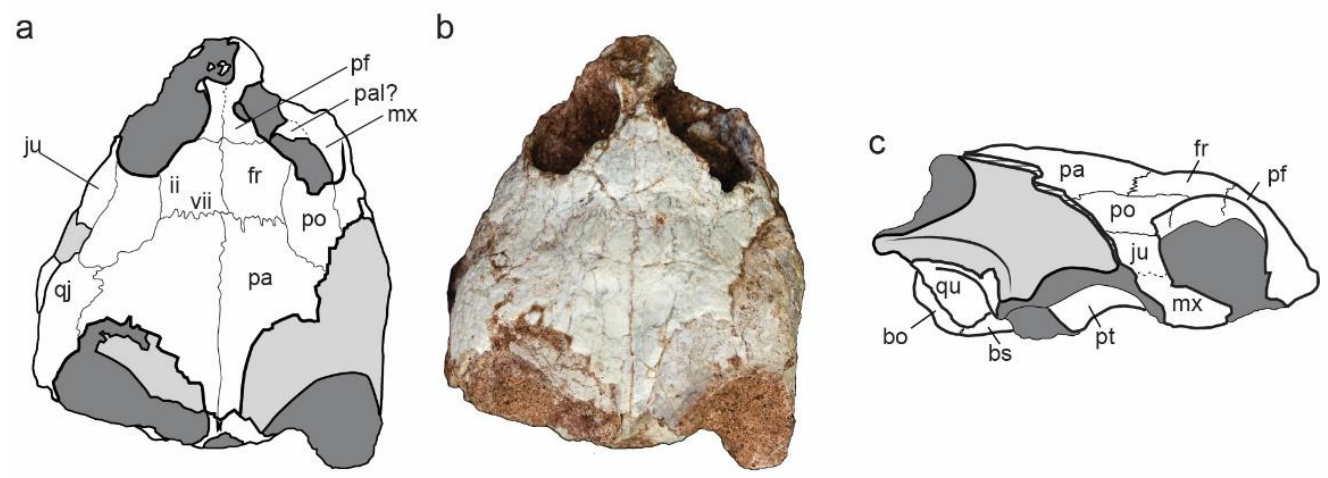

e

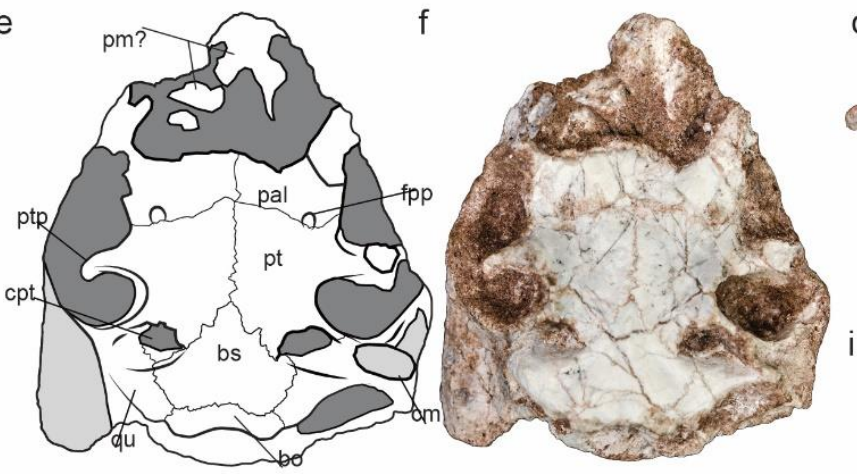

g
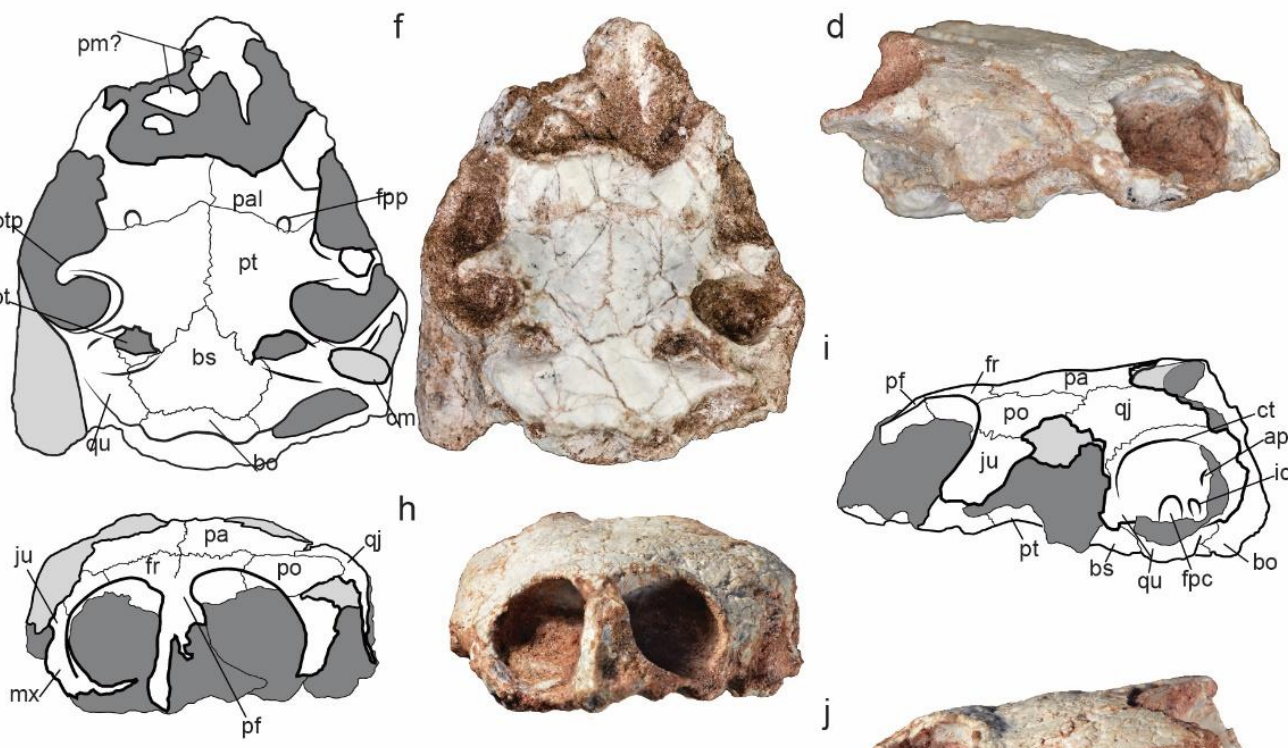

$\mathrm{k}$
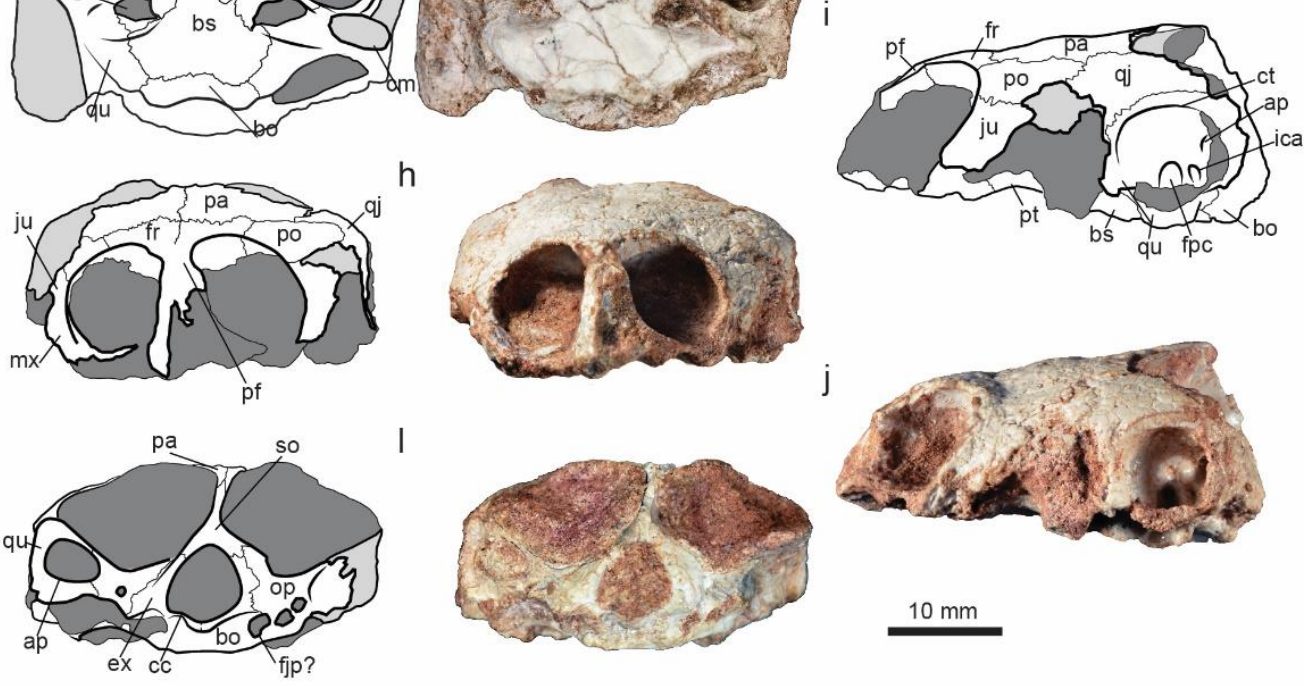

$10 \mathrm{~mm}$

Figure 4.2. Yuraramirim montealtensis, MPMA 04-0008/89. Outlines and photographs of the skull in (a, b) dorsal, $(\mathbf{c}, \mathbf{d})$ right lateral, $(\mathbf{e}, \mathbf{f})$ ventral, $(\mathbf{g}, \mathbf{h})$ anterior, $(\mathbf{i}, \mathbf{j})$ left lateral, and $(\mathbf{k}, \mathbf{l})$ posterior views. Abbreviations: ii and vii, epidermal scutes (sensu Ferreira et al. 2015); ap, antrum postoticum; bo, basioccipital; bs, basisphenoid; cc, cavum cranii; cm, condylus mandibularis; $\mathbf{c p t}$, cavum pterygoidei; ex, exoccipital; fpc, fossa precolumellaris; fpp, foramen palatinum-posterius; fr, frontal; ica, incisura columella auris; ju, jugal; mx, maxilla; op, opisthotic; pa, parietal; pal, palatine; pf, prefrontal; pm, premaxilla; po, postorbital; pt, pterygoid; ptp, processus trochlearis pterygoidei; qj, quadratojugal; qu, quadrate; so, supraoccipital. 


\subsubsection{Comment}

Peiropemydodda was used by Gaffney et al. (2011) to refer to the clade (infrafamily) formed by Peiropemys mezzalirai, Pricemys caiera and Lapparentemys vilavilensis, which was included in the family Podocnemididae. The latter name was used in a more inclusive manner than more recent usage (e.g. Romano et al. 2014; Cadena 2015), which justified the use of the suffix -odda for the infrafamily Peiropemydodda. As Podocnemididae is now more commonly used to refer to the crown-clade including the extant lineages of Podocnemis sp., Erymnochelys madagascariensis, and Peltocephalus dumerilianus (Joyce et al. 2004), the infrafamily Peiropemydodda is not anymore, a subdivision of Podocnemididae, justifying the translation of that name to Peiropemydidae, as defined above. I suggest that the name Peiropemydodda remains with its original meaning, as diagnosed by Gaffney et al. (2011), to include only Peiropemys mezzalirai, Pricemys caiera and Lapparentemys vilavilensis.

Yuraramirim gen. nov.

\subsubsection{Type species}

Yuraramirim montealtensis sp. nov.

\subsubsection{Etymology}

Composition of two Tupi (a Brazilian native language) words: yurara, meaning "turtle", and mirim, meaning "small".

\subsubsection{Diagnosis}

A small Podocnemidoidae based on the right angle formed by the processus trochlearis pterygoidei and the cavum pterygoidei; a Peiropemydidae based on the anteroventral emargination projecting above the ventral level of the orbit (Gaffney et al. 2011). Compared to other peiropemydid and Bauru Group turtles, it is similar in size to Bauruemys elegans, but smaller than all other peiropemydids; the skull is roughly the same height along its entire length, as in Peiropemys mezzalirai and Lapparentemys vilavilensis, differing from that of Bauruemys elegans; the rostral tip of the basisphenoid is acute as in Pricemys caiera, but not in Bauruemys elegans and Peiropemys mezzalirai; the foramen palatinum posterius is formed by the palatine and pterygoid, differing from Peiropemys 
mezzalirai; the fossa precolumellaris is very large as in Peiropemys mezzalirai, in contrast to Pricemys caiera; skull dermal scute vii (sensu Ferreira et al. 2015; same as interparietal scute) has the anterior margins on the frontal and lateral edges converging posteriorly as in Bauruemys elegans, Lapparentemys vilavilensis and Peiropemys mezzalirai, but differing from the latter two by an anterior notch on the midline, as also found in Bauruemys elegans.

Yuraramirim montealtensis sp. nov. (Figs. 4.2-4.6)

\subsubsection{Material}

Holotype MPMA 04-0008/89 (Figs. 4.2-4.6), a partial skull lacking both premaxillae and squamosals, most of the maxillae, and portions of several other bones (see Comparative Description) housed at the Museu de Paleontologia "Prof. Antonio Celso de Arruda Campos", Monte Alto, Brazil.

\subsubsection{Etymology}

The name refers to Monte Alto municipality where the holotype was found.

\subsubsection{Diagnosis}

As for genus.

\subsubsection{Type stratum and locality}

Reddish sandstones of the Late Cretaceous Adamantina Formation, exposed at the entrance to "Sítio da Serra” (S $21^{\circ} 15^{\prime}$ 06.9', W 48 33' 10.4”'), Monte Alto-SP, Brazil.

\subsection{Description}

The skull of MPMA 04-0008/89 is $35 \mathrm{~mm}$ long as preserved, much smaller than other peiropemydids (e.g. the holotype of Peiropemys mezzalirai is approximately $90 \mathrm{~mm}$ long excluding the crista supraoccipitalis, and the specimen AMNH 14444 referred to Lapparentemys vilavilensis is $96 \mathrm{~mm}$ long). The adductor chamber is completely filled by matrix, but parts of its roof were imprinted in the sandstone, forming a natural endocast (Fig. 4.2). The skull is relatively high at the orbital region, with a value of 0.80 for the height at 
orbit/largest height ratio, approaching the condition of Lapparentemys vilavilensis (AMNH 14444) and Peiropemys mezzalirai (MCT 147), which have 0.69 and 0.79 ratios, respectively, whereas that of Bauruemys elegans (Kischlat \& Azevedo 1991) ranges from 0.50 (MCZ 4123) to 0.55 (MCT 1753). Some epidermal scute sulci are poorly preserved, but various features can be observed: based on the preserved borders, scute vii (sensu Ferreira et al. 2015) possibly formed a small and equilateral triangle with smooth edges similar to that of Peiropemys mezzalirai and Lapparentemys vilavilensis, but the anterior sulcus shared with scute ii on the frontal and postorbital has an anterior notch on the midline, as in Bauruemys elegans (Gaffney et al. 2011); part of the posterior edge of scute ii is preserved on the postorbital, but its extension cannot be determined.

Prefrontal.-The prefrontal is partially preserved and it is therefore possible to identify its posterior contact with the frontal. The bone forms the anteromedial edge of the orbit, as in most podocnemidoids. The interorbital distance is similar to that of Bauruemys elegans, Peiropemys mezzalirai, and Lapparentemys vilavilensis (Gaffney et al. 2011), and the large orbit is directed dorsolaterally as in other peiropemydids.

Frontal.-As in most podocnemidoids, the frontal contacts the prefrontal anteriorly, the other frontal medially, the postorbital posterolaterally, and the parietal posteriorly. It has an almost squared dorsal outline, with subparallel lateral and medial edges, as in Bauruemys elegans and differing slightly from Lapparentemys villavilensis and Peiropemys mezzalirai, which have diverging lateral and medial edges. The anterior and posterior edges are also subparallel, as in Peiropemys mezzalirai, but not in Hamadachelys escuilliei, Lapparentemys villavilensis, and most Bauruemys elegans specimens (although some have subparallel edges, e.g. MCZ 4123 in Gaffney et al. 2011: fig. 13), in which the frontal-prefrontal suture projects anteromedially. The frontal forms the anteromedial margin of the orbit, as in other podocnemidoids. 


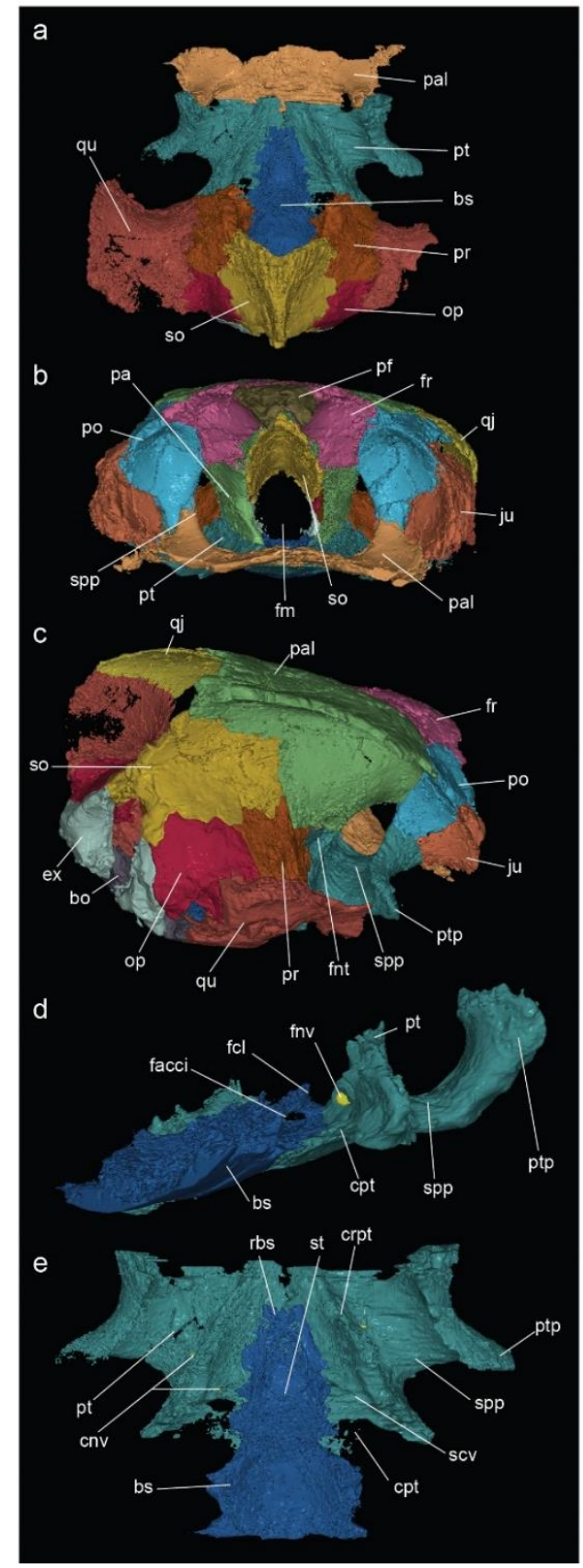

Figure 4.3. Micro-CT scan reconstructed 3-D models of the skull in (a) dorsal view without parietal, frontal and prefrontal bones, (b) anterior view, (c) oblique right lateral view, and isolated basisphenoid and pterygoid bones in (d) oblique left lateral and (e) dorsal views. Abbreviations: ap, antrum postoticum; bo, basioccipital; bs, basisphenoid; cc, cavum cranii; cm, condylus mandibularis; cnv, canalis nervi vidiani; cpt, cavum pterygoidei; ex, exoccipital; facci, foramen anterius canalis caroticus interni; fcl, foramen caroticus laterale; $\mathbf{f m}$, foramen magnum; fnt, foramen nervi trigemini; fnv, foramen nervi vidiani; fpc, fossa precolumellaris; fpp, foramen palatinum-posterius; fr, frontal; ica, incisura columella auris; ju, jugal; mx, maxilla; op, opisthotic; pa, parietal; pal, palatine; pf, prefrontal; pm, premaxilla; po, postorbital; pt, pterygoid; ptp, processus trochlearis pterygoidei; qj, quadratojugal; qu, quadrate; rbs, rostrum basisphenoidale; scv, sulcus cavernosus; so, supraoccipital sot, septum orbitotemporale; spp, sulcus palatino-pterygoideus; st, sella turcica. 
Parietal.- Only the horizontal parietal plate is exposed in MPMA 04-0008/89 and its posterior margin is not completely preserved (Fig. 4.2A). However, the limits of the posterodorsal emargination are preserved in the natural cast of the adductor chamber, and it reached half the length of the cavum tympani, as in Bauruemys elegans and Pricemys caiera, in contrast to the more extensive emargination of Hamadachelys escuilliei and the less extensive ones of Lapparentemys vilavilensis and Peiropemys mezzalirai (Tong \& Buffetaut 1996; Gaffney et al. 2011). The parietal plate meets the frontal anteriorly, the postorbital anterolaterally, the quadratojugal posterolaterally, and the other parietal medially, as seen in other podocnemidoids (Gaffney et al. 2011). As in other peiropemydids, the medial suture between the parietals extends posteriorly, and the supraoccipital either does not take part of the skull roof, or has only a slight exposure on it (Gaffney et al. 2011). With the help of micro CT images (Fig. 4.3), it is possible to identify the sutures of the processus inferior parietalis with the prootic posterolaterally, on the dorsal surface of the otic chamber, the supraoccipital posteriorly, and the pterygoid anteriorly. As in most other podocnemidoids, the parietal of MPMA 04-0008/89 forms the dorsal margin of the foramen nervi trigemini (Fig. 4.3C), along with the prootic posteriorly and the pterygoid anteriorly (Gaffney et al. 2011).

Jugal.- The jugal is fractured on both sides (Fig. 4.2) of MPMA 04-0008/89. Nevertheless, it is possible to identify some of the contacts seen in most pelomedusoids: with the maxilla anteriorly, the postorbital dorsally, and the quadratojugal posteriorly (Gaffney et al. 2006, 2011). Also, part of the ventral margin of the left jugal is preserved and, together with the natural cast of the quadratojugal on the right side (Fig. 4.2C), allows inferring the extension of the anteroventral emargination, which is composed by the jugal and quadratojugal, as in other pelomedusoids (Gaffney et al. 2006, 2011). This emargination surpasses the ventral level of the orbit dorsally (about half the height of the cavum tympani), as seen in Peiropemys mezzalirai and Lapparentemys vilavilensis, and is likely synapomorphic of Peiropemydidae (unknown in Pricemys caiera), differing from the less extensive anteroventral emarginations of Hamadachelys escuilliei and Bauruemys elegans, which do not surpass the ventral margin of the orbit (Tong \& Buffetaut 1996; Gaffney et al. 2011). 
Quadratojugal.- The quadratojugal has preserved contacts with the postorbital anteromedially, the parietal medially, the quadrate posterolaterally, and possibly the jugal anteriorly, as in other peiropemydids. The suture with the squamosal is not preserved and that with the quadrate follows the anterior curvature of the cavum tympani, as in other pelomedusoids (Gaffney et al. 2006, 2011). Compared to other non-Podocnemididae podocnemidoids, the quadratojugal of Yuraramirim montealtensisis more similar to those of Hamadachelys escuilliei, Peiropemys mezzalirai and Lapparentemys vilavilensis, differing from that of Bauruemys elegans, in which it is antero-posteriorly compressed (Tong \& Buffetaut 1996; Gaffney et al. 2011).

Postorbital.-The postorbital is antero-posteriorly elongated, forming the posterodorsal margin of the orbit and contacting the frontal medially, the parietal posteromedially, the quadratojugal posterolaterally, and the jugal laterally (Fig. 4.2I, J). This differs from the very reduced postorbital of the different species of Podocnemis, which is sometimes not even exposed in dorsal view (Gaffney et al. 2011). In Yuraramirim montealtensis it has a ventral projection that forms most of the septum orbitotemporale, contacting the jugal ventrolaterally and the pterygoid ventrally at the anterior base of the processus trochlearis pterygoidei, where it forms the posterodorsal part of the sulcus palatinopterygoideus roof (Fig. 4.3B, C), as in other pelomedusoids (Gaffney et al. 2011). In the anterior part of the septum orbitotemporale, the postorbital contacts the frontal dorsomedially, the jugal ventrolaterally, and the palatine ventromedially (Fig. 4.3B, C).

Maxilla.-Only small fragments of the right maxilla are preserved in MPMA 04$0008 / 89$. It is possible to identify its contact to the jugal posterodorsally and to the palatine posteroventrally (Fig. 4.2C).

Palatine.- The anterior portion of the palatine is not preserved and only the posterior part of the horizontal plate is exposed in MPMA 04-0008/89, with the vertical structures covered by matrix. It contacts the maxilla anterolaterally, its counterpart medially, and the pterygoid posteriorly. The palatine appears to be exposed on the orbital floor (Fig. 4.2A), covering the medial part of the maxilla, as typical of non-Podocnemididae Podocnemidoidae, but not very clear in Peiropemys mezzalirai. The foramen palatinum posterius reaches the palatine-pterygoid suture (Figs. 4.2E, 4.3A) as in Lapparentemys vilavilensis and some 
specimens of Bauruemys elegans, differing from Peiropemys mezzalirai, in which it is restricted to the palatine (Gaffney et al. 2011). The position of this foramen, however, may be variable within the same taxon, as is the case in B. elegans (Gaffney et al. 2011).

Quadrate.-As in other pleurodires, the quadrate of Yuraramirim montealtensis forms the entire cavum tympani (Gaffney 1979; Gaffney et al. 2006, 2011), contacting the lateral surface of the quadratojugal anteriorly. On the roof of the otic chamber, the quadrate contacts the prootic anteriorly and the opisthotic posteromedially (Fig. 4.3A, C). The fossa precolumellaris is very large, as in Peiropemys mezzalirai, and larger than those of other nonpodocnemidid podocnemidoids (Tong \& Buffetaut 1996; Lapparent de Broin 2000; Gaffney et al. 2011). The antrum postoticum is also well-developed (Fig. 4.2K, L), comparable in size to those of Podocnemis unifilis and Galianemys emringeri (Gaffney et al. 2006, 2011). The incisura columellae auris is completely closed by the contact of the dorsal and ventral processes of the quadrate, as in other Podocnemidoidae (Gaffney et al. 2011).

As in other pelomedusoids, the ventral surface of the quadrate of Yuraramirim montealtensis meets the basioccipital posteromedially and the basisphenoid medially, its anteromedial projection contacting the pterygoid (Fig. 4.2E, F). It also forms part of the roof of the cavum pterygoidei, where it contacts the pterygoid anterolaterally, the prootic anteromedially, and the basisphenoid posteromedially, as typical of podocnemidoids (Lapparent de Broin 2000; Gaffney et al. 2011). Although the condylus mandibularis is not preserved in MPMA 04-0008/89, it is possible to infer that it was anterior to the basisphenoid-basioccipital suture, as in all other known podocnemidoids, except for some Stereogenyina (Gaffney et al. 2011; Ferreira et al. 2015). Very little is preserved of the posterior surface of the quadrate. Only an outline of the fenestra postotica is seen (Fig. 4.2K), which is wide as in other podocnemidoids, differing from the slit-like fenestra of Cearachelyini (Gaffney et al. 2006).

Pterygoid.-As in most podocnemidoids, the pterygoid of Yuraramirim montealtensis contacts the palatine anteriorly, its counterpart medially, the quadrate posterolaterally, and the basisphenoid posteromedially. As synapomorphic for pleurodires, the pterygoid forms the processus trochlearis pterygoidei laterally, which is nearly perpendicular to the midline in MPMA 04-0008/89. This latter condition is typical of Pan- 
Podocnemididae, compared to Chelidae or Pelomedusidae (Gaffney et al. 2006, 2011). Yet, the angle formed by the lateral margin of the process is almost $90^{\circ}$, as in Podocnemis expansa, Portezueloemys patagonica, Peltocephalus dumerilianus, Peiropemys mezzalirai, and other podocnemidids (de la Fuente 2003; Gaffney et al. 2011; Cadena 2015), whereas that angle is more oblique in Bauruemys elegans, Lapparentemys vilavilensis, Hamadachelys escuilliei, Cearachelys placidoi, and most bothremydids (Tong \& Buffetaut 1996; Lapparent de Broin 2000; Gaffney et al. 2011). The pterygoid of Yuraramirim montealtensis also forms a well-developed pterygoid flange, typical of Podocnemidoidae (França \& Langer 2006), developing a complete cavum pterygoidei (Fig. 4.2E, 4.3E). The thin plate that forms the floor of the cavum pterygoidei is very fragile and usually broken in fossil specimens (Gaffney et al. 2011), but it is partially preserved in MPMA 04-0008/89 (Fig. 4.2F).

The cavum pterygoidei is also formed by the basisphenoid, prootic, and quadrate, in addition to the pterygoid, as in all podocnemidoids (Gaffney et al. 2011). Its anterior opening is large and corresponds to the foramen caroticum laterale (Fig. 4.3D), which is enlarged in Yuraramirim montealtensis, as in other peiropemydids and Podocnemis spp. (Gaffney et al. 2011). The cavity is roofed by the prootic and, hence, not continuous to the canalis cavernosus as in Peltocephalus dumerilianus and Erymnochelys madagascariensis (Lapparent de Broin 2000; Gaffney et al. 2011). Anteriorly to the foramen cavernosum formed by the prootic and the quadrate, the sulcus cavernosus extends on the dorsal surface of the pterygoid, running laterally to the rostrum basisphenoidale (Fig. 4.3E). The foramen caroticum laterale also opens in this sulcus (Gaffney 1979). Finally, the very small foramen nervi vidiani can be seen in the 3-D model as a perforation on the pterygoid inside the cavum pterygoidei as in other podocnemidoids (Gaffney et al. 2011), lateral to the foramen caroticum laterale (Fig. 4.3D). The canal for this branch of the facialis nerve (Gaffney 1979) could only be reconstructed partially; it extends anteriorly along the pterygoid, but its anteriormost portion cannot be determined (Fig. 4.3E). 
a

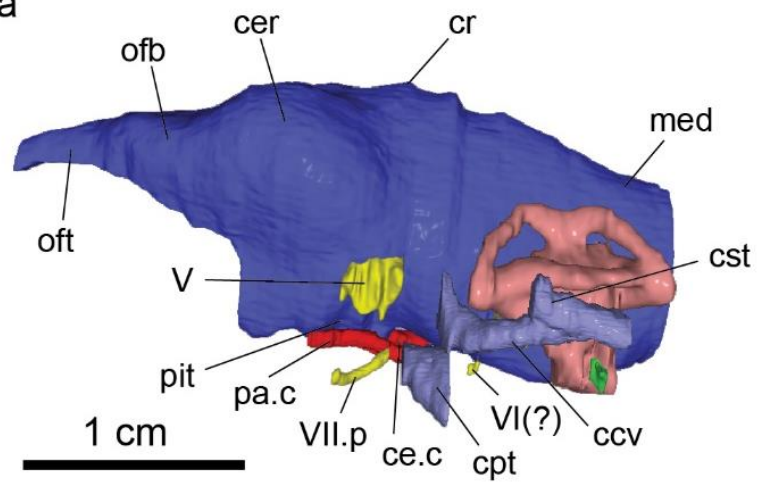

b

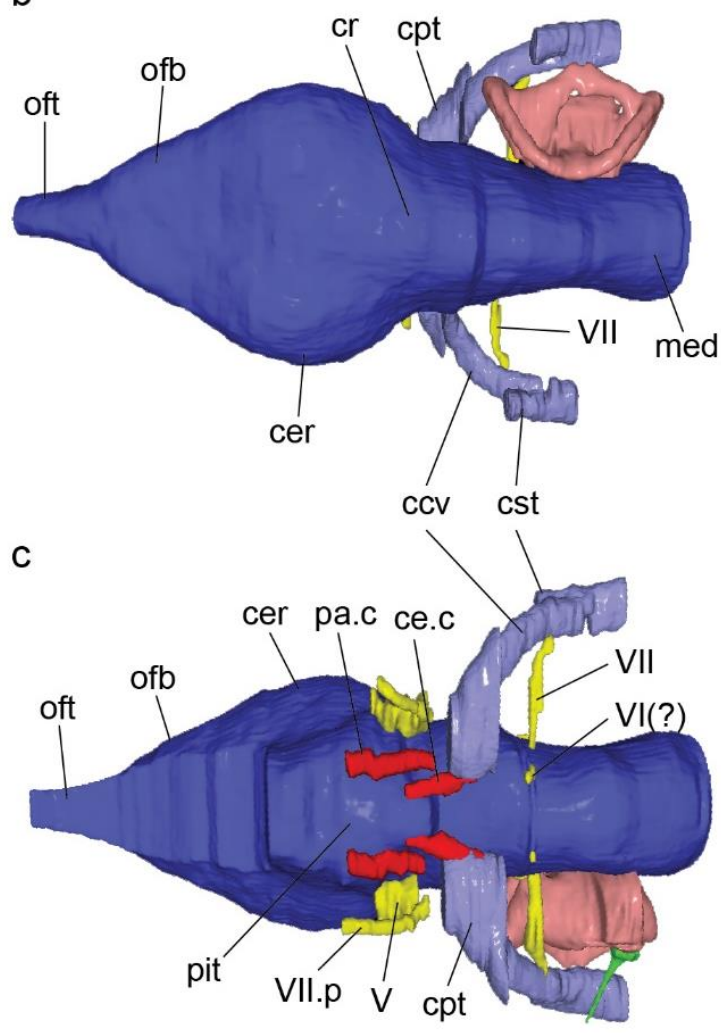

d

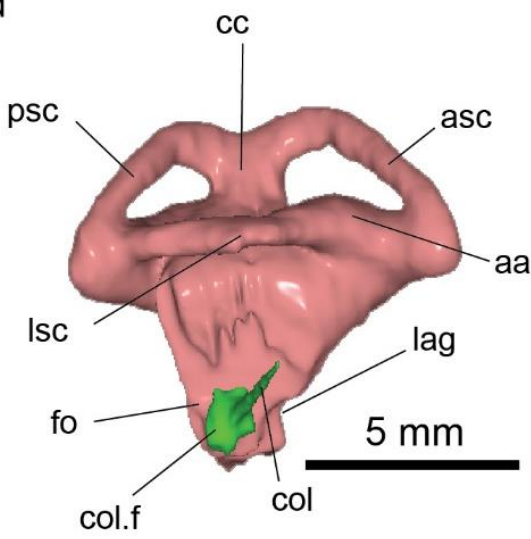

e

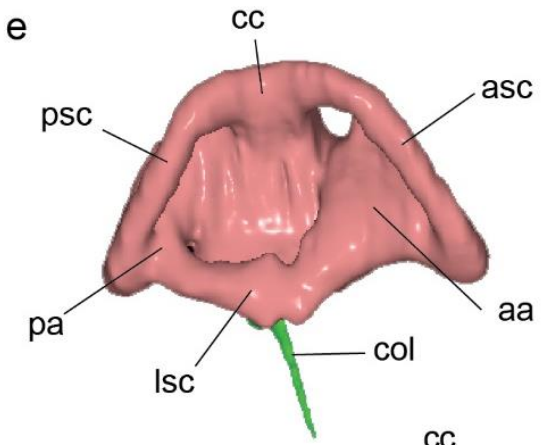

f

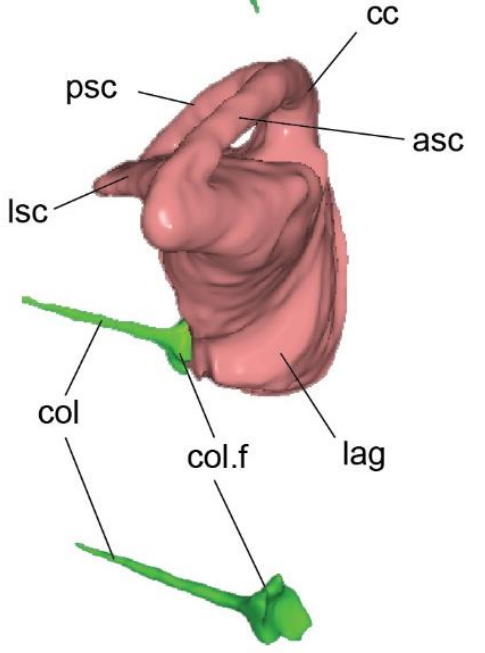

Figure 4.4. Digital endocasts of the brain with associated cranial nerves and blood vessels in (a) left lateral, (b) dorsal, and (c) ventral views, and of the endosseous labyrinth with the columella auris in (d) right lateral, (e) dorsal, and (f) anterior views. On the brain endocast models only the right labyrinth is showed for better visualization. Abbreviations: a.a, anterior ampulla; ap, antrum postoticum; asc, anterior semicircular canal; ccv, canalis cavernosus; ce.c, cerebral branch of internal carotid; cer, cerebral hemisphere; col, columella auris; col.f, columella auris footplate; cpt, cavum pterygoidei; cr, cartilaginous ridge; cru, crus communis; cst, canalis stapedio-temporalis; fo, fenestra ovalis; lag, lagena; lsc, lateral semicirular canal; med, medulla oblongata; ofb, olfactory bulbus; oft, olfactory tract; p.a, posterior ampulla; pa.c, palatal branch of internal carotid; pit, pituitary fossa; psc, posterior semicircular canal; V, trigeminal nerve; VI, abducens nerve; VII, facialis nerve; VII.p, palatine (or vidian) branch of VII. 
Supraoccipital.- The supraoccipital is not exposed on the skull roof of MPMA 040008/89 (Figs. 4.2A, 4.3C). This matches the condition of all known Peiropemydidae, the parietals of which cover almost the entire dorsal surface of that bone, in contrast to other podocnemidoids such as Bauruemys elegans and the different species of Podocnemis (Gaffney et al. 2011). Other parts of the supraoccipital of MPMA 04-0008/89 are covered by matrix and can only be seen in the micro CT images (Fig. 4.3). The bone forms the dorsal edge of the foramen magnum, contacting the exoccipitals posteroventrally, the prootic anterolaterally, the opisthotic posterolaterally, and the parietals anterodorsally (Fig. 4.3C).

Exoccipital.-The exoccipital of MPMA 04-0008/89 contacts the supraoccipital dorsally, the opisthotic laterally, and the basioccipital ventrally (Fig. 4.2K, L). The contact with the quadrate cannot be seen in this specimen, but the exoccipitals form the lateral edges of the foramen magnum. The foramina nervi hypoglossi are not preserved and the foramen jugulare posterius seems partially preserved on its right side (Fig. 4.2K), but it is not clear if it is continuous with the fenestra postotica as in Bauruemys elegans and Portezueloemys patagonica (de la Fuente 2003; Gaffney et al. 2011), or closed as in peiropemydids and podocnemidids (Gaffney et al. 2011).

Basioccipital.- In ventral view, the basioccipital of MPMA 04-0008/89 contacts the basisphenoid anteriorly and the quadrate laterally (Fig. 4.2F). The posterior most portion of the bone is not preserved and the contacts with the opisthotic and exoccipital are not clearly seen (Fig. 4.2K). Although not entirely preserved, the tubercula basioccipitale are smoother than in Bauruemys elegans and the different species of Podocnemis and the space between the tubercula appears to be wider than in those taxa (Gaffney et al. 2011), and more similar to the condition found in Lapparentemys vilavilensis and Peiropemys mezzalirai (Fig. 4.2E, F).

Prootic.- Most of the prootic is covered by matrix in MPMA 04-0008/89, but the micro-CT scan images and the 3-D reconstructions reveal its contacts and several structures (Fig. 4.3). As in all podocnemidoids, the prootic is completely covered in ventral view by the pterygoid, except inside the cavum pterygoidei, in which it forms the dorsomedial portion of its roof (Gaffney et al. 2011) and contacts the basisphenoid medially, the quadrate laterally, and the pterygoid anterolaterally. On its dorsal portion it also contacts the opisthotic 
posteriorly, the supraoccipital posteromedially, and the parietal anteromedially. Together with the parietal and pterygoid, it forms the border of the foramen nervi trigemini, which opens laterally on the fossa temporalis inferior, as in other pleurodires (Gaffney et al. 2006, 2011).

Due to the poor contrast between fossil and matrix some smaller structures are difficult to identify in the micro-CT images. The foramen nervi facialis in the prootic inside the cavum pterygoidei, as found in Pricemys caiera, Peiropemys mezzalirai, and other podocnemidoids (Gaffney et al. 2011) could not be identified. On the other hand, the canalis cavernosum, between the prootic and quadrate, as well as the canalis stapedio-temporalis, could be completely reconstructed. The former starts posteriorly, in the fenestra postotica, and extends anteriorly to the foramen cavernosus, bordered by the prootic medially and quadrate laterally, following on the pterygoid as the sulcus cavernosus. The canalis stapediotemporalis, branches from nearly half-way the length of the canalis cavernosus, carrying the arteria stapedialis to the foramen stapedio-temporalis (Gaffney 1979). The latter is also bordered by the prootic and quadrate, opening dorsally on the external surface of the otic chamber on the fossa temporalis superior, as in other podocnemidoids (Gaffney et al. 2011).

Opisthotic.- Only small parts of the opisthotic of MPMA 04-0008/89 are visible, but its dorsal surface can be seen in the micro-CT images (Fig. 4.3). It is possible to identify the contacts to the prootic anteriorly, supraoccipital medially, exoccipital posteromedially, and quadrate laterally, as in other podocnemidoids (Tong \& Buffetaut 1996; Lapparent de Broin 2000; Gaffney et al. 2011).

Basisphenoid.-The basisphenoid differs from that of most non-podocnemidid podocnemidoids (Suárez 1969; Tong \& Buffetaut 1996; Lapparent de Broin 2000), except for Pricemys caiera, in having an acute anterior tip exposed in ventral view (Fig. 4.2E, F). This could be an ontogenetic variation, as the sutural contact between the pterygoids could extend posteriorly to cover that tip in older specimens. As in other podocnemidoids, the basisphenoid of Yuraramirim montealtensis has a pentagonal shape (Fig. 4.2E). It contacts the pterygoids anteriorly and, inside the cavum pterygoidei, a small ventral exposure of the prootic anterolaterally. It also contacts the quadrate laterally and the basioccipital posteriorly. 
The latter suture is smoother than in Bauruemys elegans (Suárez 1969) and similar to those of peiropemydids (Gaffney et al. 2011).

On the dorsal surface of the basisphenoid of Yuraramirim montealtensis, as revealed by our 3D model (Fig. 4.3E), the rostrum basisphenoidale projects anteriorly over the dorsal surface of the pterygoids. Posteriorly, the sella turcica is preserved on the midline and its posterolateral walls are pierced by the foramen anterius canalis carotici interni, through which the internal carotid artery enters the cavum cranii (Gaffney 1979). The foramen nervi abducentis is smaller and opens slightly posterior to the foramen anterius canalis carotici interni, also laterally on the basisphenoid and inside the cavum pterygoidei.

Cranial endocast. - The brain endocast reconstructed for MPMA 04-0008/89 exhibits a tubular shape (Fig. 4.4A), as in other known extinct and extant turtles (Zangerl 1960; Gaffney 1977; Wyneken 2001; Paulina-Carabajal et al. 2013, 2017; Mautner et al. 2017). The medulla oblongata is located slightly below the level of the cerebral hemispheres, similar to the extant Dermochelys coriacea, Malacochersus tornieri, and Macrochelys temminckii, as well as to the extinct Corsochelys haliniches (Hopson 1979; Paulina-Carabajal et al. 2013; Mautner et al. 2017). Yet, in these taxa and in Yuraramirim montealtensis the braincase elements are found almost in the same horizontal plane (Fig. 4.4A), differing from the condition of other podocnemidoid turtles such as Bothremys cooki and Chedighaii barberi (Hopson 1979; Gaffney et al. 2006), and some sea turtles (Wyneken 2001), in which the pontine and cephalic flexures of the brain position the medula oblongata well below the cerebral hemispheres (Hopson 1979). The latter are easily discernible in MPMA 04-0008/89 and more laterally expanded than in Plesiochelys etalloni, as also seen in Bothremys cooki and Corsochelys haliniches (Hopson 1979). The olfactory bulbs project laterally just anterior to the cerebral hemispheres, and the endocast continues anteriorly forming the slender olfactory tract (Fig. 4.4A, B). Projecting ventrally from the ventral surface of the endocast it is possible to identify the pituitary cast, in which the pituitary gland is located (Fig. 4.4A).

Dorsal to the cerebellum, a subtle subtriangular area is found (Fig. 4.4A, B), corresponding to the cartilaginous ridge (Paulina-Carabajal et al. 2013), or cartilaginous “rider” (Gaffney \& Zangerl 1968; Gaffney 1982). Among extinct turtles, Bothremys cooki, Corsochelys haliniches, and the baenid Plesiobaena antiqua (Hopson 1979; Gaffney 1982), 
as well as meiolaniids (Paulina-Carabajal et al. 2017) seem to possess a more prominent version of this ridge, as in Yuraramirim montealtensis, but not in Plesiochelys etalloni (Paulina-Carabajal et al. 2013).

Only some of the cranial nerves could be reconstructed in MPMA 04-0008/89 (Fig. 4.4). The canal for the trigeminal nerve (V) projects laterally from the endocast, posteroventrally to the cerebral hemispheres and dorsally to the pituitary cast (Fig. 4.4A). The facialis nerve (VII) leaves the endocast more posteriorly, just anterior to the endosseous labyrinth, and extends laterally inside the prootic, to the canalis cavernosus (Fig. 4.4B, C). The latter, after branching off from the dorsal canalis stapedio-temporalis (Fig. 4.4A), extends anteromedially. As in peiropemydids and Podocnemis spp. (Gaffney et al. 2011), it turns into the sulcus cavernosus after leaving the foramen cavernosum, where it communicates with the ventral cavum pterygoidei (Fig. 4.4A). The canalis cavernosus contains the lateral head vein in pleurodires (Gaffney 1979), which runs anteriorly through the sulcus cavernosus, lateral to the rostrum basisphenoidale (Fig. 4.3E). The canal for the palatine (or vidian) branch of the facialis nerve (Gaffney 1979) could be partially identified inside the pterygoid. It leaves the anterior wall of the cavum pterygoidei and extends anteriorly (Figs. 4.3E, 4.4C). A small canal anteroventral to the nerve facialis could be identified in the micro-CT scan images, and could correspond to the abducens nerve (VI), which runs anteriorly (Paulina-Carabajal et al. 2013).

Finally, the cerebral and palatine branches of the internal carotid leave the cavum pterygoidei anteromedially and anteriorly, respectively (Fig. 4.4C), as in all peiropemydids and podocnemidids (Gaffney et al. 2011). The cerebral artery enters the pituitary fossa on the basisphenoid, and the palatine artery runs anteriorly to the sulcus cavernosus on the dorsal surface of the pterygoid (Figs. 4.3E, 4.4C). Thus, the split between the two branches of the internal carotid artery occurs inside the cavum pterygoidei, floored by the pterygoid flange, which extends ventrally to that split (Gaffney et al. 2011). As in all crown-turtles, the split of the internal carotid artery is, therefore, floored by bone (Sterli et al. 2010; Müller et al. 2011), but this occurs in an open space (i.e. inside the cavum pterygoidei), and not within its own canal (the canalis carotici interni; Gaffney 1979). The patterns of carotid circulation are well 
documented in cryptodires and stem-turtles (Albrecht 1976; Sterli et al. 2010; Müller et al. 2011; Rabi et al. 2013), but descriptions or both extant and extinct pleurodires are still lacking

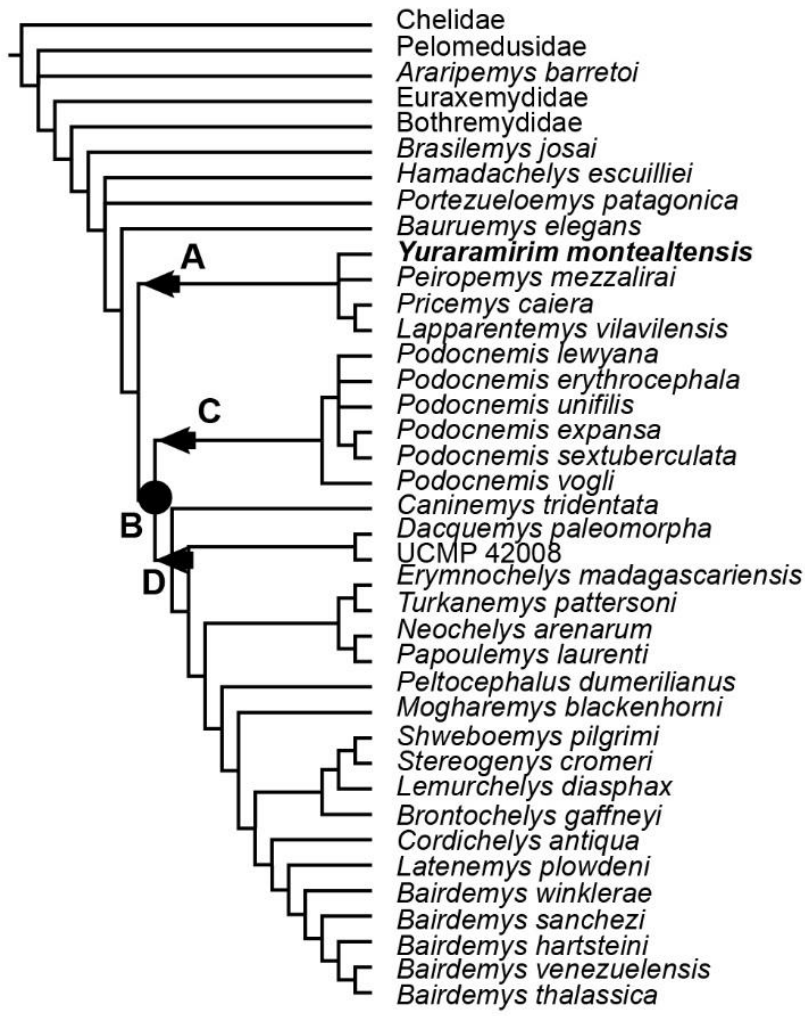

Figure 4.5. Strict consensus tree resulting from the phylogenetic analysis. Yuraramirim montealtensis (bold) is recovered inside the Peiropemydidae clade, along with Peiropemys mezzalirai, Pricemys caiera, and Lapparentemys vilavilensis. The arrows highlight the branch-based clades (A) Peiropemydidae, (C) Podocnemidinae, and (D) Erymnochelydinae, and the circle indicates the node-based clade (B) Podocnemididae.

Inner ear.-The digitally reconstructed inner ear of Yuraramirim montealtensis shows a morphology that generally resembles that of other turtles (Wever 1978; Walsh et al. 2009; Paulina-Carabajal et al. 2013, 2017): the semicircular canals are dorsoventrally low, subequal in size, and their cross-section is sub-eliptical, with a globose lagena (Fig. 4.4D).

The inner ear cast is $9.2 \mathrm{~mm}$ long. The anterior (ASC) and posterior (PSC) semicircular canals are not as dorsoventrally low as in Plesiochelys etalloni (PaulinaCarabajal et al. 2013), meiolaniids (Paulina-Carabajal et al. 2017), and some other cryptodires (e.g. Chelonoidis nigra, Chelonoidis chilensis, Trachemys scripta, and Carettochelys insculpta; Georgi \& Sipla 2008; Paulina-Carabajal et al. 2017), but more elevated as in Gopherus berlandieri, Chelydra serpentina and Malacochersus tornieri 
(Walsh et al. 2009; Mautner et al. 2017; Paulina-Carabajal et al. 2017). The vertical canals (ASC and PSC) are elongated in the anteroposterior axis (Fig. 4.4), which could indicate an aquatic behaviour according to Georgi \& Sipla (2008). As in Plesiochelys etalloni and most known turtles (Paulina-Carabajal et al. 2013, 2017), the crus communis is located at the midline of the vestibular organ (Fig. 4.4). The angle formed between the ASC and the PSC is $87.8^{\circ}$, wider than that described for Plesiochelys etalloni or Trachemys scripta (PaulinaCarabajal et al. 2013), but lower than that of any terrestrial taxa (Paulina-Carabajal et al. 2017). The lateral semicircular canal (LSC) is the thickest $(1.1 \mathrm{~mm})$ of the three, as in Plesiochelys etalloni, followed by the ASC $(0.8 \mathrm{~mm})$ and the PSC $(0.6 \mathrm{~mm})$. The ASC is slightly more elongated than the PSC (2.2 $\mathrm{mm}$ and $2.1 \mathrm{~mm}$, respectively). As in Plesiochelys etalloni (Paulina-Carabajal et al. 2013), the anterior ampulla is well developed whereas the posterior is much slender (Fig. 4.4E), in contrast to that of several testudinids (PaulinaCarabajal et al. 2017).

The lagena in Yuraramirim montealtensis is well-developed ventrally (Fig. 4.4D), similarly to those of Plesiochelys etalloni, Gopherus berlandieri, and Testudo hermanni, in contrast to those of Rhinoclemmys funerea and Kinixys belliana (Paulina-Carabajal et al. 2013, 2017), in which this region is more rounded. The fenestra ovalis is smaller than that of Malacochersus tornieri (Mautner et al. 2017). The columella auris is preserved on both sides (Fig. 4.4), except for the distal portion. Its shaft is thinner than in Plesiochelys etalloni, and projects anterolaterally, in contrast to the posterolaterally projection of the latter (PaulinaCarabajal et al. 2013). The foot plate is broad and concave medially, towards the fenestra ovalis.

\subsection{Discussion}

The phylogenetic analysis found six most parsimonious trees (MPTs) with 238 steps each (see online supplementary material). The MPTs differ in the relative position of some outgroup taxa (i.e. Araripemys barretoi, Pelomedusidae), as well as Hamadachelys escuilliei and Portezueloemys patagoinica, and some species of Podocnemis. All most parsimonious trees (Fig. 4.5) shows Yuraramirim montealtensis nested within Peiropemydidae, in a polytomy including Peiropemys mezzalirai and the clade formed by Pricemys caiera and 
Lapparentemys vilavilensis. Peiropemydidae is supported by an anteroventral emargination reaching above the ventral level of the orbit (ch. 13, state 2). The scoring of Yuraramirim montealtensis in the data matrix differs from that of Peiropemys mezzalirai by two conditions: the foramen palatinum posterius on the palatine-pterygoid suture, rather than restricted to the palatine (ch. 37) and a larger antrum postoticum (ch. 40). The size of the antrum postoticum also sets the taxon apart from Pricemys caiera and Lapparentemys vilavilensis. The larger foramen nervi abducentis (ch. 65) of the former and the shallow fossa precolumellaris (ch. 41) of the latter also differentiate those peiropemydids from Yuraramirim montealtensis. Those distinct features, associated with its smaller size and stratigraphic provenance further supports the assignment of MPMA 04-0008/89 to a distinct peiropemydid taxon. As such, it extends the record of Peiropemydidae to pre-Maastrichtian times (Fig. 4.6), with the clade surviving until the early Paleocene (Broin 1971, 1991; Gaffney et al. 2011).

Although some authors used Computed Tomography to study osteological traits (e.g. Brinkman et al. 2006; Lipka et al. 2006; Sterli et al. 2010; Cadena \& Jaramillo 2015; Lively 2015) of extinct turtles, only four other studies were published so far with digital reconstructions of endocasts of soft tissue organs (Georgi \& Sipla 2008; Paulina-Carabajal et al. 2013, 2017; Mautner et al. 2017). Indeed, this is the first study to employ these tools to assess the inner ear and neuroanatomy of an extinct pleurodire. The endocast and inner ear of Yuraramirim montealtensis are similar to those of other turtles. However, some differences are noted, such as the position of the medulla oblongata almost on the same level as the cerebral hemispheres (Fig. 4.4A), whereas the condition in the bothremydids Bothremys cooki and Chedighaii barberi (Hopson 1979) resembles that of sea turtles (Wyneken 2001), in which the medulla oblongata is located well below the cerebral hemispheres, with stronger pontine and cephalic flexures. Those differences could be related to the adaptations of bothremydids to marine environments, as suggested by some authors (e.g. Gaffney et al. 2006; Rabi et al. 2012; Joyce et al. 2016). However, with such a small sample, especially for pleurodires, it is premature to infer phylogenetic or behavioural trends from the neuroanatomy of fossil turtles. Future, more comprehensive studies may employ the data presented here to better explore the evolution of those organs in Pleurodira and Testudines. A detailed account of the cranial nerves and arteries in Yuraramirim montealtensis was also 
provided. As noted above, the patterns of carotid circulation in turtles has been mainly studied in stem-turtles and cryptodires. Given that several phylogenetic characters are related to the circulatory and nerve systems, such as skull foramina and canals (e.g. Joyce 2007; Sterli et al. 2010; Müller et al. 2011; Gaffney et al. 2006, 2011; Rabi et al. 2013), this study adds new data to understand the patterns in Pleurodira.

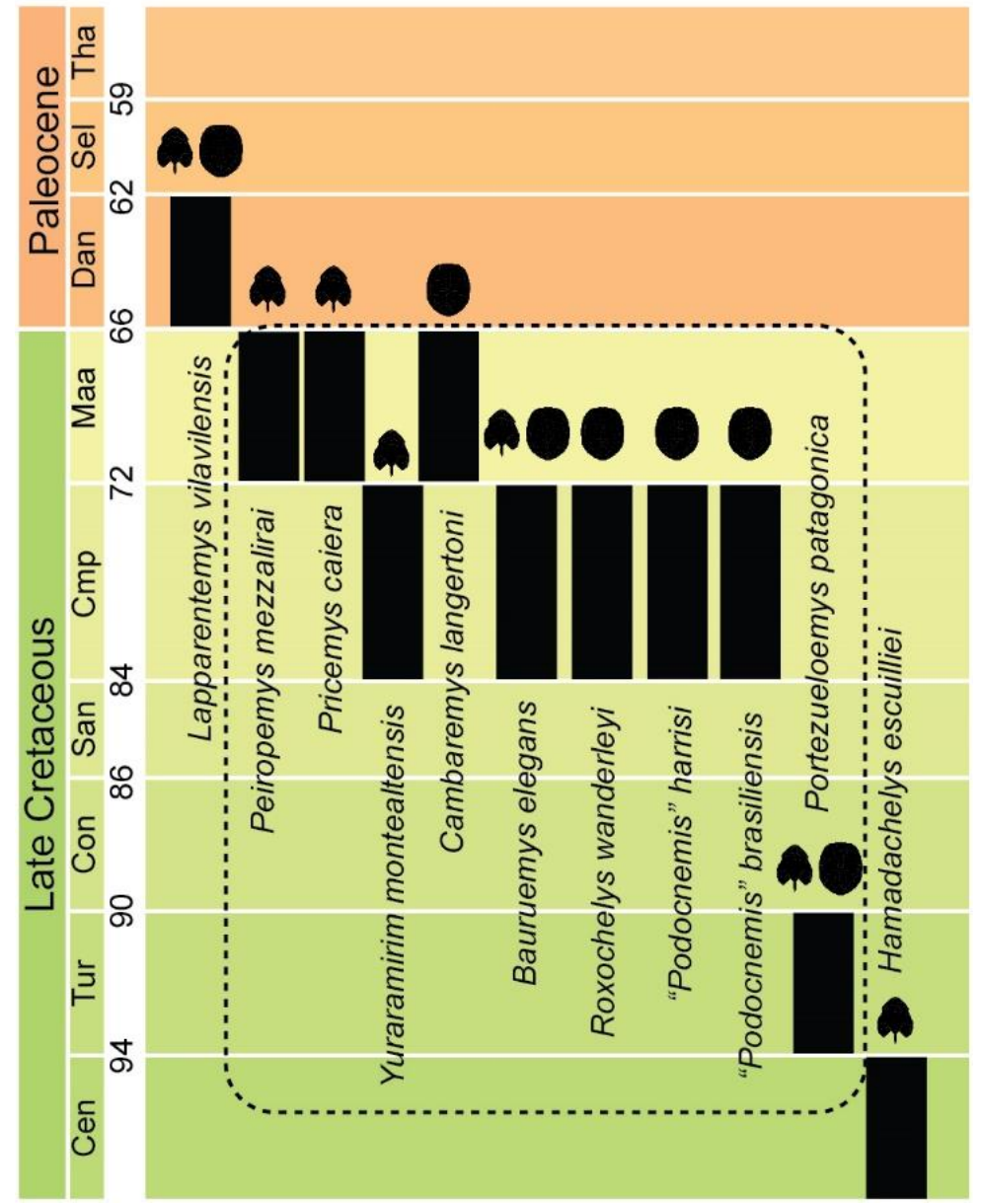

Figure 4.6. Stratigraphic plot of non-Podocnemididae podocnemidoids. Black bars represent their temporal distribution; skulls and carapaces indicated the preserved skeletal parts; dotted rectangle highlights Bauru Basin taxa. Age of the Bauru Basin taxa based on Batezelli (2015)

\subsection{Conclusions}

A partial skull from the Late Cretaceous Adamantina Formation represents the first extinct pleurodire and one of the few fossil turtles to have its neuroanatomy described based on digitally reconstructed endocast and inner ear. The large antrum postoticum and fossa 
precolumellaris, the foramen prepalatinum formed by the pterygoid and palatine, and the triangular dermal scute vii with an anterior notch on the midline, as well as its smaller size and distinct stratigraphic provenance, support the assignment of this specimen to a new taxon, Yuraramirim montealtensis, placed inside Peiropemydidae in our phylogenetic analysis. This fossil extends the range of that clade to pre-Maastrichtian times. 


\section{Chapter 5}

Feeding biomechanics suggests progressive correlation of skull architecture and neck evolution in turtles

This chapter is a manuscript submitted as:

Ferreira, G., Lautenschlager, S., Evers, S. W., Pfaff, C., Kriwet, J., \& Werneburg, I. (2018). Feeding biomechanics suggests progressive correlation between skull architecture and neck evolution in turtles. Submitted to PNAS in April 2019. 


\title{
5 Feeding biomechanics suggests progressive correlation of skull architecture and neck evolution in turtles
}

\begin{abstract}
The turtle skull is a highly modified structure compared to other reptiles and has, together with the complete reorganization of the body in consequence of the origin of the shell, hampered our understanding of the group's origin. During the evolution of turtles, a series of modifications changed their kinetic, anapsid, and compact skull into an elongated structure devoid of cranial kinesis and with temporal bone reductions. Following the posterior expansion of the temporal crests and muscle origin sites, a pulley system (called trochlear mechanism) developed in order to divert the muscle fibers around the enlarged otic chamber. All those modifications were thought to be strongly correlated to functional adaptations, especially to bite performance. Here, I conduct a series of Finite Element Analyses (FEAs) to test this hypothetical framework and provide a new view on the evolution of the turtle skull. The results do not support a relation between the akinetic nature of the skull or the trochlear mechanism with higher bite forces. Yet, the FEAs show that those modifications changed the skull architecture into an optimized structure, more resistant to higher loads in a skull largely adapted to neck mobility. With those results, I propose an evolutionary scenario of progressive correlation, started by the origin of the shell, in which a rearrangement of neck morphology is associated to the akinetic skulls in turtles, triggering the other modifications which, in turn, allowed a second wave of neck evolution, resulting in the longer and more flexible necks, characteristic of modern turtles.
\end{abstract}

Keywords: functional morphology, computer modelling, finite element analysis, Testudinata, craniocervical system 


\subsection{Introduction}

The vertebrate skull is a complex composite of various and highly integrated adaptive structures, directly related to feeding, behavior, and ecology. The skull of turtles strongly differs from that of other reptiles (Rieppel 1993; Ferreira \& Werneburg 2019, Werneburg 2019) and, together with the reorganization of the postcranium by the origin of the shell (Nagashima et al. 2012), it is one of the reasons that hamper our assessment of their phylogenetic origin (Scheyer et al., 2013; Joyce 2015). The anapsid skull (although secondarily acquired; Müller 2003; Schoch \& Sues 2016) was altered by marginal reductions of temporal bones (called emarginations; Fig. 5.1; Gaffney 1979; Werneburg 2012), which superficially resemble excavated temporal fenestrae of other amniote groups (Rieppel 1993, Werneburg 2019). Also, the cranial kinesis of early stem-turtles (e.g., Proganochelys quenstedtii: Gaffney 1990) was later lost by a series of modifications (Fig. 5.2) similarly to the akinetic conditions of mammals and crocodiles (Sterli \& de la Fuente 2010; Werneburg \& Maier 2019): (a) the fixation of the palatoquadrate to the braincase, by suturing the joint between the parabasisphenoid to the pterygoid found in early turtles (Fig. 5.1F-G; Sterli \& de la Fuente 2010; Rabi et al. 2013); (b) fixation of the snout by extensive ossification of the secondary palate, reduction of the foramen palatinum-posterius, and closure of the interpterygoid vacuities (Fig. 5.1F; Werneburg \& Maier 2019); and (c) development of a secondary lateral braincase wall by a descending process of the parietal (and plesiomorphically also by the epipterygoid in cryptodires) that reaches the pterygoid ventrally (Gaffney 1979).

Those parallels between turtles, mammals, and other reptiles can, at first, be thought to have evolved by similar processes or to be affected by common factors. However, the development of fully akinetic skulls, for example, was influenced by the specific mammalian breathing and chewing mechanisms of neonates (Thomasson \& Russel 1986; Maier et al. 1996), and by the outstanding high bite forces of crocodilians (Preuschoft \& Witzel 2002, 2005; Erickson et al. 2003), illustrating the multiple and taxon-specific factors for the origin of the similar morphological traits. Yet, the reduction of temporal coverage, which is thought to be related to jaw muscle performance in most reptiles (Rieppel 1993; Werneburg 2012, 2019, Werneburg et al. 2019), seems to be largely correlated to various degrees of neck 
flexibility and retraction capabilities of different turtle lineages (Werneburg et al. 2015a, b, Werneburg 2015). Recently, Werneburg \& Maier (2019) presented evidence for an influence of neck movements during embryonic development on the fixation of the palatoquadrate to the braincase in turtles and, consequently, on a comprehensive reduction of intracranial kinesis. These observations suggest that the reorganization of the neck muscles and the development of high flexibility and neck retraction related to the origin of the shell might have had profound influences on the peculiar skull architecture of turtles (Werneburg 2015). Importantly, the rapid diversification of the group since the Middle Jurassic (Shaffer et al., 1997; Danilov \& Parham 2008; Sterli 2010; Joyce et al. 2013) followed the acquisition of akinetic, emarginated skulls and longer, more flexible necks (Sterli \& de la Fuente 2010; Werneburg et al. 2015a, b), perhaps representing a case of adaptive radiation (Simpson 1953; Foote 1997).

In contrast to most other amniotes, turtles also possess horizontal adductor muscle fibers (Schumacher 1973; Werneburg 2011, 2013), which extend along the posterior expansion of the adductor chamber (Schumacher 1973, Rieppel 1993; Werneburg 2011, 2013, Ferreira \& Werneburg 2019). This is associated with their unique trochlear system, which redirects those fibers around the enlarged otic chamber (Gaffney 1975; Joyce 2007; Sterli \& de la Fuente 2010) and anteriorly reorients them to insert vertically to the lower jaw (Schumacher 1973; Werneburg 2011). This pulley system includes hard and soft tissue components: a transiliens cartilage (or bone; Ray 1959) that slides on a bone surface, facilitated by a synovial capsule or an infold of the mouth cavity (Schumacher 1973; Gaffney 1975; Ferreira \& Werneburg 2019). Crown-group turtles are composed of two main clades, the Cryptodira and Pleurodira (Gaffney et al. 1991; Pereira et al. 2017), each developing the trochlea in different positions - the former by a roughening or a process on the otic chamber itself (Fig. 5.1D) and the latter by a lateral projection of the pterygoid (Fig. 5.1E) (Schumacher 1973; Gaffney 1975), derived from the external process of the pterygoid, found in other turtles (Fig. 5.1B). Historically, the position of the trochlea has been used to assign fossil turtles to one of these two clades (Gaffney 1975; Gaffney et al. 1991). However, more recent phylogenetic analyses (Joyce 2007; Cadena \& Parham 2015; Joyce et al. 2016; Evers \& Benson 2019) have consistently retrieved a longer stem-lineage to both crown-groups and 
the "cryptodiran"-type trochlea (Fig. 5.1D) already appeared along the turtle stem, being likely present in the pleurodiran stem lineage before they developed their own type (Fig. 5.1E; Joyce \& Sterli 2012). Both the origin of a pulley system and its subsequent modification in pleurodires has been tentatively explained on functional grounds. The origin of the mechanism would trigger the posterior elongation of adductor fibers along with supraoccipital and squamosal crests as origin sites, resulting in stronger bites (Sterli et al., 2010). The pterygoid expansion would position the trochlea more anteriorly, allowing the fibers to insert more vertically to the lower jaw, which would result in a more efficient force transfer system (Joyce 2007). The reinforcement of the skull in turtles has also been suggested to have enabled the development of a higher muscle volume and to withstand higher bite forces (Sterli \& de la Fuente 2010). However, none of these hypotheses have so far been tested with biomechanical models.

Although mechanical adaptation to functional needs may be considered the main explanation for bone shape, it is more plausible to also account for phylogenetic, ontogenetic, and architectural constraints that bound the actual extent to which skeletal structures can be functionally optimized (Rayfield 2007). In this framework, Finite Element Analysis (FEA) may be used to model biomechanical behavior and deformation of interconnected complex structures and to explore the loading history that shaped the morphology of a given structure during its evolutionary history (Lautenschlager et al. 2013, 2016; Rayfield 2007). Here I aimed to assess the functional significance of changes in turtle skull architecture during feeding, using 3-D models segmented from micro-CT scans (Fig. 5.1) and a series of FEAs. For such, we tested $(i)$ whether reduced basipterygoid mobility and longer adductor chambers develop higher bite forces (Sterli \& de la Fuente 2010), (ii) whether the origin of the trochlear mechanisms is related to biomechanical advantages for the cranial structures (Joyce 2007; Sterli \& de la Fuente 2010), and (iii) whether an akinetic skull, by redistributing stress, enabled the reduction of temporal bone coverage in turtles (Werneburg 2015). 

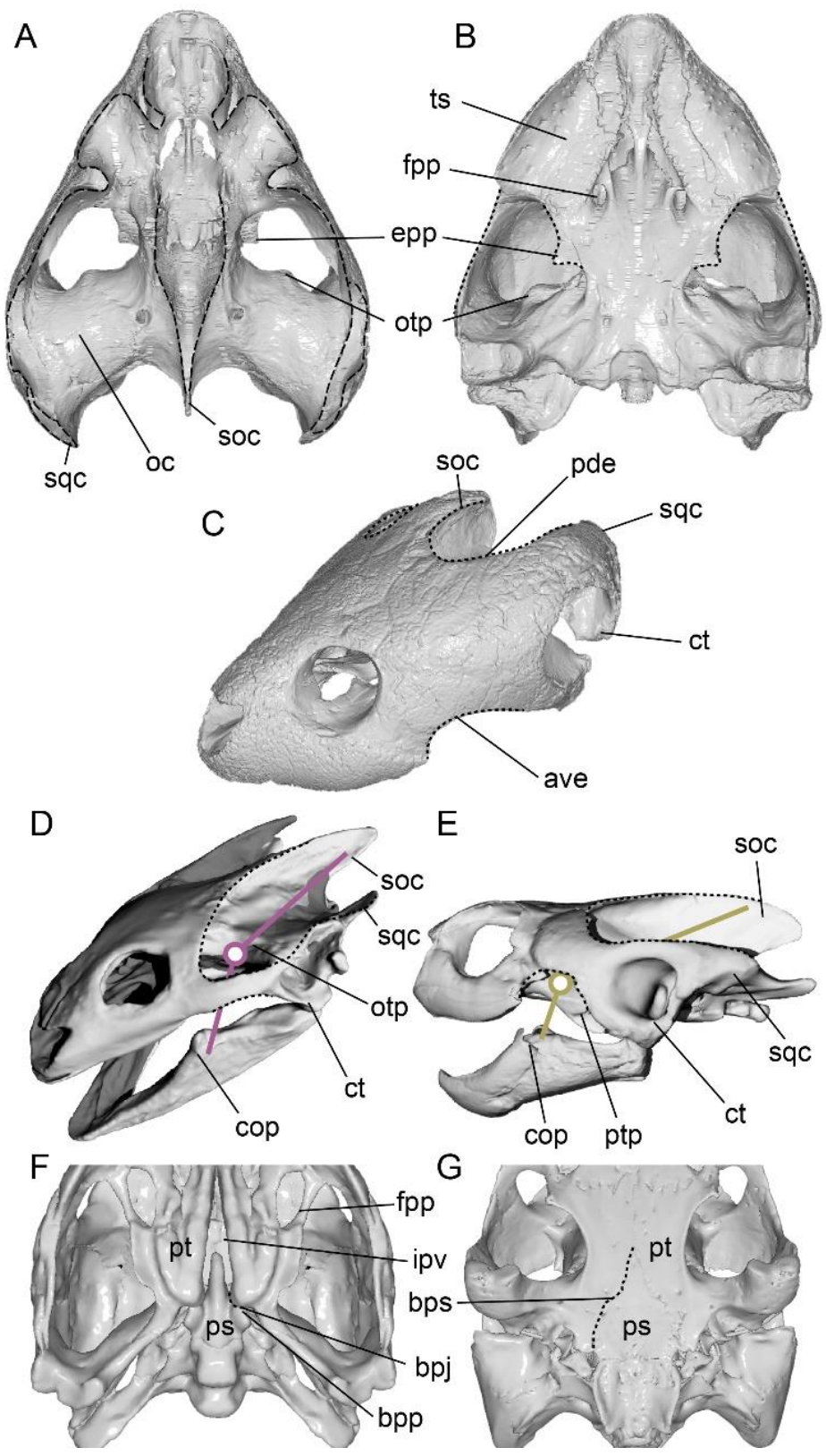

Figure 5.1. Skull morphology of (A-C) Eubaena cephalica, (D) Pelodiscus sinensis, (E) Pelomedusa subrufa, (F) Proganochelys quenstedti, and (G) Emys orbicularis in (A) dorsal view without temporal roof, $(\mathbf{B}, \mathbf{F}, \mathbf{G})$ ventral view and $(\mathbf{C}-\mathbf{E})$ left lateral view. Main course of external adductor muscles and trochlea location are plotted in purple (cryptodiran, D) and yellow (pleurodiran, E) lines and circles, respectively. Dotted curves represent the edges of the emarginations. Abbreviations: ave, anteroventral emargination; bpj, basipterygoid joint; bpp, basipterygoid process; bps, basipterygoid suture; cop, coronoid process; ct, tympanic cavity; epp, external process of the pterygoid; fpp, foramen palatinum posterius; ipv, interpterygoid vacuity; oc, otic chamber; otp, otic trochlear process; pde, posterodorsal emargination; pt, pterygoid bone; ptp, pterygoid trochlear process; ps, parabasisphenoid; soc, supraoccipital crest; sqc, squamosal crest; ts, triturating surface. 


\subsection{Material and Methods}

\subsubsection{Specimens \& skull models}

Specimens of Proganochelys quenstedti (SMNS 16980), Kayentachelys aprix (TMM 43670-2), Eubaena cephalica (DMNH 96004; Rollot et al. 2018), Pelodiscus sinensis (IW 576-2), Platysternon megacephalum (SMF 58702), Emys orbicularis (WGJ 1987a), Terrapene ornata (FMNH 23014), Chelodina reimanni (ZMB Herpetologie 49659), Emydura subglobosa (PIMUZ lab\# 2009.37), Pelomedusa subrufa (IW 938-1), and Podocnemis unifilis (SMF 55470) were $\mu \mathrm{CT}$-scanned and imported into Avizo 8 (Visualization Science Group) for manual segmentation and digital reconstruction. In order to represent more accurately their inferred life morphology (Gaffney 1990; Sterli \& Joyce 2007; Gaffney \& Jenkins 2007), the data of Pr. quenstedti and K. aprix required moderate reconstruction. Breaks and cracks were digitally removed, distortions and deformations were corrected and missing elements were reflected, following the protocol outlined by Lautenschlager (2016). In addition to the eleven standard models described above, four additional hypothetical models were also created in Avizo: (1) Pr. quenstedti with a basipterygoid suture, (2) Pr. quenstedti with a supraoccipital crest, (3) Pr. quenstedti with a basipterygoid suture and a supraoccipital crest, and (4) Eu. cephalica with a pterygoid trochlear process and explicitly modeled trochlea. Surface files for the final 17 models were generated in Avizo.

\subsubsection{Mesh Models and FEA}

The surface models were imported into Hypermesh (Version 11; Altair Engineering) to create solid mesh FE models consisting of $\sim 2,000,000$ four-noded tetrahedral elements (tet4) and to set boundary conditions. Material properties were assigned for the cranial bones fibrous connective tissue. Extant analogs for alligator bone $(E=20.49 \mathrm{GPa}, \mathrm{v}=0.40)$ (Zapata et al. 2010) and connective tissue $(E=0.09 \mathrm{GPa}, \mathrm{v}=0.30)$ (Porro et al. 2013) were used with both materials treated as isotropic and homogeneous.

Areas of origin sites and main fiber course for the eight jaw adductor muscles (nine for Pelodiscus sinensis, including the m. zygomaticomandibularis; Werneburg, 2011; Ferreira \& Werneburg 2019), obtained from the literature (Werneburg 2013) and personal 
observations, were used to assign force vectors to the FE models. To calculate contraction force values for each muscle in our models, I used muscle cross-sectional area based on PTAstained $\mu \mathrm{CT}$-scan data of all extant taxa (except Pelomedusa subrufa, for which we substituted for Pelusios niger SMNS 4625 specimen). The models were constrained from rigid body motion in all directions $(X, Y, Z)$ at the occipital (five nodes) and mandibular condyles (four nodes on each side), reflecting attachment to the vertebral column and the lower jaw. To simulate bilateral biting at different analogous positions, additional constraints (one node on each side) were applied to the maxilla, at the tip of the snout near the suture to the premaxilla. An additional set of models was created simulating the effect of the trochlear mechanism on the underlying bone during attrition of the transiliens cartilage. For this purpose, the vectors of the jaw muscles on both sides of the trochlea (i.e. cranial attachment to trochlea and trochlea to mandibular attachment) were obtained for each taxon. Load force exerted by the trochlea was calculated as the vector perpendicular to the resultant vector of the jaw muscles and the trochlea. However, explicitly simulating the trochleae in both pleurodires and cryptodires, does not change the overall pattern of stress distribution. For those reasons, the discussion focuses on the results of the simpler models (called 'standard models'), i.e. models without simulated trochleae in those groups.

All models were imported into Abaqus (Version 6.10; Simulia) for analysis and postprocessing. Biomechanical performance for each taxon/model was assessed via von Mises and tensile/compressive stress contour plot outputs, reaction forces (=bite forces) at the bite points and per-element average stress values.

\subsubsection{Institutional abbreviations}

DMNH, Denver Museum of Nature and Science, Denver, USA; FMNH, Field Museum of Natural History, Chicago, USA; IW, Ingmar Werneburg Private Collection, Tübingen, Germany; PIMUZ, Laboratory collection of Paläontologisches Institut und Museum der Universität Zürich, Switzerland; SMF, Senckenberg Museum Frankfurt, Germany; SMNS, Staatliches Museum für Naturkunde Stuttgart, Germany; TMM, Texas Memorial Museum, Austin, USA; WGJ, Walter G. Joyce Private Collection, Fribourg, Switzerland; ZMB, Zoologisches Museum Berlin, Germany. 


\subsection{Results}

\subsubsection{General stress distributions}

Stress (force per area) is generated by the interplay of a physical structure, material properties, defined constraints, and applied force. Depending on the direction of deformation, stress can be described as tension or compression or alternatively as a single scalar approximation of the three main principal stresses (von Mises stress) to estimate material failure (Rayfield 2007). The von Mises stress contour plots (Figs. 5.2-5.4) and average stress measures (Fig. 5.5) show overall lowest stress magnitudes in the early stem turtles Proganochelys quenstedti and Kayentachelys aprix. Localized stress hotspots aside from the constrained points (i.e., occipital and mandibular condyles and bite points; Fig. 5.3) can be seen anteriorly, inside the orbit (Fig. 5.2A-B), and on the palate, between the foramen palatinum posterius and the triturating surface (Fig. 5.3). Additionally, in Pr. quenstedti, the basipterygoid joint is more loaded than the overall stress pattern (Fig. 5.3), presenting higher degrees of compression (Fig. 5.6).

Extant turtles and Eubaena cephalica are characterized by increased magnitudes of overall stress in comparison to early stem turtle models (Fig. 5.5). In all of those models, regardless of clade affinity (i.e., Pleurodira, Cryptodira, or Paracryptodira; Fig. 5.2), the dorsal surface of the otic chamber is highly loaded, the basipterygoid suture shows less stress in relation to the rest of the skull, and the bar between the external nares and the orbit is highly loaded (as is also seen in Pr. quenstedti). In Pelodiscus sinensis and Chelodina reimanni (Fig. 5.3) the parabasisphenoid and the basioccipital, which have a more open and interdigitated suture in these taxa, is another stress hotspot. Taxa with extensive ventrolateral emarginations (i.e., C. reimanni, Terrapene ornata, and Emydura subglobosa) show an increased load laterally on the quadrate, inside the tympanic cavity (Fig. 5.2). Cryptodires (except for Pelod. sinensis) and Eu. cephalica, show higher compression anteriorly on the pterygoid and palatine than pleurodires (Figs. 5.3, 5.6). Chelodina reimanni and T. ornata, both turtles that lost their temporal bridges (Werneburg 2012, 2013b) show higher levels of overall skull stress (Figs. 5.2-5.3, 5.5). The trochlear process in pleurodires, as well as the external process of the pterygoid in cryptodires, show very light loads, but in Eu. cephalica, this region is highly stressed (Fig. 5.3). Although the dorsal surface of the otic chamber is 
more loaded than the overall stress distribution, the trochlear process is not particularly stressed in cryptodires and in Eu. cephalica, even when an extra trochlea, on the pterygoid is explicitly simulated on this region (Fig. 5.7D-H).

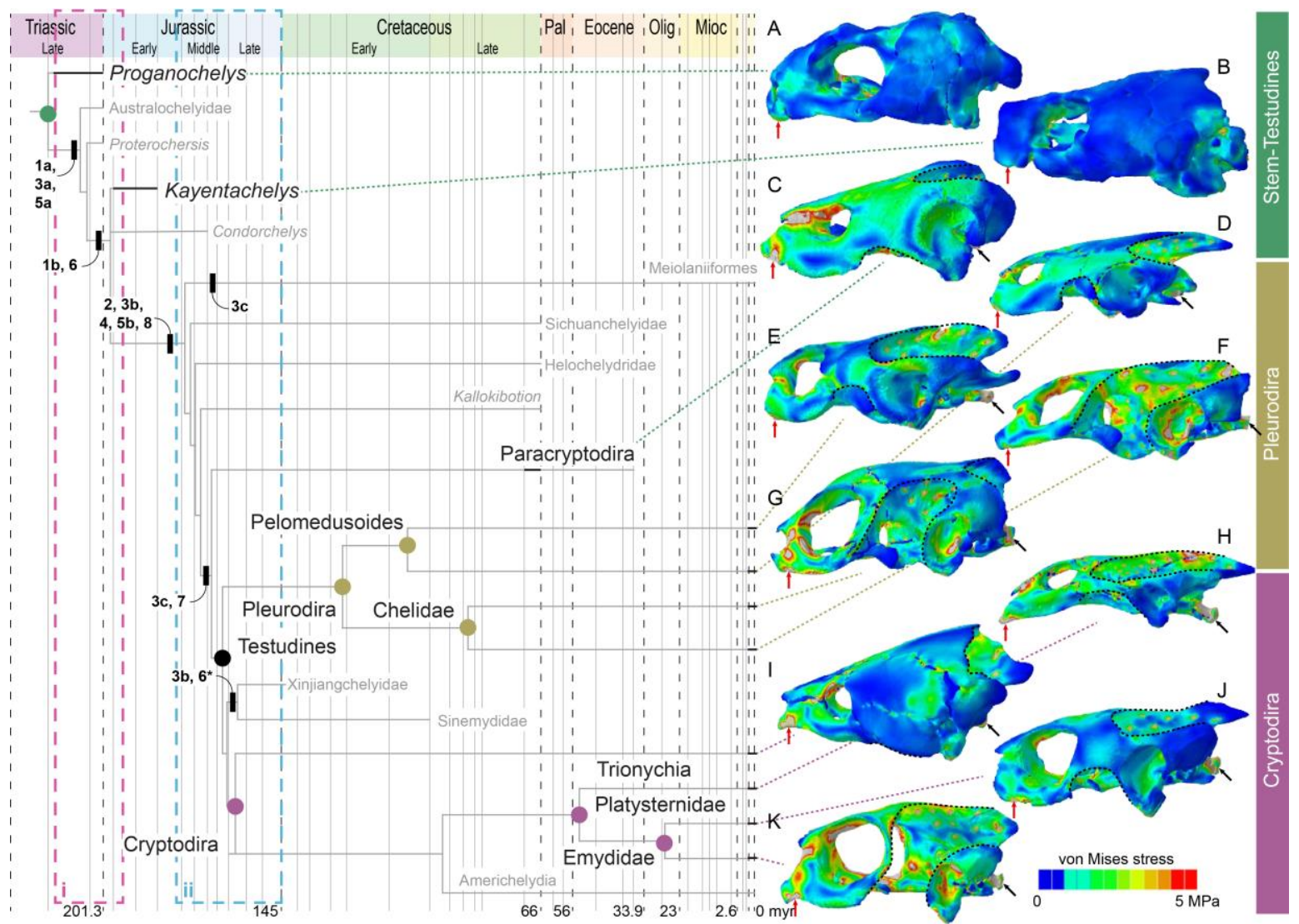

Figure 5.2. Time-calibrated phylogeny of turtles (modified from Joyce et al. 2016) and Von Mises stress contour plots for taxa analyzed in this study. Bold lines represent the stratigraphical distribution. (A) Proganochelys quenstedti, (B) Kayentachelys aprix, (C) Eubaena cephalica, (D) Podocnemis expansa, (E) Pelomedusa subrufa, (F) Chelodina oblonga, (G) Emydura subglobosa, (H) Pelodiscus sinensis, (I) Platysternon megacephalum, (J) Emys orbicularis, (K) Terrapene carolina. Contour plots are scaled to 5 MPa peak stress. 1a, enlarged otic chamber, but shallow tympanic cavity; 1b, enlarged otic chamber and deep tympanic cavity (largest); $\mathbf{2}$, adductor chamber extending posterior to otic chamber; 3a, basipterygoid process sutured and facing ventrally (low possible kinesis); $\mathbf{3 b}$, basipterygoid process sutured and facing laterally (lower possible kinesis); 3c, basipterygoid process absent (definitive akinesis); 4, secondary lateral braincase wall; 5a, reduced interpterygoid vacuities; $\mathbf{5 b}$, closed interpterygoid vacuities; $\mathbf{6}$, reduced foramen palatinum posterius; $\mathbf{7}$, reduced temporal roof by emarginations; 8, trochlear process; *, reversals. Dotted curves represent the margins of the emarginations. The purple "i" and the blue "ii" rectangles represent the first and second proposed selective regimes described below and on Fig. 5.9.

\subsubsection{Simulations in Proganochelys and Eubaena}

To test the effects of suturing the basipterygoid joint (Fig. 5.1F-G), a Pr. quenstedti model simulating a fixed joint was digitally created. The simulation (Fig. 5.7A-E) has little effect on the stress distribution in relation to its original model's contour plots (Figs. 5.2- 
5.4). Besides a slight increase in overall stress, especially on the skull roof, the most significant change is seen on the parabasisphenoid, which experiences much less stress than in the original model and in the area around the foramen palatinum posterius that shows slightly decreased loads in this hypothetical model (Fig. 5.7A, E).

Similarly, modeling a supraoccipital crest (Figs. 5.7B-F) to simulate the posteriorly extended origin sites of external jaw adductors found in later turtles (Fig. 5.2), results only in minor differences: the skull roof is somewhat more loaded, with more concentrated areas of stress on the parietal/frontal and postorbital/frontal sutures, and a less stressed cheek area (jugal/quadratojugal). More importantly, the basipterygoid articulation and the parabasisphenoid as a whole are more stressed in comparison to the original model. A third hypothetical, with both modifications (Fig. 5.7C-G) show a similar pattern to that only with the sutured basipterygoid articulation (Fig. 5.7A-E).

An additional model was also modeleld, with a pterygoid trochlea on the Eu. cephalica original model to simulate the intermediate morphology with two trochleae as was proposed by Joyce (2007). In contrast to the Pr. quenstedti models, the Eu. cephalica simulation (Fig. 5.7D-H) shows more significant effects. The external process of the pterygoid shows a much higher load when this trochlea is simulated (Fig. 5.7D) associated also to a change from compression to tension loads (Fig. 5.7H). The cheek region is under less stress (Fig. 5.7D) in comparison to the original model (Fig. 5.2C), but the border of the anteroventral emargination is slightly more compressed. Noteworthy, the basipterygoid joint shows a relief in compression when a pterygoid trochlea is present (Fig. 5.7H).

\subsubsection{Bite forces and efficiency}

Estimates for models simulating the trochlea (otic in cryptodires and pterygoid in pleurodires) show only slight decreases in bite force with the trochlea (1-15\%) in relation to the standard models (i.e., models without the explicitly modeled trochlear mechanism), except for Platysternon megacephalum, in which there was a $44 \%$ decrease in the estimated bite force (Fig. 5.8B). Yet, the decrease in bite efficiency was higher in the models with a trochlea: 12-25\%, and a 46\% decrease for Pl. megacephalum (Fig. 5.8B). Cryptodires and

pleurodires do not clearly differ in their range of bite efficiency (i.e., bite force divided by muscle force) (Fig. 5.8A), as within-group variation is higher than among-group variation 
(especially for pleurodires). Chelodina reimanni and Em. subglobosa are the least bite efficient models, whereas Eu. cephalica and Po. unifilis are the most bite efficient models. The bite efficiency (as well as the bite forces) of the stem turtles fell into the spectrum of the analyzed extant taxa (Fig. 5.8).

\subsection{Discussion}

\subsubsection{No increase of bite force in turtle evolution}

It has been thought that the origin of the trochlear mechanism in turtles enabled a biomechanical advantage with more efficient bite performances (Joyce 2007; Sterli \& de la Fuente, 2010). These, in turn, would be related to the great diversification the group experienced right after (Fig. 5.2), beginning at the Middle Jurassic (Shaffer et al., 1997; Parham \& Hutchison 2003; Danilov \& Parham 2006; Joyce et al. 2013, 2016; Evers \& Benson 2019). In this scenario, the trochleae appeared only after a series of modifications related to the origin of fully akinetic skulls in the clade including Kallokibotion bajazidi and Testudines (Joyce et al. 2016) (Fig. 5.2). These changes included the fixation of the braincase, palatoquadrate, and snout, and the development of an extensive secondary lateral wall of the braincase (Sterli \& de la Fuente 2010; Werneburg \& Maier 2019). Both the development of the trochlea and the posterior elongation of the supraoccipital and squamosal crests would be adaptive innovations related to increasing muscle power and bite forces. As such, turtles lacking both, such as Kayentachelys aprix (Sterli \& Joyce 2007), were considered not as powerful biters when compared to modern turtles (Sterli \& de la Fuente 2010). 

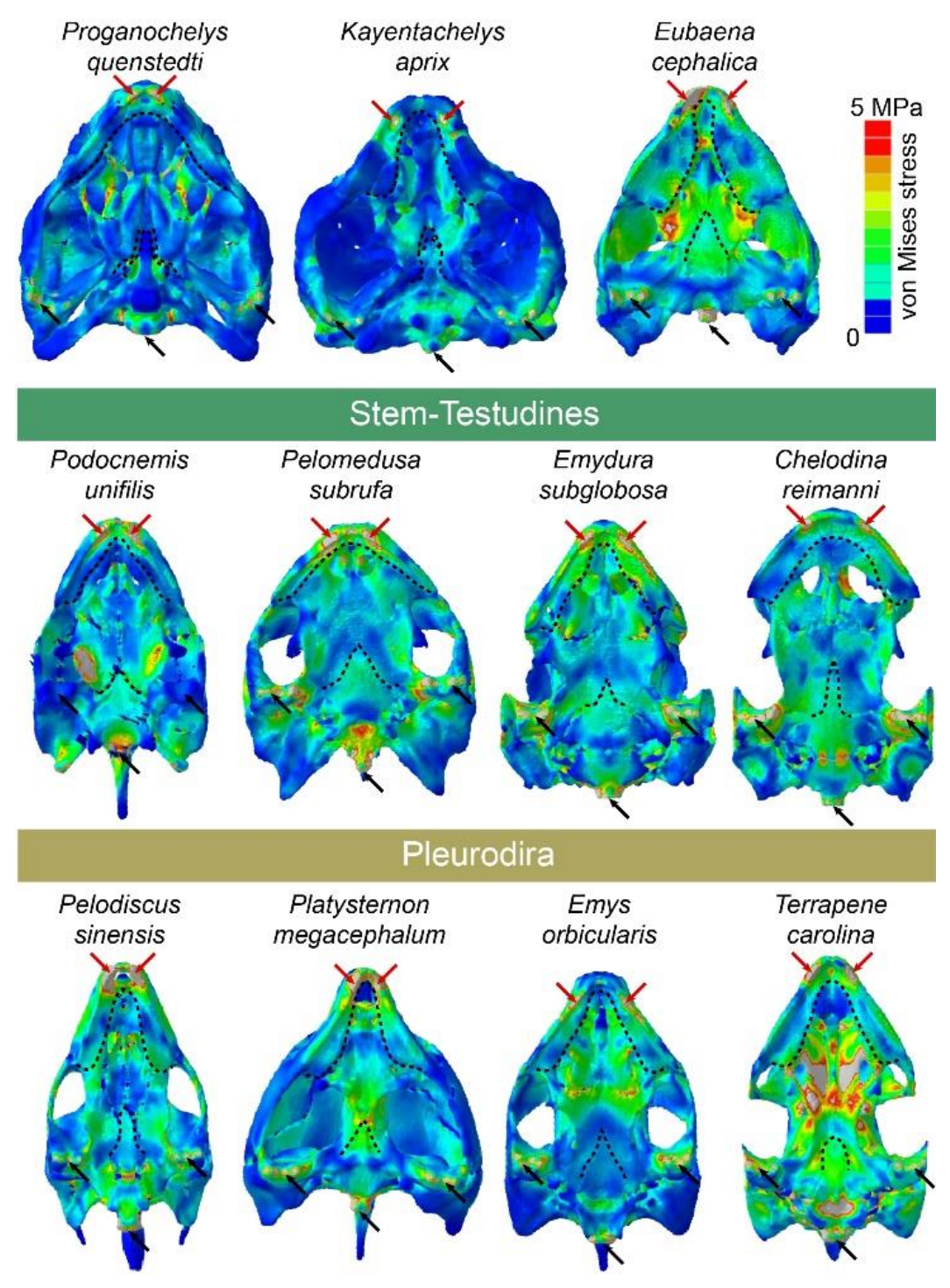

Cryptodira

Figure 5.3. Von Mises stress contour plots for sampled taxa in ventral view. Contour plots are scaled to $5 \mathrm{MPa}$ peak stress. Red and black arrows represent the bite and constrained points, respectively. Dotted curves anteriorly and posteriorly, identify the triturating surface and the basipterygoid articulation/suture.

The skull of Proganochelys quenstedti was still kinetic, but a trend towards the complete akinetic skull of Testudines began early along the stem lineage (Sterli \& de la Fuente 2010; Rabi et al. 2013). The first modifications can already be seen in K. aprix (Figs. $5.2 \mathrm{~B}, 5.3)$, in which the closure of the interpterygoid vacuities and reduction of the foramen palatinum posterius stiffened the snout and the basipterygoid articulation was sutured (Sterli \& Joyce 2007), at least decreasing movement in this region. The FEA models show that those areas were under high stress in Pr. quenstedti and that in Kay. aprix and other testudinates, 
they became less stressed at the same time that more extensive sutures developed (Fig. 5.3). However, unlike in the case of crocodilian evolution (Preuschoft \& Witzel 2002, 2005; Erickson et al. 2003), skull stiffening in turtles is associated only with a moderate increase in bite forces (Fig. 5.8B). Similarly, the posterior elongation of the adductor chamber that occurred later than the node from which Kay. aprix split (Fig. 5.2) does not seem to have considerably increased bite forces and efficiency, in opposition to what was previously thought (Sterli \& de la Fuente 2010): estimates based on the present models show K. aprix inside the spectrum of Testudines (Fig. 5.8) and simulating a supraoccipital crest on a $P r$. quenstedti model (Fig. 5.7B, F) does not result in higher bite force values either. The distribution of bite force and bite efficiency shows no clear differences between stem turtles without supraoccipital and squamosal crests, and crown turtles with them (Fig. 5.8). This might seem contra-intuitive since the posterior elongation of the adductor muscles seems to result in longer and hence stronger fibers. However, 1.) the concomitant enlargement of the otic chamber in turtles (Gaffney 1979; Joyce 2007) decreased the available volume inside the adductor chamber, so posterior elongation emerged as a mean to compensate for it. Also, 2.) even though bite force can be altered by several and non-mutually exclusive means, including the arrangement of muscle fibers and altering the composition of muscle fiber types (Gans et al. 1985), it is well-known that a trade-off related to fiber length exists between force and speed (Herrel et al. 2002). Moreover, 3.) even if the posterior elongation of the adductor chamber resulted in a volume increase, this was achieved by an increase in fiber length, which is also related to changes in speed, not necessarily to force only (Schenk \& Wainwright 2001). This might explain why more powerful bite force is not seen in turtles with posterior crests both in the FE models (Fig. 5.8) and in experimental studies (Herrel et al. 2002). 

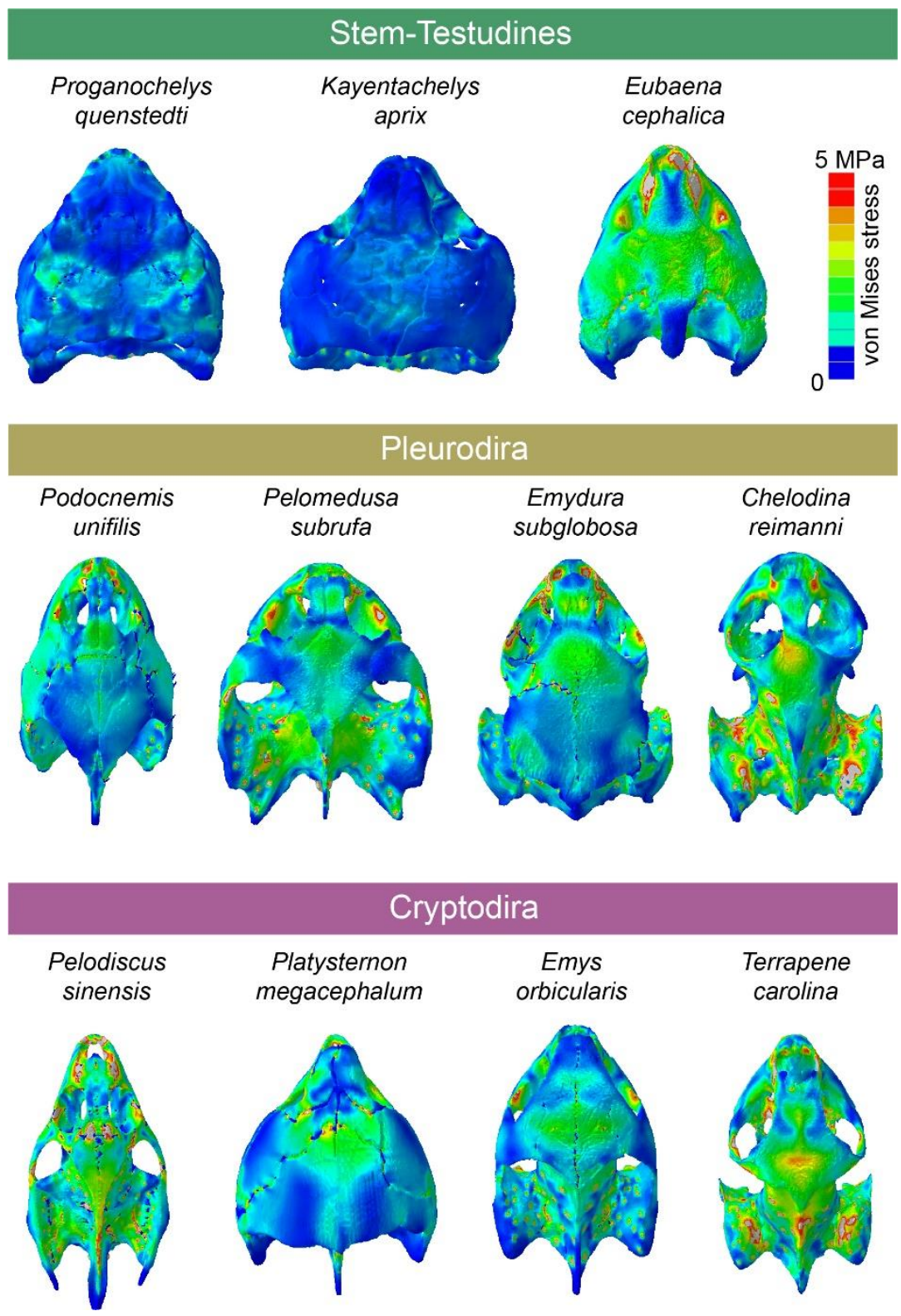

Figure 5.4. Von Mises stress contour plots for sampled taxa in dorsal view. Contour plots are scaled to $5 \mathrm{MPa}$ peak stress.

Finally, explicitly simulating the trochlea (in the otic chamber in cryptodires and in the pterygoid in pleurodires) in the models actually decreases the estimated bite force (Fig. 6.8B), which can be explained by the physical attributes of the trochlea, according to which part of the muscle force will be lost during attrition of the transiliens cartilage (Schumacher 1973) to the bone surface of the trochlear process. At the same time, empirical studies show that turtles possess similar bite forces to other reptiles (Herrel et al., 2002) (except for crocodiles), so, there is no support to believe that the origin of the supraoccipital and 
squamosal crests and the (otic) trochlear system along the stem to modern turtles resulted in more powerful jaws in comparison to their non-turtle ancestors. However, the changed line of action of the external jaw adductor muscles (Schumacher 1973; Iordansky 1996; Ferreira \& Werneburg 2019) due to the presence of a trochlear mechanism likely has a more substantial effect on the lever mechanics of the mandible. This might be affected by the height and by the anteroposterior position of the trochlea (i.e., on the otic chamber or on the pterygoid), which might change the position of the insertion site and, hence, the lever on the lower jaw. While this increased efficiency is focused in the mandible, the skull structure might have experienced no or little negative effects despite of the increased loads acting on it.

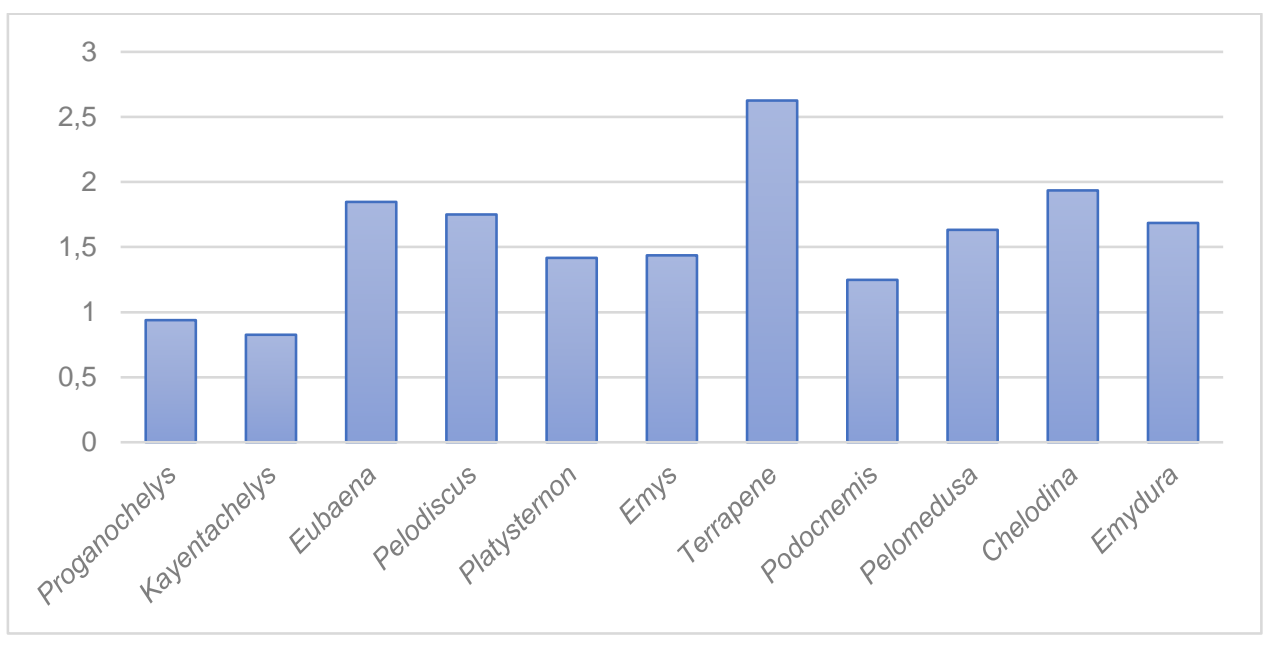

Figure 5.5. Average von Mises stress (MPa per element), i.e., total sum of skull stress divided by the number of osseous elements in the skull.

\subsubsection{Neck retraction triggers a series of skull modifications}

A common line of reasoning proposes that the posterior elongation of the adductor chamber was a consequence of the hypertrophy of the otic region, which restricts space inside the adductor chamber (Schumacher 1973; Gaffney 1975; Joyce 2007; Sterli \& de la Fuente 2010). This, though, raises the question of why turtles developed posteriorly (Romer 1956; Ferreira \& Werneburg 2019) rather than dorsally expanded skulls, a much more common strategy of fiber elongation in reptiles? Considering that extant macrocephalic turtles with high skulls, e.g., Platysternon megacephalum (Fig. 5.2I) and Chelonia mydas (Jones et al., 2012), are incapable to fully retract their head and neck inside their shells (Werneburg 2015; Werneburg \& Maier 2019), this likely represented a functional constraint during turtle 
evolution. We hypothesize that the origin of posterior crests was also related to the need to (at least) maintain ancestral bite performances in a system that accommodates neck retraction. In other words, high, dorsoventrally expanded skulls would be negatively selected in a case in which hiding the head and neck is a protective advantage (Herrel et al. 2002). Also, developing a trochlear system in the hypothesis I present here was the only solution to accomplish the posterior elongation, since, in this manner, the otic chamber would be on the course of the muscle fibers.
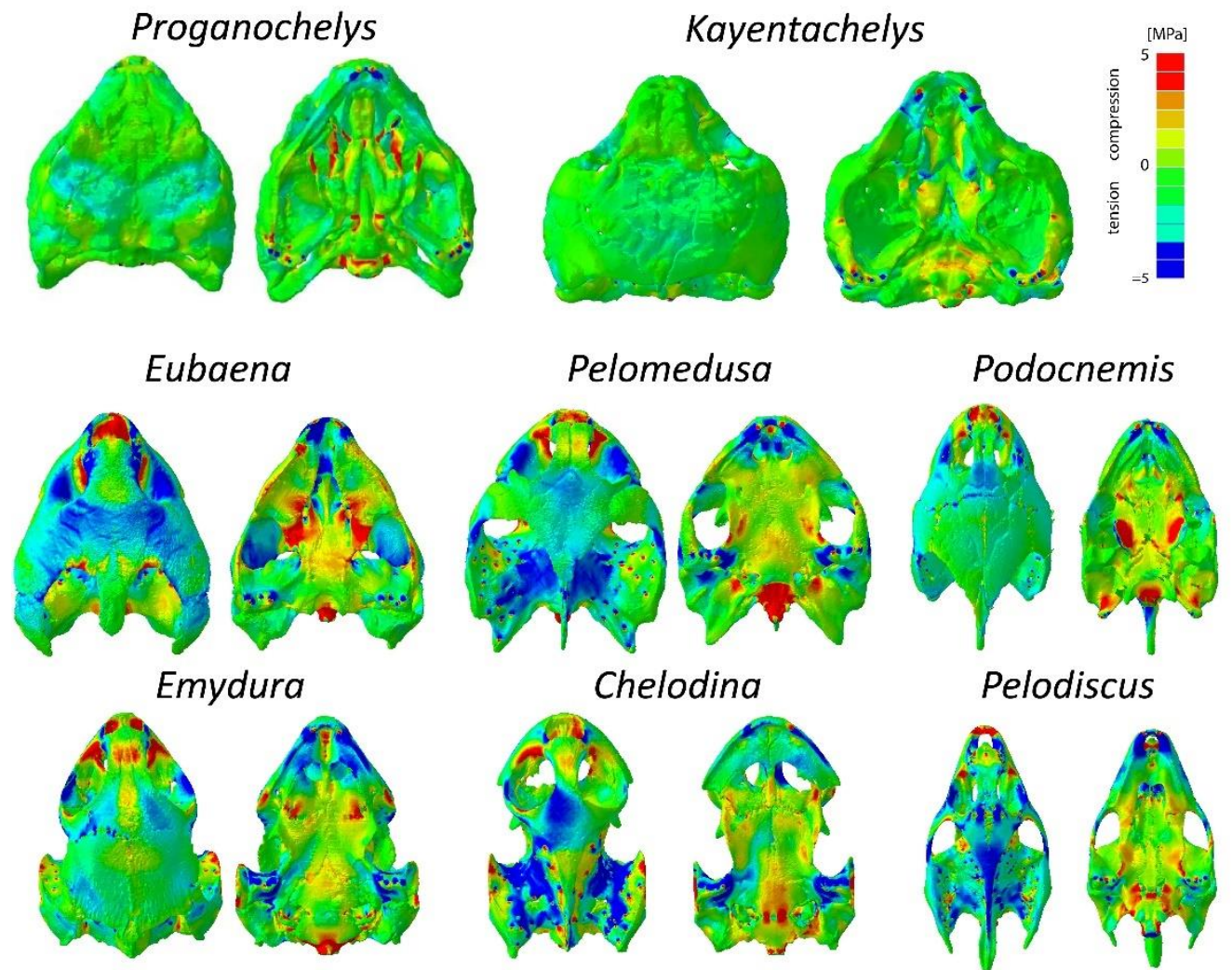

\section{Pelodiscus}
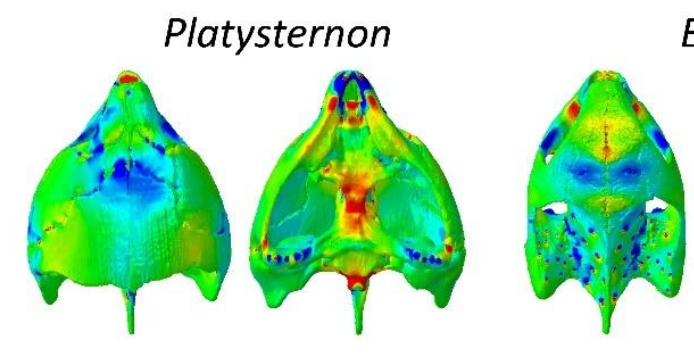

Emys
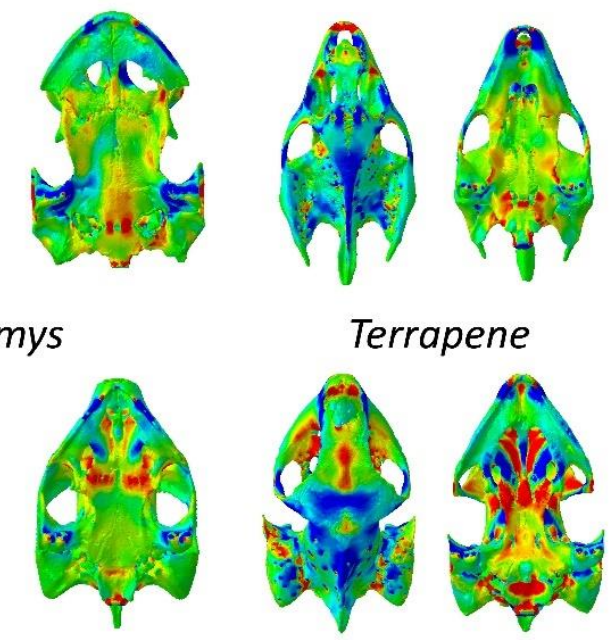

Figure 5.6. Tension/compression plots for the taxa analyzed in this chapter. Models in dorsal and ventral view on the left and right, respectively. All models are scaled to 5 to $-5 \mathrm{MPa}$ peaks stress.

Building on previous hypotheses (Werneburg et al., 2015a, b; Werneburg 2015; Werneburg \& Maier 2019), I suggest a more detailed scenario for the evolution of the highly 
modified turtle skull. I propose a progressive correlation between skull architecture and neck evolution (Fig. 5.9), that incorporates two phases of distinct selective regimes. The first, related to increased neck mobility and skull stiffening, occurring early in turtle evolutionary history ( $\alpha$ in Figs. 5.2, 5.9) and the second, closer to the diversification of crown Testudines ( $\beta$ in Figs. 5.2, 5.9), related to the posterior elongation of the adductor chamber and the pulley system, and longer necks.

$\alpha$ ) The present results show that the fixation of the snout and the basipterygoid articulation, as well as the development of a secondary lateral wall of the braincase ( $i \& i i$ in Fig. 5.9) during the first phase of turtle evolution stabilized those regions which were more fragile (Fig. 5.3) during feeding movements, even though the skull as a whole was more heavily built and stress resistant (Fig. 5.2-5.4). Both areas were under high stress in $P r$. quenstedti and became alleviated in Kay. aprix (Fig. 5.3). The Pr. quenstedti hypothetical model with a sutured basipterygoid joint also shows reduced stress around this contact, even when the supraoccipital crest is also modeled (Fig. 5.7A, C) supporting this observation. However, simply stiffening the skull in turtles does not result in higher bite forces and the present estimates do not support a higher force or efficiency in modern turtles in comparison to earlier testudinates (Fig. 5.8). As such, these biomechanical analyses do not support an increase in bite force as the main factor related to the development of cranial akinesis in turtles, in opposition to crocodiles or temnospondyls (Preuschoft \& Witzel 2002, 2005; Erickson et al. 2003; Witzmann \& Werneburg 2017). At the same time, mounting evidence has been presented for an extensive influence of increased neck mobility - and consequent muscle reorganization - on the fixation of the palatoquadrate to the braincase (Werneburg \& Maier 2019), and I here propose that this influence might have triggered the path to complete akinetic skulls in turtles (Fig. 5.9) very early in their evolution (K. aprix node in Fig. 5.2). 
A
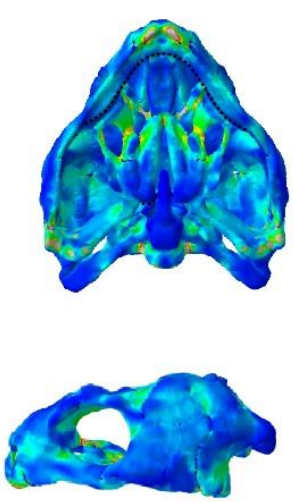

E

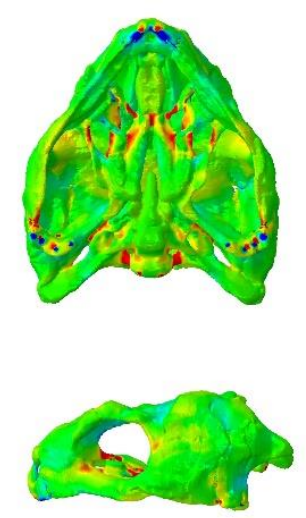

B
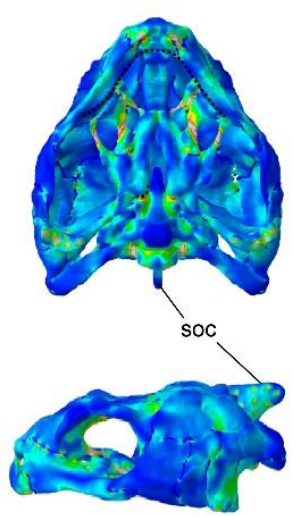

$\mathrm{F}$

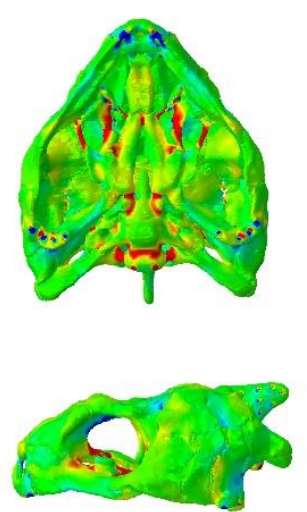

C
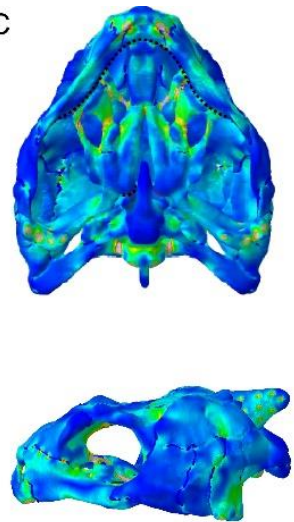

G
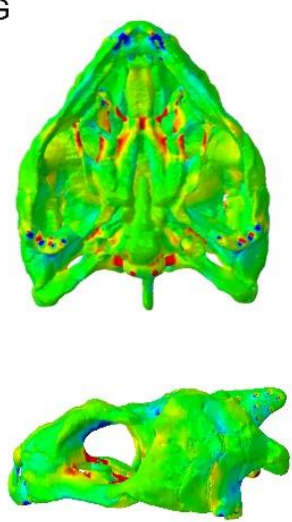
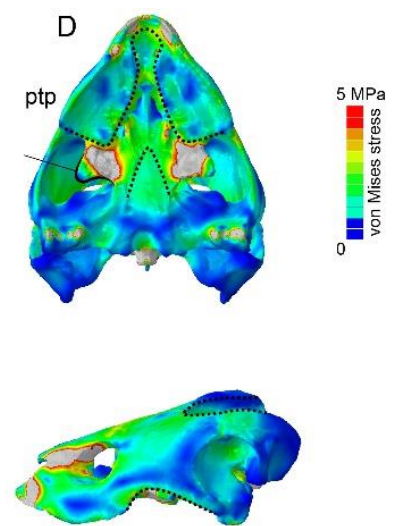

$\mathrm{H}$

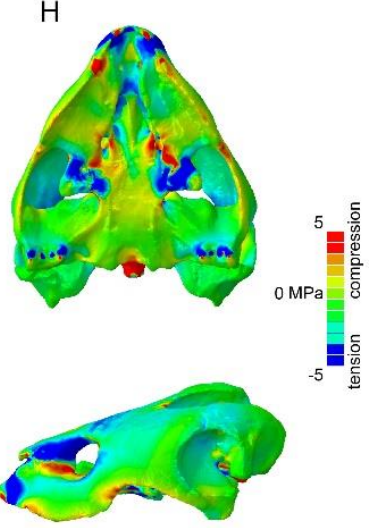

Eubaena cephalica

Figure 5.7. Von Mises stress (A-D) and tension/compression (E-H) contour plots in ventral (top row) and left lateral (bottom row) views for hypothetical models of Proganochelys quenstedti with $(\mathbf{A}, \mathbf{E})$ basipterygoid suture, (B, F) supraoccipital crest, and both basipterygoid suture and supraoccipital crest $(\mathbf{C}-\mathbf{G})$, and of Eubaena cephalica with a pterygoid trochlea $(\mathbf{D}-\mathbf{H})$. Contour plots are scaled to $5 \mathrm{MPa}$ peak stress. Dotted curves in ventral view, anteriorly and posteriorly, identify the triturating surface and the basipterygoid articulation/suture, and in lateral view the anteroventral and posterodorsal emarginations. Abbreviations: ptp, pterygoid trochlear process; soc, supraoccipital crest.

$\beta$ ) Even though the results do not support an increase in bite force related to the elongation of the adductor chamber, they evidence that elongation might have occurred in response to a decrease in volume due to the enlarged otic chamber (iii in Fig. 5.9). The first steps of otic chamber enlargement can be seen as early as in K. aprix (Sterli \& Joyce 2007), which also shows an incipient elongation of the posttemporal region (Joyce 2007). The presence of a shell, though, represented a constraint on higher skulls due to the need for tucking the head and short neck for protection (Herrel et al. 2002; Werneburg et al. 2015a, b). Thus, posteriorly expanding the supraoccipital and squamosal crests ( $v$ in Fig. 5.9) was the only way to balance the decreased volume inside the adductor chamber, but with it, the enlarged otic chamber is on the direct course of the muscle fibers (Schumacher 1973; Joyce 
2007). The fixation of the palatoquadrate to the braincase resulted in higher overall stress values on the turtle skull (Fig. 5.2-5.3), maybe because of the loss of elasticity that could buffer the loads in the whole structure (sensu Werneburg et al. 2019). Yet, at the same time, the stiffening created an optimized solution in the sense of higher maximal load resistance with minimized material (Fig. 5.5). Also, a more resistant skull enabled the quadrate to withstand the compression forces exerted by a trochlear mechanism on its surface ( $v i$ in Fig. 5.9) (Gaffney 1975; Rieppel 1990; Joyce 2007; Sterli \& de la Fuente 2010), which finally made the posterior expansion of the adductor chamber possible and a shift of the bite efficiency to the mandible without negatively impacting the skull. This opened another evolutionary path, allowing skulls to become relatively flatter ( $i v$ in Fig. 5.9), and thus creating the second selective regime of skull modifications ( $\beta$ in Figs. 5.2, 5.9).

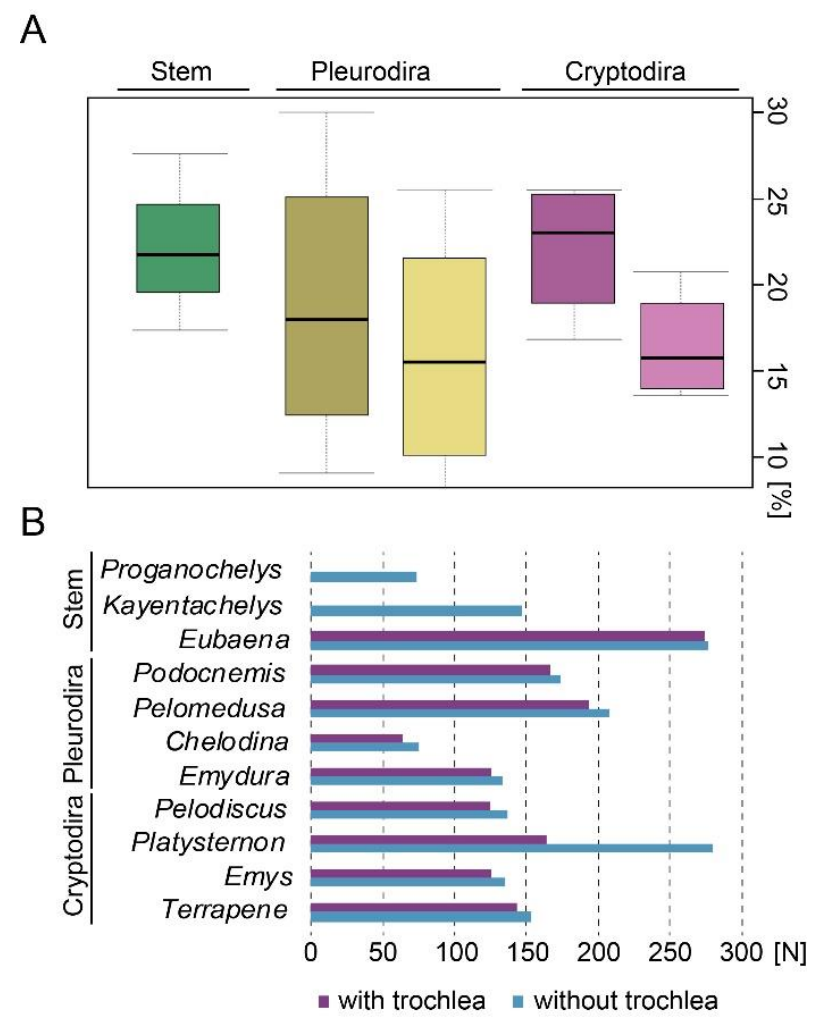

Figure 5.8. (A) Box plot of bite efficiency for Cryptodira, Pleurodira, and stem-turtles. Estimates for models with and without trochleae explicitly simulated left and right, respectively. (B) Bite force estimates for sampled taxa. Note there is no separation of the range of bite efficiency values among species.

\subsubsection{Reduction of the temporal skull coverage}

The walls of the adductor chamber in early testudinates exclusively provided the origin sites for the external jaw adductors (Ferreira \& Werneburg 2019). As such, they could 
not be reduced, even though this region may not have been structurally necessary, as evidenced by the low stress distribution on it (Fig. 5.2A-B). With the potential to evolve longer and flatter skulls created by skull stiffening ( $i$, ii \& $i v$ in Fig. 5.9) -which can be seen early in the Jurassic xinjianchelyids (Rabi et al. 2013) (Fig. 5.2) - the muscle origin sites are shifted away from the adductor chamber roof to the supraoccipital and squamosal crests (Werneburg 2011, 2013; Ferreira \& Werneburg 2019). This and the optimization for minimizing material (described above) enabled the development of marginal reductions of temporal bones (vii in Fig. 5.9) (Sterli \& de la Fuente 2010; Werneburg et al., 2013; Ferreira \& Werneburg 2019) which, in turn, freed stronger attachment sites for more complex neck muscles (viii in Fig. 5.9) (Werneburg 2015).

Also, the stabilization of the quadrate was originally obtained by the temporal coverage, and the fixation of the braincase releases it from this function (Werneburg 2012; Werneburg \& Maier 2019). This event in itself did not diminish, but actually increase stress on specific areas of the temporal roof, especially around the contacts of the jugal, quadratojugal, and squamosal (Fig. 5.4), a pattern also found in extant taxa with secondarily extensive temporal coverages, e.g., Podocnemis unifilis and Pl. megacephalum (Fig. 5.2D, I). In most turtles, those areas correspond to the temporal bridge that is almost always maintained between the anterolateral and posterodorsal emarginations (Werneburg 2013; Ferreira \& Werneburg 2019), suggesting they are important structural components of the turtle skull. The few taxa lacking those bridges, e.g. C. reimanni and T. carolina, show higher degrees of total stress (Figs. 5.2-5.3), supporting this hypothesis. Consequently, also more complex neck movements and retraction modes benefit from more extensive emarginations and broader bridges, which serve as strong and stable neck muscle attachment sites, and, in this way, only a certain part of the temporal coverage can be reduced. The increased ossification and reduction in regions that were ancestrally submitted to high or low loads, respectively, illustrate the powerful tool FEA can be for detecting morphological evolutionary patterns in complex structures.

\subsubsection{The pterygoid trochlear in pleurodires}

The muscle (Werneburg 2011, 2013; Ferreira \& Werneburg 2019) and skull reorganization (Sterli \& de la Fuente; Rabi et al. 2013; Werneburg \& Maier 2019) related to 
the pterygoid trochlea in pleurodires do not result in more efficient bites either (contra Joyce 2007) (Fig. 5.8). Also, cranial competence (i.e., the capacity to sustain stress) is not compromised by the presence of the pterygoid trochlea and other morphological changes. Hence, the presence of a pterygoid trochlear has no substantial effect on the bite force when looking at the skull, which possesses several other (competing) functions, aside from biting. It is possible, though, that an increase in efficiency can be retrieved from the lower jaws (due to changing the position and, to a lesser degree, the angle of attack of the jaw musculature), which are the main functional device for biting. Thus, it can be assumed that the hypothesized increase in bite force is solely achieved by redirecting the muscle insertion angle on the lower jaws; a hypothesis that will be tested by further FEAs based on lower jaw models. The pterygoid trochlea is actually related to a less stressed basicranium and cheek region (Figs. 5.2-5.3). The hypothetical model of Eubaena cephalica with a 'pleurodiran'-like trochlea (Fig. 5.7D-H) also shows a slightly reduced load on these regions.

In cryptodires and some late stem-turtles, e.g., Meiolania platyceps and Kallokibotion bajazidi (Gaffney 1975, 1983) (Fig. 5.2), the pterygoid is posteriorly expanded and closes the cranio-quadrate space (Joyce 2007). In pleurodires, neck forces during embryonic development reorient the palatoquadrate cartilage and prevent the pterygoid from traveling so far posteriorly. Thus, the cranio-quadrate space is closed by the formation of appositional bone, a process called the "Esswein fixation" (Werneburg \& Maier 2019). This different mode of fixation and, consequently, of skull architecture, seems to be related to a distinct stress distribution on the external process of the pterygoid: in cryptodires and Eu. cephalica, this pterygoid process is more loaded than in pleurodires (Fig. 5.3), even when a pterygoid trochlea is explicitly simulated (Fig. 5.7D-H). This, in turn, might have triggered this process to expand and to assume the function of the trochlea in Pleurodira, which decreased stress on the parabasisphenoid and basioccipital, keeping efficiency. I hypothesize that even lower loads on the basicranium of pleurodires during biting enabled the expansion of neck muscles onto its ventral surface (Werneburg 2011, 2015; Werneburg \& Maier 2019) and reduction of the cheek bones (Werneburg 2015) in this group. This association can be further explored by future FEA on additional skull models including neck musculature, for which, however, first of all, basic research on neck muscle anatomy has to be performed and fundamental homology issues have to be resolved (Werneburg 2011). 


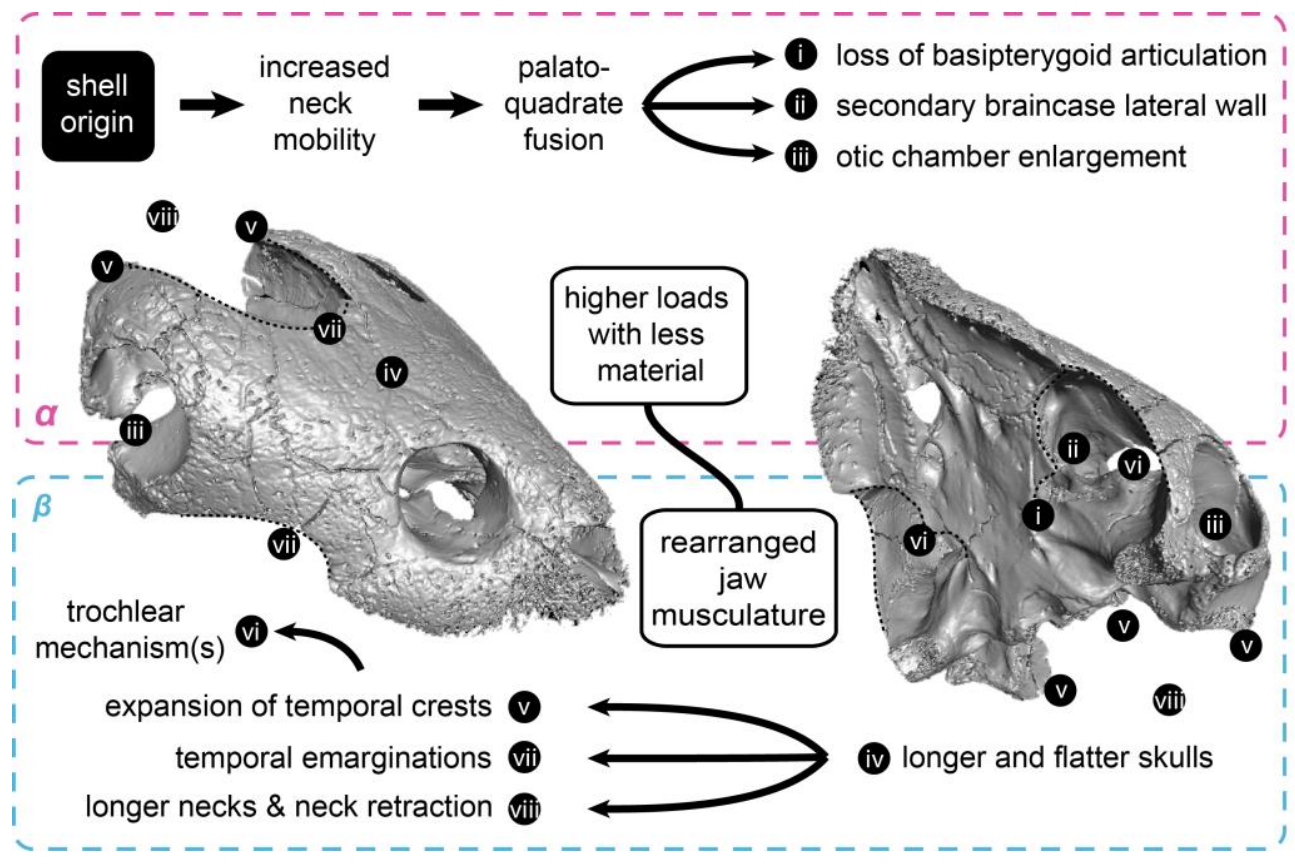

Figure 5.9. Scenario of progressive correlation between neck and head during turtle evolution. The origin of the turtle shell initiates the first selective regime $(\boldsymbol{\alpha})$ in which muscle rearrangements enable more flexible necks that overcome the lack of mobility in consequence of the shell, but also exert distinct compression and tension loads on the skull, which is solved by an increasing stiffness [through palatoquadrate fusion, closure of basipterygoid region (i), secondary braincase lateral wall (ii) formation]. The new, stiffened skull architecture can withstand higher loads at the same time allowing material reduction in the temporal region, opening the path to a second selective regime $(\boldsymbol{\beta})$. Longer and flatter skulls (iv) evolve, together with posterior expansion of the supraoccipital and squamosal crests (v), also influenced by the enlargement of the otic chamber (iii) that reduced the available volume inside the adductor chamber. Both of these triggered the appearance of a trochlear mechanism (vi) on the outer surface of the otic chamber. The expansion of the temporal crests (v) offered broader insertion sites for the neck musculature, supporting a second round of neck evolution, resulting in longer necks and modern types of neck retraction (viii). Temporal emarginations (vii) evolve in response to new forces generated by more powerful neck musculature.

\subsection{Conclusions}

In conclusion, the Finite Element Analyses of turtle skulls do not support previous hypotheses about a relation between the origin of cranial akinesis and higher bite forces and a more efficient bite related to the pleurodiran trochlear system. Yet, they do show that this new skull architecture, redistributes stress and creates a structure optimized to resist higher loads with less material and supports the trochlear mechanism to maintain mandibular bite force without negatively impacting the skull. In this manner, a chain of progressive correlation (Fig. 5.9) between the reorganization of the muscles related to the turtle's high neck mobility (Werneburg et al. 2015b) and the fixation of the palatoquadrate related to the akinetic skull is stunning. I present a scenario of associations based on our FEA and the 
available paleontological evidence (Fig. 5.9): the origin of the turtle shell is related to the evolution of increased neck mobility that compensates the stiffened body and neck retraction protects the head. The associated topological changes of neck muscles are buffered by the fusion of the palatoquadrate to the braincase and consequent closure of the basipterygoid articulation, which was particularly under high stress during bite movements (Fig. 5.3). The stiffened skull withstands higher loads while also accommodating bone reduction, freeing the potential to acquire more diverse architectures, including longer and flatter heads. Posterior elongation of the skull, trochlear mechanisms and the potential to evolve temporal emarginations, in turn, enabled the path to another round of modifications on the neck, with muscles attaching to stronger temporal bridges closer to the origin of Testudines. Finally, the potential for the development of more diverse skull architectures and longer and flexible necks opened new adaptive paths for the great diversification turtles experienced since the Jurassic. 


\section{Conclusions of this Thesis}

\subsection{Chapter 2:}

- Even though turtles have been a subject of intensive research for the last 200 years, several important aspects of their morphological, developmental, and phylogenetic evolution are still heavely debated. The overview presented in Chapter 2 summarizes important issues of morphological evolution of the craniocervical system of turtles, some of which tackled by further contributions of my thesis.

- Developmental studies, for example, might be conducted in the future to assess the potential homology of some traits in turtles and other reptiles, e.g. the eye muscle pyramidalis and the pattern of differentiation of the posterior adductor and intermandibularis muscles (similar to those in archosaurs). Ontogenetic studies on muscle development are in general rare for turtles, and constitute an area of expansion that can potentially help answering important question regarding the origin of some of the group's traits.

- The repetitive origins of temporal emarginations have been correlated to neck mobility and systems of neck retraction, but variation among taxa with similar types of neck retraction (e.g., pleurodires) hint at the possibility that there might be other factors affecting this feature. Those factors may also affect the evolution of temporal fenestration in other reptiles, being thus of broader interest. Biomechanical analyses (e.g. FEA) are a promising approach to assess that issue, and also the function of the m. zygomaticomandibularis in Trionychia. Muscles analogous to this are found in distantly related lineages (mammals, some birds, and the dinosaur Psittacosaurus), suggesting that there might be a relation to specific feeding behaviors.

- The reconstruction of the jaw adductor musculature in the earliest turtle Proganochelys quenstedti, combining anatomy, ancestral state reconstruction and 3D modeling, constitute an important step towards understanding the evolution of jaw 
muscles in turtles and amniotes in general. The resulting models might also be used to understand the functional implications of other traits, such as the trochlear mechanism, the posteriorly elongated temporal crests, and the akinetic skull (as done in Chapter 5 of this thesis).

\subsection{Chapter 3}

- The presented 3-D digital reconstructions and comparative descriptions of the endocast of the brain, nasal cavity, endosseous labyrinth, and neurovascular structures of $P$. quenstedti (and ten additional turtles) in Chapter 3 allowed the interpretation of the neuroanatomy during the initial steps of the evolution of the turtle lineage. Proganochelys quenstedti possessed a simple tube-like brain with poorly differentiated regions and likely mediocre hearing and vision, but a large nasal cavity, suggesting a well-developed olfactory sense.

- Morphological comparisons to other turtles indicate an increase in size and regionalization of brain structure in the group. The morphospace approach to investigate the endocast shape along the evolution of turtles in a larger scale, including other amniotes, as well as the morphology of the endosseous labyrinth of P. quenstedti, do not provide evidence for a fossorial habit, but support its interpretation as a land-dwelling turtle.

\subsection{Chapter 4}

- A new fossil pleurodire, Yuraramirim montealtensis, from the Late Cretaceous of the Adamantina Formation, Brazil, was presented. The new material was described comparatively and included in a phylogenetic analysis showing its affinity to Peiropemydidae, the sister-clade to the crown Podocnemididae.

- The endocasts of the brain, endosseous labyrinth and neurovascular system were reconstructed based on $\mu \mathrm{CT}$ images, so that $Y$. montealtensis represents the first fossil pleurodire to have its neuroanatomy analyzed based on digital reconstructions. Noted differences (e.g., degree of pontine and cephalic flexures) to the endocasts of other 
pleurodires, such as Bothremys cooki and Chedighaii barberi, which are similar to extant sea turtles, may be associated to a tentative marine habit of the latter. However, neuroanatomical studies of fossil turtles (specially including pleurodires) are still scarce to make reliable large-scale conclusions. The data provided in Chapter 4 is an important contribution to our understanding of this subject, including patterns of carotid circulation.

\subsection{Chapter 5}

- The previous hypotheses on the relation between (1) the akinetic skull and stronger bite forces and (2) a more efficient bite and the pleurodiran trochlear system are not confirmed by the functional analyses presented in Chapter 5.

- On the other hand, the Finite-Element Analyses (FEAs) showed that the morphological modifications related to the new skull architecture of turtles, redistributed stress, creating an optimized structure, capable of resisting higher loads with less material and supporting the new loads exerted by the trochlear mechanisms.

- The presented chain of progressive correlations between skull and neck changes connects the reorganization of the neck musculature to the turtle's high neck mobility and to the fixation of the palatoquadrate, which is itself related to the lack of cranial kinesis in the group.

- The sequence of events documented by the fossil record, in association with the results of the FEAs, permits the proposition of the following scenario: increased neck mobility compensates the clumsy and less mobile body of turtles due to the origin of the shell, and neck retraction protects the head; associated topological changes of neck musculature are buffered by the palatoquadrate fixation and the related loss of cranial kinesis; a rigid and optmized skull opens the path for novel skull architectures; the associated posterior elongation of the adductor chamber, the trochlear mechanisms, and the potential for marginal bone reductions on the skull roof, enabled the path, closer to the diversification of Testudines, for a new series of neck change, with muscles attaching to new areas on the skull. New skull architectures and longer and more flexible necks might have been associated with the great diversification of 
crown turtles since the Jurassic, a hypothesis that should be tested by analyses of macroevolutionary patterns. 


\section{References}

\footnotetext{
A bel, R. L., Laurini, C. R., \& Richter, M. (2012). A palaeobiologist's guide to "virtual" micro-CT preparation. Palaeontologia Electronica, 15(2), 6T.
}

Adler, K. (2007). The development of systematic reviews of the turtles of the world. Vertebrate Zoology, 57(2), 139-148.

Alberch, P., Gould, S. J., Oster, G. F., \& Wake, D. B. (1979). Size and shape in ontogeny and phylogeny. Paleobiology, 5(3), 296-317.

Alvarenga, H., \& Nava, W. R. (2005). Aves Enantiornithes do Cretáceo Superior da Formação Adamantina do Estado de São Paulo, Brasil. Congresso Latinoamericano de Paleontologia de Vertebrados, 20.

Amundson, R. (2005). The changing role of the embryo in evolutionary thought. https://doi.org/10.1017/cbo9781139164856

Amundson, R. (2007). Richard Owen and animal form. In R. Amundson (Ed.), Richard Owen: On the nature of limbs (pp. xv-lii). Chicago: University of Chicago Press.

Anderson, N. J. (2009). Biomechanics of feeding and neck motion in the Softshell turtle, Apalone spinifera, Rafinesque. Idaho State University.

Andrade, M. B., \& Bertini, R. J. (2008). A new Sphagesaurus (Mesoeucrocodylia: Notosuchia) from the Upper Cretaceous of Monte Alto City (Bauru Basin, Brazil), and a revision of the Sphagesauridae. Historical Biology 20, 101-136

Angielczyk, K. D., Burroughs, R. W., \& Feldman, C. (2015). Do turtles follow the rules? Latitudinal gradients in species richness, body size, and geographic range area of the world's turtles. Journal of Experimental Zoology Part B: Molecular \& Developmental Evolution 324, 270-294. doi:10.1002/jez.b.22602

Anquetin, J., Tong, H., Claude, J. (2017); A Jurassic stem pleurodire sheds light on the functional origin of neck retraction in turtles. Scientific Reports 7, 42376. doi:10.1038/srep42376 
Araújo, R., \& Polcyn, M. J. (2013). A biomechanical analysis of the skull and adductor chamber muscles in the Late Cretaceous Plesiosaur Libonectes. Palaeontologica Electronica 16(2:10A), 1-25

Araújo, R., Fernandez, V., Polcyn, M. J., Fröbisch, J., \& Martins, R. M. (2017). Aspects of gorgonopsian paleobiology and evolution: insights from the basicranium, occiput, osseous labyrinth, vasculature, and neuroanatomy. PeerJ 5, e3119.

doi:10.7717/peerj.3119

Archibald, J. D. (2011). Extinction and Radiation: how the fall of dinosaurs led to the rise of mammals. Baltimore: The Johns Hopkins University Press.

B adyaev, A. V., \& Uller, T. (2009). Parental effects in ecology and evolution: Mechanisms, processes and implications. Philosophical Transactions of the Royal Society B: Biological Sciences, 364(1520), 1169-1177. https://doi.org/10.1098/rstb.2008.0302

Báez, A. M., Gómez, R. O., Ribeiro, L. C. B., Martinelli, A. G., Teixeira, V. P. A., \& Ferraz, M. L. F. (2012). The diverse Cretaceous neobatrachian fauna of South America: Uberabatrachus carvalhoi, a new frog from the Maastrichtian Marília Formation, Minas Gerais, Brazil. Gondwana Research 22, 1141-1150

Baird, I.L. (1970). The anatomy of the reptilian ear. In C. Gans \& T. S. Parsons (Eds.), Biology of the Reptilia (pp. 193-275). London: Academic Press

Balanoff, A. M., Bever, G. S., Colbert, M. W., Clarke, J. A., Field, D. J., Gignac, P. M., ... \& Walsh, S. (2016). Best practices for digitally constructing endocranial casts: examples from birds and their dinosaurian relatives. Journal of Anatomy, 229(2), 173190

Balanoff, A. M., Bever, G. S., Rowe, T. B., \& Norell, M. A. (2013). Evolutionary origins of the avian brain. Nature, 501(7465), 93-96. https://doi.org/10.1038/nature12424

Bang, B. G. (1971). Functional anatomy of the olfactory system in 23 orders of birds. Acta Anatomica. 79, 1-76. doi:10.1159/000143668

Bang, B. G., \& Wenzel, B. M. (1985). Nasal cavity and olfactory system. In A.S. King \& J. McLelland (Eds.), Form and function in birds, (pp. 195-225). New York: Academic Press

Barrett, P. M., \& Rayfield, E. J. (2006). Ecological and evolutionary implications of dinosaur feeding behaviour. Trends in Ecology and Evolution, 21(4), 217-224. https://doi.org/10.1016/j.tree.2006.01.002 
Batezelli, A. (2015). Continental systems tracts of the Brazilian Cretaceous Bauru Basin and their relationship with the tectonic and climatic evolution of South America. Basin Research. 1-25

Baur, G. (1889). On the morphology of the vertebrate-skull. Journal of Morphology. $3,471-474$

Beldade, P., Koops, K., \& Brakefield, P. M. (2002). Developmental constraints versus flexibility in morphological evolution. Nature, 416, 844-847. https://doi.org/10.1038/416844a

Bels, V. L., Davenport, J., \& Delheusy, V. (1997). Kinematic analysis of the feeding behavior in the box turtle Terrapene carolina (L.), (Reptilia: Emydidae). The Journal of Experimental Zoology, 277,198-212

Bels, V., Baussart, S., Davenport, J., Shorten, M., O'Riordan, R. M., Renous, S., \& Davenport, J. L. (2008). Functional evolution of feeding behavior in turtles. In J. Wyneken, M. H. Godfrey, \& V. Bels (Eds.), Biology of Turtles (pp. 187212). Boca Raton, London, New York, CRC Press

Benson, R. B. J., Hunt, G., Carrano, M. T., \& Campione, N. (2018). Cope's rule and the adaptive landscape of dinosaur body size evolution. Palaeontology, 61(1), 13-48. https://doi.org/10.1111/pala.12329

Benton, M. J. (1990). Phylogeny of the major tetrapod groups: morphological data and divergence dates. Journal of Molecular Evolution, 30,409-424

Bertini, R. J., Marshall, L. G., Gayet, M., \& Brito, P. M. (1993). Vertebrate faunas from the Adamantina and Marília (Upper Bauru Group, Late Cretaceous, Brazil) in their stratigraphic and paleobiogeographic context. Neues Jahrbuch für Geologie und Paläontologie, Monatshefte, 188, 71-101

Bertini, R. J., Santucci, R. M., \& Arruda-Campos, A. C. (2001). Titanossauros (Sauropoda: Saurischia) no Cretáceo Superior continental (Formação Marília, Membro Echaporã) de Monte Alto, estado de São Paulo, e correlação com formas associadas do Triângulo Mineiro. Geociências, 20(1), 93-103

Bever, G. S., Lyson, T. R., Field, D. J., \& Bhullar, B.-A. S. (2015). Evolutionary origin of the turtle skull. Nature, 525, 239-242. doi:10.1038/nature14900

Bever, G. S., Lyson, T. R., Field, D. J., \& Bhullar, B.-A.S. (2016). The amniote temporal roof and the diapsid origin of the turtle skull. Zoology, 119, 471-473. http://dx.doi.org/10.1016/j.zool.2016.04.005

Bhullar, B.-A. S., \& Bever, G. S. (2009). An archosaur-like laterosphenoid in early turtles (Reptilia: Pantestudines). Breviora, 518, 1-11 
Bittencourt, J. S., \& Langer, M. C. (2011). Mesozoic dinosaurs from Brazil and their biogeographic implications. Anais da Academia Brasileira de Ciências, 83, 23-60

Böhmer, C., \& Werneburg, I. (2017). Deep time perspective on turtle neck evolution: Chasing the Hox code by vertebral morphology. Scientific Reports, 7(1), 1-14. https://doi.org/10.1038/s41598-017-09133-0

Bojanus, L. H. (1819). Anatome testudinis europaeae. Isis 11:1766-1769

Bona, P., \& Paulina-Carabajal, A. (2013). Caiman gasparinae sp. nov., a huge alligatorid (Caimaninae) from the late Miocene of Paraná, Argentina. Alcheringa, 37, 1-12. doi:10.1080/03115518.2013.785335

Boulenger, G. A. (1918). Sur la place des cheloniens dans la classification. Comptes Tendues A l'Academie Des Sciences Paris, 167, 614-618

Bourke, J. M., Ruger Porter, W. M., Ridgely, R. C., Lyson, T. R., Schachner, E. R., Bell, P. R., \& Witmer, L. M. (2014). Breathing life into dinosaurs: tackling challenges of soft-tissue restoration and nasal airflow in extinct species. The Anatomical Record, 297, 2148-2186. doi:10.1002/ar.23046

Bowler, P. (1983). The eclipse of Darwinism. Baltimore: The Johns Hopkins University Press.

Bramble, D. M. (1974). Occurence and significance of the os transiliens in Gopher tortoises. Copeia, 102-109

Brichta, A., Acuna, D., \& Peterson, E. (1988). Planar relations of semicircular canals in awake, resting turtles, Pseudemys scripta. Brain Behavior and Evolution, 32, 236-245

Bright, J. A. (2014). A review of paleontological finite element models and their validity. Journal of Paleontology, 88(04), 760-769. https://doi.org/10.1666/13-090

Brinkman, D., Hart, M., Jamniczky, H., \& Colbert, M. (2006). Nichollsemys baieri gen. et sp. nov., a primitive chelonioid turtle from the Late Campanian of North America. Paludicol, 5(4), 111-124

Brito, R. J., Amaral, C. R. L., \& Machado, L. P. (2006). A ictiofauna do Grupo Bauru, Cretáceo Superior da Bacia Bauru, Sudeste do Brasil. In V. Gallo, P. M. Brito, H. M. Silva, \& F. J. Figueroa (Eds.), Paleontologia de Vertebrados: Grandes Temas e Contribuições Científicas (pp. 133-143). Rio de Janeiro: Editora Interciência

Brocklehurst, N. (2017). Rates of morphological evolution in Captorhinidae: an adaptive radiation of Permian herbivores. PeerJ, 5, e3200. https://doi.org/10.7717/peerj.3200 
Broin, F. de. (1971). Une espèce nouvelle de tortue pleurodire (? Roxochelys vilavilensis n. sp.) dans le Crétacé Supérieur de Bolivie. Bulletin de la Société Géologique de France, 7(3-4), 445-452

Broin, F. de. (1991). Fossil turtles from Bolivia. In R. Suarez-Soruco (Ed.), Fosiles y Facies de Bolivia, Volume 1. Vertebrados (pp. 509-527). Revista Técnica de Yacimientos Petrolíferos Fiscales de Bolívia, 12.

Broom, R. (1924). On the classification of the reptiles. Bulletin of the American Museum of Natural History, 51, 39-65

Brusatte, S. L. (2011). Calculating the tempo of morphological evolution: rates of discrete character change in a phylogenetic context. In A. Elewa (Ed.), Computational Paleontology (pp. 53-74). Heidelberg, Dordrecht, London, New York: Springer-Verlag Berlin Heidelberg.

Burke, A. C. (1989). Development of the turtle carapace: implications for the evolution of a novel Bauplan. Journal of Morphology, 199, 363-378

Burke, A. C. (1991). The development and evolution of the turtle body plan. Inferring intrinsic aspects of the evolutionary process from experimental embryology. American Zoologist, 31, 616-627.

Cade adena, E. (2015). A global phylogeny of Pelomedusoides turtles with new material of Neochelys franzeni Schleich, 1993 (Testudines, Podocnemididae) from the middle Eocene, Messel Pit, of Germany. PeerJ, 3, e1221. doi:10.7717/peerj.1221

Cadena, E. A., \& Jaramillo, C.A. (2015). The first fossil skull of Chelus (Pleurodira: Chelidae, Matamata turtle) from the early Miocene of Colombia. Palaeontologia Electronica, 18.2.32A, 1-10

Cadena, E. A., \& Parham, J. F. (2015). Oldest known marine turtle? A new protostegid from the Lower Cretaceous of Colombia. PaleoBios, 32, 1-42

Cadena, E. A., Ksepka, D. T., Jaramillo, C. A., \& Bloch, J. I. (2012). New pelomedusoid turtles from the late Palaeocene Cerrejón Formation of Colombia and their implications for phylogeny and body size evolution. Journal of Systematic Palaeontology, 10(2), 313-331

Carabajal, A. P., Sterli, J., Müller, J., \& Hilger, A. (2013). Neuroanatomy of the marine Jurassic turtle Plesiochelys etalloni (Testudinata, Plesiochelyidae). PLoS One 8, e69264. doi:10.1371/journal.pone.0069264 
Carbonaro, F. A., Langer, M. C., Nihei, S. S., Ferreira, G. S., \& Ghilardi, R. P. (2018). Inferring ancestral range reconstruction based on trilobite records: a study-case on Metacryphaeus (Phacopida, Calmoniidae). Scientific Reports, 8, 15179. https://doi.org/10.1038/s41598-018-33517-5

Carroll, R. L. (1997). Patterns and processes of vertebrate evolution. Cambridge: Cambridge University Press.

Carroll, R. L. (2013). Problems of the ancestry of turtles. In D. B. Brinkman, P. A. Holroyd, \& J. D. Gardner (Eds.), Morphology and Evolution of Turtles (pp. 19-36). https://doi.org/10.1007/978-94-007-4309-0

Carroll, S. B. (2008). Evo-Devo and an Expanding Evolutionary Synthesis: A Genetic Theory of Morphological Evolution. Cell, 134(1), 25-36. https://doi.org/10.1016/j.cell.2008.06.030

Carus, K. (1834). Lehrbuch der Vergleichenden Zootomie (2nd ed.). Leipzig: Fleischer.

Carvalho, I. S., Vasconcellos, F. M., \& Tavares, S. A. S. (2007). Montealtosuchus arrudacamposi, a new peirosaurid crocodile (Mesoeucrocodylia) from the Late Cretaceous Adamantina Formation of Brazil. Zootaxa, 1607, 35-46

Cebra-Thomas, J. A., Betters, E., Yin, M., Plafkin, C., McDow, K., \& Gilbert, S. F. (2007). Evidence that a late-emerging population of trunk neural crest cells forms the plastron bones in the turtle Trachemys scripta. Evolution \& Development, 9(3), 267-277.

Cebra-Thomas, J. A., Terrell, A., Branyan, K., Shah, S., Rice, R., Gyi, L., ... Gilbert, S. F. (2013). Late-emigrating trunk neural crest cells in turtle embryos generate an osteogenic ectomesenchyme in the plastron. Developmental Dynamics, 242, 1223-1235. https://doi.org/10.1002/dvdy.24018

Cebra-Thomas, J., Tan, F., Sistla, S., Estes, E., Bender, G., Kim, C., Riccio, P., \& Gilbert, S. F. (2005). How the turtle forms its shell: a paracrine hypothesis of carapace formation. Journal of Experimental Zoology (Molecular \& Developmental Evolution) 304B, 558569

Cherepanov, G. O. (1997). The origin of the bony shell of turtles as a unique evolutionary model in reptiles. Russian Journal of Herpetology, 4(2), 155-162.

Clack, J. (1997). The evolution of tetrapod ears and the fossil record. Brain Behavior \& Evolution, 50, 198-212

Clark, K., Bender, G., Murray, B. P., Panfilio, K., Cook, S., Davis, R., Murnen, K., Tuan, R. S., \& Gilbert, S. F. (2001). Evidence for the neural crest origin of turtle plastron bones. Genesis, 31, 111-117 
Clark, N. D. L., Adams, C., Lawton, T., Cruickshank, A. R., \& Woods, K. (2004). The Elgin marvel: using magnetic resonance imaging to look at a mouldic fossil from the Permian of Elgin, Scotland, UK. Magnetic Resonance Imaging, 22, 269-273.

Claude, J., Pritchard, P., Tong, H., Paradis, E., \& Auffray, J. C. (2004). Ecological correlates and evolutionary divergence in the skull of turtles: a geometric morphometric assessment. Systematic Biology, 53, 933-948

Cleland, C. E. (2001). Historical science, experimental science, and the scientific method. Geology, 29(11), 987-990.

Cleland, C. E. (2002). Methodological and epistemic differences between Historical Science and Experimental Science. Philosophy of Science, 69, 474-496.

Close, R. A., Friedman, M., Lloyd, G. T., \& Benson, R. B. J. (2015). Evidence for a midJurassic adaptive radiation in mammals. Current Biology, 25(16), 2137-2142. https://doi.org/10.1016/j.cub.2015.06.047

Cope, E. D. (1864). On the limits and relations of the Raniformes. Proceedings of the Academy of Natural Sciences of Philadelphia, 1864, 181-183.

Cope, E. D. (1868). On the origin of genera. Proceedings of the Academy of Natural Sciences of Philadelphia, 1868, 242-300

Cope, E. D. (1896). The ancestry of the Testudinata. American Naturalist, 30, 398-400

Crampton, J. S., \& Haines, A. J. (1996). Users' manual for programs Hangle, Hmatch and Hcurve for the Fourier shape analysis of two-dimensional outlines. Institute of Geological and Nuclear Sciences, Science Report, 96, 1-28

Crawford, N. G., Faircloth, B. C., McCormack, J. E., Brumfield, R. T., Winker, K., \& Glenn, T. C. (2012). More than 1000 ultraconserved elements provide evidence that turtles are the sister group of archosaurs. Biology Letters, 8(5), 783-786. https://doi.org/10.1098/rsb1.2012.0331

Crawford, N. G., Parham, J. F., Sellas, A. B., Faircloth, B. C., Glenn, T. C., Papenfuss, T. J., Henderson, J. B., Hanson, M. H., \& Simison, W. B. (2015). A phylogenomic analysis of turtles. Molecular Phylogenetics and Evolution, 83, 250-257

Crouch, N. M. A., Ramanauskas, K., \& Igić, B. (2019). Tip-dating and the origin of Telluraves. Molecular Phylogenetics and Evolution, 131(October 2018), 55-63. https://doi.org/10.1016/j.ympev.2018.10.006

Cunningham, J. A., Rahman, I. A., Lautenschlager, S., Rayfield, E. J., \& Donoghue, P. C. J. (2014). A virtual world of paleontology. Trends in Ecology \& Evolution, 29(6), 347357. https://doi.org/10.1016/j.tree.2014.04.004 
Cuvier, G. (1799). Leçon d'anatomie comparée, Tome I. Paris: Baudouin, Imprimeur de L'Institut National des Sciences et des Arts.

$\mathrm{D}$ alrymple, G. H (1975). Variation in the cranial feeding mechanism of turtles of the genus Trionyx Geoffroy. PhD thesis. Toronto: University of Toronto

Dalrymple, G. H. (1977). Intraspecific variation in the cranial feeding mechanism of turtles of the genus Trionyx (Reptilia, Testudines, Trionychidae). Journal of Herpetology, $11,255-285$

Danilov, I. G., \& Parham, J. F. (2008). A reassessment of some poorly known turtles from the Middle Jurassic of China, with comments on the antiquity of extant turtles. Journal of Vertebrate Paleontology, 28, 306-318

David, R., Droulez, J., Allain, R., Berthoz, A., Janvier, P., \& Bennequin, D. (2010). Motion from the past. A new method to infer vestibular capacities of extinct species. Comptes Rendus Palevol. 9, 397-410. doi:10.1016/j.crpv.2010.07.012

Daza, J. D., Diogo, R., Johnston, P., \& Abdala, V. (2011). Jaw adductor muscles across Lepidosaurs: a reappraisal. The Anatomical Record, 294, 1765-1782. doi:10.1002/ar.21467

de Beer, G. R. (1937). The development of the vertebrate skull. Chicago and London: The University of Chicago Press

de la Fuente, M. S. (2003). Two new pleurodiran turtles from the Portezuelo Formation (Upper Cretaceous) of Northern Patagonia, Argentina. Journal of Paleontology, 77(3), 559-575

deBraga, M., \& Rieppel, O. (1997). Reptile phylogeny and the interrelationships of turtles. Zoological Journal of the Linnean Society, 120, 281-354

Deleuze, G., \& Guattari, F. (1987). A thousand plateaus: capitalism and schizophrenia (2nd ed.). Minneapolis: University of Minnesota Press.

DigiMorph. Digital Morphology - A unique biological visualization library. http://www.digimorph.org/. Last access 15.08.2017.

Diogo, R., \& Abdala, V. (2010). Muscles of vertebrates: comparative anatomy, evolution, homologies and development. Boca Bacon, New York, Oxon/Enfield: CRC Press/Science Publishers 
Diogo, R., Abdala, V., Lonergan, N., \& Wood, B. A. (2008). From fish to modern humans-comparative anatomy, homologies and evolution of the head and neck musculature. Journal of Anatomy, 213, 391-424

Donoghue, P. C. J., Bengtson, S., Dong, X. P., Gostling, N. J., Huldtgren, T., Cunningham, J. A., ... Stampanoni, M. (2006). Synchrotron X-ray tomographic microscopy of fossil embryos. Nature, 442(7103), 680-683. https://doi.org/10.1038/nature04890

Dumont Junior, M. V. (2013). Um novo podocnemídeo fossil de grande porte da Formação Solimões (Mioceno-Plioceno), Acre, Brasil e as relações filogenéticas entre os Podocnemidae. 67 pp. M.S. thesis, Brasilia: Universidade de Brasília

$\mathrm{E}$ dgeworth, F. H. (1935). The cranial muscles of vertebrates. London: Cambridge University Press

Edinger, T. (1942). The pituitary body in giant animals fossil and living: a survey and a suggestion. Quaternary Review of Biology, 17, 31-45

Eger, S. C. (2006). Morphologische und phylogenetische Untersuchungen an der Nickhautmuskulatur bei Sauropsiden (unter besonderer Berücksichtigung der Chelonia). Tübingen: Universität Tübingen

Eldredge, N. (1971). The allopatric model and phylogeny in Paleozoic invertebrates. Evolution, 25(1), 156-167.

Eldredge, N., \& Gould, S. J. (1972). Punctuated Equilibria: an alternative to phyletic gradualism. In T. J. M. Schopf (Ed.), Models in Paleobiology (pp. 82-115). San Francisco: Freeman, Cooper and Co.

Erickson, G. M., Lappin, A. K., \& Vliet, K. A. (2003). The ontogeny of bite-force performance in American alligator (Alligator mississippiensis). Journal of Zoology, 260, $317-327$

Ernst, C.H., \& Barbour, R.W. (1992). Turtles of the World. Washington: Smithsonian Institution Scholarly Press

Eßwein, S. E. (1992). Zur phylogenetischen und ontogenetischen Entwicklung des akinetischen Craniums der Schildkröten. Natürliche Konstruktionen-Mitteilungen des $S F B 230$ 7. Stuttgart: Proceedings of the II. International Symposium of the Sonderforschungsbereich 230, 1.-4.10.1991): 51-55

Evers, S. W., \& Benson, R. B. J. (2019). A new phylogenetic hypothesis of turtles with implications for the timing and number of evolutionary transitions to marine lifestyles in the group. Palaeontology, 62(1), 93-134. https://doi.org/10.1111/pala.12384 
Ezcurra, M. D., \& Butler, R. J. (2018). The rise of the ruling reptiles and ecosystem recovery from the Permo-Triassic mass extinction. Proceedings of the Royal Society B: Biological Sciences, 285(1880). https://doi.org/10.1098/rspb.2018.0361

$\mathrm{F}_{\mathrm{a}}$ achini, T. S., \& A. S. Hsiou. (2011). Presence of an “anilioid” snake from the Late Cretaceous of Adamantina Formation, Brazil. 4th Congreso Latinoamericano de Paleontología de Vertebrados 13.

Fachini, T. S., \& Iori, F. V. (2009). Primeiro registro fóssil de Squamata na região do município de Monte Alto, estado de São Paulo (Bacia Bauru, Cretáceo Superior). XXI Congresso Brasileiro de Paleontologia, 172

Falkingham, P. L. (2012). Acquisition of high resolution three-dimensional models using free, open-source, photogrammetric software. Palaeontologia Electronica, 15(1), 1T.

Farke, A. A. (2008). Frontal sinuses and head-butting in goats: a finite element analysis. Journal of Experimental Biology, 211(19), 3085-3094. https://doi.org/10.1242/jeb.019042

Fernandes, L. A., \& Coimbra, A. M. (1996). A Bacia Bauru (Cretaceo Superior, Brasil). Anais da Academia Brasileira de Ciencias, 68(2), 195- 205

Ferreira, G. S. (2016). Abordagens convergentes, novidades evolutivas e a origem da carapaça das tartarugas. Revista da Biologia, 16, 1-6. doi:10.7594/revbio.16.01.01

Ferreira, G. S., \& Werneburg, I. (2019). Evolution, diversity, and development of the craniocervical system in turtles with special reference to jaw musculature. In J. M. Ziermann, R. E. Diaz Jr., \& R. Diogo (Eds.), Heads, jaws, and muscles: anatomical, functional, and developmental diversity in chordate evolution (pp. 171-206). Basel: Springer Nature Switzerland AG. https://doi.org/10.1007/978-3-319-93560-7_8

Ferreira, G. S., Bronzati, M., Langer, M. C., \& Sterli, J. (2018a). Phylogeny, biogeography and diversification patterns of side-necked turtles (Testudines: Pleurodira). Royal Society Open Science, 5(3). https://doi.org/10.1098/rsos.171773

Ferreira, G. S., Iori, F. V., Hermanson, G., \& Langer, M. C. (2018b). New turtle remains from the Late Cretaceous of Monte Alto-SP, Brazil, including cranial osteology, neuroanatomy and phylogenetic position of a new taxon. PalZ. https://doi.org/10.1007/s12542-017-0397-x

Ferreira, G. S., Rincón, A. D., Solórzano, A., \& Langer, M. C. (2015). The last marine pelomedusoids (Testudines: Pleurodira): a new species of Bairdemys and the paleoecology of Stereogenyina. PeerJ, 3, e1063. 10.7717/peerj.1063 
Field, D. J., Gauthier, J. A., King, B. L., Pisani, D., Lyson, T. R., \& Peterson, K. J. (2014). Toward consilience in reptile phylogeny: miRNAs support an archosaur, not lepidosaur, affinity for turtles. Evolution \& Development, 16, 189-196.

doi:10.1111/ede.12081

Fisher, R. (1918). The correlation between relatives on the supposition of Mendelian inheritance. Transactions of the Royal Society of Edinburgh, 52, 399-433.

Foffa, D., Cuff, A. R., Sassoon, J., Rayfield, E. J., Mavrogordato, M. N., \& Benton, M. J. (2014). Functional anatomy and feeding biomechanics of a giant Upper Jurassic pliosaur (Reptilia: Sauropterygia) from Weymouth Bay, Dorset, UK. Journal of Anatomy, 225, 209-219. doi:10.1111/joa.12200

Foote, M. (1997). The evolution of morphological disparity. Annual Review of Ecology and Systematics, 28, 129-152

Foth, C., \& Joyce, W.G. (2016). Slow and steady: the evolution of cranial disparity in fossil and recent turtles. Proceedings of the Royal Society of London B: Biological Sciences, 283m 20161881. doi:10.1098/rspb.2016.1881

Foth, C., Rabi, M., \& Joyce, W.G. (2017). Skull shape variation in extant and extinct Testudinata and its relation to habitat and feeding ecology. Acta Zoologica, 98, 310325. doi:10.1111/azo.12181

França, M. A. G., \& Langer, M. C. (2005). A new freshwater turtle (Reptilia, Pleurodira, Podocnemidae) from the Upper cretaceous (Maastrichtian) of Minas Gerais, Brazil. Geodiversitas, 27(3), 391-411

França, M. A. G., \& Langer, M. C. (2006). Phylogenetic relationships of the Bauru Group turtles (Late Cretaceous of south-central Brazil). Revista Brasileira de Paleontologia, 9(3), 365-373

Franzosa, J. W. (2004). Evolution of the brain in Theropoda (Dinosauria). PhD dissertation. Austin: University of Texas.

Frazzetta, T. H. (1968). Adaptive problems and possibilities in the temporal fenestration of tetrapod skulls. Journal of Morphology, 125, 145-157

Frolich, L. M. (1997). The role of the skin in the origin of amniotes: permeability barrier, protective covering and mechanical support. In: S. S. Sumida, \& K. L. M. Martin (Eds.), Amniote origins. Completing the transition to land. San Diego: Academic Press

Fuchs, H. (1931). Von dem Ductus angularis oris der Arrauschildkröte (Podocnemis expansa). (Ein neues Organ?). Nachrichten von der Gesellschaft der Wissenschaften zu Göttingen, Mathematisch-Physikalische Klasse, 131-147 
Futuyma, D. (1986). Evolutionary Biology. Sunderland: Sinauer.

Futuyma, D. (2017). Evolutionary biology today and the call for an extended synthesis. Interface Focus, 7(5), 20160145. https://doi.org/10.1098/rsfs.2016.0145

G affney, E. S. (1975). A phylogeny and classification of the higher categories of turtles. Bulletin of the American Museum of Natural History, 155, 387-436

Gaffney, E. S. (1977a). An endocranial cast of the side-necked turtle, Bothremys, with a new reconstruction of the palate. American Museum Novitates, 2639, 1-12

Gaffney, E. S. (1977b). The side-necked turtle family Chelidae: a theory of relationships using shared derived characters. American Museum Novitates, 2620, 1-28

Gaffney, E. S. (1979). Comparative cranial morphology of recent and fossil turtles. Bulletin of the American Museum of Natural History, 164, 67-376

Gaffney, E. S. (1980). Phylogenetic relationships of the major groups of amniotes. In A. L. Panchen (Ed.), The terrestrial environment and the origin of land vertebrates, vol Special Volume 15. London and New York: Systematic Association. Academic Press.

Gaffney, E. S. (1982). Cranial morphology of the baenid turtles. American Museum Novitates, 2737, 1-22

Gaffney, E. S. (1983). The cranial morphology of the extinct horned turtle, Meiolania platyceps, from the Pleistocene of Lord Howe Island, Australia. Bulletin of the American Museum of Natural History, 175(4), 361-480

Gaffney, E. S. (1985). The cervical and caudal vertebrae of the cryptodiran turtle, Meiolania platyceps, from the Pleistocene of Lord Howe Island, Australia. American Museum Novitates, 2805, 1-29

Gaffney, E. S. (1990). The comparative osteology of the Triassic turtle Proganochelys. Bulletin of the American Museum of Natural History, 194, 1-263

Gaffney, E. S. (1996). The postcranial morphology of Meiolania platyceps and a review of of the Meiolaniidae. Bulleting of the American Museum of Natural History, 229, 1166

Gaffney, E. S., \& Jenkins Jr, F. A. (2010). The cranial morphology of Kayentachelys, an Early Jurassic cryptodire, and the early history of turtles. Acta Zoologica, 91, 335-368. https://doi.org/10.1111/j.1463-6395.2009.00439.x 
Gaffney, E. S., \& Kitching, J. W. (1994). The most ancient African turtle. Nature, 369, $55-58$

Gaffney, E. S., \& Kitching, J. W. (1995). The morphology and relationships of Australochelys, an Early Jurassic turtle from South Africa. American Musem Novitates, 3130, 1-29

Gaffney, E. S., \& Meylan, P. A. (1988). A phylogeny of turtles. In M. J. Benton (Ed.), The phylogeny and classification of the tetrapods. Volume 1: Amphibians, Reptiles, Birds, vol Special Vol. 35A (pp 157-219). Oxford: Clarendon Press

Gaffney, E. S., \& Zangerl, R. (1968). A revision of the chelonian genus Bothremys (Pleurodira: Pelomedusidae). Fieldiana Geologica, 16, 193-239

Gaffney, E. S., Hutchison, J. H., Jenkins, A. F., \& Meeker, L. J. (1987). Modern turtle origins: the oldest known cryptodire. Science, 237, 289-291

Gaffney, E. S., Meylan, P. A., \& Wyssz, R. (1991). A computer assisted analysis of the relationships of the higher categories of turtles. Cladistics, 7, 313-335

Gaffney, E. S., Meylan, P. A., Wood, R. C., Simons, E., \& Campos, D. A. (2011). Evolution of the side-necked turtles: the family Podocnemididae. Bulletin of the American Museum of Natural History, 350, 1-237

Gaffney, E. S., Tong, H., \& Meylan, P. A. (2006). Evolution of the side-necked turtles: The families Bothremydidae, Euraxemydidae, and Araripemydidae. Bulletin of the American Museum of Natural History, 300, 1-700

Galis, F., Van Alphen, J. J. M., \& Metz, J. A. J. (2001). Why five fingers? Evolutionary constraints on digit numbers. Trends in Ecology and Evolution, 16(11), 637-646. https://doi.org/10.1016/S0169-5347(01)02289-3

Gans, C., de Vree, F., \& Carrier, D. (1985). Usage pattern of the complex masticatory muscles in the Shingleback Lizard, Trachydosaurus rugosus: a model for muscle placement. The American Journal of Anatomy, 173, 219-240

Gardiner, B. G. (1982). Tetrapod classification. Zoological Journal of the Linnean Society, 74(3), 207-232.

Gardiner, B. G. (1993). Haematothermia: warm-blooded amniotes. Cladistics, 9, 369395

Gasc, J. P. (1981). Axial musculature. In C. Gans, \& T. S. Parsons (Eds.), Biology of the Reptilia, vol 11 (Morphology F) (pp. 355-435). London and New York: Academic press 
Gaupp, E. (1895). Zur vergleichenden Anatomie der Schläfengegend am knöchernen Wirbeltierschädel. Morphologische Arbeiten, 4, 77-131

Gauthier, J. A., Kluge, A. G., \& Rowe, T. (1988a). The early evolution of the Amniota. In M. J. Benton (Ed.) The phylogeny and classification of the tetrapods, vol. 1 (pp. 103155). Oxford: Oxford University Press

Gauthier, J., Kluge, A. G., \& Rowe, T. (1988b). Amniote phylogeny and the importance of fossils. Cladistics, 4, 105-209

Gehring, W. J. (1985). The homeobox: a key to the understanding of development? Cell, $40,3-5$.

Gehring, W. J. (1998). Master control Genes in Development and evolution: The Homeobox story. New Haven: Yale University Press.

Gehring, W. J., \& Hiromi, Y. (1986). Homeotic genes and the Homeobox. Annual Review of Genetics, 20, 147-173.

George, I. D., \& Holliday, C. M. (2013). Trigeminal nerve morphology in Alligator mississipiensis and its significance for crocodyliform facial sensation and evolution. The Anatomical Record, 296, 670-680. doi:10.1002/ar.22666

George, J. C., \& Shah, R. V. (1955). The myology of the head and the neck of the common indian pond turtle, Lissemys punctata granosa Schoepff. The Journal of Animal Morphology and Physiology, 1, 1-12

Georgi, J. A., \& Sipla, J.S. (2008). Comparative and functional anatomy of balance in aquatic reptiles and birds. In J. G. M. Thewissen, \& S. Nummela (Eds.), Sensory Evolution on Threshold: Adaptations on Secondarily Aquatic Vertebrates (pp. 233256). Berkeley: University of California Press

Gerhart, J., \& Kirschner, M. (2007). The theory of facilitated variation. Proceedings of the National Academy of Sciences, 104(Supplement 1), 8582-8589. https://doi.org/10.1073/pnas.0701035104

Gilbert, S. F., Bender, G., Betters, E., Yin, M., \& Cebra-Thomas, J. A. (2007) The contribution of neural crest cells to the nuchal bone and plastron of the turtle shell. Integrative and Comparative Biology, 47, 401-408. doi:410.1093/icb/icm1020

Gilbert, S. F., Cebra-Thomas, J. A., \& Burke, A. C. (2008). How the turtle gets its shell. In J. Wyneken, M. H. Godfrey, \& V. Bels (Eds.) Biology of Turtles (pp. 1-16). Boca Raton, London, New York: CRC Press 
Gilbert, S. F., Loredo, G. A., Brukman, A., \& Burke, A. C. (2001). Morphogenesis of the turtle shell: the development of a novel structure in tetrapod evolution. Evolution \& Development, 3, 47-58

Giles, S., \& Friedman, M. (2014). Virtual reconstruction of endocast anatomy in early ray-finned fishes (Osteichthyes, Actinopterygii). Journal of Paleontology, 88(04), 636651. https://doi.org/10.1666/13-094

Giles, S., Rücklin, M., \& Donoghue, P. C. J. (2013). Histology of "placoderm" dermal skeletons: Implications for the nature of the ancestral gnathostome. Journal of Morphology, 274(6), 627-644. https://doi.org/10.1002/jmor.20119

Gittleman, J. L. (1991). Carnivore olfactory bulbs: allometry, phylogeny and ecology. Journal of Zoology, 225, 253-272

Godoy, P. L., Ferreira, G. S., Montefeltro, F. C., Vila Nova, B. C., Butler, R. J., \& Langer, M. C. (2018). Evidence for heterochrony in the cranial evolution of fossil crocodyliforms. Palaeontology, 61(4), 543-558. https://doi.org/10.1111/pala.12354

Goette, A. (1899). Über die Entwicklung des knöchernen Rückenschildes (Carapax) der Schildkröten. Zeitschrift Für Wissenschaftliche Zoologie, 66, 407-434.

Goldschmidt, R. (1940). The material basis of evolution. New Haven: Yale University Press.

Goloboff, P. A., Farris, J. S., \& Nixon, K. C. (2008). TNT, a free-program for phylogenetic analysis. Cladistics, 24, 774-786

Goloboff, P. A., Farris, J. S., Kallerjö, M., Oxelman, B., Ramírez, M., \& Szumik, C. (2003). Improvements to resampling measures of group support. Cladistics, 19, 324332

Goodrich, E. S. (1916). On the classification of the Reptilia. Proceedings of the Royal Society of London, Series B, containing papers of a Biological Character, 89, 261-276

Goodrich, E. S. (1930) Studies on the structure and development of vertebrates. London: Macmillan and Co.

Gould, S. J. (1977). Ontogeny and Phylogeny. Cambridge: The Belknap Press of the Harvard University Press.

Gould, S. J. (2002). The structure of Evolutionary Theory. Cambridge: The Belknap Press of the Harvard University Press.

Gould, S. J., \& Eldredge, N. (1977). Punctuated equilibria: the tempo and mode of evolution reconsidered. Paleobiology, 3(2), 115-151. 
Gould, S. J., \& Lewontin, R. C. (1979). The spandrels of San Marco and the Panglossian paradigm: a critique of the adaptationist programme. Proceedings of the Royal Society B: Biological Sciences, 205, 581-598.

Gregory, W. K. (1946). Pareiasaurs versus placodonts as near ancestors to the turtles. Bulletin of the American Museum of Natural History, 86, 277-326

Gregory, W. K., \& Adams, L. A. (1915). The temporal fossæ of vertebrates in relation to the jaw muscles. Science, 41, 763-765

Guillon, J. M., Guéry, L., Hulin, V., \& Girondot, M. (2012). A large phylogeny of turtles (Testudines) using molecular data. Contributions to Zoology, 81, 147-158

Gutarra, S., Moon, B. C., Rahman, I. A., Palmer, C., Lautenschlager, S., Brimacombe, A. J., \& Benton, M. J. (2019). Effects of body plan evolution on the hydrodynamic drag and energy requirements of swimming in ichthyosaurs. Proceedings of the Royal Society B: Biological Sciences, 286, 20182786. https://doi.org/10.1098/rspb.2018.2786

$\mathrm{H}$ acker, G. (1954). Über Kiefermuskulatur und Mundfascien bei Testudo graeca. PhD thesis. Greifswald: Ernst-Moritz-Arndt-Universität

Haines, A. J., \& Crampton, J. S. (2000). Improvements to the method of Fourier shape analysis as applied in morphometric studies. Palaeontology, 43, 765-783

Haldane, J. (1932). The time of action of genes, and its bearing on some evolutionary problems. American Naturalist, 66, 5-24.

Hall, B. K. (2003). Evo-Devo: evolutionary developmental mechanisms. International Journal of Developmental Biology, 47, 491-495.

Halpern, M. (1992). Nasal chemical senses in reptiles. In C. Gans \& D. Crews (Eds.), Biology of the Reptilia, vol. 18, (pp. 423-523), Chicago and London: University of Chicago Press

Hammer, Ø., Harper, D. A. T., \& Ryan, P. D. (2001). Past: Paleontological Statistics Software Package for Education and Data Analysis. Palaeontologia Electronica, 4, 1-9

Haubitz, B., Prokop, M., Döhring, W., Ostrom, J., \& Wellnhofer, P. (1988). Computed tomography of Archaeopteryx. Paleobiology, 14(2), 206-213.

Hay, O. P. (1905). On the group of fossil turtles known as the Amphichelydia; with remarks on the origin and relationships of the suborders, superfamilies, and families of Testudines. Bulletin of the American Museum of Natural History, 21, 137-175 
Healy, S., \& Guilford, T. (1990). Olfactory-bulb size and nocturnality in birds. Evolution, 44, 339-346. doi:10. 2307/2409412

Hedges, S. B. (2012). Amniote phylogeny and the position of turtles. BMC Biology, 10, 64

Hedges, S. B., \& Poling, L. L. (1999). A molecular phylogeny of reptiles. Science, 283, 998-1001

Heiss, E., Plenk, H., \& Weisgram, J. (2008). Microanatomy of the palatal mucosa of the semiaquatic Malayan Box Turtle, Cuora amboinensis, and functional implications. The Anatomical Record, 291, 10

Henson Jr, O. (1974). Comparative anatomy of the middle ear. In W. D. Keidel, \& W. D. Neff (Eds.), Auditory System (pp. 39-110), Berlin: Springer Verlag

Hermanson, G., Ferreira, G. S., \& Langer, M. C. (2016). The largest Cretaceous podocnemidoid turtle (Pleurodira) revealed by an isolated plate from the Bauru Basin, south-central Brazil. Historical Biology, 29(6), 833-840. doi:

10.1080/08912963.2016.1248434

Herrel, A., O'Reilly, J. C., \& Richmond, A. M. (2002). Evolution of bite performance in turtles. Journal of Evolutionary Biology, 15, 1083-1094

Herrel, A., Van Damme, J., \& Aerts, P. (2008). Cervical anatomy and function in turtles. In J. Wyneken, M. H. Godfrey, \& V. Bels (Eds.), Biology of Turtles (pp 163-185). Boca Raton, London, New York: CRC Press

Herrera, Y., Fernández, M. S., \& Gasparini, Z. (2013). The snout of Cricosaurus araucanensis: a case study in novel anatomy of the nasal region of metriorhynchids. Lethaia, 46, 331-340. doi:10.1111/let.12011

Hoffmann, C. K (1890). Reptilien. 1. Schildkröten, vol 6(3). Dr. H.G. Bronn's Klassen und Ordnungen des Thier-Reichs, wissenschaftlich dargestellt in Wort und Bild. Leipzig: C.F. Wintersche Verlagshandlung,

Hofsten, N. (1941). On the phylogeny of the Reptilia. Zool Bidrag Fran Uppsala, 20, $501-521$

Holliday, C. M., \& Witmer, L. M. (2007). Archosaur adductor chamber evolution: Integration of musculoskeletal and topological criteria in jaw muscle homology. Journal of Morphology, 268, 457-484. doi:10.1002/Jmor.10524

Holloway, W. L., Claeson, K. M., \& O'Keefe, F. R. (2013). A virtual phytosaur endocast and its implications for sensory system evolution in archosaurs. Journal of Vertebrate Paleontology, 33, 848-857. doi:10.1080/02724634.2013.747532 
Hopson, J. A. (1979). Paleoneurology. In C. Gans (Ed.) Biology of the Reptilia, vol. 9 (pp. 39-146), New York: Academic Press

Hughes, A., \& Lambert, D. (1984). Functionalism, Structuralism, and "Ways of Seeing." Journal of Theoretical Biology, 111, 787-800.

I ordansky, N. N. (1987). Morphological and functional features of mandibular apparatus in turtles (Reptilia, Chelonia) and the problem of their origin. Zoologichesky Zhurnal, 66, 1716-1729

Iordansky, N. N. (1994). Tendons of jaw muscles in Amphibia and Reptilia: homology and evolution. Russian Journal of Herpetology, 1, 13-20

Iordansky, N. N. (1996). Jaw musculature of turtles: structure, functions, and evolutionary conservatism. Russian Journal of Herpetology, 3, 49-57

Iordansky, N. N. (2010). Pterygoideus muscles and other jaw adductors in amphibians and reptiles [English version of Russian original text]. Biology Bulletin, 37, 905-914

Iori, F. V., \& Carvalho, I. S. (2009). Morrinhosuchus luziae, um novo Crocodylomorpha Notosuchia da Bacia Bauru, Brasil. Revista Brasileira de Geociências, 39, 717-725

Iori, F. V., \& Carvalho, I. S. (2010). Ocorrência de um quelônio de grande porte no município de Monte Alto, estado de São Paulo, Brasil (Bacia Bauru, Cretáceo Superior). VII Simpósio Brasileiro de Paleontologia de Vertebrados 44

Iori, F. V., \& Carvalho, I. S. (2011). Caipirasuchus paulistanus, a new sphagesaurid (Crocodylomorpha, Mesoeucrocodylia) from the Adamantina Formation (Upper Cretaceous, Turonian-Santonian), Bauru Basin, Brazil. Journal of Vertebrate Paleontology, 31, 1255-1264

Iori, F. V., \& Garcia, K. L. (2012). Barreirosuchus franciscoi, um novo Crocodylomorpha Trematochampsidae da Bacia Bauru, Brasil. Revista Brasileira de Geociências, 42, 397-410

J ablonski, D. (2005). Mass extinctions and macroevolution. Paleobiology, 31(2), 192210.

Jablonski, D. (2017). Approaches to Macroevolution: 1. General Concepts and Origin of Variation. Evolutionary Biology, 44(4), 427-450. https://doi.org/10.1007/s11692-0179420-0 
Jaekel, O. (1918). Die Wirbeltierfunde aus dem Keuper von Halberstadt. Serie II.

Testudinata. Teil 1. Stegochelys dux, n.g., n.sp. Paläontologische Zeitschrift, 2, 88-214

Jaffe, A. L., Slater, G. J., \& Alfaro, M. E. (2011). The evolution of island gigantism and body size variation in tortoises and turtles. Biology Letters, 7, 558-561. https://doi.org/10.1098/rsbl.2010.1084

Jannel, A. (2015). Neck mobility, grazing habits, and intraspecific combat behaviour in the Giant Pleistocene horned turtle Meiolania platyceps. Uppsala: Uppsala Universitet

Jirak, D., \& Janacek, J. (2017). Volume of the crocodilian brain and endocast during ontogeny. PLoS One, 12, e0178491. doi:10.1371/journal.pone.0178491

Jones, M. E. H., Curtis, N., O'Higgins, P., Fagan, M., \& Evans, S. E. (2009). The head and neck muscles accociated with feeding on Sphenodon (Reptilia: Lepidosauria: Rynchocephalia). Palaeontologia Electronica, 12:7A, 1-56

Jones, M. E. H., Werneburg, I., Curtis, N., Penrose, R., O’Higgins, P., Fagan, M. J., \& Evans, S. E. (2012). The head and neck anatomy of sea turtles (Cryptodira: Chelonioidea) and skull shape in Testudines. PLoS One, 7, e47852. doi:10.1371/journal.pone.0047852

Joyce, W. G. (2007). Phylogenetic relationships of Mesozoic Turtles. Bulletin of the Peabody Museum of Natural History, 48, 3-102

Joyce, W. G. (2015). The origin of turtles: a paleontological perspective. Journal of Experimental Zoology. Part B, Molecular and Developmental Evolution, 324B, 181-193. https://doi.org/10.1002/jez.b.22609

Joyce, W. G., \& Gauthier, J. A. (2004). Palaeoecology of Triassic stem turtles sheds new light on turtle origins. Proceedings of the Royal Society of London B: Biological Sciences, 271, 1-5

Joyce, W. G., \& Lyson, T. R. (2015). A review of the fossil record of turtles of the clade Baenidae. Bulletin of the Peabody Museum of Natural History, 56, 147-183. doi:10.3374/014.056.0203

Joyce, W. G., \& Sterli, J. (2012). Congruence, non-homology, and the phylogeny of basal turtles. Acta Zoologica, 93(2), 149-159. https://doi.org/10.1111/j.14636395.2010.00491.x

Joyce, W. G., Lucas, S. G., Scheyer, T. M., Heckert, A. B., \& Hunt, A. P. (2009). A thinshelled reptile from the Late Triassic of North America and the origin of the turtle shell. Proceedings of the Royal Society B: Biological Sciences, 276(1656), 507-513. https://doi.org/10.1098/rspb.2008.1196 
Joyce, W. G., Lyson, T.R., \& Kirkland, J.I. (2016a). An early bothremydid (Testudines, Pleurodira) from the Late Cenomanian of Utah, North America. PeerJ, 4, e2502

Joyce, W. G., Parham, J. F., \& Gauthier, J. A. (2004). Developing a protocol for the conversion of rank-based taxon names to phylogenetically defined clade names, as exemplified by turtles. Journal of Paleontology, 78, 989-1013

Joyce, W. G., Parham, J. F., Lyson, T. R., Warnock, R. C. M., \& Donoghue, P. C. J. (2013a) A divergence dating analysis of turtles using fossil calibrations: an example of best practice. Journal of Paleontolog,y 87, 612-634

Joyce, W. G., Rabi, M., Clark, J. M., Xu, X. (2016b). A toothed turtle from the Late Jurassic of China and the global biogeographic history of turtles. BMC Evolutionary Biology, 16, 236. doi:10.1186/s12862-016-0762-5

Joyce, W. G., Werneburg, I., \& Lyson, T.R. (2013b) The hooked element in the pes of turtles (Testudines): a global approach to exploring homology. Journal of Anatomy, 223, $421-441$

$\mathrm{K}_{\mathrm{arl}, \mathrm{n}}$

H. V. (1997); Zur Taxonomie und Morphologie einiger tertiärer Weichschildkröten unter besonderer Berücksichtigung von Trionychinae Zentraleuropas (Testudines: Trionychidae). PhD thesis, Salzburg: Universität Salzburg

Kilias, R. (1957). Die funktionell-anatomische und systematische Bedeutung der Schläfenreduktion bei Schildkröten. Mitteilungen aus dem Zoologischen Museum in Berlin, 33, 307-354

Kischlat, E. E. (1994). Observações sobre Podocnemis elegans Suarez (Chelonii, Pleurodira, Podocnemididae) do Neocreatáceo do Brasil. Acta Geologica Leopoldensia, $17,345-351$

Kischlat, E. E. (2015). A new pleurodire turtle (Chelonii) from Adamantina Formation (Bauru Group), Upper Cretaceous of Brazil. PeerJ Preprints, 3, e1075

Kischlat, E. E., \& Azevedo, S. A. K. (1991). Sobre novos restos de quelônios podocnemidios do Grupo Bauru, estado de São Paulo, Brasil. XII Congresso Brasileiro de Paleontologia 12, 25-26

Klingenberg, C. P. (1998). Heterochrony and allometry: the analysis of evolutionary change in ontogeny. Biological Reviews, 73, 79-123. https://doi.org/10.1111/j.1469185X.1997.tb00026.x 
Kohlsdorf, T., \& Wagner, G. P. (2006). Evidence for the reversibility of digit loss: a phylogenetic study of limb evolution in Bachia (Gymnophthalmidae: Squamata). Evolution, 60(9), 1896-1912. https://doi.org/10.1554/06-056.1

Kohlsdorf, T., Lynch, V. J., Rodrigues, M. T., Brandley, M. C., \& Wagner, G. P. (2010). Data and data interpretation in the study of limb evolution: A reply to Galis et al. on the reevolution of digits in the lizard genus Bachia. Evolution, 64(8), 2477-2485. https://doi.org/10.1111/j.1558-5646.2010.01042.x

Kuhn-Schnyder, E. (1974). Die Triasfauna der Tessiner Kalkalpen. Zürich: Kommissionsverlag Lemann AG.

Kuraku, S., Usuda, R., \& Kuratani, S. (2005). Comprehensive survey of carapacial ridgespecific genes in turtle implies co-option of some regulatory genes in carapace evolution. Evolution and Development, 7(1), 3-17. https://doi.org/10.1111/j.1525142X.2005.05002.x

Kuratani, S., Kuraku, S., \& Nagashima, H. (2011). Evolutionary developmental perspective for the origin of turtles: the folding theory for the shell based on the developmental nature of the carapacial ridge. Evolution \& Development, 13, 1-14

L aaß, M., Schillinger, B., \& Kaestner, A. (2017). What did the "unossified zone" of the non-mammalian therapsid braincase house? Journal of Morphology, 278, 10201032. doi:10.1002/jmor.20583

Lakatos, I. (1976). Falsification and the methodology of Scientific Research Programmes. In S. G. Harding (Ed.), Can theories be refuted? (pp. 205-259). Dordrecht: D. Reidel Publishing Company.

Lakjer, T. (1926). Studien über die Trigeminus-versorgte Kaumuskulatur der Sauropsiden. Copenhagen: C.A. Reitsel Buchhandlung

Laland, K., Feldman, M. W., Laland, K. N., Uller, T., Feldman, M. W., Sterelny, K., ... Odling-smee, J. (2015). The extended evolutionary synthesis: its structure, assumptions and predictions. Proceedings of the Royal Society B: Biological Sciences, 282, 20151019. https://doi.org/10.1098/rspb.2015.1019

Laland, K., Uller, T., Feldman, M., Sterelny, K., Müller, G. B., Moczek, A., ... Strassmann, J. E. (2014). Does evolutionary theory need a rethink? Nature, 514(7521), 161-164. https://doi.org/10.1038/514161a

Lambertz, M., Böhme, W., \& Perry, S. F. (2010). The anatomy of the respiratory system in Platysternon megacephalum Gray, 1831 (Testudines: Cryptodira) and related species, 
and its phylogenetic implications. Comparative Biochemistry and Physiology, Part A, 156, 7. doi:10.1016/j.cbpa.2009.12.016

Lapparent de Broin, F. (2000). The oldest prepodocnemidid turtle (Chelonii, Pleurodira), from the Early Cretaceous, Ceará State, Brasil, and its environment. Treballs del Museu de Geologia de Barcelona, 9, 43-95

Laurin, M. (2002). Tetrapod phylogeny, amphibian origins, and the definition of the name Tetrapoda. Systematic Biology, 51, 6

Laurin, M., \& Piñeiro, G. H. (2017). A reassessment of the taxonomic position of mesosaurs, and a surprising phylogeny of early amniotes. Frontiers in Earth Sciences, 5, 88. doi: 10.3389/feart.2017.00088.

Laurin, M., \& Reisz, R. R. (1995). A reevaluation of early amniote phylogeny. Zoological Journal of the Linnean Society, 113, 165-223

Lautenschlager, S. (2014a). Morphological and functional diversity in therizinosaur claws and the implications for theropod claw evolution. Proceedings of the Royal Society of London B: Biological Sciecnes, 281, 20140497. doi:10.1098/rspb.2014.0497

Lautenschlager, S. (2014b). Palaeontology in the third dimension: a comprehensive guide for the integration of three-dimensional content in publications.

Paläontologisches Zeitschrift, 88, 111-121. doi:10.1007/s12542-013-0184-2

Lautenschlager, S. (2016). Reconstructing the past: methods and techniques for the digital restoration of fossils. Royal Society Open Science, 3, 160342. https://doi.org/10.1098/rsos.160342

Lautenschlager, S., \& Butler, R. J. (2016). Neural and endocranial anatomy of Triassic phytosaurian reptiles and convergence with fossil and modern crocodylians. PeerJ, 4, e2251. doi:10.7717/peerj.2251

Lautenschlager, S., \& Rücklin, M. (2014). Beyond the print-virtual paleontology in science publishing, outreach, and education. Journal of Paleontology, 88(4), 727-734. https://doi.org/10.1666/13-085

Lautenschlager, S., Brassey, C. A., Button, D. J., \& Barrett, P. M. (2016a). Decoupled form and function in disparate herbivorous dinosaur clades. Scientific Reports, 6, 26495. https://doi.org/10.1038/srep26495

Lautenschlager, S., Ferreira, G. S., \& Werneburg, I. (2018a). Sensory evolution and ecology of early turtles revealed by digital endocranial reconstructions. Frontiers in Ecology and Evolution, 6(FEB). https://doi.org/10.3389/fevo.2018.00007 
Lautenschlager, S., Gill, P. G., Luo, Z., Fagan, M. J., \& Rayfield, E. J. (2018b). The role of miniaturization in the evolution of the mammalian jaw and middle ear. Nature, 561, 533-537. https://doi.org/10.1038/s41586-018-0521-4

Lautenschlager, S., Witmer, L. M., Altangerel, P., \& Rayfield, E. J. (2013). Edentulism, beaks, and biomechanical innovations in the evolution of theropod dinosaurs. Proceedings of the National Academy of Sciences of the United States of America, 110(51), 20657-20662. https://doi.org/10.1073/pnas.1310711110

Lautenschlager, S., Witzmann, F., \& Werneburg, I. (2016b). Palate anatomy and morphofunctional aspects of interpterygoid vacuities in temnospondyl cranial evolution. The Science of Nature, 103, 79. doi:10.1007/s00114-016-1402-z

Lee, M. S. Y. (1993). The origin of the turtle body plan: bridging a famous morphological gap. Science, 261(5129), 1716-1720. Retrieved from http://www.ncbi.nlm.nih.gov/pubmed/17794877

Lee, M. S. Y. (1995). Historical burden in systematics and the interrelationships of 'parareptiles'. Biological Reviews, 70, 459-547

Lee, M. S. Y. (1996). Correlated progression and the origin of turtles. Nature, 379, 812851.

Lee, M. S. Y. (1997). Pareiasaur phylogeny and the origin of turtles. Zoological Journal of the Linnean Society, 120, 197-280

Lee, M. S. Y. (2013). Turtle origins: insights from phylogenetic retrofitting and molecular scaffolds. Journal of Evolutionary Biology, 26, 2729-2738

Lee, M. S. Y., Cau, A., Naish, D., \& Dyke, G. J. (2014). Sustained miniaturization and anatomical innovation in the dinosaurian ancestor of birds. Science, 345(6196), 562-567. https://doi.org/10.1126/science. 1252243

Lemell, C., \& Weisgram, J. (1997) Feeding patterns of Pelusios castaneus (Chelonia: Pleurodira). Netherlands Journal of Zoology, 47, 429-441

Lemell, P., Beisser, C. J., Gumpenberger, M., Snelderwaard, P., Gemel, R., \& Weisgram, J. (2010). The feeding apparatus of Chelus fimbriatus (Pleurodira; Chelidae)-adaptation perfected? Amphibia-Reptilia, 31, 97-107

Lemell, P., Lemell, C., Snelderwaard, P., Gumpenberger, M., Wochesländer, R., \& Weisgram, J. (2002). Feeding patterns of Chelus fimbriatus (Pleurodira: Chelidae). Journal of Experimental Biology, 205, 1495-1506

Lewis, E. B. (1978). A gene complex controlling segmentation in Drosophila. Nature, $276,565-570$. 
Li, C., Fraser, N. C., Rieppel, O., \& Wu, X. (2018). A Triassic stem turtle with an edentulous beak. Nature, 560, 476-479. https://doi.org/10.1038/s41586-018-0419-1

Li, C., Wu, X. -C., Rieppel, O., Wang, L. -T., \& Zhao, L. -J. (2008). An ancestral turtle from the Late Triassic of southwestern China. Nature, 456, 497-501.

doi:10.1038/nature07533

Lipka, T. R., Therrien, F., Weishampel, D.B., Jamniczky, H.A., Joyce, W.G., Colbert, M.W., \& Brinkman, D.B. (2006). A new turtle from the Arundel clay facies (Potomac Formation, Early Cretaceous) of Maryland, U.S.A. Journal of Vertebrate Paleontology, 26(2), 300-307

Liu, J., Rieppel, O., Jiang, D. -Y., Aitchison, J. C., Motani, R., Zhang, Q. -Y., Zhou, C. -Y., \& Sun, Y. -Y. (2011). A new pachypleurosaur (Reptilia: Sauropterygia) from the Lower Middle Triassic of Southwestern China and the phylogenetic relationships of Chinese pachypleurosaurs. Journal of Vertebrate Paleontology, 85, 32-36

Lively, J. R. (2015). A new species of baenid turtle from the Kaiparowits Formation (Upper Cretaceous, Campanian) of southern Utah. Journal of Vertebrate Paleontology, e1009084. doi:10.1080/02724634.2015.1009084

Loredo, G. A., Brukman, A., Harris, M. P., Kagle, D., Leclair, E. E., Gutman, R., Denney, E., Henkelman, E., Murray, B. P., Fallon, J. F., Tuan, R. S., \& Gilbert, S. F. (2001). Development of an evolutionarily novel structure: fibroblast growth factor expression in the carapacial ridge of turtle embryos. Journal of Experimental Zoology (Molecular \& Developmental Evolution), 291, 274-281

Løvtrup, S. (1977). The phylogeny of Vertebrata. London: John Wiley

Løvtrup, S. (1985). On the classification of the taxon Tetrapoda. Systematic Zoology, 34, $463-470$

Lowery, C. M., Bralower, T. J., Owens, J. D., Rodríguez-Tovar, F. J., Jones, H., Smit, J., ... Zylberman, W. (2018). Rapid recovery of life at ground zero of the end-Cretaceous mass extinction. Nature, 558, 288-291. https://doi.org/10.1038/s41586-018-0163-6

Luo, Z. X., Meng, Q. J., Grossnickle, D. M., Liu, D., Neander, A. I., Zhang, Y. G., \& Ji, Q. (2017). New evidence for mammaliaform ear evolution and feeding adaptation in a Jurassic ecosystem. Nature, 548, 326-329. https://doi.org/10.1038/nature23483

Luo, Z.-X. (2011). Developmental patterns in Mesozoic evolution of mammal ears. Annual Review of Ecology, Evolution, and Systematics, 42(1), 355-380. https://doi.org/10.1146/annurev-ecolsys-032511-142302

Luther, A. (1914). Über die vom N. trigeminus versorgte Muskulatur der Amphibien mit einem vergleichenden Ausblick über den Adductor mandibulae der Gnathostomen, und 
einem Beitrag zum Verständnis der Organisation der Anurenlarven. Acta Societatis Scientiarum Fenniciae, 44, 1-151

Lyson, T. R., \& Joyce, W. G. (2012). Evolution of the turtle bauplan: the topological relationship of the scapula relative to the ribcage. Biology Letters, 8, 1028-1031. https://doi.org/10.1098/rsbl.2012.0462

Lyson, T. R., Bever, G. S., Bhullar, B.-A. S., Joyce, W. G., \& Gauthier, J. A. (2010). Transitional fossils and the origin of turtles. Biology Letters, 6, 830-833. doi:10.1098/rsbl.2010.0371

Lyson, T. R., Bever, G. S., Scheyer, T. M., Hsiang, A. Y., \& Gauthier, J. A. (2013). Evolutionary origin of the turtle shell. Current Biology, 23, 1-7

Lyson, T. R., Rubidge, B. S., Scheyer, T. M., de Queiroz, K., Schachner, E. R., Smith, R. M. H., Botha-Brink, J., \& Bever, G. S. (2016). Fossorial origin of the turtle shell. Current Biology, 26, 1887-1894. doi:10.1016/j.cub.2016.05.020

Lyson, T. R., Schachner, E. R., Botha-Brink, J., Scheyer, T. M., Lambertz, M., Bever, G. S., Rubidge, B. S., \& de Queiroz, K. (2014). Origin of the unique ventilatory apparatus of turtles. Nature Communications, 5, 1-11

$\mathrm{M}$ aier, W. (1999). On the evolutionary biology of early mammals. With methodological remarks on the interaction between ontogenetic adaptation and phylogenetic transformation. Zoologische Anzeiger, 238, 55-74.

Maier, W., van den Heever, J., \& Durand, F. (1996). New therapsid specimens and the origin of the secondary hard and soft palate of mammals. Journal of Zoological Systematics and Evolutionary Research, 34, 9-19

Mannen, H., \& Li, S. S. L. (1999). Molecular evidence for a clade of turtles. Molecular Phylogenetics and Evolution, 13, 144-148

Martinelli, A. G., \& Nava, W. R. (2011). A new squamate lizard from the Upper Cretaceous Adamantina Formation (Bauru Group), São Paulo State, Brazil. Anais da Academia Brasileira de Ciências, 83, 291-299

Matsumoto, R., \& Evans, S. E. (2017). The palatal dentition of tetrapods and its functional significance. Journal of Anatomy, 230, 47-65. doi:10.1111/joa.12534

Mautner, A. -K., Latimer, A.E., Fritz, U., \& Scheyer, T.M. (2017). An updated description of the osteology of the pancake tortoise Malacochersus tornieri (Testudines: Testudinidae) with special focus on intraspecific variation. Journal of Morphology, 278, 321-333. doi:10.1002/jmor.20640 
Maynard Smith, J. (1984). Evolution: Palaeontology at the high table. Nature, 309, 401402.

Maynard Smith, J., Burian, R., Kauffman, S., Alberch, P., Campbell, J., Goodwin, B., ... Wolpert, L. (1985). Developmental constraints and evolution. The Quarterly Review of Biology, 60(3), 265-287.

Mayr, E. (1963). Animal species and evolution. Cambridge: The Belknap Press of the Harvard University Press.

McNamara, K. J. (1982). Heterochrony and phylogenetic trends. Paleobiology, 8(2), $130-142$.

Meckel, J. F. (1824). System der Vergleichenden Anatomie. Teil. 2. Abth. 1. Halle: Renger.

Méndez, A. H., Novas, F. E., \& Iori, F. V. (2014). New record of abelisauroid theropods from the Bauru Group (Upper Cretaceous), São Paulo State, Brazil. Revista Brasileira de Paleontologia, 17(1), 23-32

Menegazzo, M. C., Bertini, R. J., \& Manzini, F. F. (2015). A new turtle from the Upper Cretaceous Bauru Group of Brazil, updated phylogeny and implications for age of the Santo Anastácio Formation. Journal of South American Earth Sciences, 58, 18-32

Menegazzo, M. C., Catuneanu, O., \& Chang, H. K. (2016). The South American retroarc foreland system: the development of the Bauru Basin in the back-bulge province. Marine and Petroleum Geology, 73, 131-156

Meylan, P. A., Gaffney, E. S., \& Campos, D. A. (2009). Caninemys, a new side-necked turtle (Pelomedusoides: Podocnemididae) from the Miocene of Brazil. American Museum Novitates, 3639, 1-26

Mulcahy, D. G., Noonan, B. P., Moss, T., Townsend, T. M., Reeder, T. W., Sites Jr, J. W., \& Wiens, J. J. (2012). Estimating divergence dates and evaluating dating methods using phylogenomic and mitochondrial data in squamate reptiles. Molecular Phylogenetics and Evolution, 65, 974-991. http://dx.doi.org/10.1016/j.ympev.2012.08.018

Mulisch, M., \& Welsch, U. (2015). Romeis-Mikroskopische Technik. Berlin and Heidelberg: Springer-Verlag

Müller, G. B. (2007). Evo-devo: extending the evolutionary synthesis. Nature Reviews Genetics, 8, 943-949. https://doi.org/10.1016/0169-5347(94)90181-3

Müller, G. B. (2017). Why an extended evolutionary synthesis is necessary. Interface Focus, 7(5), 20170015. https://doi.org/10.1098/rsfs.2017.0015 
Müller, G. B., \& Wagner, G. P. (1991). Novelty in Evolution: restructuring the concept. Annual Review of Ecology and Systematics, 22, 229-256. https://doi.org/10.1007/978-3319-56096-0_2

Müller, J. (2003). Early loss and multiple return of the lower temporal arcade in diapsid reptiles. Naturwissenschaften, 90, 473-476. https://doi.org/10.1007/s00114-003-0461-0

Müller, J., Sterli, J., \& Anquetin. J. (2011). Carotid circulation in amniotes and its implications for turtle relationships. Neues Jahrbuch für Geologie und Paläontologie, 261, 289-297

$\mathrm{N}_{\mathrm{a}-3}$ agashima, H., Kuraku, S., Uchida, K., Kawashima-Ohya, Y., Narita, Y., \& Kuratani, S. (2013a). Origin of the turtle body plan: the folding theory to illustrate turtle-specific developmental repatterning. In D. B. Brinkman, P. A. Holroyd, \& J. D. Gardner (Eds.), Morphology and Evolution of Turtles (pp. 37-50). Dordrecht, Heidelberg, New York, London: Springer

Nagashima, H., Kuraku, S., Uchida, K., Kawashima-Ohya, Y., Narita, Y., \& Kuratani, S. (2007). On the carapacial ridge in turtle embryos: its developmental origin, function and the chelonian body plan. Development, 134, 2219-2226

Nagashima, H., Kuraku, S., Uchida, K., Kawashima-Ohya, Y., Narita, Y., \& Kuratani, S. (2012). Body plan of turtles: an anatomical, developmental and evolutionary perspective. Anatomical Science International, 87(1), 1-13. https://doi.org/10.1007/s12565-0110121-y

Nagashima, H., Kuratani, S., \& Hirasawa, T. (2013b). The endoskeletal origin of the turtle carapace. Nature Communications, 4, 1-7. https://doi.org/10.1038/ncomms3107

Nagashima, H., Sugahara, F., Takechi, M., Sato, N., \& Kuratani, S. (2015). On the homology of the shoulder girdle in turtles. Journal of Experimental Zoology (Molecular \& Developmental Evolution), 324B, 244-254. doi: 10.1002/jez.b.22584

Nagashima, H., Sugahara, F., Takeshi, M., Ericsson, R., Kawashima-Ohya, Y., Narita, Y., \& Kuratani, S. (2009). Evolution of the turtle body plan by the folding and creation of new muscle connections. Science, 325, 193-196

Natchev, N., Heiss, E., Lemell, P., Stratev, D., \& Weisgram, J. (2009). Analysis of prey capture and food transport kinematics in two Asian box turtles, Cuora amboinensis and Cuora flavomarginata (Chelonia, Geoemydidae), with emphasis on terrestrial feeding patterns. Zoology, 112, 113-127

Natchev, N., Lemell, P., Heiss, E., Beisser, C., \& Weisgram, J. (2010). Aquatic feeding in a terrestrial turtle: a functional-morphological study of the feeding apparatus in the 
Indochinese box turtle Cuora galbinifrons (Testudines, Geoemydidae). Zoomorphology, $129,111-119$

Natchev, N., Tzankov, N., Werneburg, I., \& Heiss, E. (2015). Feeding behaviour in a 'basal' tortoise provides insights on the transitional feeding mode at the dawn of modern land turtle evolution. PeerJ, 3, e1172. doi:10.7717/peerj.1172.

Neenan, J. M., \& Scheyer, T. M. (2012). The braincase and inner ear of Placodus gigas (Sauropterygia, Placodontia)-a new reconstruction based on micro-computed tomographic data. Journal of Vertebrate Paleontology, 32, 1350-1357. doi:10.1080/02724634.2012.695241

Neenan, J. M., Klein, N., \& Scheyer, T. M. (2013). European origin of placodont marine reptiles and the evolution of crushing dentition in Placodontia. Nature Communications, 4, 1621. doi: 10.1038/ncomms2633.

Nicholson, D. B., Holroyd, P. A., Benson, R. B. J., \& Barrett, P. M. (2015). Climatemediated diversification of turtles in the Cretaceous. Nature Communications, 6, 1-8. https://doi.org/10.1038/ncomms8848

Nicholson, D. B., Holroyd, P. A., Valdes, P., \& Barrett, P. M. (2016). Latitudinal diversity gradients in Mesozoic non-marine turtles. Royal Society Open Science, 3, 160581. https://doi.org/10.1098/rsos.160581

Nick, L. (1912). Das Kopfskelett von Dermochelys coriacea L. Zoologische Jahrbücher, Abteilung für Anatomie und Ontogenie der Tiere, 33, 1-238

Nyakatura, J. A., Melo, K., Horvat, T., Karakasiliotis, K., Allen, V. R., Andikfar, A., ... Ijspeert, A. J. (2019). Reverse-engineering the locomotion of a stem amniote. Nature, 565, 351-355. https://doi.org/10.1038/s41586-018-0851-2

Nyhart, L. K. (1995). Biology takes form: animal morphology and the German universities, 1800-1900. Chicago and London: The University of Chicago Press.

$\mathrm{O}$ dling-Smee, J. (2010). Niche inheritance. In M. Pigliucci \& G. B. Müller (Eds.), Evolution-the extended synthesis (pp. 175-209). Cambridge and London: The MIT Press.

Ogushi, K. (1911). Anatomische Studien an der japanischen dreikralligen Lippenschildkröte (Trionyx japanicus). I. Mitteilung. Morphologisches Jahrbuch, 43, 1106

Ogushi, K. (1913a). Anatomische Studien an der japanischen dreikralligen Lippenschildkröte (Trionyx japanicus). II. Mitteilung: Muskel- und peripheres Nervensystem. Morphologisches Jahrbuch, 46, 299-562 
Ogushi, K. (1913b). Zur Anatomie der Hirnnerven und des Kopfsympathicus von Trionyx japonicus nebst einigen kritischen Bemerkungen. Morphologisches Jahrbuch, 45, 441480

Ogushi, K. (1914). Der Kehlkopf von Trionyx japonicus. Anatomischer Anzeiger, 45, 481-503

Olson, E. C. (1947). The Family Diadectidae and its nearing on the classification of turtles. Fieldiana Geology, 11, 1-53

Osborn, H. F. (1903). On the primary division of the Reptilia into two sub-classes, Synadsida and Diapsida. Science, 17, 275-276

$\mathrm{P}$ acheco, J. A. (1913). Notas sobre a geologia do Vale do Rio Grande, a partir da foz do Rio Pardo até a sua confluência com o Rio Paranahyba. In J. Dourados (Ed.) Exploração do Rio Grande e de seus Afluentes (pp. 33-38), São Paulo: Comissão de Geografia e Geologia

Parham, J. F., \& Hutchison, J. H. (2003). A new eucryptodiran turtle from the Late Cretaceous of North America (Dinosaur Provincial Park, Alberta, Canada). Journal of Vertebrate Paleontology, 23, 783-798

Parsons, T. S. (1959). Nasal anatomy and the phylogeny of reptiles. Evolution, 13, 175187

Parsons, T. S. (1970). The Nose and Jacobson's Organ. In C. Gans (Ed.) Biology of the Reptilia, Vol. 2B (pp. 99-191), New York: Academic Press

Paulina-Carabajal, A., Sterli, J., Georgi, J., Poropat, S. F., \& Kear, B. P. (2017). Comparative neuroanatomy of extinct horned turtles (Meiolaniidae) and extant terrestrial turtles (Testudinidae), with comments on the palaeobiological implications of selected endocranial features. Zoological Journal of the Linnean Society, zlw024, 1-21. doi: 10.1093/zoolinnean/zlw024

Paulina-Carabajal, A.P., Sterli, J., Müller, J., \& Hilger, A. (2013). Neuroanatomy of the marine Jurassic turtle Plesiochelys etalloni (Testudinata, Plesiochelyidae). PLoS One, $8(7)$, e69264

Pereira, A. G., Sterli, J., Moreira, F. R. R., \& Schrago, C. G. (2017). Molecular phylogenetics and evolution multilocus phylogeny and statistical biogeography clarify the evolutionary history of major lineages of turtles. Molecular Phylogenetics and Evolution, 113, 59-66. https://doi.org/10.1016/j.ympev.2017.05.008 
Pierce, S. E., Clack, J. A., \& Hutchinson, J. R. (2012). Three-dimensional limb joint mobility in the early tetrapod Ichthyostega. Nature, 486, 523-526. https://doi.org/10.1038/nature11124

Pierce, S. E., Williams, M., \& Benson, R. B. (2017). Virtual reconstruction of the endocranial anatomy of the early Jurassic marine crocodylomorph Pelagosaurus typus (Thalattosuchia). PeerJ, 5, e3225. doi:10.7717/peerj.3225

Pigliucci, M. (2001). Phenotypic plasticity: beyond nature and nurture. Baltimore and London: The Johns Hopkins University Press.

Pigliucci, M. (2007). Do we need an extended evolutionary synthesis? Evolution, 61(12), 2743-2749. https://doi.org/10.1111/j.1558-5646.2007.00246.x

Pigliucci, M., \& Müller, G. B. (2010). Elements of an Extended Evolutionary Synthesis. In M. Pigliucci \& G. B. Müller (Eds.), Evolution-the extended synthesis (pp. 3-18). Cambridge and London: The MIT Press.

Pinheiro, A. E. P., Bertini, R. J., Andrade, M. A., \& Martins Neto, R. G. (2008). A new specimen of Stratiotosuchus maxhechti (Baurusuchidae, Crocodyliformes) from the Adamantina Formation (Upper Cretaceous), Southeastern Brazil. Revista Brasileira de Paleontologia, 11(1), 37-50

Poglayen-Neuwall, I. (1953). Untersuchungen der Kiefermuskulatur und deren Innervation bei Schildkröten. Acta Zoologica, 34, 241-292

Poglayen-Neuwall, I. (1954). Die Kiefermuskulatur der Eidechsen und ihre Innervation. Zeitschrift für wissenschaftliche Zoologie, 158, 79-132

Poglayen-Neuwall, I. (1966). Bemerkungen zur Morphologie und Innervation der Trigeminusmuskulatur von Chelus fimbriatus (Schneider). Zoologische Beiträge, 12, 4365

Poropat, S. F., Mannion, P. D., Upchurch, P., Hocknull, S. A., Kear, B. P., Kundrát, M., ... Elliott, D. A. (2016). New Australian sauropods shed light on Cretaceous dinosaur palaeobiogeography. Scientific Reports, 6, 34467. https://doi.org/10.1038/srep34467

Porro, L. B., Metzger, K. A., Iriarte-Diaz, J., \& Ross, C. F. (2013). In vivo bone strain and finite element modeling of the mandible of Alligator mississippiensis. Journal of Anatomy, 223, 195-227. https://doi.org/10.1111/joa.12080

Porter, W. R., \& Witmer, L. M. (2015). Vascular patterns in iguanas and other squamates: Blood vessels and sites of thermal exchange. PLoS ONE, 10(10), e0139215. https://doi.org/10.1371/journal.pone.0139215 
Preuschoft, H., \& Witzel, U. (2002). Biomechanical investigations on the skulls of reptiles and mammals. Senckenbergiana Lethaea, 82, 207-222

Preuschoft, H., \& Witzel, U. (2005). Functional shape of the skull in vertebrates: which forces determine skull morphology in lower primates and ancestral synapsids? The Anatomical Record, 283, 402-413

Price, L. I. 1953. Os quelônios da Formação Bauru, Cretáceo terrestre do Brasil Meridional. Boletim da Divisão de Geologia e Mineralogia Departamento Nacional de Produção Mineral, 147, 1-34

Pritchard, P. C. H. (1984). Piscivory in Turtles, and Evolution of Long-necked Chelidae. In M. W. J. Ferguson (Ed.) The Structure, Development and Evolution of Reptiles. A Festschrift in honour of Professor A.d'A. Bellairs on the occasion of his retirement. Symposia of the Zoological Society of London, vol 52. London and Orlando: Academic Press

$\mathrm{R}$ abi, M., Sukanov, V. B., Egorova, V. N., Danilov, I., \& Joyce, W. G. (2014). Osteology, relationships, and ecology of Annemys (Testudines, Eucryptodira) from the Late Jurassic of Shar Teg, Mongolia and phylogenetic definitions for Xinjiangchelyidae, Sinemydidae, and Macrobaenidae. Journal of Vertebrate Paleontology, 34, 327-352

Rabi, M., Tong, H., \& Botfalvai, G. (2012). A new species of the side-necked turtle Foxemys (Pelomedusoides: Bothremydidae) from the Late Cretaceous of Hungary and the historical biogeography of the Bothremydini. Geological Magazine, 149, 662-674

Rabi, M., Zhou, C. -F., Wings, O., Ge, S., \& Joyce, W. G. (2013). A new xinjiangchelyid turtle from the Middle Jurassic of Xinjiang, China and the evolution of the basipterygoid process in Mesozoic turtles. BMC Evolutionary Biology, 13, 1-28

Raff, R. A. (1996). The shape of life. Chicago: University of Chicago Press.

Raff, R. A. (2000). Evo-devo: the evolution of a new discipline. Nature Reviews Genetics, 1, 74-79. https://doi.org/10.1038/35049594

Raff, R. A. (2007). Written in stone: fossils, genes and evo-devo. Nature Reviews Genetics, 8, 911-920. https://doi.org/10.1038/nrg2225

Rahman, I. A., \& Smith, S. Y. (2014). Virtual paleontology: computer-aided analysis of fossil form and function. Journal of Paleontology, 88(4), 633-635. https://doi.org/10.1666/13-001i

Rahman, I. A., Zamora, S., Falkingham, P. L., \& Phillips, J. C. (2015). Cambrian cinctan echinoderms shed light on feeding in the ancestral deuterostome. Proceedings of the 
Royal Society B: Biological Sciences, 282, 20151964. https://doi.org/10.1098/rspb.2015.1964

Rathke, H. (1848). Uber die Entwicklung der Schildkröten. Braunshweig: Friedrich Vieweg und Sohn.

Ray, C. E. (1959). A sesamoid bone in the jaw musculature of Gopherus polyphemus (Reptilia: Testudininae). Anatomischer Anzeiger, 107, 85-91

Rayfield, E. J. (2007). Finite Element Analysis and understanding the biomechanics and evolution of living and fossil organisms. Annual Review of Earth Planetary Sciences, 35, 541-576. https://doi.org/10.1146/annurev.earth.35.031306.140104

Reisz, R. R., \& Head, J. J. (2008). Turtle origins out to sea. Nature, 456, 450-451

Reyment, R. A. (2011). Morphometric analysis of polyphenism in Lower Cretaceous ammonite genus Knemiceras. In A. M. T. Elewa (Ed.), Computational Paleontology (pp. 95-110). Heidelberg, Dordrecht, London, New York: Springer-Verlag Berlin Heidelberg.

Rhodin, A. G. J., Iverson, J. B., Bour, R., Fritz, U., Georges, A., Shaffer, H. B., \& van Dijk, P. P. J. (2017). Turtles of the World: Annotated Checklist and Atlas of Taxonomy, Synonymy, Distribution, and Conservation Status ( $8^{\text {th }}$ Ed.). In A. G. J. Rhodin, J. B. Iverson, P. P. van Dijk, R. A. Saumure, K. A. Buhlmann, P. C. H. Pritchard, \& R. A. Mittermeier (Eds.), Conservation Biology of Freshwater Turtles and Tortoises: a Compilation Project of the IUCN/SSC Tortoise and Freshwater Turtle Specialist Group. Chelonian Research Monographs, 7, 1-292

Rice, R., Kallonen, A., Cebra-Thomas, J., \& Gilbert, S. F. (2016). Development of the turtle plastron, the order-defining skeletal structure. Proceedings of the National Academy of Sciences of the United States of America, 113(19), 5317-5322. doi:10.1073/pnas.1600958113

Rieppel, O. (1980). The trigeminal jaw adductor musculature of Tupinambis, with comments on the phylogenetic relationship of the Teiidae (Reptilia, Lacertilia). Zoological Journal of the Linnean Society, 69, 1-29

Rieppel, O. (1984). The structure of the skull and jaw adductor musculature in the Gekkota, with comments on the phylogenetic-relationships of the Xantusiidae (Reptilia, Lacertilia). Zoological Journal of the Linnean Society, 82, 291-318

Rieppel, O. (1987a). The development of the trigeminal jaw adductor musculature and associated skull elements in the lizard Podarcis sicula. Journal of Zoology, 212, 131-150

Rieppel, O. (1987b). The development of the trigeminal jaw adductor musculature and associated skull elements in the lizard Podarcis sicula. Journal of Zoology, 212, 131-150 
Rieppel, O. (1990). The structure and development of the jaw adductor musculature in the turtle Chelydra serpentina. Zoological Journal of the Linnean Society, 98, 27-62

Rieppel, O. (1993). Patterns of Diversity in the Reptilian Skull. In J. Hanken, \& B. K. Hall (Eds.) The Skull, Volume 2: Patterns of Structural and Systematic Diversity (pp 344389), Chicago: University of Chicago Press

Rieppel, O. (2000). Turtles as diapsid reptiles. Zoologica Scripta, 29, 199-212

Rieppel, O. (2001). Turtles as hopeful monsters. BioEssays, 23(11), 987-991.

Rieppel, O. (2004). Kontroversen innerhalb der Tetrapoda - die Stellung der Schildkröten (Testudines). Sitzungsberichte der Gesellschaft Naturforschender Freunde zu Berlin, 43, 201-221

Rieppel, O. (2007). The Relationships of Turtles within Amniotes. In J. Wyneken, M.H. Godfrey, \& V. Bels (Eds.), Biology of turtles: from structures to strategies of life, (pp. 345-353), Boca Raton: CRC Press

Rieppel, O. (2008). The relationships of turtles within amniotes. In J. Wyneken, M. H. Godfrey, \& V. Bels (Eds.), Biology of Turtles (pp 345-353). Boca Raton, London, New York: CRC Press

Rieppel, O. (2013). The evolution of the turtle shell. In D.B. Brinkman, P.A. Holroyd, \& J.D. Gardner (Eds.), Morphology and evolution of turtles, (pp. 51-61), Heidelberg: Springer. doi:10.1007/978-94-007-4309-0_5

Rieppel, O. (2017). Turtles as hopeful monster. Bloomington: Indiana University Press.

Rieppel, O., \& deBraga, M. (1996). Turtles as diapsid reptiles. Nature, 384(6608), 453455. https://doi.org/10.1038/384453a0

Rieppel, O., \& Reisz, R. R. (1999). The origin and early evolution of turtles. Annual Review of Ecology and Systematics, 30, 1-22

Rodrigues, J. F. M., \& Diniz-Filho, J. A. F. (2016). Ecological opportunities, habitat, and past climatic fluctuations influenced the diversification of modern turtles. Molecular Phylogenetics and Evolution, 101, 352-358. https://doi.org/10.1016/j.ympev.2016.05.025

Rodrigues, J. F. M., Villalobos, F., Iverson, J. B., \& Diniz-Filho, J. A. F. (2019). Climatic niche evolution in turtles is characterized by phylogenetic conservatism for both aquatic and terrestrial species. Journal of Evolutionary Biology, 32, 66-75. https://doi.org/10.1111/jeb.13395

Rohlf, F. (2010). TPSDig2, version 2.16. New York: Stony Brook 
Rollot, Y., Lyson, T. R., \& Joyce, W. G. (2018). A description of the skull of Eubaena cephalica (Hay, 1904) and new insights into the cranial circulation and innervation of baenid turtles. Journal of Vertebrate Paleontology, e1474886, 1-11. https://doi.org/10.1080/02724634.2018.1474886

Romano, P. S. R., \& Azevedo, S. A. K. (2007). Morphometric analysis of the Upper Cretaceous Brazilian side-necked turtle Bauruemys elegans (Suárez, 1969) (Pleurodira, Podocnemididae). Arquivos do Museu Nacional, 65(4), 395-402

Romano, P. S. R., Oliveira, G. R., Azevedo, S. A. K., Kellner, A. W. A., \& Campos, D. A. (2013). New information about Pelomedusoides (Testudines: Pleurodira) from the Cretaceous of Brazil. In D. Brinkman, P. Holroyd, and J. Gardner (Eds.) Morphology and Evolution of Turtles (pp. 267-274). Dordrecht: Springer

Romer, A. S. (1956). Osteology of the reptiles. Chicago: University of Chicago Press

Rougier, G. W., de la Fuente, M. S., Arcucci, A. B. (1995). Late Triassic turtles from South America. Science, 268, 855-858

Rücklin, M., Donoghue, P. C. J., Johanson, Z., Trinajstic, K., Marone, F., \& Stampanoni, M. (2012). Development of teeth and jaws in the earliest jawed vertebrates. Nature, 491, 748-751. https://doi.org/10.1038/nature11555

$\mathrm{S}$ aint-Hilaire, G. (1809). Sur les tortues molles, nouveau genre sous le nom de Trionyx, et sur la formation des carapaces. Annales Muséum National D'Histoire Naturelle Paris, $14,1-20$.

Sánchez-Villagra, M. R. (2012). Embryos in deep time: the rock record of biological development. Berkeley, Los Angeles, London: University of California Press.

Santucci, R. M., \& Arruda-Campos, A. C. (2011). A new sauropod (Macronaria, Titanosauria) from the Adamantina Formation, Bauru Group, Upper Cretaceous of Brazil and the phylogenetic relationships of Aeolosaurini. Zootaxa, 3085, 1-33

Schenk, S. C., \& Wainwright, P. C. (2001). Dimorphism and the functional basis of claw strength in six brachyuran crabs. Journal of Zoology, 255, 105-119

Scheyer, T. M., \& Sander, P. M. (2007). Shell bone histology indicates terrestrial palaeoecology of basal turtles. Proceedings of the Royal Society B: Biological Sciences, 274, 1885-1893. doi:DOI 10.1098/rspb.2007.0499

Scheyer, T. M., Brüllmann, B., \& Sánchez-Villagra, M. R. (2008). The ontogeny of the shell in side-necked turtles, with emphasis on the homologies of costal and neural bones. Journal of Morphology, 269(8), 1008-1021. https://doi.org/10.1002/jmor.10637 
Scheyer, T. M., Neenan, J. M., Bodogan, T., Furrer, H., Obrist, C., \& Plamondon, M. (2017). A new, exceptionally preserved juvenile specimen of Eusaurosphargis dalsassoi (Diapsida) and implications for Mesozoic marine diapsid phylogeny. Scientific Reports, 7, 4406. doi:10.1038/s41598-017-04514-X

Scheyer, T. M., Werneburg, I., Mitgutsch, C., Delfino, M., \& Sánchez-Villagra, M. R. (2013). Three ways to tackle the turtle: integrating fossils, comparative embryology, and microanatomy. In D. Brinkman, P. Holroyd, \& J. Gardner (Eds.), Morphology and Evolution of Turtles (pp. 63-70). Dordrecht: Springer. https://doi.org/10.1007/978-94007-4309-0

Schoch, R. R., \& Sues, H. D. (2015). A Middle Triassic stem-turtle and the evolution of the turtle body plan. Nature, 523, 584-587. doi:10.1038/nature14472

Schoch, R. R., \& Sues, H. D. (2016). The diapsid origin of turtles. Zoology, 119, 3. doi:10.1016/j.zool.2016.01.004

Schoch, R. R., \& Sues, H. D. (2017). Osteology of the Middle Triassic stem-turtle Pappochelys rosinae and the early evolution of the turtle skeleton. Journal of Systematic Palaeontology, 16(11), 927-965. doi:10.1080/14772019.2017.1354936

Schulman, H. (1906). Vergleichende Untersuchungen über die Trigeminus-Musculatur der Monotremen, sowie die dabei in Betracht kommenden Nerven und Knochen. In G. Fischer (Ed.) Jenaische Denkschriften, vol 6. Zoologische Forschungsreisen in Australien und dem Malayischen Archipel. Mit Unterstützung des Herrn Dr. Paul von Ritter ausgeführt in den Jahren 1891-1893 (III. 2. Teil), vol 2 (pp. 297-400), Jena

Schumacher, G. H. (1954/55). Beiträge zur Kiefermuskulatur der Schildkröten: II. Mitteilung. Bau des M. adductor mandibularis unter spezieller Berücksichtigung der Fascien des Kopfes bei Platysternon megacephalum, Emys orbicularis, Testudo graeca, Pelomedusa subrufa, Clemmys caspica riculata, Graptemys geographica, Hardella thurrjii, Macrochelys temminckii, Emydura krefftii, Hydromedusa tectifera, Chelodina longicollis, Trionyx punctatus, Amyda sinensis und Dogania subplana. Wissenschaftliche Zeitschrift der Ernst Moritz Arndt-Universität Greifswald - Mathematischnaturwissenschaftliche Reihe, 4, 501-518

Schumacher, G. H. (1954a). Beiträge zur Kiefermuskulatur der Schildkröten. I. Mitteilung. Bau des M. adductor mandibularis unter spezieller Berücksichtigung des M. pterygoideus bei Chelone, Podocnemis, Sternothaerus und Testudo elephantopus. $\mathrm{PhD}$ thesis. Greifswald: Ernst-Moritz-Arndt-Universität

Schumacher, G. H. (1954b). Beiträge zur Kiefermuskulatur der Schildkröten: III. Mitteilung. Bau des M. adductor mandibularis bei Macrochelys temminckii, Platysternon megacephalum, Clemmys caspica rivulata, Emys orbicularis, Graptemys geographica, Hardella thurjii, Testudo graeca, Amyda sinensis, Dogania subplana, Trionyx punctatus, Pelomedusa subrufa, Chelodina longicollis, Hydromedusa tectifera und Emydura krefftii. 
Wissenschaftliche Zeitschrift der Ernst Moritz Arndt-Universität Greifswald Mathematisch-naturwissenschaftliche Reihe, 4, 559-588

Schumacher, G. H. (1956). Morphologische Studie zum Gleitmechanismus des M. adductor mandibulae externus bei Schildkröten. Anatomischer Anzeiger, 103, 1-12

Schumacher, G. H. (1972). Die Kopf- und Halsregion der Lederschildkröte Dermochelys coriacea (LINNAEUS 1766) - Anatomische Untersuchungen im Vergleich zu anderen rezenten Schildkröten - Mit 7 Figuren im Text und 31 Tafeln, vol 2. Abhandlungen der Akademie der Wissenschaften der DDR. Berlin: Akademie-Verlag

Schumacher, G. H. (1973). The head muscles and hyolaryngeal skeleton of turtles and crocodilians. In C. Gans, \& T. S. Parsons (Eds.), Biology of the Reptilia, vol 4. Morphology D (pp. 101-199), London and New York: Academic Press

Seeley, H. G. (1892). On a new reptile from Welte Vreden (Beaufort West) Eunotosaurus africanus (Seeley). Quaterly Journal of the Geological Society, 48, 583-585

Sellers, K. C., Middleton, K. M., Davis, J. L., \& Holliday, C. M. (2017). Ontogeny of bite force in a validated biomechanical model of the American alligator. Journal of Experimental Biology, 220, 2036-2046. https://doi.org/10.1242/jeb.156281

Shaffer, H. B. (2009). Turtles (Testudines). In S. B. Hedges, \& S. Kumar (Eds.), The TimeTree of Life (pp. 398-401), New York: Oxford University Press

Shaffer, H. B., Meylan, P., \& McKnight, M. L. (1997). Tests of turtle phylogeny: molecular, morphological, and paleontological approaches. Systematic Biology, 46(2), 235-268

Siler, C. D., \& Brown, R. M. (2011). Evidence for repeated acquisition and loss of complex body-form characters in an insular clade of southeast Asian semi-fossorial skinks. Evolution, 65(9), 2641-2663.

Simpson, G. G. (1944). Tempo and mode in evolution. New York: Columbia University Press.

Simpson, G. G. (1953). The major features of evolution. New York: Columbia University Press

Smith, A. B. (1998). What does palaeontology contribute to systematics in a molecular world? Molecular Phylogenetics and Evolution, 9(3), 437-447. https://doi.org/10.1006/mpev.1998.0488

Smith, F. A., Boyer, A. G., Brown, J. H., Costa, D. P., Dayan, T., Ernest, M., ... Uhen, M. D. (2010). The evolution of maximum body size of terrestrial mammals. Science, 330, 1216-1220. https://doi.org/10.1126/science1194830 
Spoor, F. (2003). The semicircular canal system and locomotor behaviour, with special reference to hominin evolution. Courier-Forschungsinstitut Senckenberg, 93-104

Spoor, F., Garland, T., Krovitz, G., Ryan, T.M., Silcox, M.T., \& Walker, A. (2007). The primate semicircular canal system and locomotion. Proceedings of the National Academy of Sciences of Philadelphia. 104, 10808-10812. doi:10.1073/pnas.0704250104

Staesche, K. (1937). Podocnemis brasiliensis n. sp. aus der Oberen Kreide Brasiliens. Neues Jahrbuch für Mineralogie, Geologie und Paläntologie B, 77, 291-309

Stayton, C. T. (2011). Terrestrial feeding in aquatic turtles: environment-dependent feeding behavior modulation and the evolution of terrestrial feeding in Emydidae. Journal of Experimental Biology, 214, 4083-4091

Sterli, J. (2010). Phylogenetic relationships among extinct and extant turtles: the position of Pleurodira and the effects of the fossils on rooting crown-group turtles. Contributions to Zoology, 79, 93-106

Sterli, J., \& de la Fuente, M. S. (2010). Anatomy of Condorchelys antiqua Sterli, 2008, and the origin of the modern jaw closure mechanism in turtles. Journal of Vertebrate Paleontology, 30(2), 351-366. https://doi.org/10.1080/02724631003617597

Sterli, J., \& Joyce, W. G. (2007). The cranial anatomy of the Early Jurassic turtle Kayentachelys aprix. Acta Palaeontologica Polonica, 52, 675-694

Sterli, J., de la Fuente, M. S., \& Rougier, G. W. (2019). New remains of Condorchelys antiqua (Testudinata) from the Early-Middle Jurassic of Patagonia: anatomy, phylogeny, and paedomorphosis in the early evolution of turtles. Journal of Vertebrate Paleontology, 38(4), 1-17. https://doi.org/10.1080/02724634.2018.1480112

Sterli, J., Müller, J., Anquetin, J., \& Hilger, A. (2010). The parapasisphenoid complex in Mesozoic turtles and the evolution of the testudinate basicranium. Canadian Journal of Earth Sciences, 47, 1337-1346

Suárez, J. M. (1969). Um quelônio da Formação Bauru. In XXIII Congresso Brasileiro de Geologia, Anais 3 (pp. 168-176)

Summers, A. P., Darouian, K. F., Richmond, A. M., \& Brainerd, E. L. (1998) Kinematics of aquatic and terrestrial prey capture in Terrapene carolina, with implications for the evolution of feeding in cryptodire turtles. Journal of Experimental Zoology, 281, 280287

Sutton, M. D., Rahman, I. A., \& Garwood, R. J. (2014). Techniques for virtual palaeontology. Oxford: John Wiley \& Sons, Ltd. 
Sutton, M., Rahman, I., \& Garwood, R. (2017). Virtual Paleontology—an Overview. The Paleontological Society Papers, 22, 1-20. https://doi.org/10.1017/scs.2017.5

Szczygielski, T. (2017). Homeotic shift at the dawn of the turtle evolution. Royal Society Open Science, 4, 160933. https://doi.org/10.1098/rsos.160933

Szczygielski, T., \& Sulej, T. (2016). Revision of the Triassic European turtles Proterochersis and Murrhardtia (Reptilia, Testudinata, Proterochersidae), with the description of new taxa from Poland and Germany. Zoological Journal of the Linnean Society, 177, 395-427. https://doi.org/10.1111/zoj.12374

$\mathrm{T}$ anner, J. B., Dumont, E. R., Sakai, S. T., Lundrigan, B. L., \& Holekamp, K. E. (2008). Of arcs and vaults: the biomechanics of bone-cracking in spotted hyenas (Crocuta crocuta). Biological Journal of the Linnean Society, 95, 246-255. https://doi.org/10.1111/j.1095-8312.2008.01052.x

Tarsitano, S. F., Oelofsen, B., Frey, E., \& Riess, J. (2001). The origin of temporal fenestra. South African Journal of Science, 97, 334-336

Tavares, S. A. S., Branco, F. R., \& Santucci, R. M. (2014). Theropod teeth from the Adamantina Formation (Bauru Group, Upper Cretaceous), Monte Alto, São Paulo, Brazil. Cretaceous Research, 50, 59-71

Taylor, A. C., Lautenschlager, S., Qi, Z., \& Rayfield, E. J. (2017). Biomechanical evaluation of different musculoskeletal arrangements in Psittacosaurus and implications for cranial function. The Anatomical Record, 300, 49-61. https://doi.org/10.1002/ar.23489

Thomason, J. J., \& Russel, A. P. (1986). Mechanical factors in the evolution of the mammalian secondary palate: a theoretical analysis. Journal of Morphology, 189, 199213

Thomson, J. T. (1932); The Anatomy of the Tortoise. The Scientific Proceedings of the Royal Dublin Society New Series, 20, 359-461

Tokita, M. (2004). Morphogenesis of parrot jaw muscles: Understanding the development of an evolutionary novelty. Journal of Morphology, 259, 69-81. doi: 10.1002/Jmor.10172

Tong, H., \& Buffetaut, E. (1996). A new genus and species of pleurodiran turtle from the Cretaceous of southern Morocco. Neues Jahrbuch für Geologie und Paläontologie Abhandlungen, 199, 133-150 
Tsai, H. P., \& Holliday, C. M. (2011). Ontogeny of the Alligator cartilago transiliens and its significance for sauropsid jaw muscle evolution. PLoS One, 6, e24935

Tsuji, L. A., \& Müller, J. (2009). Assembling the history of the Parareptilia: phylogeny, diversification, and a new definition of the clade. Fossil Record, 12, 71-81

Tucker, A. S., Watson, R. P., Lettice, L. A., Yamada, G., \& Hill, R. E. (2004). Bapx1 regulates patterning in the middle ear: altered regulatory role in the transition from the proximal jaw during vertebrate evolution. Development, 131(6), 1235-1245. https://doi.org/10.1242/dev.01017

Tvarožková, B. (2006). Development of the temporal emargination in turtles and the temporal fenestration in crocodilians: the origin of an anapsid-like chelonian skull. Masters thesis, Prague: Charles University in Prague

$\mathrm{U}$ nderwood, G. (1970). The eye. In C. Gans, \& T. S. Parsons (Eds.), Biology of the Reptilia, vol 2. Morphology B (pp. 1-97). London and New York: Academic Press

Uyeda, J. C., \& Harmon, L. J. (2014). A novel Bayesian method for inferring and interpreting the dynamics of adaptive landscapes from phylogenetic comparative data. Systematic Biology, 63(6), 902-918. https://doi.org/10.1093/sysbio/syu057

\section{$\mathrm{V}$} állen, E. (1942). Beitäge zur kenntnis der Ontogenie und der vergleichenden Anatomie des Schildkrötenpanzers. Acta Zoologica, 23, 1-127.

Varela, L., Tambusso, P. S., Mcdonald, H. G., \& Fariña, R. A. (2019). Phylogeny, macroevolutionary trends and historical biogeography of Sloths: insights from a Bayesian morphological clock analysis. Systematic Biology, 68(2), 204-218. https://doi.org/10.1093/sysbio/syy058

Versluys, J. (1919). Über die Phylogenie der Schläfengruben und Jochbogen bei den Reptilia. Sitzungsberichte der Heidelberger Akademie der Wissenschaften, Mathematisch-naturwissenschaftliche Klasse, Abteilung B Biologische Wissenschaften, $13,1-29$

Via, S., \& Lande, R. (1985). Genotype-environment interaction and the evolution of phenotypic plasticity. Evolution, 39(3), 505-522. https://doi.org/10.2307/2408649

Vieira, L. G., Santos, A. L. Q., Lima, F. C., \& Pinto, J. G. S. (2009). Ontogeny of the plastron of the Giant Amazon River Turtle, Podocnemis expansa (Schweigger, 1812) (Testudines, Podocnemididae). Zoological Science, 26, 491-495. https://doi.org/10.2108/zsj.26.491 
Vitek, N. S., \& Joyce, W. (2015). A review of the fossil record of New World turtles of the clade Pan-Trionychidae. Bulletin of the Peabody Museum of Natural History, 56, $185-244$

von Baczko, M. B., \& Desojo, J. B. (2016). Cranial anatomy and palaeoneurology of the archosaur Riojasuchus tenuisceps from the Los Colorados Formation, La Rioja, Argentina. PLoS One, 11, e0148575. doi:10.1371/journal.pone.0148575

\section{$\mathrm{W}$} agner, G. P. (2007). The developmental genetics of homology. Nature Reviews Genetics, 8, 473-479. https://doi.org/10.1038/nrg2099

Wagner, G. P. (2014). Homology, genes, and evolutionary innovation. Princeton and Oxford: Princeton University Press.

Wagner, G. P., \& Altenberg, L. (1996). Complex adaptations and the evolution of evolvability. Evolution, 50(3), 967-976.

Wagner, G. P., \& Chiu, C.-H. (2001). The tetrapod limb: a definition and a hypothesis on its origin. Journal of Experimental Zoology (Mol. Dev. Evol.), 291, 226-240.

Wagner, G. P., \& Draghi, J. (2010). Evolution of evolvability. In M. Pigliucci \& G. B. Müller (Eds.), Evolution-the extended synthesis (pp. 379-400). Cambridge and London: The MIT Press.

Wagner, P., Plotnick, R. E., \& Lyons, S. K. (2018). Evidence for trait-based dominance in occupancy among fossil taxa and the decoupling of macroecological and macroevolutionary success. The American Naturalist, 192(3), E120-E138. https://doi.org/10.1086/697642

Walker Jr., W. F. (1973). The Locomotor Apparatus of Testudinines. In C. Gans, \& T. S. Parsons (Eds.) Biology of the Reptilia, vol 4. Morphology D (pp. 1-100). London and New York: Academic Press

Walsh, S. A., Barrett, P. M., Milner, A. C., Manley, G., \& Witmer, L.M. (2009). Inner ear is a proxy for deducing auditory capability and behaviour in reptiles and birds. Proceedings of the Royal Society B: Biological Sciences, 276, 1355-1360

Walsh, S. A., Iwaniuk, A. N., Knoll, M. A., Bourdon, E., Barrett, P. M., Milner, A. C., ... Sterpaio, P. Dello. (2013). Avian cerebellar floccular fossa size is not a proxy for flying ability in birds. PLOS ONE, 8(6), e67176. https://doi.org/10.1371/journal.pone.0067176

Wang, Z., Pascual-Anaya, J., Zadissa, A., Li, W., Niimura, Y., Huang, Z., Li, C., White, S., Xiong, Z., Fang, D., Wang, B., Ming, Y., Chen, Y., Zheng, Y., Kuraku, S., Pignatelli, M., Herrero, J., Beal, K., Nozawa, M., Li1, Q., Wang, J., Zhang, H., Yu, L., Shigenobu, 
S., Wang, J., Liu, J., Flicek, P., Searle, S., Wang, J., Kuratani, S., Yin, Y., Aken, B., Zhang, G., \& Irie, N. (2013). The draft genomes of soft-shell turtle and green sea turtle yield insights into the development and evolution of the turtle-specific body plan. Nature Genetics, 46(6), 701-708. doi:10.1038/ng.2615

Watson, D. M. S. (1914). Eunotosaurus africanus Seeley, and the ancestry of the Chelonia. Proceedings of the Zoological Society of London, 11, 1011-1020

Weisgram, J. (1985). Feeding mechanisms of Claudius angustatus COPE 1865. In H. R. Dunker, \& G. Fleischer (Eds.) Fortschritte der Zoologie. Functional Morphology in Vertebrates, vol 30 (pp. 256-260). Stuttgart and New York: Gustav Fischer Verlag

Weishampel, D. B., Dodson, P., \& Osmólska, H. (2004). The Dinosauria (2nd ed.). Berkeley: University of California Press.

Welscher, P., Zuniga, A., Kuijper, S., Drenth, T., Goedemans, H. J., Meijlink, F., \& Zeller, R. (2002). Progression of vertebrate limb development through SHH-mediated counteraction of GLI3. Science, 298, 827-830. https://doi.org/10.1126/science.1075620

Werneburg, I. (2011). The cranial musculature of turtles. Palaeontologia Electronica, 14, 1-99. doi:10.5167/uzh-48569

Werneburg, I. (2012). Temporal bone arrangements in turtles: an overview. Journal of Experimental Zoology. Part B, Molecular and Developmental Evolution, 318(4), 235249. https://doi.org/10.1002/jez.b.22450

Werneburg, I. (2013a). Jaw musculature during the dawn of turtle evolution. Organisms, Diversity \& Evolution, 13, 225-254

Werneburg, I. (2013b), The tendinous framework in the temporal skull region of turtles and considerations about its morphological implications in amniotes: a review. Zoological Science, 31, 141-153

Werneburg, I. (2015). Neck motion in turtles and its relation to the shape of the temporal skull region. Comptes Rendus Palevol, 14, 527-548. https://doi.org/10.1016/j.crpv.2015.01.007

Werneburg, I. (2019). Functional categories and ontogenetic origin of temporal skull openings in amniotes. Frontiers in Earth Sciences, 7, 13. https://doi.org/10.3389/feart.2019.00013

Werneburg, I., \& Maier, W. (2019). Diverging development of akinetic skulls in cryptodire and pleurodire turtles: an ontogenetic and phylogenetic study. Vertebrate Zoology, 69(2), 113-143. https://doi.org/10.26049/VZ69-2-2019-01 
Werneburg, I., \& Sánchez-Villagra, M. R. (2009). Timing of organogenesis support basal position of turtles in the amniote tree of life. BMC Evolutionary Biology, 9, 1-9. doi: $10.1186 / 1471-2148-9-82$

Werneburg, I., Esteve-Altava, B., Bruno, J., Ladeira, M. T., \& Diogo, R. (2019). Unique skull network complexity of Tyrannosaurus rex among land vertebrates. Scientific Reports, 9(1520). https://doi.org/10.1038/s41598-018-37976-8

Werneburg, I., Hinz, J. K., Gumpenberger, M., Volpato, V., Natchev, N., \& Joyce, W. G. (2015a). Modeling neck mobility in fossil turtles. Journal of Experimental Zoology, Part B, Molecular and Developmental Evolution, 324, 230-243

Werneburg, I., Maier, W., \& Joyce, W. G. (2013). Embryonic remnants of intercentra and cervical ribs in turtles. Biology Open, 2, 1103-1107

Werneburg, I., Wilson, L. A. B., Parr, W. C. H., \& Joyce, W. G. (2015b). Evolution of neck vertebral shape and neck retraction at the transition to modern turtles: an integrated geometric morphometric approach. Systematic Biology, 64, 187-204

Wever, E. G. (1978). The Reptile Ear. Princeton, New Jersey: Princeton University Press

Williams, E. E. (1950). Variation and selection in the cervical central articulations of living turtles. Bulletin of the American Museum of Natural History, 94, 509-561

Williston, S. W. (1917). The phylogeny and classification of reptiles. Journal of Geology, $25,411-421$

Witmer, L. M., Ridgely, R. C., Dufeau, D. L., \& Semones, M. C. (2008). Using CT to peer into the past: $3 \mathrm{D}$ visualization of the brain and ear regions of birds, crocodiles, and nonavian dinosaurs. In H. Endo, \& R. Frey (Eds.) Anatomical imaging (pp. 67-87), Tokyo: Springer

Witzmann, F., \& Werneburg, I. (2017). The palatal interpterygoid vacuities of temnospondyls and the implications for the associated eye- and jaw musculature. The Anatomical Record, 300, 1240-1269. doi:10.1002/ar.23582

Wochesländer, R., Hilgers, H., \& Weisgram, J. (1999). Feeding mechanism of Testudo hermanni boettgeri (Chelonia, Cryptodira). Netherlands Journal of Zoology, 49, 1-13

Wright, S. (1931). Evolution in Mendelian population. Genetics, 16, 97-159.

Wroe, S., Parr, W. C. H., Ledogar, J. A., Bourke, J., Evans, S. P., Fiorenza, L., ... Yokley, T. R. (2018). Computer simulations show that Neanderthal facial morphology represents adaptation to cold and high energy demands, but not heavy biting. Proceedings of the 
Royal Society B: Biological Sciences, 285, 20180085. https://doi.org/10.1098/rspb.2018.0085

Wyneken, J. (2001). The Anatomy of Sea Turtles. Miami: US Department of Commerce NOAA Technical Memorandum NMFS-SEFSC-470.

Y i, H., \& Norell, M.A. (2015). The burrowing origin of modern snakes. Science Advances, 1, e1500743. doi: 10.1126/sciadv.1500743

Yntema, C. L. (1968). A series of stages in the embryonic development of Chelydra serpentina. Journal of Morphology, 125, 219-251.

Z angerl, R. (1948). The methods of comparative anatomy and its contribution to the study of evolution. Evolution, 2, 351-374

Zangerl, R. (1960). A new specimen of Desmatochelys lowii Williston; a primitive sea turtle from the Cretaceous of South Dakota. Fieldiana, Geology, 14, 7-40

Zangerl, R. (1969). The turtle shell. In C. Gans, A. d'A Bellairs, \& T. S. Parsons (Eds.), Biology of the Reptilia, Morphology A, vol 1 (pp. 311-339). London: Academic Press.

Zapata, U., Metzger, K., Wang, Q., Elsey, R. M., Ross, C. F., \& Dechow, P. C. (2010). Material properties of mandibular cortical bone in the American alligator, Alligator mississippiensis. Bone, 46, 860-867. https://doi.org/10.1016/j.bone.2009.11.010

Zardoya, R., \& Meyer, A. (1998). Complete mitochondrial genome suggests diapsid affinities of turtles. Proceedings of the National Academy of Sciences USA, 95, 1422614231

Zardoya, R., \& Meyer, A. (2001). The evolutionary position of turtles revised. Naturwissenschaften, 88, 193-200

Zdansky, O. (1923). Über die Temporalregion des Schildkrötenschädels. Bulletin of the Geological Institution of the University of Upsala, 19, 89-114

Zelenitsky, D. K., Therrien, F., \& Kobayashi, Y. (2009). Olfactory acuity in theropods: palaeobiological and evolutionary implications. Proceedings of the Royal Society of London B: Biological Sciences, 276, 667-673

Zelenitsky, D. K., Therrien, F., Ridgely, R. C., McGee, A. R., \& Witmer, L. W. (2011). Evolution of olfaction in non-avian theropod dinosaurs and birds. Proceedings of the 
Royal Society of London B: Biological Sciences, 278, 3625-3634.

doi:10.1098/rspb.2008.1075

Zhou, C. -F., \& Rabi, M. (2015). A sinemydid turtle from the Jehol Biota provides insights into the basal divergence of crown turtles. Scientific Reports, 5, 16299. doi:10.1038/srep16299 